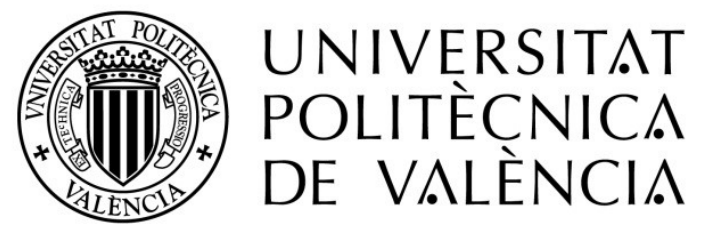

\title{
Microspore embryogenesis: cell wall dynamics and reprogramming of cell fate
}

Carolina Camacho Fernández

\author{
Supervisors: \\ José María Seguí Simarro \\ Patricia Corral Martínez
}

December 2020 

"Alone you can go fast, together we can go far" 



\section{Abstract}

Doubled haploids are a great tool for hybrid breeding due to their complete homozygosity achievable in only one in vitro generation. Among the several techniques used to obtain these plants, induction of microspore embryogenesis, via anther or microspore culture, is the most common and efficient approach. Microspore embryogenesis is also an example of totipotency of plant cells due to their ability to reprogram themselves from a gametophytic to a sporophytic pathway, where cells proliferate in an organized way to create a new organism. As in many other in vitro procedures, culture conditions must be optimized in order to increase efficiency. In the present Doctoral Thesis, we used two plant species as experimental systems to study and optimize microspore culture. On one hand, we used eggplant (Solanum melongena) as an example of economically important crop where protocols have still room for optimization. Optimization of cell density and growth regulators demonstrated to be useful to modify the efficiency of eggplant microspore cultures. On the other hand, we used B. napus microspore cultures principally for basic studies since it is widely used as a model to understand cellular processes occurring during this developmental switch. A standardized protocol for Brassica napus microspore culture is detailed, which was used in all the cultures included in this Thesis to explore a series of processes and cellular structures potentially involved in the developmental switch towards embryogenesis. These included endoplasmic reticulum stress, programmed cell death, autophagy, and cell wall structure and composition. We studied in parallel microspore cultures from two $B$. napus genotypes with different androgenic response cultured in standard conditions and adding Trichostatin A, a epigenetic modulator shown to be beneficial for the androgenic response in some cases. Together, this Thesis represents an advance in the optimization of microspore cultures in these species, and sheds light on the role of some processes within the context of microspore embryogenesis. 


\section{Resumen}

Los dobles haploides son una gran herramienta para la mejora genética de híbridos debido a que se puede alcanzar la homocigosis completa en una sola generación. Entre las técnicas usadas para obtener estas plantas, la inducción de la embriogénesis de microsporas, mediante el cultivo de anteras o de microsporas, es la más eficiente y la más usada. La embriogénesis de microsporas es también un ejemplo de totipotencia de las células vegetales gracias a su habilidad de reprogramar su desarrollo gametofítico hacia una ruta esporofítica, donde las células proliferan de forma organizada para crear un nuevo organismo. Como en muchos otros procesos in vitro, las condiciones de cultivo deben ser optimizadas para incrementar la eficiencia. En la presente Tesis Doctoral, hemos usado dos especies como sistemas experimentales para estudiar y optimizar el cultivo de microsporas. Por un lado, usamos berenjena (Solanum melongena) como un ejemplo de cultivo de importancia económica en el que los protocolos todavía tienen mucho margen de mejora. La optimización de la densidad celular y los reguladores de crecimiento han demostrado ser útiles para modificar la eficiencia del cultivo de microsporas de berenjena. Por otra parte, hemos utilizado el cultivo de microsporas de Brassica napus para estudios básicos puesto que ha sido ampliamente usado como modelo para entender procesos celulares que ocurren durante este cambio en el desarrollo. Se detalla un protocolo estandarizado para el cultivo de microsporas de B. napus, el cual ha sido utilizado en todos los cultivos en esta Tesis para explorar una serie de procesos y estructuras celulares potencialmente implicados en el cambio de desarrollo hacia embriogénesis. Estos procesos incluyen estrés del retículo endoplásmico, muerte celular programada, autofagia y estructura y composición de la pared celular. Estudiamos en paralelo el cultivo de microsporas de dos genotipos de $B$. napus con diferente respuesta androgénica en condiciones estándar y añadiendo Tricostatina A, un modulador epigenético que ha mostrado ser beneficioso para la respuesta androgénica en algunos casos. En conjunto, esta Tesis representa un avance en la optimización del cultivo de microsporas en estas especies y arroja luz sobre el papel de algunos procesos en el contexto de embriogénesis de microsporas. 


\section{Resum}

Els dobles haploides són una gran eina en millora vegetal per a la producció d'híbrids, a causa de la seua total homozigosi, que es pot aconseguir en només una generació in vitro. Entre les diverses tècniques que s'utilitzen per tal d'obtenir aquestes plantes, la inducció de l'embriogènesi de microspores, mitjançant cultiu d'anteres o microspores, és la més comuna i eficient. L'embriogènesi de microspores també és un exemple de la totipotència de les cèl-lules vegetals, capaços de reprogramar-se d'una via gametofítica a una via esporofítica, on proliferen de manera organitzada per crear un nou organisme. Com en moltes altres tecniques in vitro, s'han d'optimitzar les condicions del cultiu per tal d'augmentar l'eficiència. En la present Tesi Doctoral, hem utilitzat dues espècies de plantes com a sistemes experimentals per estudiar i optimitzar el cultiu de microspores. Per una banda, hem utilitzat l'albergínia (Solanum melongena) com a exemple de cultiu d'importància econòmica on els protocols encara tenen marge per a l'optimització. La optimització de la densitat de cèl-lules en cultiu i la concentració de reguladors de creixement van demostrar ser útils per modificar l'eficiència de la resposta dels cultius de microspores d'albergínia. D'altra banda, hem utilitzat cultius de microspores de Brassica napus principalment per a estudis bàsics, ja que s'utilitza àmpliament com a model per entendre els processos cel-lulars que es produeixen durant aquest canvi de desenvolupament. Es detalla un protocol estandarditzat per al cultiu de microspores de B. napus, que s'ha utilitzat en tots els cultius inclosos en aquesta Tesi per explorar una sèrie de processos i estructures cel-lulars potencialment implicades en el canvi de desenvolupament cap a l'embriogènesi. Aquests inclouen l'estrès del reticle endoplasmàtic, la mort cel-lular programada, l'autofàgia i l'estructura i composició de la paret cel-lular. Vam estudiar en paral-lel cultius de microspores de dos genotips de B. napus amb diferent resposta androgènica, cultivats en condicions estàndard i afegint-hi Tricostatina A, un modulador epigenètic que s' ha demostrat beneficiós per a la resposta androgènica en alguns casos. En conjunt, aquesta Tesi representa un avanç en l'optimització dels cultius de microsporas en aquestes espècies i aporta llum sobre el paper d'alguns processos en el context de l'embriogènesi de microspores. 


\section{Index}

\section{Introduction}

Hybrids in plant breeding $\quad 1$

Haploids and doubled haploids $\quad 2$

Methods for doubled haploid production $\quad 3$

Methods for induction of microspore embryogenesis $\quad 6$

$\begin{array}{ll}\text { Anther culture } & 7\end{array}$

Microspore culture $\quad 7$

Factors influencing induction of microspore $\begin{array}{lr}\text { embryogenesis } & 8\end{array}$

Microspore-derived structures $\quad 9$

$\begin{array}{ll}\text { References } & 11\end{array}$

Objectives..................................................................15

Block 1.............................................................................19

Chapter 1: Comparison of six different methods $\begin{array}{ll}\text { to calculate cell densities } & 21\end{array}$

Chapter 2: Role of growth regulators and cell density in Solanum melongena L. isolated microspore culture

Chapter 3: Isolated microspore culture in Brassica napus 83 
Block 2...........................................................................105

Chapter 4: The highly and barely embryogenic populations of $B$. napus microspore cultures undergo different levels of ER stress, autophagy and programmed cell death

Chapter 5: Cell wall composition and structure defines the developmental fate of embryogenic microspores in Brassica napus

Chapter 6: TSA influences cell wall composition and structure in embryogenic microspores of Brassica napus

General discussion 233

Refining the methods for microspore embryogenesis 236

A step further in the knowledge about microspore Embryogenesis 



\section{Abbreviations}

$\begin{array}{ll}\text { CC } & \text { Compact callus } \\ \text { DH } & \text { Doubled haploid } \\ \text { EE } & \text { Exine enclosed } \\ \text { ER } & \text { Endoplasmic reticulum } \\ \text { GR } & \text { Growth regulators } \\ \text { LBS } & \text { Loose bicellular structure } \\ \text { LC } & \text { Loose callus } \\ \text { MDE } & \text { Microspore-derived structure } \\ \text { PCD } & \text { Programmed cell death } \\ \text { SL } & \text { Subintinal layer } \\ \text { SUS } & \text { Suspensor-bearing embryo } \\ \text { TSA } & \text { Trichostatin A } \\ \text { UPR } & \text { Unfolded protein response }\end{array}$





\section{Introduction}





\section{Introduction}

\section{Hybrids in plant breeding}

Since the beginning of agriculture, human beings have been domesticating profitable species facilitating their culture and maximizing benefits while minimizing effort. Although in a reducing trend, the varieties obtained via the traditional, selection-based methods are composed by heterogeneous populations containing a mix of genotypes that allow the cultivar to respond against the changing environmental conditions. Nowadays, and every day more and more, homogeneous varieties are desired in order to optimize yield in fixed conditions. For this, it is necessary to develop lines where only one genotype is present, either pure lines or hybrids (Cubero 2003).

Pure lines are groups of individuals totally homozygous for all their loci in which inbreeding effects are expressed. They have been used in breeding almost from the beginning of the $20^{\text {th }}$ century either for removing undesirable genes or for recurrent selection. However, it is significantly more advantageous to use them to exploit hybrid vigor or heterosis, i.e. the increased expression in the progeny of certain traits as a consequence of a cross between two genetically distant lines, which is the opposite to inbreeding depression. This phenomenon is exploitable by crossing two pure lines to obtain hybrid varieties, in which all the individuals of the population have the same genetic configuration (Cubero 2003).

Traditionally, pure lines have been obtained via several selfing cycles of individuals from one population and the subsequent selection of interesting lines. Once pure lines are obtained, they are intercrossed to obtain a hybrid line whose characteristics are superior to the parental lines. All this requires the maintenance of the parental pure lines to produce new hybrid seed each season. The use of $\mathrm{F}_{2}$, segregating seed from the hybrid would generate heterogeneous populations, undesired by farmers. This is what guarantees the commercialization of new hybrid seed every year (Cubero 2003; Seguí Simarro 2010). Pure lines obtained by selfing, usually across 7-8 successive generations, do not reach $100 \%$ 
homozygosity in all the loci because some parts of the genome have a low probability of undergo recombination and they remain unaltered through generations (Martín 2002). This can be avoided by using other methods of pure lines generation, like doubled haploid production.

\section{Haploids and doubled haploids}

A haploid individual presents the number of chromosomes found in a gamete of this species, which is half the number of chromosomes of a normal adult individual. During fertilization, the haploid chromosome set from one gamete is added to the haploid set provided by the other gamete, thereby generating a new diploid individual. Haploids can occur naturally in the absence of gamete fusion when a new individual directly develops from a gamete, or when, after gamete fusion, the haploid genome of one parental is somehow inactivated and eliminated. This process is known as gynogenesis, when the new haploid individual comes from the female gametes or their precursors, or androgenesis when it comes from the male gametes or their precursors. Once a haploid individual is generated, a doubled haploid (DH) is produced by duplication of the haploid genome, induced or spontaneously, which ends in an individual 100\% homozygous for all the loci (Seguí Simarro 2010).

Due to the total homozygosity of DHs, their production has been used as an alternative to the traditional methods for the generation of pure lines, to be used either as varieties per se or as parental lines for the production of hybrid varieties. The main reason why this alternative is the most profitable one is the cost and time reduction -from 7-8 generations to only one in vitro- (Seguí Simarro 2010). Furthermore, these lines are self-perpetuating, or in other words, the offspring obtained by selfing has the same genetic composition than the parental plant (Seguí-Simarro 2010). In addition to hybrid and pure line production, DHs can be helpful in other steps of the breeding program. For instance, the offspring obtained from a cross between two genetically distant lines could be used for $\mathrm{DH}$ production in order to select more efficiently within the obtained $\mathrm{DH}$ population, both for qualitative and quantitative traits, since the effects of dominance are eliminated and interesting recessive traits can be revealed. They could also be used as 
parental lines to develop synthetic varieties, to estimate additive values or specific combinatory aptitude (Snape 1989).

Other uses of DHs include the detection of recessive mutants in a mutagenesis process. They can be used as a tool for gene mapping of quantitative traits, such as yield or quality, through the calculation of recombination frequencies in a recombinant inbred lines (RILs) population, facilitating phenotypic evaluation. The use of haploids for genetic transformation is a faster way to avoid hemizygotes, since their genome can be duplicated after the transformation and the transgene will be fixed in homozygosity. Moreover, double haploid production process is a useful system for the study of embryogenesis in vitro without interferences from the maternal tissue.

\section{Methods for double haploids production}

Several pathways could be used to obtain haploids or DHs, using male or female gametes or their precursors, due to the natural totipotency of plant cells that allows them to change their developmental pathway. In most cases, the haploid genome must be duplicated by the application of different chemicals like colchicine, an antimicrotubular drug that prevents chromosome migration during mitosis and prevents cytokinesis, thereby doubling the number of chromosomes without division (Seguí Simarro 2010).

Gynogenesis is used in species, as sugar beet and onion, where other doubled haploid induction techniques were not successful. The immature ovule is cultivated until the embryo sac matures, where a haploid embryo develops. In most cases the embryo comes from the egg cell, but seldom it comes from the synergids or antipodal cells (SeguíSimarro 2010). Something similar can be achieved using hybridization of sexually incompatible species, where the development of a haploid embryo is induced directly from the female gamete, stimulated by germination of the male gametophyte, but without fertilization. A similar process happens in interspecific or intergeneric hybridization, often used to decrease the ploidy, but after fertilization. An example of this process is the production of dihaploids in potato (Solanum tuberosum) by intergeneric cross using Solanum phureja pollen, whose genome is not 
present in the resulting dihaploid, so the resulting organisms present half the chromosomes of the mother plant (Liu and Douches 1993). A different strategy is the induction of parthenogenesis with mentor pollen, inactivated by treatments with, for example, toluidine blue or irradiation, and unable to fuse with the egg cell (Seguí-Simarro 2010).

Androgenesis barely happens in nature. Nevertheless, it is possible to induce the embryogenic development from several immature stages of male gametophytes. Microspore and pollen development (microsporogenesis and microgametogenesis) spans from the occurrence of microspore mother cells up to mature pollen grains. First of all, meiosis takes place and four young microspores are released from tetrads, the first stage of the male gametophyte where a haploid genome is in each individual cell. Young microspores grow in size, creating the pollen coat which will protect them from the environment once they are released from the anthers as mature pollen. A large vacuole appears at the late uninucleated stage and the nucleus moves to one side of the cell, thereby facilitating the asymmetry of the first pollen mitosis. In the young bicellular pollen stage, a small compact generative cell is next to the vegetative nucleus, usually larger, less compact and centered in the cell. The generative cell will later undergo mitosis and two sperm cells (the male gametes) will be produced for fertilization of the egg cell (Halbritter et al. 2018).

In figure 1 different male gametophyte-reprograming pathways are detailed. Haploids can be obtained from meiocytes, in which case we could obtain individuals coming from the fusion of two meiocytes (nondoubled haploids) and/or individuals coming from only one meiocyte whose genome was duplicated (route 3 in figure 1). Doubled haploids can also be obtained from fertilization where nuclei do not fuse due to inactivation of the female nucleus (route 1 in figure 1). Androgenesis can be induced from the vacuolated microspore or young bicellular pollen stage through the application of stress treatments, either by direct or indirect embryogenesis (route 2 in figure 1) (Seguí-Simarro 2010). 


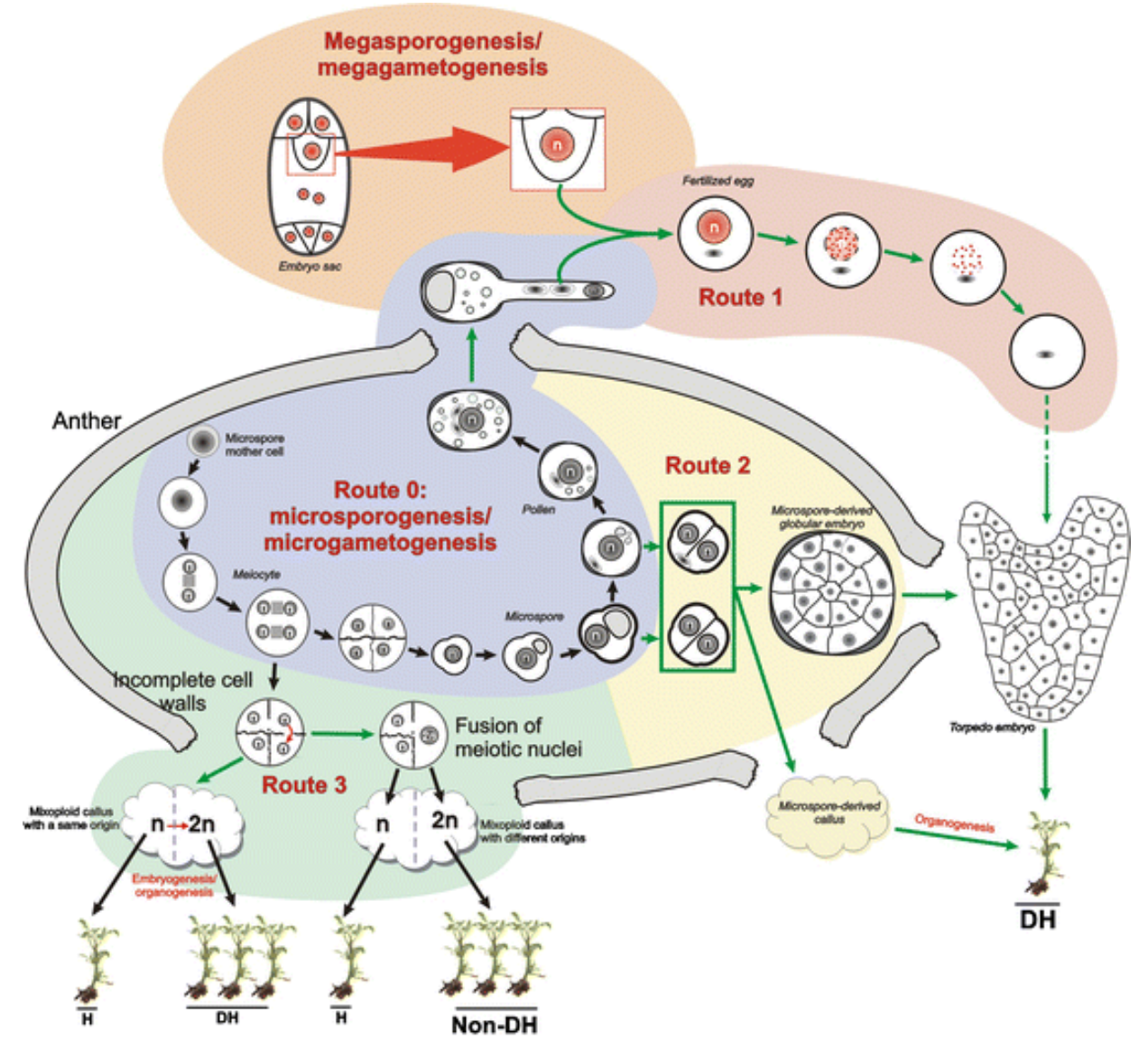

Figure 1. Different routes for reprograming the gametophytic development of microspores or pollen towards androgenesis. Route 1 requires the inactivation of the egg cell genome once fertilization occurs. Route 2 illustrates embryogenesis or callogenesis from vacuolated microspore or young bicellular pollen. Route 3 shows DH formation from the duplication of a haploid meiocyte, and non-DH by fusion of meiocytes. Image from Seguí-Simarro (2010).

In addition to reprograming the gametophytic pathway towards embryogenesis, a new procedure for haploid production was developed in 2010 (Ravi and Chan 2010). This method relies in the genetic modification of the $\mathrm{CENH}_{3}$ histone, responsible for the control of kinetochore assembly and the recruitment of the spindle microtubulebinding factors, essential for chromosome segregation during mitosis (Black and Bassett 2008). Experimental modification of $\mathrm{CENH}_{3}$ in one of the parental lines leads to the elimination of the selected parental 
genome, due to the presence of defective kinetochores in their chromosomes, and therefore to haploid embryo formation (Ravi and Chan 2010; Dwivedi et al. 2015). Although it was initially developed in Arabidopsis, several projects aim to apply it to other species such as barley, cotton, sugarbeet, tobacco or rice (Tek et al. 2015).

Among all the described methods for doubled haploid production, those based on androgenesis are the most used, especially microspore embryogenesis, which is the most effective. This method has some advantages over other methods:

- Microspore embryogenesis induction protocols have been set up for a higher number of species than the rest of the methods.

- It is the most effective method due to the enormous amount of microspores/pollen that can be obtained from a single flower bud.

- The number of individuals that spontaneously duplicate their genome is higher than in other methods, which could avoid additional treatments (Parra-Vega et al. 2015).

On the other hand, androgenesis itself has a series of limitations. There are recalcitrant species, like tomato (Seguí-Simarro et al. 2011), in which it is still not possible to develop an efficient protocol for microspore embryogenesis. In other species, malformed embryos are sometimes produced, most of the times due to a deficient development of the shoot meristem (Kim et al. 2008). Furthermore, regeneration to full plants from calli or androgenic embryos could be a limiting step (Rivas-Sendra et al. 2015).

\section{Methods for induction of microspore embryogenesis}

Methodologically, microspore embryogenesis can be induced by two main techniques: anther and microspore culture. 


\section{Anther culture}

It was the first technique established to change the developmental pathway of microspores towards embryogenesis. Guha and Maheswari (1964) were pioneers to describe this technique in Datura sp. From both microspore embryogenesis techniques, anther culture is the simplest. The procedure consists in collecting flower buds in the precise moment when anthers are in the correct stage for the induction and subject their anthers to proper culture conditions. Solid media is commonly used for anther culture, but some species have been reported to prefer liquid media (Mayakaduwa and Silva 2018). Anther tissue provides cells with substances that facilitate growth and maintain microspore viability, so the culture medium does not need to have a very refined composition. However, although anther culture results technically simpler than microspore culture and usually more successful, it also has a number of limitations. First of all, the efficiency of induction is much lower than in isolated microspore culture, because only a few embryos are obtained per cultured anther (Miyoshi 1996). In addition, regeneration from somatic tissue of anther walls may take place in parallel to microspore embryogenesis, so that a later molecular marker analysis is needed in order to determine whether the individual is diploid or haploid/doubled haploid. Finally, anther tissue makes difficult to control culture conditions (Seguí Simarro 2010).

\section{Microspore culture}

For this procedure, microspores need to be released from the anthers, once flower buds are collected and sterilized, to culture them in liquid media. In this case, the media is the only source of exogenous substances that microspores have, so medium composition requires a better design than in anther culture. The fact that microspores develop freely in the liquid media increases the probability of obtaining a higher number of regenerated plants. With all these advantages, microspore culture solves the problems that anther culture presented even though it makes more complex the optimization of culture conditions (Seguí Simarro 2010) and therefore it has been optimized in a lower number of species. 


\section{Factors influencing induction of microspore embryogenesis}

To succeed in inducing microspores towards embryogenesis, there are several points that should be considered to optimize the conditions:

- Donor plant conditions:

- Genotype: some species are recalcitrant and others respond easily to these techniques. Furthermore, some species present high, low or null response to androgenesis in different genotypes.

- Age of the plant: the androgenic capacity tends to diminish with age.

- Growth conditions: temperature, photoperiod, fertilizer and relative humidity are examples of factors that could influence the response to androgenesis. Culture in greenhouse, growing chamber or field may also make a difference on the response.

- Developmental stage of the microspore: among all conditions, the developmental stage of the microspore is, together with the genotype, the most crucial factor. The stage should be optimal for the induction, otherwise it will not happen. For most species, the window where induction is possible revolves around the first pollen mitosis: the vacuolated microspore and the young bicellular pollen stages (Seguí Simarro 2010).

- Induction treatment: to achieve the switch in developmental pathway of microspores, a stress needs to be applied. Among others, cold treatment (Gu et al. 2004), heat shock (Pechan and Smykal 2001), starvation (Islam and Tuteja 2012), even electric fields (Delaitre and Ochatt 2005) are used as stress treatment to induce embryogenesis. 
- Culture conditions: the physiochemical environment of the microspore is a critical factor for microspores development and embryo formation. As for all other types of in vitro culture, the composition of the culture medium must be adjusted, as well as light and temperature conditions (Seguí Simarro 2010). In microspore culture, cell density is another important parameter to take into account, because microspores need a specific density that allows them to communicate effectively without disturbing to each others (Camacho-Fernández et al. 2018).

\section{Microspore-derived structures}

As mentioned above, microspore embryogenesis is a process where pollen precursors reprogram and switch their developmental pathway from gamethophytic to embryogenic. Usually, that switch is possible thanks to the application of stresses that induce changes in the architecture of cells and allow them to divide symmetrically and proliferate (Pechan and Smykal 2001; Testillano 2019). Some species start with an asymmetric division and each of them will develop with a different tissue pattern, like some monocots (Massonneau et al. 2005), giving rise to a structure similar to the endosperm and an embryo. In dicots, microspore-derived structures can be proper embryos, with or without suspensor (Custers 2004; Corral-Martínez et al. 2020), but also calli from which regeneration steps are needed afterwards (Rivas-Sendra et al. 2015). Usually, cultured microspore populations are complex and heterogeneous, coexisting in the same culture plate calli, structures with some differentiation but abnormal meristems, embryogenic clusters, etc. Sometimes, as it happens in eggplant, structures develop as embryos until they arrive to the globular stage and, before the switch from radial to bilateral symmetry, structures are not able to continue and external cells start to dedifferentiate, generating only calli at the end of the culture (Corral-Martínez and Seguí-Simarro 2014). In vitro culture conditions can be modified in order to increase or reduce the percentages of some of the microspore-derived structures present in the heterogeneous population, trying to select the most interesting ones (Corral-Martínez and Seguí-Simarro 2014; Ahmadi et al. 2014; Mousa et al. 2014). For that reason, not only experimental data about how 
microspore cultured populations respond to changes in the culture media or induction treatment is needed to improve microspore embryogenesis, but also understanding the cellular processes going on could be useful to do so in a targeted way. In the present Doctoral Thesis, both approaches are presented, developed and discussed aiming to provide a wide vision of how microspore embryogenesis could be improved in recalcitrant species (such as eggplant) by modifying their conditions but also understanding how this process takes place in model species (such as rapeseed).

Brassica napus is considered a model species for microspore embryogenesis thanks to its versatility in response to different stresses and high embryo yields in some genotypes. Numerous studies have focus on it in order to unravel cellular and molecular processes taking place during microspore embryogenesis (Corral-Martínez et al. 2013; Soriano et al. 2014; Parra-Vega et al. 2015). Solanum melongena could be considered as a recalcitrant species because, although androgenic induction is possible (Corral-Martínez and Seguí-Simarro 2014; Calabuig-Serna et al. 2020), yields are still low, most of the times obtaining only calli and therefore needing regeneration steps afterwards which usually represent a bottleneck for the final number of obtained plants (Seguí-Simarro 2016). Miyoshi (1996) was the pioneer in obtaining structures derived from eggplant microspores and since then, several studies have tried to optimize the protocol. Due to its economic importance, especially in the Mediterranean region where these experiments were performed (Chapman 2019), our main goal during these years was to optimize the eggplant protocol by modification of culture conditions and understanding more deeply microspore embryogenesis itself using $B$. napus as model in order to provide that knowledge to be applied to other important recalcitrant species. 


\section{References}

Ahmadi B, Shariatpanahi M, Ojaghkandi M, Heydari A (2014) Improved microspore embryogenesis induction and plantlet regeneration using putrescine, cefotaxime and vancomycin in Brassica napus L. Plant Cell Tissue Organ Cult 118 (3):497-505. doi:10.1007/s11240-014-0501-9

Black BE, Bassett EA (2008) The histone variant CENP-A and centromere specification. Curr Opin Cell Biol 20 (1):91-100. doi:http://dx.doi.org/10.1016/j.ceb.2007.11.007

Calabuig-Serna A, Porcel R, Corral-Martínez P, Seguí-Simarro JM (2020) Anther Culture in Eggplant (Solanum melongena L.). In: Bayer M (ed) Plant Embryogenesis: Methods and Protocols, vol 2122. Methods in Molecular Biology,. Springer US, New York, NY, pp 283-293. doi:10.1007/978-1-0716-0342-0_20

Camacho-Fernández C, Hervás D, Rivas-Sendra A, Marín MP, Seguí-Simarro JM (2018) Comparison of six different methods to calculate cell densities. Plant Methods 14 (1):30. doi:10.1186/s13007-018-0297-4

Corral-Martínez P, Parra-Vega V, Seguí-Simarro JM (2013) Novel features of Brassica napus embryogenic microspores revealed by high pressure freezing and freeze substitution: evidence for massive autophagy and excretion-based cytoplasmic cleaning. J Exp Bot 64 (10):3061-3075. doi:10.1093/jxb/ert151

Corral-Martínez P, Seguí-Simarro JM (2014) Refining the method for eggplant microspore culture: effect of abscisic acid, epibrassinolide, polyethylene glycol, naphthaleneacetic acid, 6-benzylaminopurine and $\begin{array}{llll}\text { arabinogalactan } & \text { proteins. } & \text { Euphytica } & \end{array}$ doi:10.1007/s10681-013-1001-4

Corral-Martínez P, Siemons C, Horstman A, Angenent GC, de Ruijter N, Boutilier K (2020) Live Imaging of embryogenic structures in Brassica napus microspore embryo cultures highlights the developmental plasticity of induced totipotent cells. Plant Reprod. doi:10.1007/s00497-020-00391-z

Cubero JI (2003) Introducción a la mejora genética vegetal, $2^{\mathrm{a}}$ edición. Ediciones Mundi-Prensa, Madrid, Spain

Custers JBM Efficient in vitro production of embryos with suspensors in a refined Brassica napus microspore culture procedure. In: Proceedings 
of the COST action 851. Workshop of the Working Group 1:Technology advancement in gametic embryogenesis of recalcitrant genotypes., Palermo, Italy, 2004.

Chapman MA (2019) Introduction: The Importance of Eggplant. In: Chapman MA (ed) The Eggplant Genome. Springer, pp 1-10

Delaitre C, Ochatt S (2005) Electric fields foster embryogenesis and androgenic plant regeneration in Asparagus officinalis. In: XI International Asparagus Symposium 776, 2005. pp 313-318

Dwivedi SL, Britt AB, Tripathi L, Sharma S, Upadhyaya HD, Ortiz R (2015) Haploids: Constraints and opportunities in plant breeding. Biotechnol Adv $33 \quad$ (6 30 Pt 1$): 812-829$. doi:http://dx.doi.org/10.1016/j.biotechadv.2015.07.001

Gu HH, Hagberg P, Zhou WJ (2004) Cold pretreatment enhances microspore embryogenesis in oilseed rape (Brassica napus L.). Plant Growth Regul 42 (2):137-143

Guha S, Maheshwari SC (1964) In vitro production of embryos from anthers of Datura. Nature 204:497

Halbritter H, Ulrich S, Grímsson F, Weber M, Zetter R, Hesse M, Buchner R, Svojtka M, Frosch-Radivo A (2018) Pollen Development. In: Illustrated Pollen Terminology. Springer International Publishing, Cham, pp 2335. doi:10.1007/978-3-319-71365-6_2

Islam SMS, Tuteja N (2012) Enhancement of androgenesis by abiotic stress and other pretreatments in major crop species. Plant Sci 182 (o):134-144. doi:10.1016/j.plantsci.2011.10.001

Kim M, Jang I-C, Kim J-A, Park E-J, Yoon M, Lee Y (2008) Embryogenesis and plant regeneration of hot pepper (Capsicum annuum L.) through isolated microspore culture. Plant Cell Rep 27 (3):425-434

Liu C-A, Douches DS (1993) Production of haploids of potato (Solanum tuberosum subsp. tuberosum) and their identification with electrophoretic analysis. Euphytica 70 (1-2):113-126

Martín A (2002) Los marcadores genéticos en la mejora vegetal. In: Nuez F, Carrillo Becerril JM, Lozano R (eds) Genómica y Mejora Vegetal. Mundi-Prensa, Sevilla, pp 37-63

Massonneau A, Coronado MJ, Audran A, Bagniewska A, Mol R, Testillano PS, Goralski G, Dumas C, Risueño MC, Matthys-Rochon E (2005) Multicellular structures developing during maize microspore culture express endosperm and embryo-specific genes and show different embryogenic potentialities. Eur J Cell Biol 84 (7):663-675 
Mayakaduwa D, Silva TD (2018) Anther culture as a supplementary tool for rice breeding. Rice crop-current developments IntechOpen, Rijeka:1-15

Miyoshi K (1996) Callus induction and plantlet formation through culture of isolated microspores of eggplant (Solanum melongena L). Plant Cell Rep 15 (6):391-395

Mousa MA, Haridy AG, Abbas HS, Mohammed MF (2014) Improved Androgenesis of Broccoli (Brassica oleracea var italica) Anthers Using Sucrose and Growth Regulators. Asian Journal of Crop Science 6 (2):133-141

Parra-Vega V, Corral-Martínez P, Rivas-Sendra A, Seguí-Simarro JM (2015) Induction of embryogenesis in Brassica napus microspores produces a callosic subintinal layer and abnormal cell walls with altered levels of callose and cellulose. Front Plant Sci 6:1018. doi:10.3389/fpls.2015.01018

Pechan PM, Smykal P (2001) Androgenesis: affecting the fate of the male gametophyte. Physiol Plant 111 (1):1-8

Ravi M, Chan SWL (2010) Haploid plants produced by centromere-mediated genome elimination. Nature 464 (7288):615-618. doi:10.1038/nature08842

Rivas-Sendra A, Corral-Martínez P, Camacho-Fernández C, Seguí-Simarro JM (2015) Improved regeneration of eggplant doubled haploids from microspore-derived calli through organogenesis. Plant Cell Tissue Organ Cult 122 (3):759-765. doi:10.1007/s11240-015-0791-6

Seguí-Simarro JM (2010) Androgenesis revisited. Bot Rev 76 (3):377-404. doi:10.1007/s12229-010-9056-6

Seguí-Simarro JM (2016) Androgenesis in solanaceae. In: Germanà MA, Lambardi M (eds) In vitro embryogenesis, vol 1359. Methods in Molecular Biology. Springer Science + Business Media, New York, pp 209-244. doi:10.1007/978-1-4939-3061-6_9

Seguí-Simarro JM, Corral-Martínez P, Parra-Vega V, González-García B (2011) Androgenesis in recalcitrant solanaceous crops. Plant Cell Rep 30 (5):765-778. doi:10.1007/s00299-010-0984-8

Seguí Simarro JM (2010) Biología y biotecnología reproductiva de las plantas. Editorial Universitat Politècnica de València, Valencia, Spain

Snape JW (1989) Doubled haploid breeding: theoretical basis and practical applications. In: Mujeeb-Kazi A, Sitch LA (eds) Review of advances in plant biotechnology, 1985-1988: 2nd International Symposium on Genetic Manipulation in Crops. Mexico y Filipinas: CIMMYT y IRRI, pp 19-30 
Soriano M, Li H, Jacquard C, Angenent GC, Krochko J, Offringa R, Boutilier K (2014) Plasticity in Cell Division Patterns and Auxin Transport Dependency during in vitro Embryogenesis in Brassica napus. Plant Cell 26 (6):2568-2581. doi:10.1105/tpc.114.126300

Tek AL, Stupar RM, Nagaki K (2015) Modification of centromere structure: a promising approach for haploid line production in plant breeding. Turkish Journal of Agriculture and Forestry 39 (4):557-562

Testillano PS (2019) Microspore embryogenesis: targeting the determinant factors of stress-induced cell reprogramming for crop improvement. doi:10.1093/jxb/ery464 


\section{Objectives}




\section{Objectives}

- Evaluate the precision, accuracy and reproducibility of different methods available to measure cell densities in in vitro cultures.

- Deepen in some environmental conditions of microspore culture, like cell density or growth regulator composition, in order to explore the possibilities of this in vitro technique.

- Definition of a standard protocol for microspore culture in a model species (B. napus).

- Understanding the processes related to endoplasmic reticulum stress, programmed cell death and autophagy that take place during microspore embryogenesis.

- Exploration of cell wall characteristics of different types of structures obtained in B. napus microspore culture.

- Evaluation of the effect of the epigenetic modification caused by TSA in the structure and composition of cell walls of B. napus cultured microspores.

- Comparison among genotypes with different androgenic response in terms of response to TSA at cell wall level in different types of structures obtained in microspore culture. 
Block 1 


\section{Chapter 1}

\section{Comparison of six different methods to calculate cell densities}

Carolina Camacho-Fernández ${ }^{1}$, David Hervás², Alba Rivas-Sendra ${ }^{1}$, $\mathrm{M}^{\mathrm{a}}$ Pilar Marín ${ }^{3}$ and Jose M. Seguí-Simarro ${ }^{1}$

${ }^{1}$ COMAV - Universitat Politècnica de València, Spain.

2 Biostatistics Unit - IIS La Fe, Valencia, Spain.

3 Microscopy Service - IIS La Fe, Valencia, Spain.

Keywords: Automated cell counter, Cell counting, Flow cytometry, Fluorospheres, Hemacytometer, Image analysis, Microscopy, Microspore culture

Running title: Comparison of methods to calculate cell density

This article has been published as: Camacho et al. (2018) Comparison of six different methods to calculate cell densities. Plant Methods Vol 14:30. 


\section{Abstract}

\section{Background}

For in vitro culture of plant and animal cells, one of the critical steps is to adjust the initial cell density. A typical example of this is isolated microspore culture, where specific cell densities have been determined for different species. Out of these ranges, microspore growth is not induced, or is severely reduced. A similar situation occurs in many other plant and animal cell culture systems. Traditionally, researchers have used counting chambers (hemacytometers) to calculate cell densities, but little is still known about their technical advantages. In addition, much less information is available about other, alternative methods. In this work, using isolated eggplant microspore cultures and fluorescent beads (fluorospheres) as experimental systems, we performed a comprehensive comparison of six methods to calculate cell densities: (1) a Neubauer improved hemacytometer, (2) an automated cell counter, (3) a manual-counting method, and three flow cytometry methods based on (4) autofluorescence, (5) propidium iodide staining, and (6) side scattered light (SSC).

\section{Results}

Our results show that from a technical perspective, hemacytometers are the most reasonable option for cell counting, which may explain their widely spread use. Automated cell counters represent a good compromise between precision and affordability, although with limited accuracy. Finally, the methods based on flow cytometry were, by far, the best in terms of reproducibility and agreement between them, but they showed deficient accuracy and precision.

\section{Conclusions}

Together, our results show a thorough technical evaluation of each counting method, provide unambiguous arguments to decide which one is the most convenient for the particular case of each laboratory, and in general, shed light into the best way to determine cell densities for in vitro cell cultures. They may have an impact in such a practice not only in the context of microspore culture, but also in any other plant cell culture procedure, or in any process involving particle counting. 


\section{Background}

Successful in vitro cell cultures depend upon a proper cell density at the onset of the culture. A correct calculation of cell plating density is a critical step for cell cultures, including somatic plant cells (Kobayashi et al. 1999), protoplasts (Schween et al. 2003) and microspore cultures. In isolated microspore cultures there is a minimum plating density below which, no embryogenic response is observed (Hoekstra et al. 1993; Castillo et al. 2000; Kim et al. 2008). On the other hand, microspore densities higher than optimal may inhibit the embryogenic response (Huang et al. 1990) and reduce the number of viable embryos due to the reduced availability of nutrients and/or to the presence of inhibitory toxins generated by the microspores (Castillo et al. 2000; Li and Devaux 2003; Kim et al. 2008). Each species has its own optimal culture density. Thus, an optimal plating density was established at $4 \times 104$ microspores/ml for Brassica napus microspore cultures (Huang et al. 1990), whereas for pepper it was proposed to be $8 \times 10^{4}-10 \times 10^{4}$ (Kim et al. 2008), $8 \times 10^{4}$ for rice (Raina and Irfan 1998), $12.5 \times 10^{4}$ for rye (Ma et al. 2004), and even $140 \times 10^{4}$ for apple (Höfer 2004).

A survey among 400 researchers working with animal cell cultures (Ongena et al. 2010) revealed that $71 \%$ used counting chambers, also known as hemacytometers, to perform cell density calculations. In isolated microspore cultures, the vast majority of the (few) papers that mentioned the system used to calculate microspore density, referred the use of hemacytometers. Among them, the most used by far is the Neubauer Improved (Regner 1996; Castillo et al. 2000; Nelson et al. 2009; Corral-Martínez et al. 2013; Kim et al. 2013, for some examples), although others such as the Fuch-Rosenthal (Simmonds et al. 1991) or the Burker chamber (Gémes Juhász et al. 2009; Lantos et al. 2012) have been occasionally used. Although scarce, there are also studies that use estimations based on the volume of the pelleted microspores (Nageli et al. 1999), broad assumptions like " $\mathrm{X}$ buds (or anthers) equals to $\mathrm{Y}$ microspores" (Hoekstra et al. 1993; Gu et al. 2003), or density units of the type "a ratio of X buds/ml" (Rudolf et al. 1999) or "X Petri dishes containing microspores isolated from Y flower buds" (Sato et al. 2005). The use of other counting methods, not based on counting chambers, has 
been negligible. Indeed, fast, easy and accurate alternatives such as flow cytometry (Nicoloso et al. 1994) have not been used for microspore cultures. As far as we know, flow cytometry has only been used to identify populations of embryogenic and non-embryogenic microspores (Schulze and Pauls 1998) and to identify cellulose deposition in embryogenic microspores (Schulze and Pauls 2002). Interestingly, these studies did not use this method for the initial adjustment of microspore density. Other methods based on automated cell counting have not been described in the literature.

Considering the importance of an accurate calculation of the initial microspore density and in general, of cultured cell density, it is surprising that, to our knowledge, comparative studies of the different methods available for this are still very scarce. In this work, we developed a comparative study to determine the accuracy, precision, reproducibility, and in summary, the reliability of six different methods to calculate cell densities, including the most popular (the hemacytometer), but also others, less used but potentially useful as well. We compared the following methods: (1) hemacytometer, (2) automated cell counting, (3) a manual-counting method based on counting microscope fields, (4) flow cytometry-based detection of microspore autofluorescence, (5) flow cytometry-based detection of propidium iodide (PI)-stained microspores, and (6) flow cytometry-based detection of side scattered light (SSC). To test these methods, we used isolated microspore cultures of eggplant, a well-established system in our laboratory (Corral-Martínez and Seguí-Simarro 2012, 2014; RivasSendra et al. 2015; Rivas-Sendra et al. 2017), and also fluorospheres, fluorescent spherical beads certified to be at a known concentration and therefore used as standards for absolute counts. Our results show remarkable differences between the performance of the different methods, supporting the use of some of them, and discouraging the use of others. 


\section{Methods}

\section{Plant materials, microspore culture, and fluorospheres}

As donors of eggplant microspores, we used cv. Ecavi (a F1 hybrid from Rijk Zwaan) and the doubled haploid lines $\mathrm{DH}_{5}, \mathrm{DH}_{29}, \mathrm{DH}_{3} 6$ and DH40, produced in our laboratory (Rivas-Sendra et al. 2017) from cv. Bandera (a F1 hybrid from Seminis). Plants were grown in $30 \mathrm{~cm}$ pots at COMAV greenhouses (Universitat Politècnica de València) set up at 20 ${ }^{\circ} \mathrm{C}$ under natural light. Flower buds at the appropriate stage of development (Salas et al. 2012) were immediately transported to the laminar flowhood under melting ice, and processed as previously described in Corral-Martínez and Seguí-Simarro 2012. Unless otherwise stated, the estimation of the initial culture density was carried out using an Improved Neubauer Chamber.

We also used fluorescent microspheres (Flow-Count Fluorospheres, Ref. 7547053, from Beckman Coulter), typically used as internal controls for counting cell populations. Fluorospheres are excitable at $488 \mathrm{~nm}$, emit in a range between 525 and $700 \mathrm{~nm}$, and are uniform in size $(\sim 10$ $\mu \mathrm{m})$ and fluorescence intensity. According to manufacturer's specifications, the assayed concentration was 1,030,000 fluorospheres/ml. From this batch, different 1:1 (undiluted), 1:2 and 1:10 dilutions in distilled water (containing 1,030,000, 515,000 and 103,000 fluorospheres $/ \mathrm{ml}$ respectively) were prepared for each different round of measurements with the different methods used.

In order to compare direct and indirect estimation of microspore densities by fluorosphere counting, mixed samples of microspores and fluorospheres were prepared, including $100 \mu \mathrm{l}$ of fluorospheres in $1 \mathrm{ml}$ of microspore suspension.

\section{Pipetting technique verification procedure}

In order to verify the accuracy of pipetting and to rule out pipetting errors in all the pipetting steps performed in this work, we used the 26 
pipetting technique verification procedure described in the Flow-Count Fluorosphere specifications provided by the manufacturer (www. beckmancoulter.com). Basically, this procedure consists of placing a test tube and a weighting vessel on an analytical balance and, after taring the balance, pipetting $100 \mu \mathrm{l}$ of sample into the test tube and recording the weight. Then, the balance is tared again, and the procedure is fully repeated 10 times with 10 different $100 \mu \mathrm{l}$ samples. For each pipette, the mean, standard deviation and percent coefficient of variation (\%CV) of all the repeats was calculated. According to manufacturer standards, pipettes are well calibrated when the $\% \mathrm{CV}$ is $\leq 2.0 \%$ and the weight measured is the expected for the volume used.

\section{Field counting with microscope images}

We also used a manual-counting method based on a user counting cells in microscope fields. For field counting, 10 images of each microspore culture and fluorosphere dish were taken in a light microscope with a $20 \times$ objective. To ensure randomness for each image, we used a computer program (Hervás 2014) to generate random paths along the dish, which provides different, random-generated coordinates for each field to be imaged. For each image, the total number of particles present in the image was counted, and the average of the 10 images was calculated. In mixed samples, fluorospheres and microspores were individually counted. To avoid inter-counter variation, all countings were performed by the same operator. To calculate particle concentration, the depth of the culture medium on the dish $(1.41 \mathrm{~mm})$ was obtained dividing the volume inoculated to the culture dish $\left(3 \mathrm{~cm}^{3}\right)$ by the area of the culture dish $\left(21.24 \mathrm{~cm}^{2}\right)$. Then, the volume of culture corresponding to the area imaged in the 10 micrographs used $\left(3.1 \mathrm{~mm}^{3}\right.$, $\sim 3 \mu \mathrm{l}$ ) was obtained by multiplying the culture depth $(1.41 \mathrm{~mm})$, by the area of the 10 micrographs $\left(0.22 \mathrm{~mm}^{2} \times 10=2.2 \mathrm{~mm}^{2}\right)$. For fluorosphere counting, the different dilutions were poured into $3 \mathrm{~cm}$-wide culture dishes. Procedures and calculations were identical to those used for microspore cultures, but using a depth of $1.24 \mathrm{~mm}$. 


\section{Automated cell counting}

We used the Micro Counter 3100 system from Celeromics (Grenoble, France). This system is based on the use of an inverted microscope-coupled digital camera to take sets of images of cultured cells or particles within sealed culture dishes. Then, an image analysis algorithm automatically identifies and counts the particles present in images, and the system calculates their density per area and volume unit, according to the parameters previously established during system calibration. For calibration, the culture depth previously calculated was used. For each counted dish, 10 different $20 \times$ images were taken. A computer program (Hervás 2014) was used to generate random paths along which images were taken.

For this procedure (hereinafter referred to as the Neubauer method), we used a Neubauer Improved glass counting chamber (Electron Microscopy Sciences, Hatfield, PA) with a grid of perpendicular lines etched in the middle region (Additional file 1: Figure S1). To allow for comparisons between automated, field and Neubauer counting, we made the three counting efforts similar by adjusting the number of Neubauer cells to be counted. With automated and field counting, a total volume of $3.1 \mathrm{~mm} 3$ of microspore culture and a similar volume of fluorosphere suspension was counted (10 images $\times 0.22 \mathrm{~mm}^{2}$ of area for each image $\times$ the calculated depth, $1.41 \mathrm{~mm}$ ). To count a similar volume with a Neubauer chamber, we calculated the number of Neubauer large squares (Additional file 1: Figure S1) to be counted by dividing $3.1 \mathrm{~mm}^{3}$ by $0.1 \mathrm{~mm}^{3}$, which is the volume loaded to each Neubauer large square. The result (31 large squares) was approximated to 30 , which corresponded to counting all the microspores present in five large squares of the two cells of the chamber, and repeating this three times ( 5 squares $\times 2$ cells $\times 3$ chambers $=30$ ). To fill each chamber cell, the content of each culture dish was poured into a $15 \mathrm{ml}$ conical flask. Immediately after a thorough resuspension of microspores or fluorospheres, $10 \mu \mathrm{l}$ were pipetted out and loaded into the chamber cells by capillarity until they were entirely filled, discarding the unloaded volume. Counting was performed under an inverted microscope with a $10 \times$ objective. In mixed samples, fluorospheres and microspores were individually counted. To avoid inter-counter variation, all counting was performed by the same operator. 


\section{Particle counting by flow cytometry}

Flow cytometry allows for the fast detection and quantification of fluorescent particles when they are excited with a fluorescent light source. Usually, cells are stained with a fluorescent dye to make them fluorescent. We used three flow cytometry methods based on the detection of (1) microspore autofluorescence, (2) propidium iodide (PI)stained microspores, and (3) side scattered light (SSC), which is proportional to granularity and internal complexity of the measured particle (Shapiro 1994) with no need for fluorescence emission. We used a Partec CyFlow Ploidy Analyser (Partec, Gürlitz, Germany) equipped with a UV LED lamp (365 nm), a Nd-YAG green laser at $532 \mathrm{~nm}$ (30 $\mathrm{mW}$ ), and filters for PI (long pass filter $590 \mathrm{~nm}$ ) and for DAPI (long pass filter $435 \mathrm{~nm}$ ). For direct counting of unstained microspores, the contents of culture dishes were resuspended and loaded into plastic vials and directly charged into the loading port. For autofluorescence detection (hereinafter referred to as the FC-unstained method), a UV LED lamp and DAPI excitation/emission filters were used. The suspension was loaded in the flow cytometer, which provided the number of fluorescent counts recorded, their fluorescent intensity, and the volume where the counts were recorded. For PI fluorescence-based flow cytometry (hereinafter referred to as the FC + PI method), the NdYAG green laser and the PI excitation/emission filters were used. For cell counting, $1 \mathrm{ml}$ of microspore suspension was taken from each culture dish. The suspension was incubated with $0.5 \mathrm{ml}$ of Partec nuclei extraction buffer during $60 \mathrm{~s}$, and then with $2 \mathrm{ml}$ of Partec staining buffer $+12 \mu \mathrm{l}$ PI for $1 \mathrm{~h}$ at $4{ }^{\circ} \mathrm{C}$.

The stained suspension was loaded in the flow cytometer, which provided the number of fluorescent counts recorded, their fluorescent intensity, and the volume where the counts were recorded. For fluorosphere counting, 500 $\mu \mathrm{l}$ of 1:1 (undiluted), 1:2 and 1:10 fluorosphere dilutions were placed in plastic vials. Additional $500 \mu \mathrm{l}$ of water were added for a final loading volume of $1 \mathrm{ml}$ of 1:2, 1:4 or 1:20 dilutions, respectively. The data obtained were multiplied by 2 to be comparable with those of other methods. Vials were directly charged into the loading port. To calculate particle density based on the SSC emission (the SSC method), the flow cytometer provided the number of SSC counts recorded, their SSC intensity, and the volume where the counts 
were recorded. For SSC, the Nd-YAG green laser and the PI excitation/emission filters were used. To test to what extent sedimentation of microspores at the bottom of the vial, where the aspiration system cannot reach, could be reducing the number of counted microspores, we counted the cells suspended in the vial, washed the vial thrice with one additional $\mathrm{ml}$ of culture medium to resuspend the potentially sedimented microspores, counted the cells of each washing medium, and then calculated the density by dividing the total number of microspores counted in all rounds (including washings) by the initial volume where microspores were suspended (excluding washings). For all flow cytometry-based methods and cultures, three different samples were taken and processed, their individual densities calculated and then averaged. For all methods, particle densities were calculated dividing the total number of counts by the volume loaded for these counts. In mixed samples, fluorosphere and microspore densities were individually calculated using SSC counts from all the peaks obtained. After each counting round, the whole system was thoroughly cleaned to prevent wrong counts from previous samples.

\section{Parameters used and statistical analysis}

Based on the definitions of the International Organization of Standardization (ISO, www.iso.org; Additional file 2: Table S1), we calculated the following parameters for the comparisons described in this work:

- Precision: the closeness between independent test results under the same conditions.

- Accuracy: the closeness of agreement between the data and the real or reference value.

- Reproducibility: the similarity of data obtained with the same method from samples in different conditions.

In addition, we defined concordance as the agreement of measurements obtained with different methods. 
Precision was assessed by analyzing the dispersion of data obtained in repeated measures of the microspore/fluorosphere suspensions with the same initial density with the same method. Accuracy was assessed by calculating the percentage of deviation of each individual measurement from the theoretical (for microspores) or real value (for fluorospheres). For a visual and easy-to-understand representation of accuracy and precision results, box and whiskers graphs were developed for each method and group of samples. In all cases, repeated measurements were summarized by their mean and standard deviation. To assess the reproducibility of each method, two different measurements were performed in the same cultures, the first at days 3 and the second at days 18. Reproducibility was assessed by Bland-Altman plots comparing both measurements, computing their coefficient of repeatability (CR) and performing an ANOVA analysis. The average bias and 95\% limits of agreement were also computed for each plot. Concordance among methods was assessed using pairwise Bland-Altman plots (Bland and Altman 1999). As alternative concordance estimation, Lin's concordance correlation coefficient (Lin 1989) was also computed in each case. Statistical analysis and charts were performed with the $\mathrm{R}$ software (version 3.1.1, Team 2011).

\section{Results}

For evaluation of precision, accuracy, reproducibility and concordance between methods, a total of 17 microspore cultures were performed and measured using the different methods tested in this work. For each of these, the initial density was adjusted to 400,000 microspores/ ml using the Neubauer method as described in Methods. Microspore density was estimated for each culture at days 3 and 18. 3 day-old cultures are formed by microspores induced towards embryogenesis, together with non-induced (pollen-like), dead and arrested individuals. However, this culture stage is still too early to detect important morphological differences between them. Thus, in terms of morphology, cultures at this stage are characterized by the presence of regular eggplant microspores, identical to those present in 
the anther, and microspores swollen as a consequence of the androgenic switch that makes them to enlarge within the exine (arrows in Fig. 1a). In turn, 18 day-old cultures present enlarged microspores or microsporederived embryos, produced as a consequence of cell divisions within the exine (arrows in Fig. 1b). However, most of the cultured structures are arrested and/or dead microspores, or pollen-like structures.
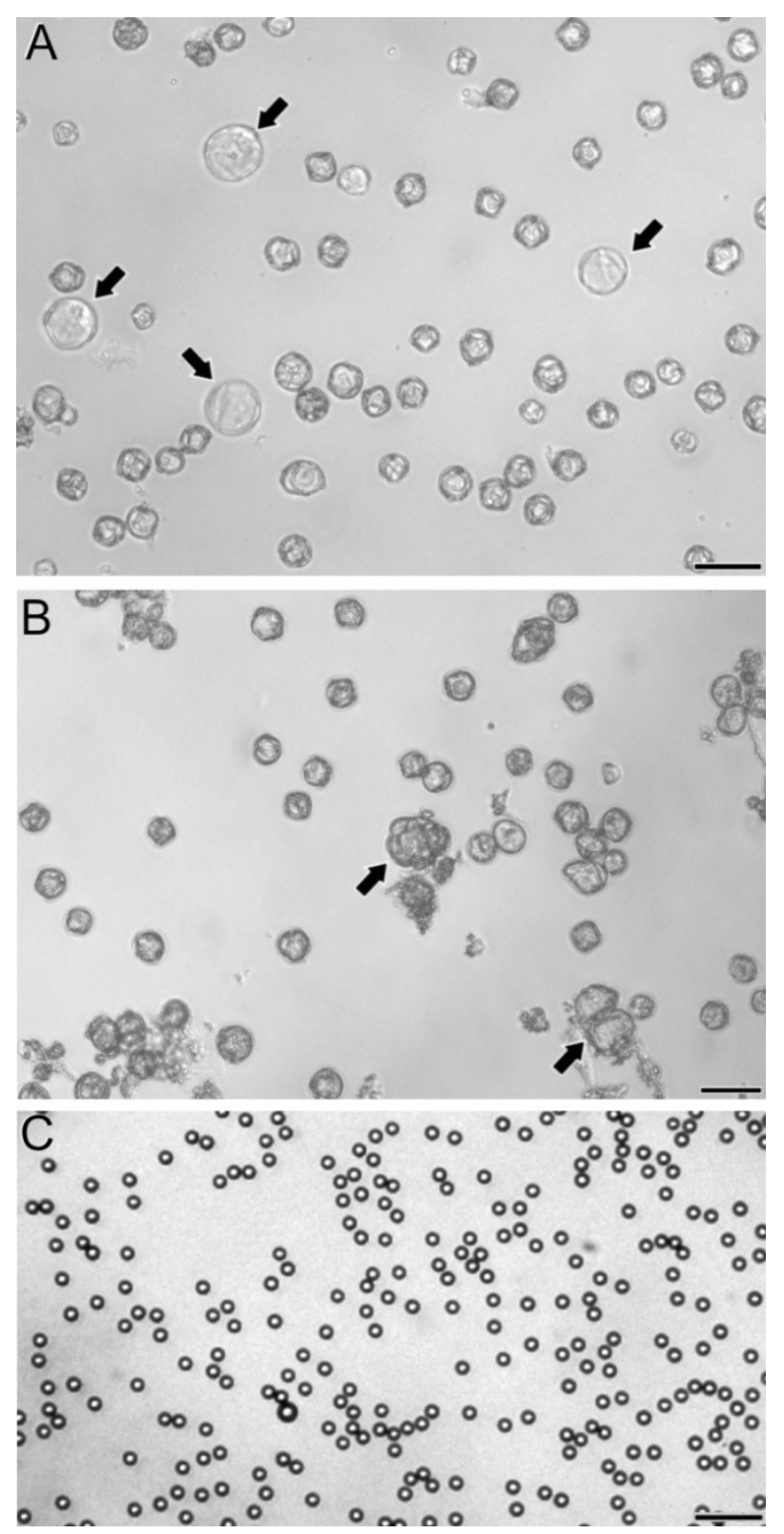

Figure 1: A: 3 day-old eggplant microspore culture. Cultures at this stage are principally composed of regular eggplant microspores together with few slightly enlarged microspores (arrows). B: 18 day-old eggplant microspore culture. Cultures at this stage are principally composed of regular eggplant microspores together with few enlarged microspores or microspore-derived embryos (arrows). C: Fluorospheres. These particles are very regular in size and shape. Bars: 50 $\mu \mathrm{m}$. 
These different developmental fates imply size increases only in embryogenic and pollen-like microspores, but the total number initially inoculated in culture dishes remains unchanged. In turn, suspended fluorospheres (Fig. 1c) look as isolated, uniform particles dispersed in the culture.

\section{Precision and accuracy of methods}

As a preliminary step to be confident with all the analysis performed, we checked the precision of the pipettes used in this work. The pipetting verification procedure described in Materials and methods yielded \%CVs of 0.6 and $0.08 \%$ for the $10-100 \mu$ and the $100-1000 \mu \mathrm{l}$ pipette, respectively. These \%CVs are notably below the $2 \%$ threshold established as a reference by the manufacturer. Therefore, we assumed that our pipettes were well calibrated, and therefore valid for this study.

We calculated the mean, standard deviation, median and 1st and 3rd quartiles of measurements performed with each method (Table 1). Figure 2a shows a graphical representation of the measurements in cultures at days 3 and 18. Next, we performed five independent measurements of fluorosphere suspensions with each method, using the undiluted, 1:2 and 1:10 dilutions. Results are shown in Table 2 and represented in Fig. 2b. For both microspore cultures and fluorosphere suspensions, counts with the Neubauer chamber were in general higher than with all other methods, deviating up to $~ 50 \%$ in average from the rest of methods in the case of fluorospheres. All the means were below the theoretical or real density. In terms of precision, the methods based on flow cytometry showed the highest values (lowest dispersion) and the Neubauer method showed the highest dispersion of data in microspore measurements (Fig. 2). Nevertheless, the Neubauer method showed a high precision in fluorosphere measurements. The precision of methods that count cells from images taken from the dish (automated and manual-counting methods) presented the lowest values. In terms of accuracy, the Neubauer chamber presented the highest means, therefore closest to the expected values ( $\sim 13 \%$ below in average). Results were remarkably closer to the assumed reference value when undiluted suspensions were measured with the Neubauer method, deviating only 22.5\%. However, all other methods were markedly below, with an 
average difference of $\sim 42 \%$, indicating a low accuracy. In undiluted suspensions, some methods seemed to deviate from the expected value more than at higher dilutions, suggesting that their accuracy may depend on particle density (Fig. 2b). That was the case of imagedependent methods (manual-counting and automatic counter methods).

Table 1: Descriptive statistics for each counting method in microspore cultures at days 3 and 18. Values are expressed in thousands of microspores $/ \mathrm{ml}$. Each data set includes: in the first row, mean (SD); in the second row, median ( $1^{\text {st }}-$ $3^{\text {rd }}$ quartile); in the third row, percentage of deviation from the initial value / CV expressed in percentage.

\begin{tabular}{ccc} 
Method & Day 3 & Day 18 \\
\hline \multirow{2}{*}{ Neubauer } & $371.8(65.2)$ & $383.3(79.3)$ \\
& $359.4(322.2-434.2)$ & $400.8(328.6-437.2)$ \\
& $7.1 \% / 17.5 \%$ & $4.2 \% / 20.7 \%$ \\
\hline \multirow{2}{*}{ FC unstained } & $220.3(90.1)$ & $255.2(108.4)$ \\
& $197.8(173.7-247.6)$ & $255.2(216.9-293.6)$ \\
\hline \multirow{2}{*}{ FC + PI } & $44.9 \% / 40.9 \%$ & $36.2 \% / 42.5 \%$ \\
\hline \multirow{2}{*}{ SSC } & $309.0(60.2)$ & $332.0(60.5)$ \\
& $298.8(273.3-324.6)$ & $320.6(289.2-350.4)$ \\
& $22.8 \% / 19.5 \%$ & $17.0 \% / 18.2 \%$ \\
\hline \multirow{2}{*}{ Automated } & $305.4(57.4)$ & $329.6(60.5)$ \\
counter & $354.0(269.2-323.3)$ & $317.8(285.9-350.2)$ \\
& $23.7 \% / 18.8 \%$ & $17.6 \% / 18.4 \%$ \\
\hline & $12.7 \% / 14.4 \%$ & $335.5(52.9)$ \\
Field counting & $358.1(315.8-467.9)$ & $349.5(301.2-376.5)$ \\
& $3.3 \% / 21.1 \%$ & $16.0 \% / 15.9 \%$ \\
\hline
\end{tabular}




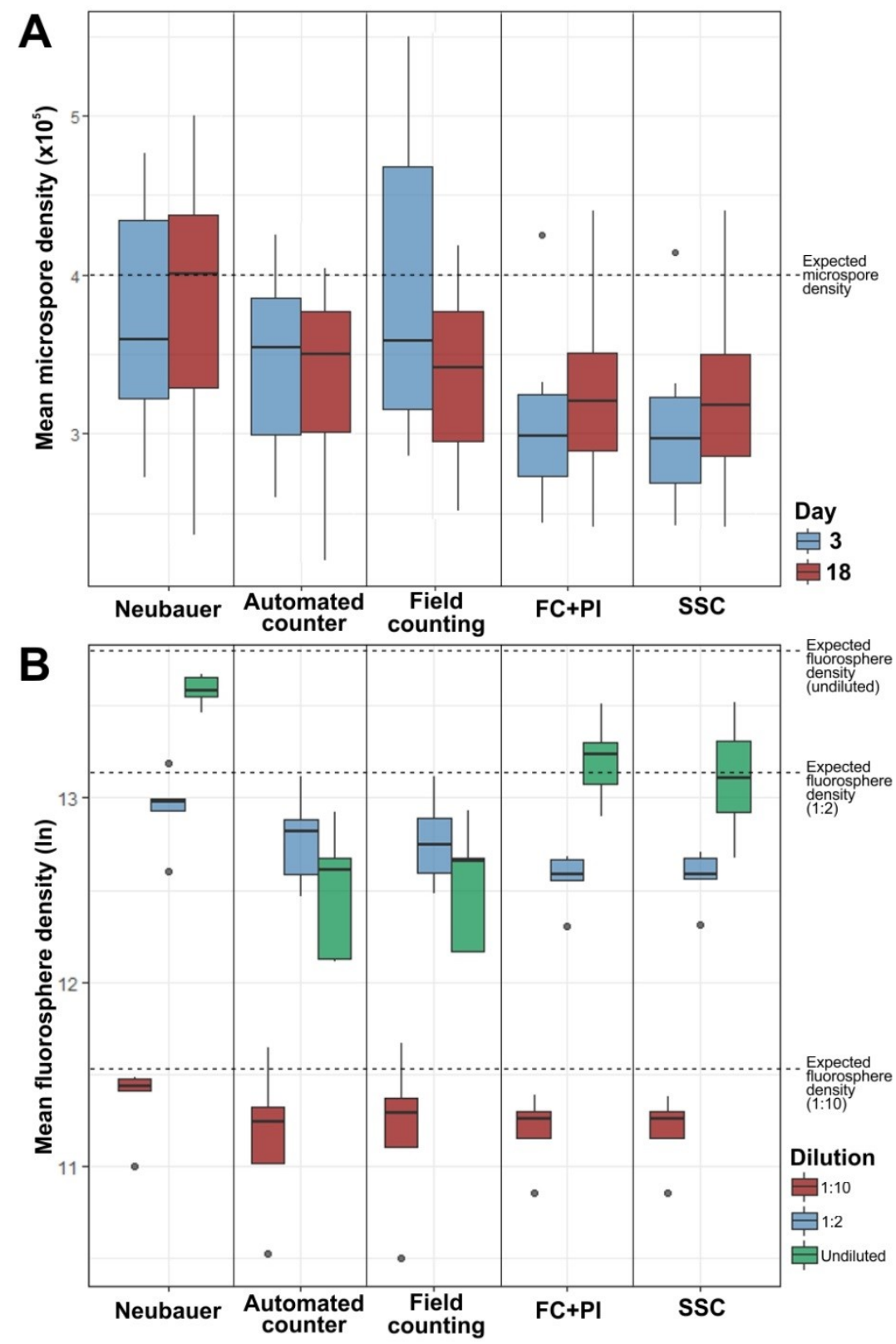

Figure 2: Box-and-whiskers plots for (A) mean densities of 17 different eggplant microspore cultures measured at days 3 and 18 and (B) fluorospheres at three different concentrations: 1:10, 1:2 and 1:1 (undiluted, 1,030,000 microspores $/ \mathrm{ml}$ ). Dashed lines represent the expected microspore (in A) and fluorosphere densities (inB). Note that values in B are expressed as neperian logarithms of mean fluorosphere densities. See text for further details. 
Table 2: Descriptive statistics for each counting method and dilution of fluorosphere suspensions. Values are expressed in thousands of microspores/ml. Each data set includes: in the first row, mean (SD); in the second row, median ( $1^{\text {st }}-3^{\text {rd }}$ quartile); in the third row, percentage of deviation from the initial value certified by the manufacturer / CV expressed in percentage.

\begin{tabular}{rccc} 
Method & 1/10 dilution & 1/2 dilution & Undiluted \\
\hline \multirow{2}{*}{ Neubauer } & $87.2(15.5)$ & $423.3(84.3)$ & $797.9(67.8)$ \\
& $92.7(90.0-96.3)$ & $432.3(412.7-440.0)$ & $795.0(769.7-854.7)$ \\
& $15.3 \% / 17.8 \%$ & $17.8 \% / 29.9 \%$ & $22.5 \% / 8.5 \%$ \\
\hline \multirow{2}{*}{ FC + PI } & $73.5(13.8)$ & $287.2(40.4)$ & $554.6(128.3)$ \\
& $77.3(69.8-80.7)$ & $292.7(283.4-317.6)$ & $559.0(477.4-599.4)$ \\
& $28.7 \% / 18.8 \%$ & $44.2 \% / 14.1 \%$ & $46.2 \% / 23.1 \%$ \\
\hline \multirow{2}{*}{ SSC } & $73.4(13.8)$ & $289.5(42.7)$ & $513.7(166.1)$ \\
& $28.2(69.7-80.6)$ & $293.3(284.8-318.6)$ & $491.2(411.1-602.1)$ \\
Automated & $74.1(28.4)$ & $43.8 \% / 14.7 \%$ & $50.1 \% / 32.3 \%$ \\
\hline counter & $76.1(60.7-82.4)$ & $369.5(291.7-392.1)$ & $299.1(184.8-318.6)$ \\
& $28.1 \% / 38.3 \%$ & $29.7 \% / 25.6 \%$ & $73.0 \% / 34.7 \%$ \\
\hline \multirow{2}{*}{ Field } & $77.2(29.2)$ & $359.2(91.9)$ & $286.2(95.1)$ \\
counting & $79.9(66.4-86.9)$ & $343.9(295.2-397.1)$ & $315.1(192.2-318.6)$ \\
& $25.0 \% / 37.8 \%$ & $30.3 \% / 25.6 \%$ & $72.2 \% / 33.2 \%$ \\
\hline Real value & 103.0 & 515.0 & 1030.0 \\
\hline
\end{tabular}

The use of flow cytometry to measure autofluorescence of unstained microspores was the method that showed the worst performance for all parameters tested (Table 1). In an attempt to find out the cause of such a discrepancy, we speculated that it could be due to sedimentation of microspores at the bottom of the vial, where the aspiration system cannot reach. To test this, we designed a set of experiments (see "Methods" section) consisting of recovering the potentially sedimented microspores through successive washing rounds. However, the results of these experiments were not different from those without washings (data not shown). Therefore, we concluded that microspore autofluorescence was not sufficiently high or homogeneous to detect all the microspores passed through the flow cytometer. As a consequence, we decided to discard flow cytometry with unstained microspores for further experiments. 


\section{Reproducibility of methods}

For the analysis of the reproducibility of methods, we compared measurements in samples at two different moments of culture progression (days 3 and 18). Differences between measurements for each method are depicted by Bland-Altman plots in Fig. 3. As a formal measure, the coefficient of repeatability (CR) was obtained for each method (Table 3) using data of these two different conditions. Moreover, we performed an ANOVA analysis comparing data from both days 3 and 18 where none of the methods showed significant differences (Table 3). Our results showed that both FC + PI (Fig. 3a) and SSC methods (Fig. 3 b) were the most reproducible, showing narrow limits of agreement and the lowest CR values (Table 3). The Neubauer method (Fig. 3c) and the automated counter (Fig. 3d) appeared as moderately reproducible, as they presented wider limits of agreement and higher CR values (Table 3). Finally, field counting (Fig. 3e) was the least reproducible method. It showed a high CR, the widest limits of agreement, and a bias $(\sim 35$ above) much higher than other methods, where bias ranged between 17 and 3 .

Table 3: Assessment of the repeatability and reproducibility of each of the methods tested, expressed by a coefficient of repeatability (CR) and p-value of ANOVA analysis comparing day 3 and day 18 . Bracketed numbers represent the 95\% confidence limits $(\mathrm{Cl})$.

\begin{tabular}{rccc}
\multicolumn{1}{c}{ Method } & \multicolumn{2}{c}{ CR [95\% Cl] } & $\boldsymbol{p}$-value ANOVA \\
\hline Neubauer Chamber & 175.9 & {$[100.6,233]$} & 0,4976 \\
FC + PI & 39.2 & {$[18.1,53.6]$} & 0,6597 \\
SSC & 36.3 & {$[19.5,50.8]$} & 0,6652 \\
Automated counter & 109.6 & {$[66.7,156.8]$} & 0,8236 \\
Field counting & 148.4 & {$[113.3,177.5]$} & 0,1479
\end{tabular}




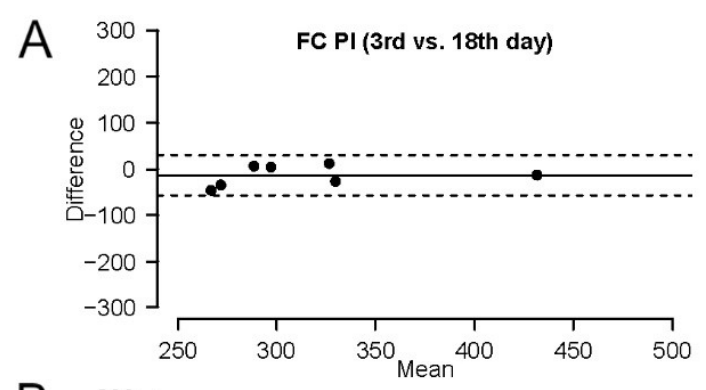

Figure 3: Bland-Altman comparisons of reproducibility of each method by comparing 3 and 18 day-old microspore culture data. Difference values of the $\mathrm{Y}$ axis are expressed in thousands.

B

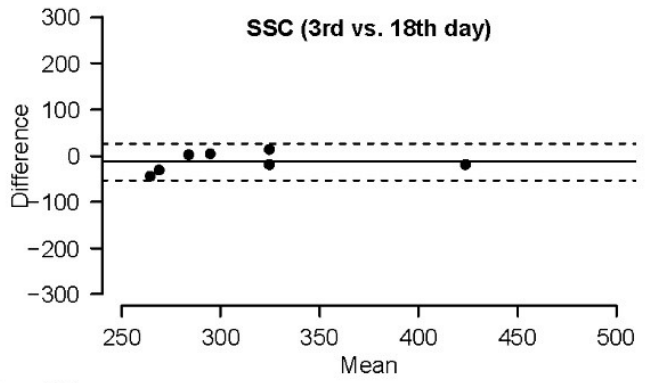

C

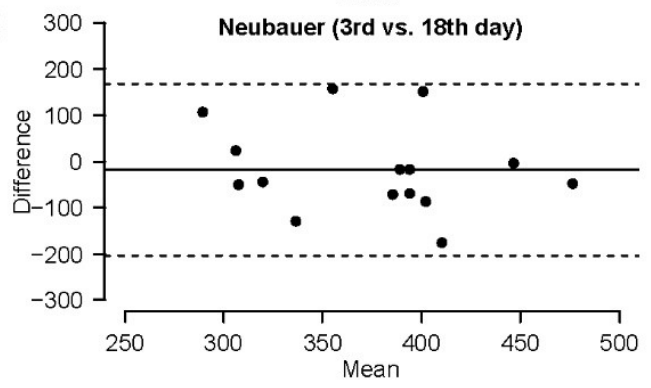

D $\left.\begin{array}{l}300 \\ 200\end{array}\right] \quad$ Automated Counter(3rd vs. 18th day)
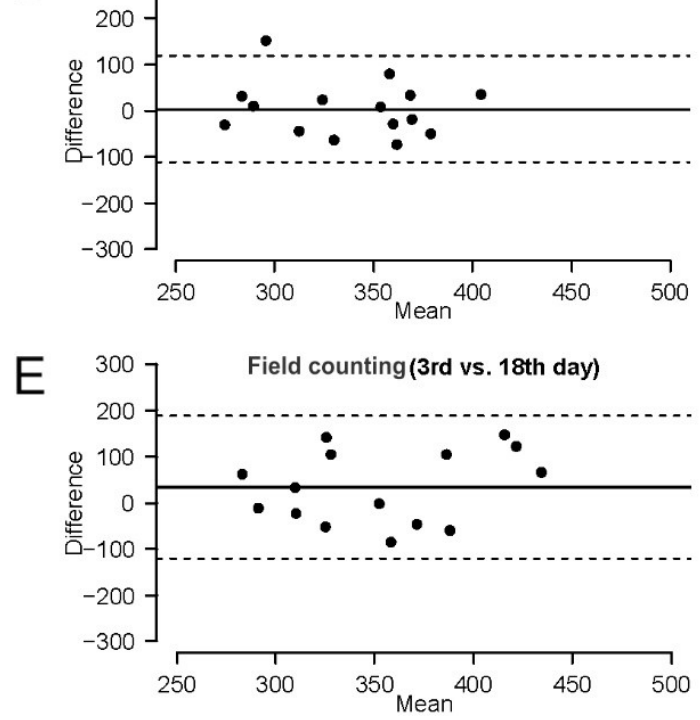


\section{Concordance between methods}

In order to analyze the level of agreement between methods, we performed Bland-Altman plots from microspore density measurements (Fig. 4). The lowest limits of agreement appeared when Neubauer, SSC and FC + PI methods were compared between them (Fig. 4a-c). SSC and FC + PI (Fig. 4c) showed the highest level of agreement, as revealed by the minimal limits of agreement and non significant bias of their comparisons. However, comparisons between Neubauer and cytometrybased methods (Fig. 4a, b) presented a very high bias. Thus, despite their good level of agreement, flow cytometry methods seem to induce a nonnegligible underestimation, at least, with respect to Neubauer method. In general, automated counter and field counting methods showed low concordance with the rest of methods (Fig. $4 \mathrm{~d}-\mathrm{j}$ ), presenting the highest bias when compared to the Neubauer method (Fig. 4d, e), and wide limits of agreement with all methods except between themselves (Fig. 4f). Fluorosphere measurements were not used for this comparison because they have a known, real value to compare with.

Additionally, we assessed agreement between all methods using Lin's concordance correlation coefficient (Table 4). For comparisons between methods, the Lin's concordance correlation coefficient is preferred over the standard Pearson correlation coefficient because a Pearson correlation does not detect constant biases, yielding perfect correlations between remarkably differing methods that have a constant bias. On the other hand, with the Lin's concordance correlation coefficient it is possible to detect the presence of constant bias. Using it, we obtained results similar to those of the Bland-Altman plots. In general, microspore counts showed in all cases values higher than fluorosphere counts. Concordances between methods were minimal when high fluorosphere concentrations were used, with concordance coefficient values near to zero. The best levels of agreement were found in comparisons between flow cytometry-based methods (concordance coefficient ranging from 0.7 to 1.0) and between field and automatic counter (from 0.5 to 1). The Neubauer method showed moderate concordance values when compared to flow cytometry methods (from 0.5 to 0.8 ) except for high fluorosphere concentrations. The lowest level of concordance in microspore counts was found when the field counting method was compared with the Neubauer, PI and SSC. 

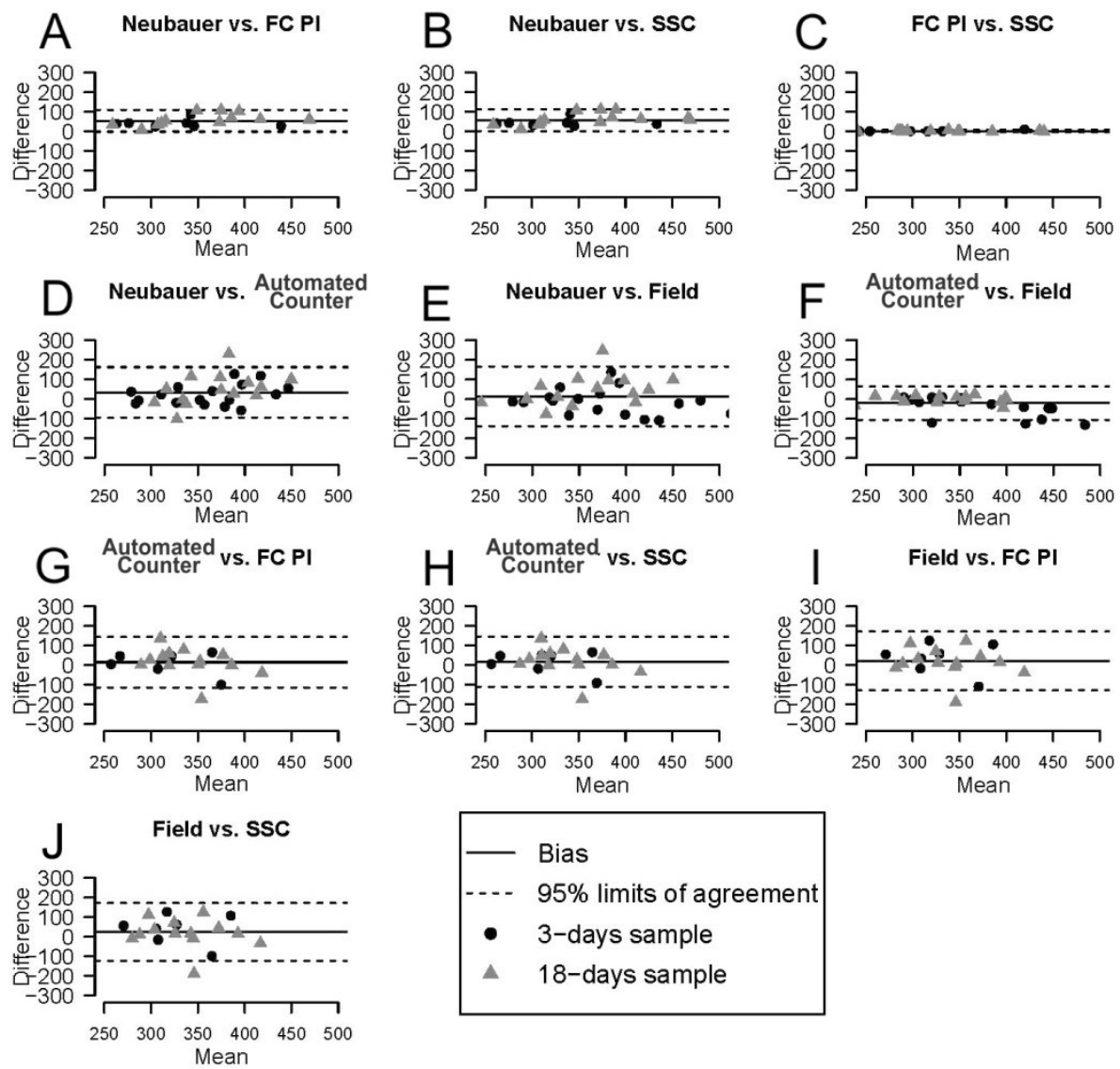

Figure 4: Bland-Altman comparisons of agreement between methods. Difference values of the $Y$ axis are expressed in thousands. 
Table 4: Agreement between methods using Lin's concordance correlation coefficient. See text for further details. High, moderate and low agreement values are represented in bold, regular and italics characters, respectively.

Lin's concordance correlation coefficient

\begin{tabular}{|c|c|c|c|c|c|c|}
\hline & & \multicolumn{2}{|c|}{ Microspore cultures } & \multicolumn{3}{|c|}{ Fluorosphere suspensions } \\
\hline \multicolumn{2}{|c|}{ Comparison } & Day 3 & Day 18 & Undiluted & $\begin{array}{c}1: 2 \\
\text { dilution }\end{array}$ & $\begin{array}{c}\text { 1:10 } \\
\text { dilution }\end{array}$ \\
\hline \multirow[t]{4}{*}{ Neubauer } & $\mathrm{FC}+\mathrm{PI}$ & 0,75 & 0,52 & 0,01 & 0,01 & $\mathbf{0 , 6 3}$ \\
\hline & $\mathrm{SSC}$ & 0,72 & 0,49 & 0,04 & 0,01 & $\mathbf{0 , 6 3}$ \\
\hline & $\begin{array}{r}\text { Automated } \\
\text { counter }\end{array}$ & 0,35 & 0,45 & $o$ & 0,22 & 0,07 \\
\hline & $\begin{array}{r}\text { Field } \\
\text { counting }\end{array}$ & $-0,01$ & 0,52 & $-O, 01$ & 0,21 & $-0,04$ \\
\hline \multirow[t]{3}{*}{$\mathbf{F C}+\mathbf{P I}$} & SSC & $\mathbf{1}$ & $\mathbf{1}$ & $\mathbf{0 , 6 9}$ & $\mathbf{1}$ & $\mathbf{1}$ \\
\hline & $\begin{array}{l}\text { Automated } \\
\text { counter }\end{array}$ & 0,4 & 0,64 & 0,23 & $-0,2$ & 0,22 \\
\hline & $\begin{array}{r}\text { Field } \\
\text { counting }\end{array}$ & $-0,01$ & 0,52 & 0,24 & $-0,14$ & 0,1 \\
\hline \multirow[t]{2}{*}{ SSC } & $\begin{array}{r}\text { Automated } \\
\text { counter }\end{array}$ & 0,41 & 0,62 & 0,2 & $-0,22$ & 0,22 \\
\hline & $\begin{array}{r}\text { Field } \\
\text { counting }\end{array}$ & 0,01 & 0,51 & 0,21 & $-0,16$ & 0,1 \\
\hline $\begin{array}{r}\text { Automated } \\
\text { Counter }\end{array}$ & $\begin{array}{r}\text { Field } \\
\text { counting }\end{array}$ & 0,48 & $\mathbf{0 , 8 8}$ & $\mathbf{0 , 9 9}$ & $\mathbf{0 , 9 9}$ & $\mathbf{0 , 9 8}$ \\
\hline
\end{tabular}

\section{Adjustment of the initial density with different counting methods}

The results presented above were based on microspore cultures whose density was initially adjusted to 400,000 microspores $/ \mathrm{ml}$ using the Neubauer method. All these results revealed a positive bias of the Neubauer method with respect to most of the other methods (Fig. 4). In order to double check this surprising observation, we performed 12 new cultures and adjusted their initial densities using the Neubauer, cell counter, field and FC + PI counting methods (3 cultures adjusted with each method). Since previous results of FC + PI and SSC showed a nearly exact match (Fig. 4j), we omitted the use of SSC for these experiments, assuming practical equivalence of both methods. Then, we checked culture densities at 3 and 18-day old cultures using each of the four methods, as usual. As seen in Fig. 5, an initial adjustment to 400,000 microspores/ml with the Neubauer method made that 3 and 
18-day measurements with the same method were notably similar (2.7 and $4.8 \%$ deviation), but $9.2-21.1 \%$ higher than those of the other methods. When the automated cell counter was used for the initial adjustment, all counts (with the exception of the automated counter) were above 400,000, being notably higher in the case of the Neubauer method (26.8 and $29.1 \%$ for 3 and 18-day old cultures, respectively). An initial adjustment with the field counting method resulted in values around 400,000 when counted with the Neubauer method, but 8.621.1\% lower when counted with the other three methods, including the initial (field counting). When cultures were initially adjusted with the flow cytometer, counts at days 3 with all four methods revolved around 400,000, but they were clearly below at days 18, except for the Neubauer method. Nevertheless, a tendency to underestimate its own initial count was found for flow cytometry at both timepoints. From these results, we could conclude that the automated counter, field counting and flow cytometry tended to underestimate densities, since when they were used to adjust the initial density, all other methods yielded higher counts at both timepoints. This was specially dramatic in the case of flow cytometry and field counting, which at days 3 and 18 yielded counts lower than in the initial adjustment made using the same methods. As to the Neubauer method, it could be thought that it tends to overestimate densities, since in general, this was the method yielding highest counts. However, it must be noted that in most cases, the Neubauer method showed the counts closest to the expected value of 400,000 microspores/ml. 

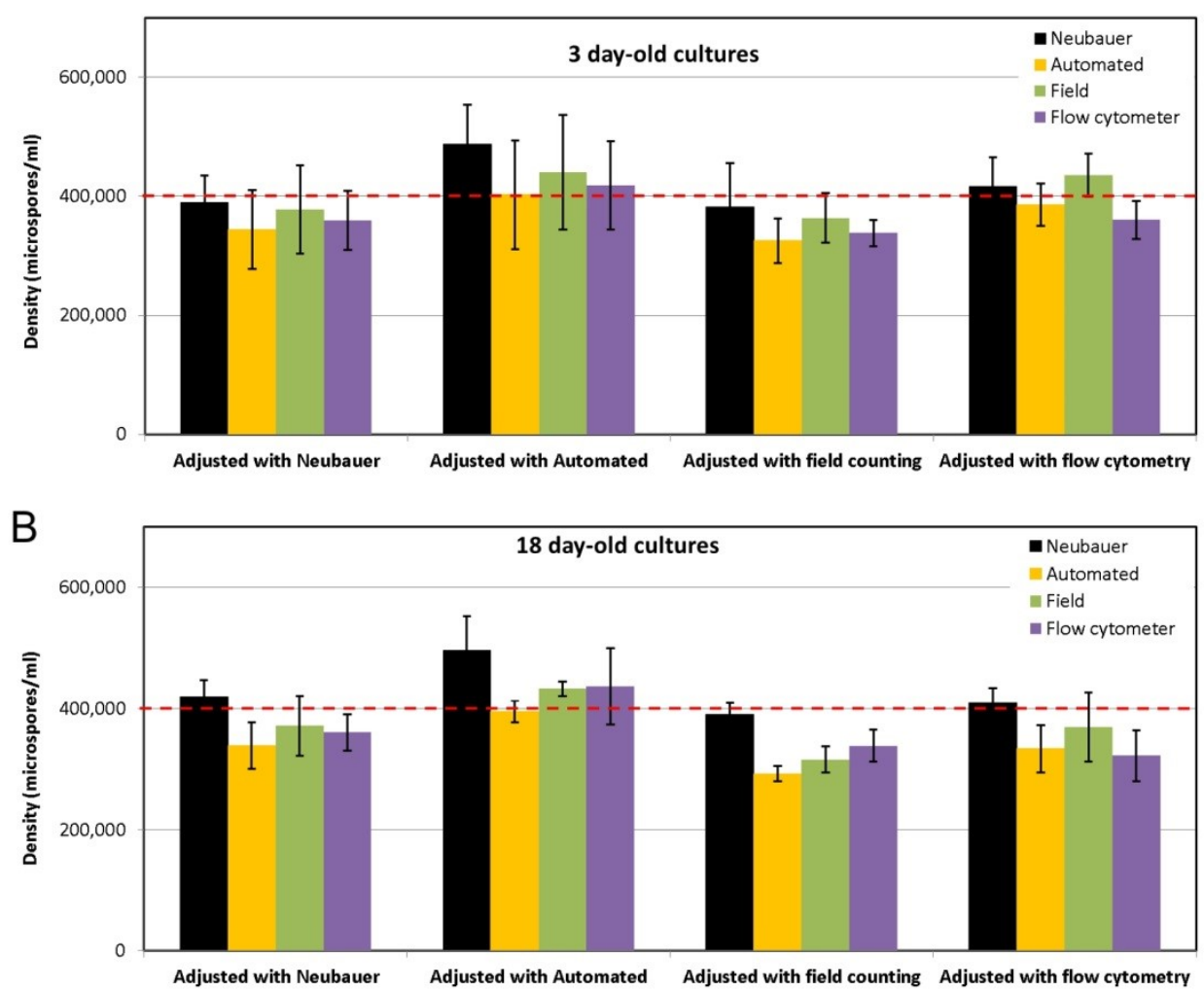

Figure 5: Comparison of microspore density measurements performed at days 3 (A) and 18 (B) with four counting methods in cultures whose initial microspore density was adjusted to 400.000 microspores $/ \mathrm{ml}$ (red dashed line) with each method. Error bars represent standard deviation. See text for further details.

\section{Microspore density estimation from fluorosphere counting in mixed samples}

The common use of fluorospheres to estimate cell densities implies their use as internal standards mixed with cell suspensions, usually for flow cytometry. In our study, we also tried to estimate microspore density from a known quantity of fluorospheres mixed with cells. Measurements were performed with Neubauer, automated counter, field counting and SSC method. FC + PI method was omitted because of its similarity with SSC. Results of these assays are shown in Table 5. The 
automated counter image detection system was unable to differentiate between fluorospheres (smaller) and microspores (larger), so we could not obtain any estimation in this case. For the rest of cases, estimations of microspore density were always above the theoretical value, ranging from 19 to $37 \%$ of deviation. Thus, we concluded that at least for microspores, this method, although fast and straightforward, is not accurate enough, at least when used with non flow cytometry methods. Indeed, the best results were obtained with the latter, which is reasonable since this counting strategy has been designed for flow cytometry.

Table 5: Microspore densities in 3-day old cultures calculated from fluorosphere counting in mixed samples Values are expressed in thousands of particles/ml. Each data set includes in the first row the mean (and SD) and in the second row the percentage of deviation from the adjusted density (shown in the last row).

\begin{tabular}{rc} 
Method & Values \\
\hline Neubauer & $621.9(205.2)$ \\
& $36.8 \%$ \\
SSC & $540.7(83.2)$ \\
& $19 \%$ \\
Field counting & $540.5(151.6)$ \\
\hline Adjusted density & $18.9 \%$ \\
\hline
\end{tabular}

\section{Discussion}

For most cell culture systems, optimal cell progression depends on the optimization of the initial cell density at the onset of the culture. A paradigmatic example of this is isolated microspore culture, where the developmental switch relies on the successful optimization of many different experimental parameters that critically affect the efficiency of the process, and one of them is the density at which microspores are 
suspended in liquid medium. It affects not only the efficiency of the induction of microspores towards embryogenesis, but also a successful conversion of induced microspores into viable, germinating embryos (Reynolds 1997; Castillo et al. 2000; Wang et al. 2000; Ma et al. 2004; Kim et al. 2008; Kim et al. 2013). Due to the importance of this initial step, not only for microspore culture but for virtually all animal and plant cell cultures, in this work we compared the use of different methods that have been used or could potentially be used to calculate particle densities using two different particles: eggplant microspores and fluorospheres. In light of our results, we can divide the methods used in three groups: flow cytometry methods, automated counter and field counting, and Neubauer chamber. Each has both positive and negative aspects. They are summarized in Table 6 and discussed below.

\section{Flow cytometry methods are the most reproducible, but they have low accuracy and precision}

We evaluated three different methods based on the use of flow cytometry. The first method consisted on the analysis of unstained microspores, assuming that the natural autofluorescence of the exine coat could be sufficiently high to be detected and quantified by the system. However, the analysis of seven 3-day old cultures was enough to realize that this method presented serious limitations. It seemed that exine autofluorescence is not sufficiently intense and/or homogeneous to be detected in all the microspores, at least in our eggplant microspore cultures. Obviously, we strongly discourage its use.

The FC + PI method, together with SSC, provided the most reproducible results, despite the different physical principles used to identify and count flowing microspores. FC + PI and SSC exhibited almost identical results in all the experiments and statistical tests performed. Nevertheless, evaluation of accuracy (using a standard with a known concentration) and precision (with a high number of measurements) lead us to conclude that cytometry methods are not as accurate and precise as the rest. In addition, they repeatedly showed a negative bias with respect to other methods, specially the Neubauer method. Thus, a question arises as to why the flow cytometry methods 
we used have such a low performance. The use of fluorescent beads is a well- known method to calculate cell densities through flow cytometry, at least for animal cell cultures (Raina and Irfan 1998; Kim et al. 2008; Huang et al. 2010). Our work is not the only one showing a consistent bias (either positive or negative) of the Neubauer method compared to others (Bailey et al. 2007). However, other studies have compared hemacytometers versus automated counting methods in animal cells (Tucker et al. 1994; Collins et al. 2010; Huang et al. 2010; Johnston 2010; Ongena et al. 2010; Louis and Siegel 2011; Cadena-Herrera et al. 2015), and no significant bias has been reported. After a thorough study of the different user-based technical factors that could potentially cause such a bias (including bad calculations, wrong chamber dimensions, pipetting errors, uneven cell distribution, contamination, user-to-user variation, and filling problems, among others), we found a possible cause that might explain such a bias. Several studies comparing methods to calculate the flow rate of flow cytometer fluidics systems, have acknowledged the limitations of many flow cytometers to perform a proper estimation of the volume loaded (Storie et al. 2004; Marie et al. 2005), which may preclude a right estimation of particle densities. This led us to evaluate the volume estimation accuracy of our flow cytometer and, as expected, the effective volume loaded never coincided with the volume estimated by the device (data now shown). This could surely explain the negative bias and the low accuracy and precision of the flow cytometry-based methods we used.

On the other hand, flow cytometers are expensive systems, even in their basic, compact versions. As to FC + PI, a CyFlow cytometer equipped with a Nd-YAG green laser for PI is around $€_{35}, 000$. It is possible to use other fluorescent stains excitable by UV LED light sources, which are cheaper than Nd-YAG green lasers. For example, the CellTracker Blue CMAC Dye from Molecular Probes. However, although UV LED light sources could drop the price of this system down to $\sim$ €29,000, this alternative may still be expensive for many research groups. Another limitation of this method is the need for staining. We used $1 \mathrm{~h}$ to ensure a complete and reproducible PI staining. Possibly, this time could be optimized trying different combinations of incubation time and PI concentration, or even other dyes. Anyway, a staining step will always be needed, which may slow down the whole process considerably. 
The third flow cytometry-based method tested was SSC analysis. Although we performed this analysis with PI-stained samples, the physics of this method allows for an estimation of the internal complexity of individual particles independent of their fluorescent emission. This means that the time-consuming staining step could be avoided, needing only few min to analyze tens of thousands cells. However, it must be noted that the basic equipment needed to perform this type of analysis has an estimated round cost revolving around $€_{35}$,000. A similar model with two light sources (a Nd-YAG green laser + a UV LED lamp) may be around $€$ 40,00o. Clearly, this equipment may not be routinely available for all cell culture laboratories. Alternatively, the user might carry culture vessels to a flow cytometry facility. However, this would imply long times and potential risks for cultured cells, perhaps incompatible with routine cell culturing. Clearly, we discourage this method for that purpose.

\section{Automated counter and field counting methods have problems associated with image acquisition}

The second group of methods tested was field and automatic counting. The working principle of both methods is similar, but as a difference, the field counting method needs only a microscope, and is largely based on an interaction with the user, who must acquire the images or observe microscopic fields, and then count all the particles observed. In principle, it could be thought that a human eye would be more accurate than a machine for cell identification and counting. The different comparisons of the automated counter with field counting revealed that in general, results are very similar between them, which indicates that automated image analysis is at least as correct as human observations. In addition, user-based methods use to be time-consuming and subjected to user bias and putative lack of expertise. Therefore, we postulate that, despite their reduced price and ease of use, the methods that imply a higher user interaction should be avoided in order to increase accuracy and reduce the experimental variation between cultures. 
On the other hand, these two methods showed a low accuracy and a moderate precision (see Table 6). In our experience, we have detected some image acquisition issues that might explain it. First of all, we have consistently observed that cells and fluorospheres do not distribute homogeneously in the culture dish, which may make mandatory a software-based tool to compensate for such uneven distribution. The second reason could be automatic focusing, which is common to most image-based automatic counting devices. The algorithm of the equipment we used searches the most contrasted area in the z-axis and takes pictures of it. The problem appears when not all particles are well focused or they are in different focal planes, which preclude their proper identification. Moreover, in the case of fluorospheres, suspended in a viscous solution, long times are needed for them to settle down. In some cases, they do not even settle down, and stay floating. Summarizing, automatic and manual counting methods may not be the best choice to estimate cell or particle suspension densities because they are prone to miss particles out of the focal plane.

The estimated price of the automated counter we used is around $€ 15,000-€ 20,000$. However, it must be noted that it includes a built-in microscope. Other, basic versions of this system need a microscope to be coupled to, but they are much cheaper, which makes it more convenient when the laboratory is already equipped with a light microscope. Once installed and calibrated, it is a rather straightforward and easy-to-use system that allows for quick measurements of cell densities. Other systems such as the Cellometer Auto T4 (Nexcelom Biosciences) have a built-in CCD chip in order to load, image and analyze the sample in the same machine, or use non-image-based methods to count cells, such as the Scepter Cell Counter from Millipore, which uses the impedancebased Coulter principle to detect cells. This avoids the need for a microscope, but for some microscope-independent systems, the cost is similar to that of a microscope + a microscope-coupled automated counter. In addition, Coulter-based systems are applicable only to a limited range of particle sizes. All this considered, automated cell counters appear as a more affordable alternative to flow cytometers. 
Table 6: Comparison of the five methods used to calculate microspore density. Accuracy is expressed in terms of deviation from the real/inicial value, precision in terms of coefficient of variation (CV) and reproducibility in terms of coefficient of repeatability (CR). Estimated round prices are given for a Partec Cyflow cytometer excluding taxes.

\begin{tabular}{|c|c|c|c|c|c|}
\hline & Neubauer & $\mathbf{F C}+\mathbf{P I}$ & SSC & $\begin{array}{c}\text { Automated } \\
\text { counter }\end{array}$ & $\begin{array}{l}\text { Field } \\
\text { counting }\end{array}$ \\
\hline $\begin{array}{c}\text { Accuracy } \\
\text { (\% deviation) }\end{array}$ & High (13\%) & Low (32\%) & Low (30\%) & Low (32\%) & Low (33\%) \\
\hline Precision (CV) & High (17\%) & Low (26\%) & Low (27\%) & $\begin{array}{l}\text { Moderate } \\
(19 \%)\end{array}$ & $\begin{array}{l}\text { Moderate } \\
(21 \%)\end{array}$ \\
\hline $\begin{array}{l}\text { Reproducibility } \\
\text { (CR) }\end{array}$ & $\begin{array}{c}\text { Moderate } \\
(175.9)\end{array}$ & High (39.2) & High (36.3) & $\begin{array}{c}\text { Moderate } \\
(109.6)\end{array}$ & Low (248.4) \\
\hline $\begin{array}{c}\text { Approximate } \\
\text { time needed } \\
\text { (min) }\end{array}$ & 45 & 901 & 15 & 15 & 30 \\
\hline Ease of use & Very easy & Moderate & Easy & Very easy & Easy \\
\hline $\begin{array}{c}\text { Estimated } \\
\text { round basic } \\
\text { price }\end{array}$ & $\begin{array}{c}€ 260+ \\
\text { microscope }\end{array}$ & $\begin{array}{c}\sim € 35.000 \\
\text { (optional } \\
\sim € 29.000 \text { ) }\end{array}$ & $\sim €_{35.000}$ & $\begin{array}{l}€ 15.000- \\
€ 20.000\end{array}$ & $\begin{array}{l}\text { Inverted } \\
\text { microscope }\end{array}$ \\
\hline Strength & $\begin{array}{c}\text { Cheap, } \\
\text { straightforward } \\
\text { and accurate }\end{array}$ & $\begin{array}{c}\text { Highly } \\
\text { reproducible }\end{array}$ & $\begin{array}{c}\text { Fast, highly } \\
\text { reproducible, } \\
\text { straightforward }\end{array}$ & $\begin{array}{l}\text { Fast and } \\
\text { easy }\end{array}$ & $\begin{array}{l}\text { Very cheap and } \\
\text { straightforward }\end{array}$ \\
\hline Weakness & $\begin{array}{l}\text { Only good } \\
\text { precision with } \\
\text { high number of } \\
\text { countings }\end{array}$ & $\begin{array}{c}\text { Slow, } \\
\text { expensive, } \\
\text { low accuracy } \\
\text { and } \\
\text { precision }\end{array}$ & $\begin{array}{l}\text { Expensive, low } \\
\text { accuracy and } \\
\text { precision }\end{array}$ & $\begin{array}{l}\text { Moderately } \\
\text { expensive } \\
\text { and accurate }\end{array}$ & $\begin{array}{l}\text { Laborious, low } \\
\text { accuracy and } \\
\text { reproducibility }\end{array}$ \\
\hline
\end{tabular}

${ }^{1}$ Including the duration of incubation with PI

\section{The Neubauer chamber showed the best overall performance}

As mentioned in the introduction, the methods based on the use of counting chambers appear as the most popular and widely used to calculate cell densities. Most likely, this is due to its affordability. Indeed, this method requires only a Neubauer chamber (around $€ 260$ ) and a basic microscope, available in most laboratories. There may also be a general assumption that, since the use of these methods is widely extended, they must be sufficiently well known and therefore, accurate and reliable. After many different experiments, using both microspores and fluorospheres, the Neubauer method repeatedly showed a positive bias with respect to the other methods used, but its means were always 
near the theoretical value, whereas the other methods were always below. In addition, analysis of accuracy and precision demonstrated that it is the most reliable method on the basis of its low dispersion and high accuracy. However, it must be noted that the number of cells counted in this work is much higher than that of common routine counts, which surely compensated for the very different results we observed in individual data from each chamber grid (data not shown). Due to this, a major limitation of this method might be the reduced number of cells counted in routine procedures. However, it can be easily overcome by increasing the amount of counted particles.

\section{Conclusions}

Based on our results, it seems evident that among the methods used, those based on flow cytometry are, by far, the most reproducible and concordant, but the worst in terms of accuracy and precision, likely due to an improbable flow rate measurement. Automatic counter and field counting methods showed a low accuracy but a moderate precision. Their actual problem relates to the image acquisition system, improvable too. Perhaps the most important conclusion of this work is that counting chambers and in particular Improved Neubauer chambers are the most reasonable option to routinely measure cell densities. This is important since their use is widely extended among the research community, but there are not abundant comprehensive comparisons to support its use from a technical perspective. In most cases, the reason for this adoption has been "because it was used previously in the protocol we are applying". Nevertheless, our advice to future users of Neubauer chambers would be to increase the number of cells counted in each assay, in order to reach these standards of accuracy and low dispersion. 


\section{References}

Bailey E, Fenning N, Chamberlain S, Devlin L, Hopkisson J, Tomlinson M (2007) Validation of Sperm Counting Methods Using Limits of Agreement. J Androl 28 (3):364-373. doi:10.2164/jandrol.106.002188

Bland JM, Altman DG (1999) Measuring agreement in method comparison studies. Statistical Methods in Medical Research 8:135-160

Cadena-Herrera D, Esparza-De Lara JE, Ramírez-Ibañez ND, López-Morales CA, Pérez NO, Flores-Ortiz LF, Medina-Rivero E (2015) Validation of three viable-cell counting methods: Manual, semi-automated, and automated. Biotechnology Reports 7:9-16. doi:http://dx.doi.org/10.1016/j.btre.2015.04.004

Castillo AM, Valles MP, Cistue L (2000) Comparison of anther and isolated microspore cultures in barley. Effects of culture density and regeneration medium. Euphytica 113 (1):1-8

Collins CE, Young NA, Flaherty DK, Airey DC, Kaas JH (2010) A rapid and reliable method of counting neurons and other cells in brain tissue: a comparison of flow cytometry and manual counting methods. Front Neuroanat 4:5. doi:10.3389/neuro.05.005.2010

Corral-Martínez P, Parra-Vega V, Seguí-Simarro JM (2013) Novel features of Brassica napus embryogenic microspores revealed by high pressure freezing and freeze substitution: evidence for massive autophagy and excretion-based cytoplasmic cleaning. J Exp Bot 64 (10):3061-3075. doi:10.1093/jxb/ert151

Corral-Martínez P, Seguí-Simarro JM (2012) Efficient production of callusderived doubled haploids through isolated microspore culture in eggplant (Solanum melongena L.). Euphytica 187 (1):47-61. doi:10.1007/s10681-012-0715-Z

Corral-Martínez P, Seguí-Simarro JM (2014) Refining the method for eggplant microspore culture: effect of abscisic acid, epibrassinolide, polyethylene glycol, naphthaleneacetic acid, 6-benzylaminopurine and arabinogalactan proteins. Euphytica $195 \quad$ (3):369-382. doi:10.1007/s10681-013-1001-4

Gémes Juhász A, Kristóf Z, Vági P, Lantos C, Pauk J (2009) In vitro anther and isolated microspore culture as tools in sweet and spice pepper breeding. Acta Hort 829:61-64 
Gu HH, Zhou WJ, Hagberg P (2003) High frequency spontaneous production of doubled haploid plants in microspore cultures of Brassica rapa ssp chinensis. Euphytica 134 (3):239-245

Hervás D (2014) random_path: Shortest route for random sampling in circles. ZENODO. doi:10.5281/zenodo.11825

Hoekstra S, Vanzijderveld MH, Heidekamp F, Vandermark F (1993) Microspore culture of Hordeum vulgare L. - The influence of density and osmolality. Plant Cell Rep 12 (12):661-665

Höfer M (2004) In vitro androgenesis in apple-improvement of the induction phase. Plant Cell Rep 22 (6):365-370. doi:10.1007/s00299-003-0701-y

Huang B, Bird S, Kemble R, Simmonds D, Keller W, Miki B (1990) Effects of culture density, conditioned medium and feeder cultures on microspore embryogenesis in Brassica napus L. cv. Topas. Plant Cell Rep 8 (10):594-597

Huang L-C, Lin W, Yagami M, Tseng D, Miyashita-Lin E, Singh N, Lin A, Shih S-J (2010) Validation of cell density and viability assays using Cedex automated cell counter. Biologicals 38 (3):393-400. doi:10.1016/j.biologicals.2010.01.009

Johnston G (2010) Automated handheld instrument improves counting precision across multiple cell lines. BioTechniques 48 (4):325-327

Kim M, Jang I-C, Kim J-A, Park E-J, Yoon M, Lee Y (2008) Embryogenesis and plant regeneration of hot pepper (Capsicum annuum L.) through isolated microspore culture. Plant Cell Rep 27 (3):425-434

Kim M, Park E-J, An D, Lee Y (2013) High-quality embryo production and plant regeneration using a two-step culture system in isolated microspore cultures of hot pepper (Capsicum annuum L.). Plant Cell Tissue Organ Cult 112 (2):191-201. doi:10.1007/s11240-012-0222-x

Kobayashi T, Higashi K, Saitou T, Kamada H (1999) Physiological properties of inhibitory conditioning factor(s), inhibitory to somatic embryogenesis, in high-density cell cultures of carrot. Plant Sci 144:69-75

Lantos C, Juhasz AG, Vagi P, Mihaly R, Kristof Z, Pauk J (2012) Androgenesis induction in microspore culture of sweet pepper (Capsicum annuum L.). Plant Biotechnol Rep 6 (2):123-132. doi:10.1007/s11816-011-0205-0

Li HC, Devaux P (2003) High frequency regeneration of barley doubled haploid plants from isolated microspore culture. Plant Sci 164 (3):379-386. doi:10.1016/s0168-9452(02)00424-7

Lin LI (1989) A concordance correlation coefficient to evaluate reproducibility. Biometrics 45:255-268 
Louis KS, Siegel AC (2011) Cell Viability Analysis Using Trypan Blue: Manual and Automated Methods. In: Stoddart MJ (ed) Mammalian Cell Viability, vol 740. Methods in Molecular Biology. Humana Press, pp 712. doi:10.1007/978-1-61779-108-6_2

Ma R, Guo YD, Pulli S (2004) Comparison of anther and microspore culture in the embryogenesis and regeneration of rye (Secale cereale). Plant Cell Tissue Organ Cult 76 (2):147-157

Marie D, Simon N, Vaulot D (2005) Phytoplankton Cell Counting By Flow Cytometry. In: Alndersen RA (ed) Algal Culturing Techniques, vol 17. Elsevier, Burlington, MA, USA, pp 253-267. doi:10.1016/B978012088426-1/50018-4

Nageli M, Schmid JE, Stamp P, Buter B (1999) Improved formation of regenerable callus in isolated microspore culture of maize: impact of carbohydrates, plating density and time of transfer. Plant Cell Rep 19 (2):177-184

Nelson M, Mason A, Castello M-C, Thomson L, Yan G, Cowling W (2009) Microspore culture preferentially selects unreduced (2n) gametes from an interspecific hybrid of Brassica napus L. $\times$ Brassica carinata Braun. Theor Appl Genet 119 (3):497-505. doi:10.1007/s00122-009-1056-8

Nicoloso FT, Val J, Vanderkeur M, Vaniren F, Kijne JW (1994) Flow-cytometric cell counting and DNA estimation for the study of plant cell population dynamics. Plant Cell Tissue Organ Cult 39 (3):251-259. doi:10.1007/bfooo35978

Ongena K, Das C, Smith JL, Gil S, Johnston G (2010) Determining Cell Number During Cell Culture using the Scepter Cell Counter. Journal of Visualized Experiments : JoVE (45):2204. doi:10.3791/2204

Raina SK, Irfan ST (1998) High-frequency embryogenesis and plantlet regeneration from isolated microspores of indica rice. Plant Cell Rep 17 (12):957-962

Regner F (1996) Anther and microspore culture in Capsicum. In: Jain SM, Sopory SK, Veilleux RE (eds) In vitro haploid production in higher plants, vol 3. Kluwer Academic, Dordrecht, The Netherlands, pp 77-89

Reynolds TL (1997) Pollen embryogenesis. Plant Mol Biol 33 (1):1-10

Rivas-Sendra A, Campos-Vega M, Calabuig-Serna A, Seguí-Simarro JM (2017) Development and characterization of an eggplant (Solanum melongena) doubled haploid population and a doubled haploid line with high androgenic response. Euphytica 213 (4):89. doi:10.1007/s10681-017-1879-3 
Rivas-Sendra A, Corral-Martínez P, Camacho-Fernández C, Seguí-Simarro JM (2015) Improved regeneration of eggplant doubled haploids from microspore-derived calli through organogenesis. Plant Cell Tissue Organ Cult 122 (3):759-765. doi:10.1007/s11240-015-0791-6

Rudolf K, Bohanec B, Hansen M (1999) Microspore culture of white cabbage, Brassica oleracea var. capitata L.: Genetic improvement of nonresponsive cultivars and effect of genome doubling agents. Plant Breed $118(3): 237-241$

Salas P, Rivas-Sendra A, Prohens J, Seguí-Simarro JM (2012) Influence of the stage for anther excision and heterostyly in embryogenesis induction from eggplant anther cultures. Euphytica 184 (2):235-250. doi:10.1007/s10681-011-0569-9

Sato S, Katoh N, Iwai S, Hagimori M (2005) Frequency of spontaneous polyploidization of embryos regenerated from cultured anthers or microspores of Brassica rapa var. pekinensis L. and B. oleracea var. capitata L. Breed Sci 55 (1):99-102

Schulze D, Pauls KP (1998) Flow cytometric characterization of embryogenic and gametophytic development in Brassica napus microspore cultures. Plant Cell Physiol 39 (2):226-234

Schulze D, Pauls KP (2002) Flow cytometric analysis of cellulose tracks development of embryogenic Brassica cells in microspore cultures. New Phytol 154 (1):249-254

Schween G, Hohea A, Koprivova A, Reski R (2003) Effects of nutrients, cell density and culture techniques on protoplast regeneration and early protonema development in a moss, Physcomitrella patens. J Plant Physiol 160:209-212

Shapiro H (1994) Practical Flow Cytometry. 3rd edn. Alan R. Liss, New York

Simmonds DH, Long NE, Keller WA (1991) High plating efficiency and plant regeneration frequency in low density protoplast cultures derived from an embryogenic Brassica napus cell suspension Plant Cell Tissue Organ Cult 27 (3):231-241. doi:10.1007/bfoo157586

Storie I, Sawle A, Goodfellow K, Whitby L, Granger V, Ward RY, Peel J, Smart T, Reilly JT, Barnett D (2004) Perfect count: A novel approach for the single platform enumeration of absolute $\mathrm{CD}_{4}+$ T-lymphocytes. Cytometry Part B: Clinical Cytometry 57B (1):47-52. doi:10.1002/cyto.b.10065

Team RDC (2011) R: A Language and Environment for Statistical Computing. . Vienna, Austria : the R Foundation for Statistical Computing. 
Tucker KG, Chalder S, Al-Rubeai M, Thomas CR (1994) Measurement of hybridoma cell number, viability, and morphology using fully automated image analysis. Enzyme Microb Technol 16 (1):29-35. doi:10.1016/0141-0229(94)90106-6

Wang M, van Bergen S, Van Duijn B (2000) Insights into a key developmental switch and its importance for efficient plant breeding. Plant Physiol 124 (2):523-530

\section{Supplegmentary material}

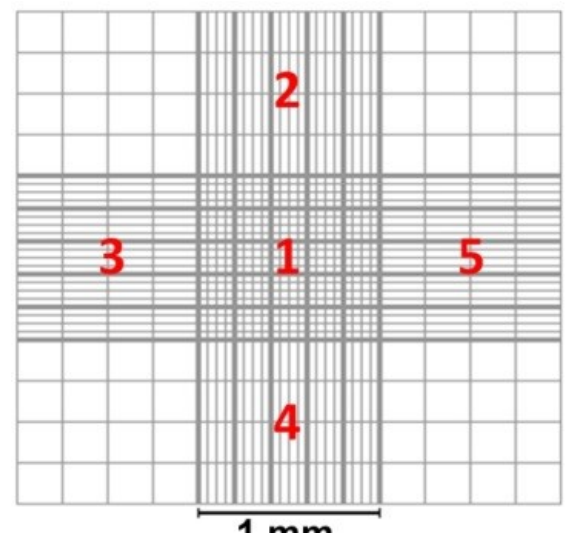

$1 \mathrm{~mm}$

Supplementary Figure S1: Improved Neubauer chamber showing the different large and small grids.

Supplementary Table S1: Definition of the different parameters used in this article based on ISO normative.

Accuracy The closeness of agreement between a test result and the accepted reference value.

Bias The difference between the expectation of the test results and an accepted reference value.

Precision The closeness of agreement between independent test results obtained under stipulated conditions.

Reproducibility Precision under different conditions. 


\section{Chapter 2}

\section{Role of growth regulators and cell density in Solanum melongena $\mathrm{L}$. isolated microspore culture}

Carolina Camacho-Fernández, Alba Rivas-Sendra and Jose M. SeguíSimarro

Cell Biology Group - COMAV Institute, Universitat Politècnica de València, Valencia, Spain.

Keywords: growth regulators, hormones, microspore culture, microspore embryogenesis, eggplant, Solanum melongena, cell density.

A part of this work is published in Euphytica (2020)216:167 https://doi.org/10.1007/s10681-020-02709-4. 


\section{Abstract}

As many other processes in vitro, microspore culture requires certain conditions to develop new individuals from differentiated cells using natural plant totipotency. Among others, cell density and growth regulators have shown to have an important role in these processes. In this work, different cell densities and overall growth regulators level in culture media were used to test the effect they have over microspore embryogenesis. Endogenous and exogenous growth regulator levels were measured in microspores and medium culture using HPLC technique. Our results showed that 200.000 microspores $/ \mathrm{ml}$ as plating density and lower levels of GRs promoted the best efficiency and morphology in obtaining microspore-derived structures. GRs dynamics in eggplant microspore culture is unraveled in the present chapter. 


\section{Introduction}

Nowadays, many of the breeding programs in important crops are aimed to obtain hybrids with improved and uniform characters. Hybrids are obtained by crossing two pure lines, homozygous for all the characters (Cubero 2003). There are several ways to obtain this pure line, but one of the easiest and fastest is obtaining double haploids by microspore embryogenesis. Inducing embryogenesis to microspores requires optimal in vitro culture conditions in order to develop embryos from these haploid cells (Corral-Martínez and Seguí-Simarro 2014). There are two techniques of in vitro culture that pursue this objective: anther culture and isolated microspore culture (Seguí-Simarro 2010). In this work we focus on the culture conditions needed for microspore embryogenesis in isolated microspore culture.

As all in vitro system, isolated microspore culture requires a reprogramming of cell fate to obtain a new complete individual using the natural totipotency of plant cells (Soriano et al. 2013). In vitro environmental conditions are crucial for the correct development of cultured cells or tissue. In the system we use in the present study, eggplant microspores are induced to divide via starvation and heat shock during 3 days. After some days (7-14 days after isolation) cells start dividing and develop as a globular embryo (Corral-Martínez and SeguíSimarro 2012). Once they reach this point, structures are not able to perform the transition from globular to radial symmetry required to finish embryogenesis, so they start dedifferentiate and develop as calli, visible with a naked eye 30 days after the isolation. Among others, growth regulators have shown to have a very important role in all the stages of an in vitro system (Hoekstra et al. 1996; Ahmadi et al. 2014; Rodríguez-Sanz et al. 2015). For microspore embryogenesis, there have been several studies that shed light in the specific role of this type of molecules, but still optimization is needed in each protocol, depending on the species, genotype, etc.

Auxins and cytokinins control cellular division and morphogenesis (Skoog F. 1973). Their function is antagonistic and depends on the genome and the tissue. They are not generally applied in microspore culture but in anther culture. Even when they are acting at the same 60 
time, auxins and cytokinins have control over different processes: auxins are involved in DNA replication and cytokinins in mitosis and cytokinesis (den Boer and Murray 2000). In microspore embryogenesis, levels and ratio between auxins and cytokinins have shown an important role in the transition from radial to bilateral symmetry in embryo development (Żur et al. 2015).

Abscisic acid is involved in response to biotic and abiotic stresses (Campalans et al. 1999; Jin et al. 2000; Ku et al. 2018). A positive influence has been observed between accumulation of $\mathrm{ABA}$ and effectivity of induction and regeneration in vitro. It seems like induction to embryogenesis requires a certain threshold, genotype specific, of ABA in order to trigger a signaling cascade that initiates the embryogenic developmental program (Żur et al. 2015). Nevertheless, the ratio between auxins, cytokinins and $\mathrm{ABA}$ is more important than the individual concentration of each of them. ABA role as growth regulator in microspore embryogenesis is complex: anti-stress factor that increase the viability during microspore embryogenesis, cascade signaling to activate important genes, interaction with other GRs, among others (Żur et al. 2015). Furthermore, it has an important role also in seed dormancy and embryo germination (Huang et al. 2017; Yan et al. 2020).

Other growth regulators are also important for microspore embryogenesis: gibberellic acid (GA), jasmonic acid, salicylic acid (SA), etc. (Żur et al. 2015). For example, GA has shown to have a role in normal development of pollen, anthers and seed, and probably in broad spectrum responses (Singh et al. 2002). On the other hand, SA is considered an endogenous regulator that showed a role in stress defense mechanisms (Zhao et al. 2017); it is a mobile molecule that could signalize the beginning of the embryogenic program (Seguí-Simarro and Nuez 2008).

Here we focus on auxins and cytokinins, in terms of media modification, because they are the GRs most commonly used, but we analyzed also the endogenous content of other hormones. Different effects of applied hormones might be due to different endogenous concentration in each genotype. Apart from auxins/cytokinins/ABA ratio, it is important to consider in/out of the cell ratio, because each genotype may have a different endogenous concentration and same 
exogenous concentration will act differently. Furthermore, plant sensibility to GR may vary depending on the moment of development, tissue, environment, etc.; so it must not be surprising if there are differences between combinations of genotypes, species, stresses and GR (Żur et al. 2015).

Sometimes, growth regulators are replaced by immature ovaries coculture in microspore culture (Broughton 2008; Abdollahi 2015). Also, it is possible to use conditioned media in which high responsive genotype microspores have been cultured, in order to use signaling molecules released to culture media to induce non-responsive genotypes microspores (Żur et al. 2015). These practices make evident that microspores release molecules to the culture media and that these molecules influence the efficiency or success capacity of cells cultured. Another key in vitro factor plays a role in that process: cell density. Depending on the system, a different cell density is used (CamachoFernández et al. 2018) and eggplant microspore density has not been reviewed since the publication of the initial protocol (Miyoshi 1996). In the following experiment we also address this issue, in addition to growth regulators, in order to optimize the eggplant microspore culture protocol and to improve the knowledge we have referring to these topics.

\section{Materials and methods}

\section{Plant material}

One eggplant $\mathrm{DH}$ line was used in this study as donor plant. The DH36 line is a highly androgenic DH line developed in our group (RivasSendra et al. 2017), derived from cv. 'Bandera', originally commercialized by Seminis (Spain). Seeds were germinated in growth chambers in seedling trays and kept at $20^{\circ} \mathrm{C}$ with a photoperiod of $16 / 8$. After one month, seedlings were transplanted to $30 \mathrm{~cm}$ pots in a pollinator-free greenhouse at the COMAV greenhouses (campus of Universitat Politècnica de València, Spain, GPS coordinates: $39^{\circ} 29^{\prime} 01^{\prime \prime}$ $\left.\mathrm{N}, \mathrm{O}^{\circ} 2 \mathrm{O}^{\prime} 27^{\prime \prime} \mathrm{W}\right)$. Pots were filled with commercial growing substrate and irrigated and fertilized using a drip irrigation system. Plants were grown 
under controlled temperature $\left(22 \pm 3^{\circ} \mathrm{C}\right)$ and natural light, and pruned and trained with vertical strings. Phytosanitary treatments were performed when necessary.

\section{Isolated microspore culture}

Prior to performing isolated microspore cultures, the length of the anther containing mostly vacuolate microspores and young bicellular pollen was determined for each genotype. Isolated microspore culture was performed according to Corral-Martínez and Seguí-Simarro (2014). Anthers containing mostly vacuolated microspores were dissected from the bud, surface sterilized with $70 \%$ ethanol for 30 seconds and with 4 $\mathrm{g} / \mathrm{l}$ sodium hypochlorite for 5 minutes, and rinsed three times in sterile distilled water. Anthers were crushed in a small beaker with sterile distilled water using a syringe piston, and their locular content was isolated by filtration through a $41 \mu \mathrm{m}$ nylon mesh (Millipore), and by three centrifugation steps at $100 \mathrm{~g}$ for $4 \mathrm{~min}$ each. Microspores were plated and incubated at $35^{\circ} \mathrm{C}$ in darkness for 3 days to induce embryogenesis. After induction treatment, microspores were collected by centrifugation, resuspended at the same density in the culture medium and incubated at $25^{\circ} \mathrm{C}$ in darkness for the progression of culture. The basal culture medium used for eggplant microspore culture was NLN salts and vitamins (Nitsch 1972) supplemented with 2\% sucrose, 0.5 $\mathrm{mg} / \mathrm{l}$ 1-naphthaleneacetic acid and $0.5 \mathrm{mg} / \mathrm{l}$ 6-benzilaminopurine.

\section{Medium modifications}

Different modifications of growth regulators (GR) concentration in the culture medium above described were tested. Standard GR concentration was consider $100 \%$ and reductions where represented as a percentage of the standard concentration (20, 10 or $0 \%)$. Reductions were applied either from the beginning or at different time points during the culture (7 or 12 days after isolation). Microspore density was initially adjusted to 500,000 microspores/ml for all the experiments, unless otherwise specified. In the experiment of different plating densities, we evaluated the response of cultures with the following plating densities: 
50,000, 100,000, 200,000, 300,000, 400,000, 500,000, 1,000,000 and 2,000,000 microspores/ml. For all cases, we adjusted the different densities using a Neubauer improved chamber according to CamachoFernández et al. (2018).

\section{Growth regulators quantification}

Three different samples were taken from the microspore cultures in order to quantify growth regulator content: microspores, fresh medium and conditioned medium, i.e. the media where the microspores were cultivated. These samples were collected at different time points: day 0 , $2,4,7,14$ and 21 after isolation, in three biological replicates, and GRs were quantified at IBMCP as described previously in Seo et al. (2011). Microspores were separated from the medium by centrifugation and frozen in liquid nitrogen for storage and further processing. Media were lyophilized and storage at $4^{\circ} \mathrm{C}$ until processing.

Material (about $100 \mathrm{mg}$ fresh/dry weight) was suspended in 80\% methanol-1\% acetic acid containing internal standards and mixed by shaking during one hour at $4^{\circ} \mathrm{C}$. The extract was kept a $-20^{\circ} \mathrm{C}$ overnight and then centrifuged and the supernatant dried in a vacuum evaporator. The dry residue was dissolved in $1 \%$ acetic acid and passed through a Oasis HLB (reverse phase) column as described in (Seo et al. 2011).

For GAs, IAA, ABA, SA and JA quantification, the dried eluate was dissolved in $5 \%$ acetonitrile-1\% acetic acid, and the hormones were separated using an autosampler and reverse phase UHPLC chromatography (2.6 $\mu$ m Accucore RP-MS column, 50 mm length x 2.1 $\mathrm{mm}$ i.d.; ThermoFisher Scientific) with a 5 to $50 \%$ acetonitrile gradient containing $0.05 \%$ acetic acid, at $400 \mu \mathrm{L} / \mathrm{min}$ over $14 \mathrm{~min}$. For CKs, the extracts were additionally passed through a Oasis MCX (cationic exchange) and eluted with $60 \%$ methanol- $5 \% \mathrm{NH} 4 \mathrm{OH}$ to obtain the basic fraction containing cytokinins. The final eluate was dried and dissolved in $5 \%$ acetonitrile- $1 \%$ acetic acid and cytokinins were separated with a a 5 to $50 \%$ acetonitrile gradient over $7 \mathrm{~min}$.

The hormones were analyzed with a Q-Exactive mass spectrometer (Orbitrap detector; ThermoFisher Scientific) by targeted Selected Ion 
Monitoring (SIM). The concentrations of hormones in the extracts were determined using embedded calibration curves and the Xcalibur 2.2 SP1 build 48 and TraceFinder programs. The internal standards for quantification of each of the different plant hormones were the deuterium-labelled hormones, except for JA, for which the compound dhJA was used.

\section{Data collection and statistical analysis}

In order to evaluate the effect of different culture conditions on the androgenic performance, the total number of calli as an estimation of induction efficiency was counted. On the other hand, the number of calli larger than $1 \mathrm{~mm}$ (calli $>1 \mathrm{~mm}$ ) was counted as an estimation of callus growth. Both parameters were expressed per $\mathrm{ml}$ of culture medium. In those cases where it was necessary, the morphological differences between treatments were observed and images were taken in order to record them. Microspore cultures performed in different culture conditions were always repeated at least three times. An ANOVA test ( $\mathrm{p} \leq 0.05$ ) was performed to assess global significant differences, and then a LSD test for multiple comparisons was performed in order to group the effect of the treatments in groups of homogeneity, considering significant differences when $\mathrm{p}$-value was $<0.05$.

\section{Results}

\section{Response to different plating densities}

To test whether cell density has an effect on microspore induction and growth, as well as in callus production, we tested a range of different initial plating densities from 50,000 to 2,000,000 microspores per $\mathrm{ml}$. After 30 days of culture, the total number of calli and the number of calli $>1 \mathrm{~mm}$ was recorded. In order to exclude the effect of the different densities used, numbers of calli were expressed using a normalized parameter, the number of calli per 500,000 microspores, which is the 
standard density used so far in eggplant microspore cultures (Miyoshi 1996; Corral-Martínez and Seguí-Simarro 2014; Rivas-Sendra et al. 2015) and in this work as the control to compare with.

ANOVA analysis of the response using plating density as a category factor showed a significant effect of the density in response, either considering total calli or calli $>1 \mathrm{~mm}$ (both $p$-value $<0.05$ ). A density reduction of the plating density below the standard density had in general a positive effect on the number of total calli and the number of calli $>1 \mathrm{~mm}$. When 200,000 microspores $/ \mathrm{ml}$ where plated, the total number of calli/500,000 microspores reached a maximum (1.4-fold higher than the control). This density increased the number of calli $>1 \mathrm{~mm} / 500,000$ microspores too, although the highest increase (1.6fold higher than control) was observed for 300,000 microspores $/ \mathrm{ml}$ (Fig. 1). A reduction to 100,000 microspores/ml reduced dramatically the total number of calli (7.7-fold lower than control), and dishes with a density of 50,000 microspores/ml were unable to produce calli at all (Fig. 1). On the other side, an increase to $1,000,000$ microspores $/ \mathrm{ml}$ showed no change versus control, and dishes with 2,000,000 microspores/ml were unable to produce any calli, because bacterial contamination appeared systematically in all culture dishes (data not shown). These results showed that eggplant microspores respond differently to different plating densities. In general, the response is higher with densities below the standard generally established for eggplant hybrids, but up to a certain threshold below which, response is inhibited. 
Total calli

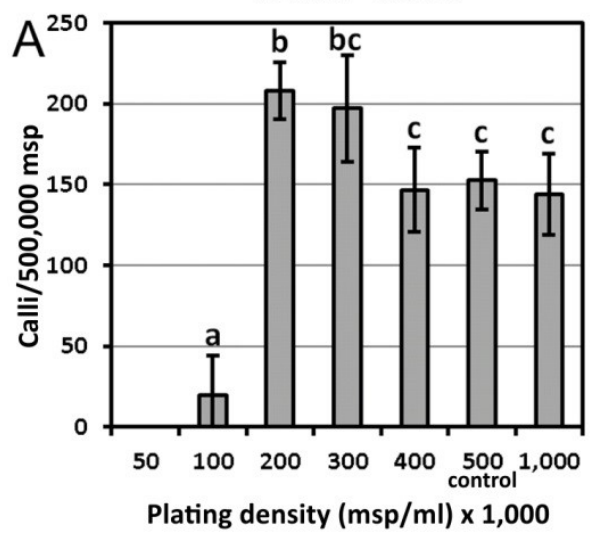

Calli $>1 \mathrm{~mm}$

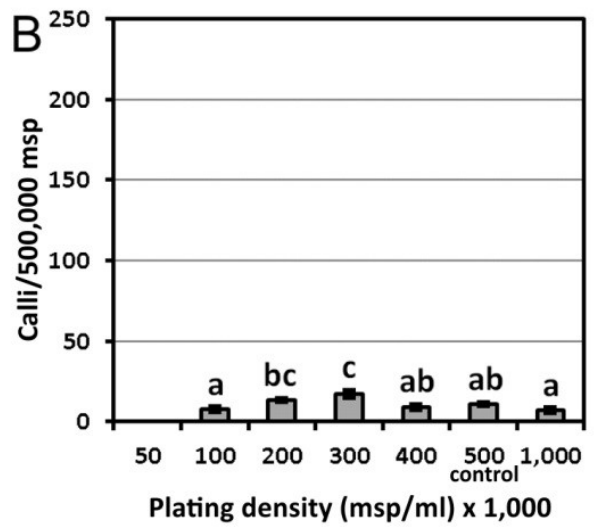

Figure 1. Effect of different plating densities in $\mathrm{DH}_{3} 6$ microspore cultures. A represents the number of total calli formed after 30 days of culture, B represents the number of calli $>1 \mathrm{~mm}$ after 30 days of culture. For comparison among densities, efficiency is expressed as calli per 500,000 plated microspores (calli/500,000 msp). Different letters indicate statistically significant differences according to LSD test ( $p$-value $<0,05$ ).

\section{Effect of reduction in growth regulators} concentration in the culture media

Following the results of (Corral-Martínez and Seguí-Simarro 2014) showing a best performance of eggplant microspore cultures with a lower GR concentration, we tested the effect of reducing the concentration of GR at different time points in androgenic response of $\mathrm{DH}_{3} 6$. Using $100 \%$ and $20 \%$ as starting concentrations, growth regulators were reduced to $20 \%, 10 \%$ or $0 \%$ at 7 and 12 days from the isolation, when the first cell divisions are taking place (Corral-Martínez and Seguí-Simarro 2012), refreshing the media by centrifugation, in order to observe the effect in microspore embryogenesis. Statistical analysis of the effect of treatments in calli production showed that number of total calli was significantly affected by the treatments (Table 1), although none of the reductions in GR concentration in the medium increased the overall response in total calli (Fig. 2). According to total calli obtained after 30 days of culture, partial reduction from $100 \%$ of GR to $20 \%$, either at day 7 or 12 , does not reduce the total amount of calli 
obtained after 30 days of culture (Fig. 2A). However, number of calli bigger than $1 \mathrm{~mm}$ of diameter, significantly increased when GR were $20 \%$ from the beginning of the culture and they remained $20 \%$ or were reduced to $0 \%$ after 12 days (Fig. $2 \mathrm{~B}$ ).
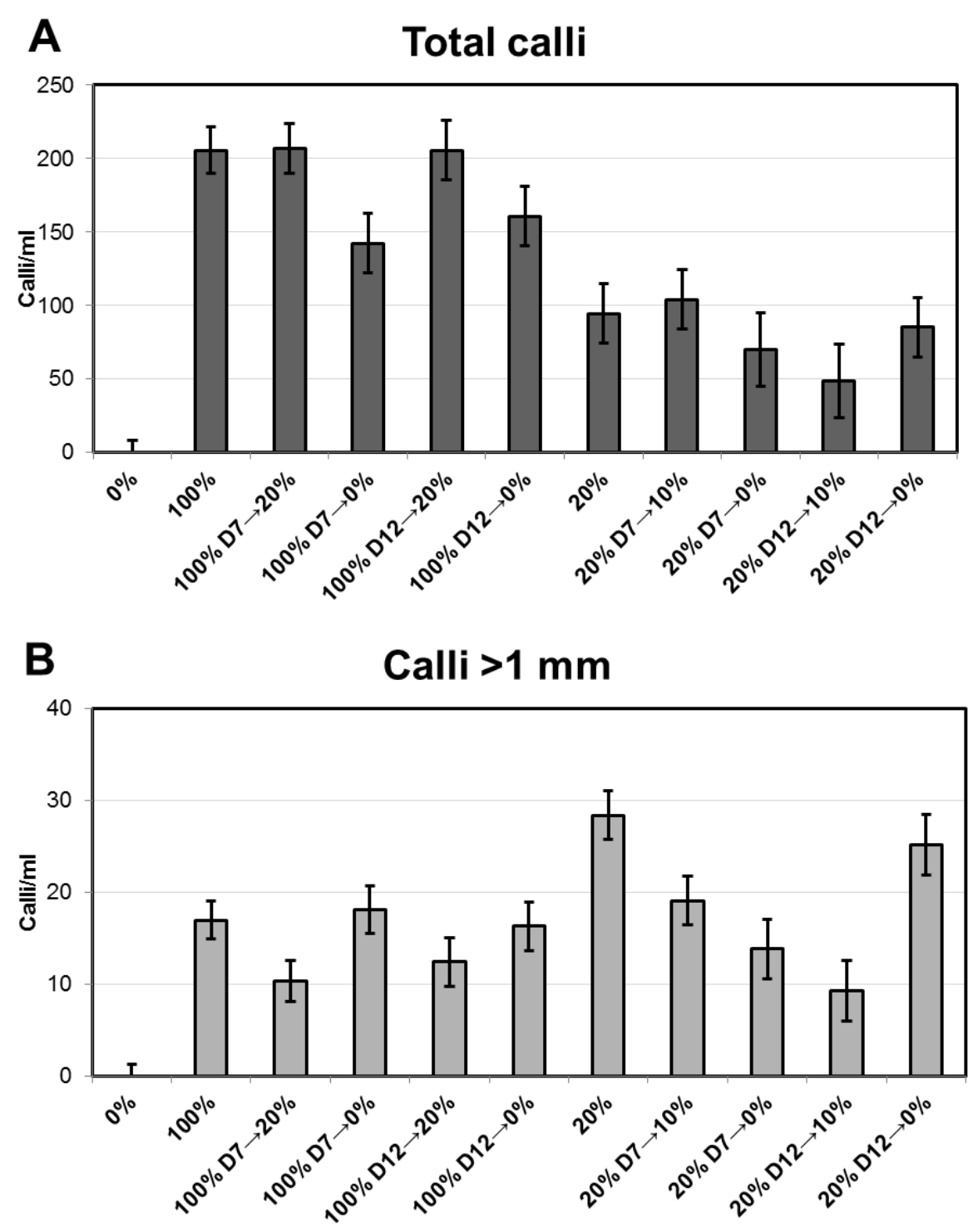

Figure 2. Effect of different applications of growth regulators on $\mathrm{DH}_{3} 6$ microspore cultures. A represents the number of total calli formed after 30 days of culture, $\mathbf{B}$ represents the number of calli with bigger diameter than $1 \mathrm{~mm}$ after 30 days of culture. 
A detail analysis by planned contrasts of the data provided some more information about the behavior of overall calli production in eggplant microspore culture (Table 1). Culture medium containing 20\% of GR instead of $100 \%$ (control) reduced the total calli obtained after 30 days of culture. A partial reduction of the GR (to 20 or $10 \%$, depending on the initial concentration) produced higher number of calli than a total reduction (to o\%). No significant differences were found among different days of reduction and reduction of GR does not affect the final production of calli in general.

The treatments did not produce a severe increase of calli production (Fig. 2) but morphological observations provided interesting data (Fig. 3). Cultures starting from $20 \%$ of growth regulators showed, in general, a better morphology, more similar to embryo, than those starting from $100 \%$ (Fig. 3). Furthermore, when GR concentration was reduced from $20 \%$ to $0 \%$, either at 7 and 12 days from isolation, roots started to appear from calli. These observations suggest that there might be an internal misbalanced rate between auxins and cytokinins.

Table 1: ANOVA and planned contrasts of the effect of growth regulators reduction in culture medium on total calli production in eggplant microspore culture. Asterisks represent significant differences between groups of that comparison.

\begin{tabular}{|c|c|c|c|c|c|}
\hline Source & & df & SS & $\mathbf{F}$ & $p$-value \\
\hline Total & 32 & 189794.06 & - & & - \\
\hline Treatments & 10 & 177473.39 & 31.69 & & $<0.001^{*}$ \\
\hline $\begin{array}{l}\text { 1. Initial 100\% vs. } 20 \% \text { when } \\
\text { reduced }\end{array}$ & 1 & 106400.17 & 189.99 & & $<0.001^{*}$ \\
\hline 2. Partial vs. total reduction & 1 & 14113.5 & 25.20 & & $<0.001^{*}$ \\
\hline 3. Reduction D7 vs. D12 & 1 & 2053.5 & 3.67 & & 0.069 \\
\hline 4. Reduction vs. no reduction & 1 & 418.13 & 0.75 & & 0.397 \\
\hline 5. $100 \%$ vs. $20 \%$ not reduced & 1 & 21961.5 & 39.21 & & $<0.001^{*}$ \\
\hline 6. $100 \%$ vs. $20 \%$ & 1 & 128184.03 & 228.89 & & $<0.001^{*}$ \\
\hline $\begin{array}{l}\text { 7. } 100 \% \text { vs. } 100 \% \text { reduced after } 7 \\
\text { or } 12 \text { days }\end{array}$ & 1 & 570.42 & 1.02 & & 0.324 \\
\hline $\begin{array}{l}\text { 8. } 20 \% \text { vs. } 20 \% \text { reduced after } 7 \text { or } \\
12 \text { days }\end{array}$ & 1 & $25 \cdot 35$ & 0.05 & & 0.833 \\
\hline Error & 22 & 12320,67 & - & & \\
\hline
\end{tabular}



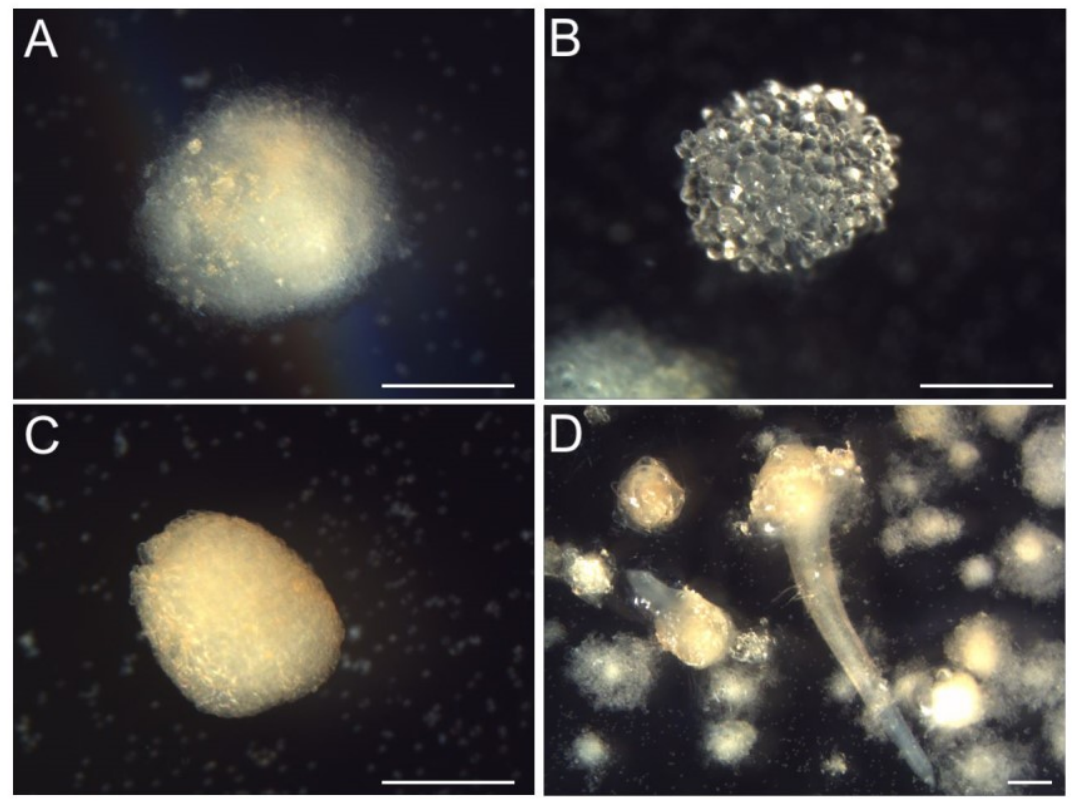

Figure 3. Different morphologies observed in eggplant microspore cultures 21 days after isolation with different application of growth regulators. A. 100\% GR changed to $20 \% 12$ days after isolation. B. $100 \%$ GR changed to $0 \% 7$ days after isolation. C. $20 \%$ GR changed to $0 \% 7$ days after isolation. D. 20\% GR changed to $0 \% 12$ days after isolation. Bars: $500 \mu \mathrm{m}$.

\section{Growth regulator levels during microspore culture}

Different growth regulators were analyzed in microspores and media samples in order to evaluate the progression of their levels through time. In Fig. 4, most important results are represented, corresponding to indole-3-acetic acid (IAA), abscisic acid (ABA), salicylic acid (SA) and gibberellic acid 1 (GA1). There are significant differences between fresh media and conditioned media, which mean that microspores in culture release different GR to the media. Endogenous levels of IAA and ABA are considerably lower in microspores than in media during all the studied stages (see Fig. $4 \mathrm{~A}$ and B). In addition to these general observations, there are some relevant peaks in the concentration of the GR that must be considered. 
A

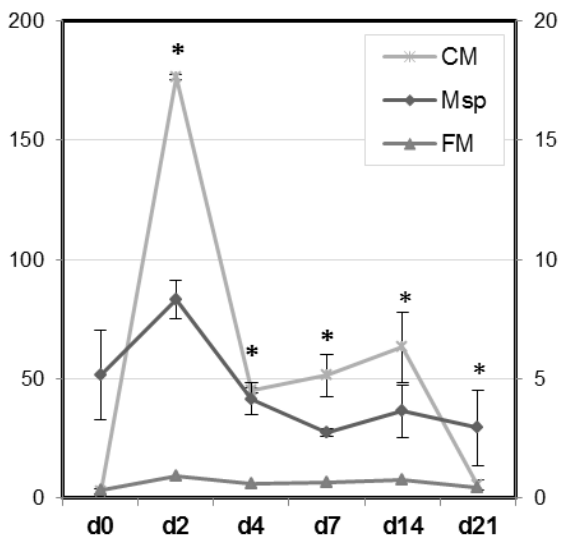

C

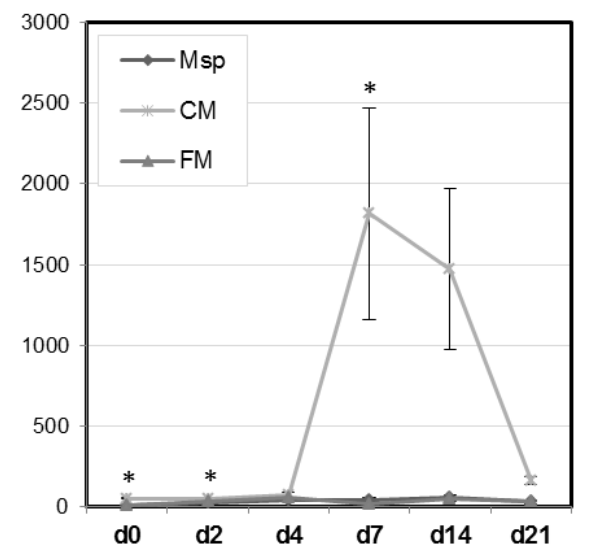

B

ABA

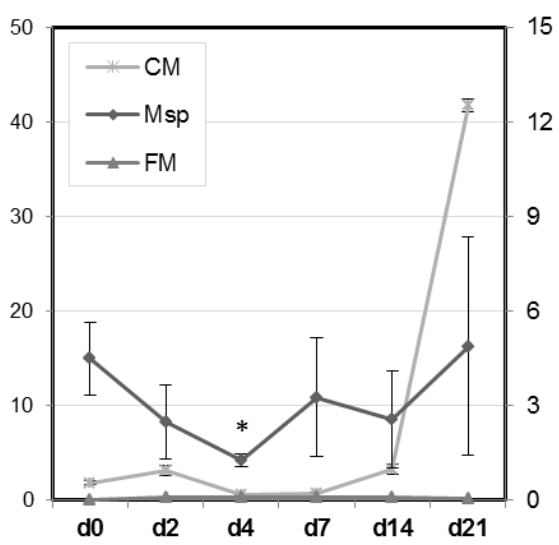

D $\quad$ GA1

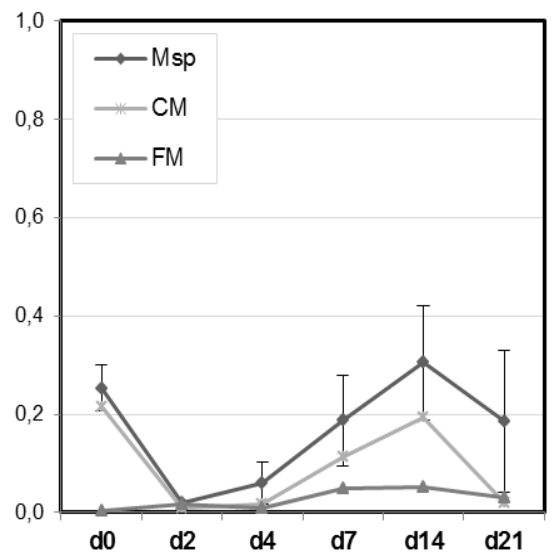

Figure 4. Evolution of different growth regulators in $\mathrm{DH}_{3} 6$ microspore cultures through time. Microspores (Msp), conditioned medium (CM) and fresh medium (FM) are represented in these graphs. A. IAA (indole-3-acetic acid), B. ABA (abscisic acid), C. SA (salicylic acid), D. GA1 (gibberellic acid 1). Note: Yaxis in $\mathbf{A}$ and $\mathbf{B}$ are different for conditioned and fresh media (left) and for microspores (right). Different growth regulators have different Y-axis scale. Asterisks show statistical differences between two samples of each day (Msp and $\mathrm{CM})$ according to $t$-student test $(p<0,05)$. 
IAA has a peak at day 2 in conditioned medium. Microspores evolve similarly but the concentration of this hormone increase more significantly in the media (Fig. 4A). ABA has a significantly higher level at day 21 in conditioned medium (Fig. 4B). In this case, microspores don't have a clear evolution related to the conditioned medium. SA increases its concentration during days 7-14, dropping again at day 21 (Fig. 4C). Microspores don't show any remarkable development in SA content. GA1 shows a perfect coevolution of microspores and conditioned media (Fig. 4D). There are no statistically differences between both samples.

\section{Discussion}

\section{Lower plating density reduces competence and allows for a higher efficiency}

In most in vitro culture systems, determining the optimal plating density is crucial for success. This may influence not only the number of calli or MDEs produced, but also the quality and the speed of development (Castillo et al. 2000; Kim et al. 2008). In the case of microspore cultures, a different plating density is used in each species, from as low as 40,000 microspores/ml in B. napus (Robert et al. 2015) and maize (Aulinger 2002), 50,000 in tobacco (Touraev and HeberleBors 2003), 100,000 in pepper (Kim et al. 2013) or wheat (Sinha and Eudes 2015), to the very high 1,000,000 in barley (Esteves et al. 2014) or 1,400,000 in apple (Höfer 2004). In order to check whether cell density affected the efficiency of the process in $\mathrm{DH}_{3} 6$, we tested a wide range of plating densities. Our results showed that lower densities (200,000300,000 microspores $/ \mathrm{ml}$ ) allowed for higher rates of total callus production, but also of callus $>1 \mathrm{~mm}$, confirming that high densities negatively affect MDE induction. This might be due to excessive accumulation of compounds, excreted by cells, which may be toxic and/or inhibitory for embryogenesis induction, or simply due to the competence of more cells for a limited amount of space and resources available. All our other experiments point to the second option, since they showed a similar inverse relationship between the total number of 72 
calli and the number of calli $>1 \mathrm{~mm}$. These were already induced structures, no affected by the putative presence of inhibitory substances. Thus, it seems that when the embryogenesis rate is boosted, more MDEs are forced to share and therefore to compete for a limited (fixed) amount of space and in vitro resources, reducing the chances of reaching older stages.

Our results also showed that a minimum cell density is needed for embryogenesis to be induced, since very few calli were obtained at 100,000 microspores $/ \mathrm{ml}$ and no one at 50,000 microspores $/ \mathrm{ml}$. A similar observation was reported by (Kim et al. 2008) in hot pepper microspore cultures. Embryogenic microspores release different substances to the culture medium, including GRs and arabinogalactan proteins among others, which have a positive effect in other microspores, promoting their switch to embryogenesis (Paire et al. 2003; Borderies et al. 2004; Żur et al. 2015). If cell density is too low, these substances are too diluted to be effective.

Other interesting observation was that bacterial contamination systematically appeared at high densities (10x our optimal density). The most likely explanation for this is the presence of endogenous bacteria inside eggplant anthers, since during isolation, it is only possible to surface-sterilize them before microspore extraction. Lower densities would contribute a bacterial inoculum insufficient to proliferate, but there is a threshold beyond which contamination is manifested. These observations are not exceptional, since endogenous bacterial contamination has been repeatedly reported in pepper microspore cultures, making the use of antibiotics mandatory (Supena et al. 2006; Lantos et al. 2012; Parra-Vega and Seguí-Simarro 2013).

\section{GR balance affects morphology of microspore- derived structures}

Embryogenic microspores suffer several cellular modifications during the induction. One of the most important is the change in the division plane from asymmetric to symmetric, as in somatic cells. Microspore derived embryos (MDEs) develop similarly to zygotic embryos, but they have some differences probably due to environmental 
conditions. An appropriate auxin balance is needed for radial to bilateral symmetry transition in embryo development. For example, in rapeseed IAA levels are lower in MDEs than in zygotic embryos and a certain level of ABA is needed for a correct germination of embryos (Seguí-Simarro and Nuez 2008).

Most of the model species with high embryogenic response in microspore cultures do not need the addition of GRs to the culture medium. This is the case of tobacco (Touraev et al. 1996a) and B. napus (Custers 2003), and also non-model species as maize (Gaillard et al. 1991) and wheat (Touraev et al. 1996b). In these species, embryos are produced instead of calli with none or very low GR addition needed for proper embryo induction, which suggests that their endogenous GR production suffices their needs. However, this is not the case of recalcitrant species, where exogenous application of auxins and cytokinins is needed to control cell division and morphogenesis.

In our results, different GR level reductions were tested, showing an effect in the morphology of the structures observed without affecting dramatically the efficiency of the response. Some of them were more similar to a normal embryo, but in most cases production of roots was observed, suggesting that endogenous levels of auxins were too high for the correct development. This GR unbalance may be negatively affecting eggplant MDE progression and causing the transformation of globular MDEs into calli, the main bottleneck in eggplant microspore culture (Corral-Martínez and Seguí-Simarro 2012; Rivas-Sendra et al. 2015). Indeed $\mathrm{DH}_{3} 6$ was able to respond (though at low frequency) even in absence of GRs, producing calli with an external appearance closer to MDEs than to regular calli. All these results suggest that eggplant microspore culture could be optimized modifying balance of GR. Next steps for optimization of the protocol should include variations in auxins/cytokinins balance, starting with lower concentrations and refreshing the media in different stages of the culture development. 


\section{Growth regulators dynamics help us to understand embryo development in microspore culture}

Analysis of growth regulators in microspore culture has shown several interesting trends that may be discussed. In summary, we can say that there is a progression in the appearance of different GRs: first a peak of IAA at day 2 (during the induction treatment), later SA shows an increasing trend during days 7 and 14 (when first divisions appear), more or less in parallel with a similar trend in GA1, and finally a big peak in ABA is observed at day 21 (multicellular structures or even calli is present already). That dynamics provide a lot of information about what is happening inside microspore cells.

As it was already mention before in this chapter, IAA peak at the beginning of the culture must be related with the initiation of the embryogenesis, though it is involved in the DNA replication necessary for the first divisions (Żur et al. 2015). This result together with the modification of GRs level in the media, mean that the endogenous level of auxin in embryogenic microspores must be high. The fact that the media was refreshed in those experiments and lower concentration of exogenous hormones were applied, give more importance to the endogenous levels, which might be masked when the media is maintained during the whole process, being the exogenous levels way too high, most likely.

After heat shock and starvation period, a reaction to those stress is probably the reason for what we see SA increase at days 7-14 (SeguíSimarro and Nuez 2008), which is signaling the beginning of the embryogenic program. ABA has been shown to be related to starvation stress; it increases in tobacco and barley microspores after starvation treatment (Shariatpanahi et al. 2006).

Starvation seems to promote degradation processes in pollen that end up in embryogenesis induction. Certain stresses, like osmotic pressure and cold, promote ABA production (Davies and Jones 1991). In some species, a high endogenous level of ABA has been related to high androgenic potential. Increment of ABA levels during pretreatment in barley is related to high regeneration efficiency (van Bergen et al. 1999). One of the effects is to prevent the formation of binucleated microspores. 
Results suggested that stress-related ABA production might be essential for viability. Low production of $\mathrm{ABA}$ was also related to albino plant production (van Bergen et al. 1999). ABA improves efficiency in suboptimal conditions. Stresses that induce endogenous production of $\mathrm{ABA}$ are enough and increasing exogenous levels doesn't improve efficiency or viability. In fact, only the addition of ABA is not enough to limit stress effects, there are other factors. It seems like endogenous ABA production during first 24 hours of pretreatment avoids microspore death and represses pollen development (van Bergen et al. 1999).

ABA slightly promoted induction to embryo but not their progression in previous studies in eggplant microspore culture. More microspores were induced and divided faster when applied to the media. It seemed to limit the damage occasioned by osmotic stress, blocking hydrogen peroxide production. Low doses of ABA could have a slightly positive effect during initial stages in androgenesis but not in later stages. Previously, an initial positive but negative in long term basis effect of ABA was described in defense strategies in plants. Nevertheless, ABA seemed to interact with other factors masking positive effects by reducing the effect of stress during the induction (Corral-Martínez and Seguí-Simarro 2014).

Nevertheless, the observed peak of ABA doesn't match with the idea of being related to the stress response. ABA plays a fundamental role in maintaining seed dormancy under unfavorable conditions until GA increases to remove dormancy status. ABA and GA act antagonistically in seed germination: reduction of $\mathrm{ABA}$ plus increment of GA levels induce germination. Ratio between them determines timing of seed germination (Yan and Chen 2017). Regarding to the GA1 dynamics in these cultures, embryos developing from microspore could enter in a dormancy stage due to the incapacity to form a proper heart-shaped embryo.

In order to discover if ABA peak during day 21 stage of the embryos in eggplant microspore culture could be related to the transition between globular and heart-shaped embryo stages, two strategies may be used: refreshing the media when the peak of ABA appear in order to reduce its level, or using inhibitors of this hormone, like Fluridone (Żur et al. 2015). 


\section{Conclusions}

The best performance of eggplant isolated microspores in culture was obtained when 200.000 microspores/ml was used as plating density. Modifying overall GRs level in the media has an effect in the morphology of the embryos obtained in microspore culture. The study of the GR dynamics in microspore culture might be an interesting tool to understand how embryos develop and which could be the potential key factors in order to obtain embryos instead of calli in recalcitrant species.

\section{References}

Abdollahi, Mohammad. (2015). The influence of phytohormones, wheat ovary co-culture, and temperature stress on anther culture response of watermelon (Citrullus lanatus L.). Brazilian Journal of Botany. 10.1007/s40415-015-0152-z.

Ahmadi B, Shariatpanahi ME, Teixeira da Silva JA (2014) Efficient induction of microspore embryogenesis using abscisic acid, jasmonic acid and salicylic acid in Brassica napus L. Plant Cell Tissue Organ Cult 116 (3):343-351. doi:10.1007/s11240-013-0408-x

Aulinger IE (2002) Combination of in vitro androgenesis and biolistic transformation: an approach for breeding transgenic maize (Zea mays L.) lines. Swiss Federal Institute of Technology, Zurich

Borderies G, le Bechec M, Rossignol M, Lafitte C, Le Deunff E, Beckert M, Dumas C, Matthys-Rochon E (2004) Characterization of proteins secreted during maize microspore culture: arabinogalactan proteins (AGPs) stimulate embryo development. Eur J Cell Biol 83 (5):205-212

Broughton, Sue. (2008). Ovary co-culture improves embryo and green plant production in anther culture of Australian spring wheat (Triticum aestivum L.). Plant Cell, Tissue and Organ Culture. 95. 185-195. 10.1007/s11240-008-9432-7.

Camacho-Fernández C, Hervás D, Rivas-Sendra A, Marín MP, Seguí-Simarro JM (2018) Comparison of six different methods to calculate cell densities. Plant Methods 14 (1):30. doi:10.1186/s13007-018-0297-4 
Campalans A, Messeguer R, Goday A, Pages M (1999) Plant responses to drought, from $\mathrm{ABA}$ signal transduction events to the action of the induced proteins. Plant Physiology and Biochemistry 37 (5):327-340

Castillo AM, Valles MP, Cistue L (2000) Comparison of anther and isolated microspore cultures in barley. Effects of culture density and regeneration medium. Euphytica 113 (1):1-8

Corral-Martínez P, Seguí-Simarro JM (2012) Efficient production of callusderived doubled haploids through isolated microspore culture in eggplant (Solanum melongena L.). Euphytica 187 (1):47-61. doi:10.1007/s10681-012-0715-Z

Corral-Martínez P, Seguí-Simarro JM (2014) Refining the method for eggplant microspore culture: effect of abscisic acid, epibrassinolide, polyethylene glycol, naphthaleneacetic acid, 6-benzylaminopurine and arabinogalactan proteins. Euphytica $195 \quad$ (3):369-382. doi:10.1007/s10681-013-1001-4

Cubero JI (2003) Introducción a la mejora genética vegetal, $2^{\mathrm{a}}$ edición. Ediciones Mundi-Prensa, Madrid, Spain

Custers J (2003) Microspore culture in rapeseed (Brassica napus L.). In: Maluszynski M, Kasha KJ, Forster BP, Szarejko I (eds) Doubled haploid production in crop plants. Kluwer Academic Publishers, Dordrecht, The Netherlands, pp 185-193

Davies WJ, Jones HG (eds) (1991) In: Abscisic acid physiology and biochemistry. Bio's Scientfic, Oxford UK, pp 63-77

den Boer BGW, Murray JAH (2000) Triggering the cell cycle in plants. Trends Cell Biol 10 (6):245-250

Esteves P, Clermont I, Marchand S, Belzile F (2014) Improving the efficiency of isolated microspore culture in six-row spring barley: II-exploring novel growth regulators to maximize embryogenesis and reduce albinism. Plant Cell Rep:In press. doi:10.1007/s00299-014-1563-1

Gaillard A, Vergne P, Beckerte M (1991) Optimization of maize microspore isolation and culture conditions for reliable plant regeneration. Plant Cell Rep 10:55-58

Höfer M (2004) In vitro androgenesis in apple-improvement of the induction phase. Plant Cell Rep 22 (6):365-370. doi:10.1007/s00299-003-0701-y

Huang Y, Sun M-M, Ye Q, Wu X-Q, Wu W-H, Chen Y-F (2017) Abscisic Acid Modulates Seed Germination via ABA INSENSITIVE5-Mediated PHOSPHATE1. Plant Physiol $175 \quad$ (4):1661-1668. doi:10.1104/pp.17.00164 
Hoekstra S, vanBergen S, vanBrouwershaven IR, Schilperoort RA, Heidekamp F (1996) The interaction of 2,4-D application and mannitol pretreatment in anther and microspore culture of Hordeum vulgare L cv Igri. J Plant Physiol 148 (6):696-700

Jin S, Chen CS, Plant AL (2000) Regulation by ABA of osmotic-stress-induced changes in protein synthesis in tomato roots. Plant Cell Environ 23 (1):51-60

Kim M, Jang I-C, Kim J-A, Park E-J, Yoon M, Lee Y (2008) Embryogenesis and plant regeneration of hot pepper (Capsicum annuum L.) through isolated microspore culture. Plant Cell Rep 27 (3):425-434

Kim M, Park E-J, An D, Lee Y (2013) High-quality embryo production and plant regeneration using a two-step culture system in isolated microspore cultures of hot pepper (Capsicum annuum L.). Plant Cell Tissue Organ Cult 112 (2):191-201. doi:10.1007/s11240-012-0222-x

Ku, Y. S., Sintaha, M., Cheung, M. Y., \& Lam, H. M. (2018). Plant Hormone Signaling Crosstalks between Biotic and Abiotic Stress Responses. International journal of molecular sciences, 19(10), 3206. https://doi.org/10.3390/ijms19103206

Lantos C, Juhasz AG, Vagi P, Mihaly R, Kristof Z, Pauk J (2012) Androgenesis induction in microspore culture of sweet pepper (Capsicum annuum L.). Plant Biotechnol Rep 6 (2):123-132. doi:10.1007/s11816-011-0205-O

Miyoshi K (1996) Callus induction and plantlet formation through culture of isolated microspores of eggplant (Solanum melongena L). Plant Cell Rep 15 (6):391-395

Nitsch JP (1972) Haploid plants from pollen. Z Pflanzenzüchtg 67:3-18

Paire A, Devaux P, Lafitte C, Dumas C, Matthys-Rochon E (2003) Proteins produced by barley microspores and their derived androgenic structures promote in vitro zygotic maize embryo formation. Plant Cell Tissue Organ Cult 73 (2):167-176

Parra-Vega V, Seguí-Simarro JM (2013) Improvement of an isolated microspore culture protocol for Spanish sweet pepper (Capsicum annuum L.). In: Lanteri S, Rotino GL (eds) Breakthroughs in the genetics and breeding of Capsicum and Eggplant. Universita degli Studi di Torino, Torino, Italy, pp 161-168

Rivas-Sendra A, Corral-Martínez P, Camacho-Fernández C, Seguí-Simarro JM (2015) Improved regeneration of eggplant doubled haploids from microspore-derived calli through organogenesis. Plant Cell Tissue Organ Cult 122 (3):759-765. doi:10.1007/s11240-015-0791-6 
Rivas-Sendra A, Campos-Vega M, Calabuig-Serna A, Seguí-Simarro JM (2017) Development and characterization of an eggplant (Solanum melongena) doubled haploid population and a doubled haploid line with high androgenic response. Euphytica 213 (4):89. doi:10.1007/s10681-017-1879-3

Rivas-Sendra A, Corral-Martínez P, Camacho-Fernández C, Seguí-Simarro JM (2015) Improved regeneration of eggplant doubled haploids from microspore-derived calli through organogenesis. Plant Cell Tissue Organ Cult 122 (3):759-765. doi:10.1007/s11240-015-0791-6

Robert HS, Grunewald W, Sauer M, Cannoot B, Soriano M, Swarup R, Weijers D, Bennett M, Boutilier K, Friml J (2015) Plant embryogenesis requires AUX/LAX-mediated auxin influx. Development 142 (4):702-711. doi:10.1242/dev.115832

Rodríguez-Sanz H, Solís M-T, López M-F, Gómez-Cadenas A, C. Risueño M, S. Testillano P (2015) Auxin biosynthesis, accumulation, action and transport are involved in stress-induced microspore embryogenesis initiation and progression in Brassica napus. Plant Cell Physiol 56 (7):1401-1417. doi:10.1093/pcp/pcvo58

Seguí-Simarro JM (2010) Androgenesis revisited. Bot Rev 76 (3):377-404. doi:10.1007/s12229-010-9056-6

Seguí-Simarro JM, Nuez F (2008) How microspores transform into haploid embryos: changes associated with embryogenesis induction and microspore-derived embryogenesis. Physiol Plant 134:1-12. doi:10.1111/j.1399-3054.2008.01113.x

Seo M, Jikumaru Y, Kamiya Y (2011) Profiling of Hormones and Related Metabolites in Seed Dormancy and Germination Studies. In: Kermode AR (ed) Seed Dormancy: Methods and Protocols. Humana Press, Totowa, NJ, pp 99-111. doi:10.1007/978-1-61779-231-1_7

Shariatpanahi ME, Bal U, Heberle-Bors E, Touraev A (2006) Stresses applied for the re-programming of plant microspores towards in vitro embryogenesis. Physiol Plant 127 (4):519-534

Singh, D. P., Jermakow, A. M., \& Swain, S. M. (2002). Gibberellins are required for seed development and pollen tube growth in Arabidopsis. The Plant cell, 14(12), 3133-3147. https://doi.org/10.1105/tpc.003046

Sinha R, Eudes F (2015) Dimethyl tyrosine conjugated peptide prevents oxidative damage and death of triticale and wheat microspores. Plant Cell Tissue Organ Cult:1-11. doi:10.1007/s11240-015-0763-x

Skoog F. (1973) Cytokinins in Regulation of Plant Growth. In: Srb A.M. (eds) Genes, Enzymes, and Populations. Basic Life Sciences, vol 2. Springer, Boston, MA. https://doi.org/10.1007/978-1-4684-2880-3_11 
Soriano M, Li H, Boutilier K (2013) Microspore embryogenesis: establishment of embryo identity and pattern in culture. Plant Reprod 26 (3):181-196. doi:10.1007/s00497-013-0226-7

Supena EDJ, Suharsono S, Jacobsen E, Custers JBM (2006) Successful development of a shed-microspore culture protocol for doubled haploid production in Indonesian hot pepper (Capsicum annuum L.). Plant Cell Rep 25 (1):1-10

Touraev A, Heberle-Bors E (2003) Anther and microspore culture in tobacco. In: Maluszynski M, Kasha KJ, Forster BP, Szarejko I (eds) Doubled haploid production in crop plants. Kluwer Academic Publishers, Dordrecht, The Netherlands, pp 223-228

Touraev A, Ilham A, Vicente O, Heberle-Bors E (1996a) Stress-induced microspore embryogenesis in tobacco: an optimized system for molecular studies. Plant Cell Rep 15 (8):561-565

Touraev A, Indrianto A, Wratschko I, Vicente O, Heberle-Bors E (1996b) Efficient microspore embryogenesis in wheat (Triticum aestivum L.) induced by starvation at high temperatures. Sex Plant Reprod 9 (4):209-215

van Bergen S, Kottenhagen MJ, van der Meulen RM, Wang M (1999) The role of abscisic acid in induction of androgenesis: A comparative study between Hordeum vulgare L-cvs. Igri and Digger. J Plant Growth Regul 18 (3):135-143

Yan A, Chen Z (2017) The pivotal role of abscisic acid signaling during transition from seed maturation to germination. Plant Cell Rep 36 (5):689-703. doi:10.1007/s00299-016-2082-z

Yan J, Fang L, Yang L, He H, Huang Y, Liu Y, Zhang A (2020) Abscisic acid positively regulates l-arabinose metabolism to inhibit seed germination through ABSCISIC ACID INSENSITIVE4-mediated transcriptional promotions of MUR4 in Arabidopsis thaliana. New Phytol o (o). doi:10.1111/nph.16149

Zhao, Pingzhi \& Lu, Gui-Hua \& Yang, Yonghua. (2017). Salicylic Acid Signaling and its Role in Responses to Stresses in Plants. 10.1002/9781118889022.ch17.

Żur I, Dubas E, Krzewska M, Janowiak F (2015) Current insights into hormonal regulation of microspore embryogenesis. Front Plant Sci 6 (424). doi:10.3389/fpls.2015.00424 


\section{Chapter 3}

\section{Isolated microspore culture in Brassica napus.}

Patricia Corral-Martínez, Carolina Camacho-Fernández and Jose M.

Seguí-Simarro

Cell Biology Group - COMAV Institute, Universitat Politècnica de València, Valencia, Spain.

Keywords: Androgenesis, doubled haploid, embryogenesis, haploid, microspores, pollen, rapeseed, tissue culture.

This chapter has been published as: Corral-Martínez et al. (2018)

Chapter 19: Isolated Microspore Culture in Brassica napus.

Book section in: Plant Embryogenesis: Methods and Protocols. 


\section{Abstract}

Isolated microspore culture is the most efficient technique among those used to induce microspore embryogenesis. In the particular case of Brassica napus, it is also the most widely used and optimized. In this chapter, we describe a protocol for microspore culture in B. napus which includes the steps necessary to isolate and culture microspores, to induce microspore-derived embryos, to produce $\mathrm{DH}$ plants from them, as well as to check for the developmental stage of the microspores isolated, their viability, and the ploidy level of regenerated plantlets. 


\section{Introduction}

Androgenesis is the process of obtaining an individual with a genome coming exclusively from a male donor. These individuals are usually derived from haploid microspores and young pollen grains. Microspore-derived embryos (MDEs) may remain haploid or become doubled haploid (DH) individuals spontaneously or through the application of some treatments for genome duplication (Seguí-Simarro and Nuez 2008b). MDEs are obtained from microspores/pollens upon changing their originally gametophytic developmental program towards embryogenesis (Seguí-Simarro 2010). This developmental switch is typically induced through the application of a species-specific in vitro stress treatment (Shariatpanahi et al. 2006) to microspores and pollen grains at defined developmental stages (Seguí-Simarro and Nuez 2008a).

DHs are very useful tools in plant breeding. Among their many different advantages (reviewed in Forster et al. 2007; Dwivedi et al. 2015), their most important application is to reduce time and resources to produce pure lines for hybrid seed production. Hybrid seeds are typically obtained by crossing two pure, 100\% homozygous parental lines, which makes mandatory the previous production of pure lines. Using conventional approaches, this is a laborious process which requires several years (5-10) of selfing and selection. However, DH technology is able to reduce this time (and obviously the resources needed) to some months when the experimental protocols are optimized. From a more basic research perspective, microspore embryogenesis is an inducible morphogenic process convenient for the study of different aspects of plant cell totipotency and embryogenesis itself.

There are two main ways to induce microspore embryogenesis: anther culture and isolated microspore culture. Both are in vitro culture techniques whose objective is to generate MDEs from immature pollen or microspores. Anther culture is simpler, since microspore isolation from the anther is not needed, but it is less efficient as well, and the control of culture conditions is more difficult. On the other hand, microspore culture is more technically demanding, but also more efficient and controlled. This makes it the choice for those species where 86 
both methods are available, which unfortunately is not the case in many agronomically interesting crops. However, Brassica napus (rapeseed) is a model species for microspore embryogenesis, as well as Nicotiana tabacum (tobacco) and Hordeum vulgare (barley) (Forster et al. 2007). In some lines and cultivars of this species, this process can be easy and efficiently induced with the use of optimized methods. In this chapter we describe a method for isolated microspore culture in B. napus. In addition, we present methods to identify the most suitable developmental stages for microspore/pollen isolation, to determine their viability, and to check the ploidy of the produced MDEs/plantlets.

\section{Materials}

\section{Plant Material}

This step-by-step protocol was developed using two different Brassica napus double haploid breeding lines: DH12075 (a low-response line widely used in different studies on Brassica breeding and genomics, as well as on DH research) and DH4O79 (a high-response, model line for microspore embryogenesis in Brassica species, selected from cultivar Topas). It could be used for other B. napus lines or genotypes as long as the most suitable bud lengths for isolation of microspores at the right developmental stage (see Note 1) are previously determined.

\section{Equipment}

1. Laminar flood hood.

2. Refrigerated centrifuge (see Note 2).

3. Incubators at $32^{\circ} \mathrm{C}$ and $25^{\circ} \mathrm{C}$.

4. Growth chamber at $25^{\circ} \mathrm{C}$.

5. Inverted microscope. 
6. Fluorescence microscope equipped with $358 / 461 \mathrm{~nm}$ and $480 / 520$ $\mathrm{nm}$ filter combinations for DAPI and FDA observation, respectively.

7. Stereo microscope with micrometer.

8. Flow cytometer.

9. Autoclave.

10. General laboratory equipment: precision balance, $\mathrm{pH}$ meter, rotatory shaker, refrigerator, etc.

\section{Material for disinfection, isolation, culture, ploidy analysis and acclimation}

- Reusable material:

1. Sterile glass bottles for liquid media.

2. Tea sieves (See Note 3).

3. Honey jars with $70 \%(\mathrm{v} / \mathrm{v})$ ethanol at $4^{\circ} \mathrm{C}$.

4. Honey jars (approx. $500 \mathrm{ml}$ ) with $4 \mathrm{~g} / \mathrm{l}$ sodium hypochlorite with $0.05(\mathrm{v} / \mathrm{v})$ Tween at $4^{\circ} \mathrm{C}$ for bud disinfection.

5. 3 honey jars (approx. $500 \mathrm{ml}$ ) with sterile $\mathbf{d H}_{2} \mathbf{O}$.

6. Syringe plungers kept in $70 \%$ ethanol.

7. Sterile beakers (previously wrapped in aluminum foil and autoclaved) with an internal diameter larger than that of the syringe plungers used.

8. Sterile Erlenmeyer flask with a funnel containing $30 \mu \mathrm{m}$-mesh nylon filters (previously wrapped in aluminum foil and autoclaved).

9. Neubauer improved counting chamber (hemacytometer) to calculate microspore plating densities (See Note 4).

10. A Bunsen-type burner, or similar, for flame sterilization.

11. Forceps.

12. Motorized or manual pipette. 
13. Microscope slides and coverslips (See Note 5).

14. Micropipette (1-10 $\mu \mathrm{l})$.

15. Sterile baby food jars (200 ml) with plastic lids.

16. Autoclavable, $90 \times 100 \mathrm{~mm}$ plastic pots.

17. $30 \mu \mathrm{m}$-mesh filters for flow cytometry.

- Disposable material

1. Sterile syringes.

2. Sterile $0.2 \mu \mathrm{m}$ membrane filters.

3. Ice (see Note 6).

4. Sterile $15 \mathrm{ml}$ centrifuge tubes.

5. Sterile Whatman paper.

6. Sterile 10 and $25 \mathrm{ml}$ disposable pipettes.

7. Pipette tips for the micropipettes used.

8. Sterile culture dishes (See Note 7).

9. $1.5 \mathrm{ml}$ conical microtubes.

10. Parafilm.

11. $9 \mathrm{~cm}$ culture dishes for MDE germination.

12. Vermiculite.

13. Composite soil.

14. Plastic tubes $3.5 \mathrm{ml}$ (for flow cytometry).

15. Razor blades.

\section{Culture Media and Chemicals}

1. Medium for microspore isolation and washing: $13 \%(\mathrm{w} / \mathrm{v})$ sucrose in $\mathrm{dH}_{2} \mathrm{O}$, pH 5.8 (see Note 8).

2. NLN-13 medium for microspore culture (Table 1), made of NLN basal medium (see Note 9) supplemented with $13 \%$ (w/v) sucrose and $0.5 \mathrm{~g} / \mathrm{l} \mathrm{Ca}\left(\mathrm{NO}_{3}\right)_{2} \bullet 4 \mathrm{H}_{2} \mathrm{O}$. Adjust $\mathrm{pH}$ to 5.8 and sterilize by 
filtration through sterile $0.2 \mu \mathrm{m}$ membrane filters within a laminar flow hood. Store at $4^{\circ} \mathrm{C}$ for a maximum of one month.

3. 4,6-Diamidino-2-phenylindole (DAPI) stain to visualize nuclear DNA and determine the most suitable bud size. First, a $1 \mathrm{mg} / \mathrm{ml}$ stock solution is needed. To prepare it, dissolve $1 \mathrm{mg}$ DAPI in 1-2 drops of DMSO. Add milliQ water up to $1 \mathrm{ml}$.

4. Nuclear Isolation Buffer (NIB) to prepare the DAPI working solution. Prepare a $10 \mathrm{mM}$ spermine-tetrahydrochloride, $10 \mathrm{mM}$ $\mathrm{NaCl}$ and $200 \mathrm{mM}$ hexylene glycol (2,5-hexanediol) in Tris- $\mathrm{HCl}$ buffer 0.01M, pH 7. It can be stored at $4^{\circ} \mathrm{C}$ for up to one year.

5. DAPI working solution $(1.25 \mu \mathrm{g} / \mathrm{ml})$ from stock DAPI and NIB solutions as described by Custers (Custers 2003). Briefly, mix well the following components in a small beaker: $5 \mathrm{ml} \mathrm{NIB,} \mathrm{12,5 \mu l}$ DAPI stock solution, $50 \mu \mathrm{l}$ Triton X-100, and $2 \mathrm{ml}$ Glycerol. Fill up to $10 \mathrm{ml}$ with glycerol (around $3 \mathrm{ml}$ more). Cover beaker with aluminum foil and shake overnight. Next day DAPI can be stored at $4^{\circ} \mathrm{C}$ for months.

6. Fluorescein diacetate (FDA) stock solution (0.2\% FDA in acetone) to check cell viability before and after the stress treatment (see Note 10).

7. Medium for MDE germination and conversion into plantlets: $\mathbf{B}_{5^{-}}$ Gamborg medium (Table 1) supplemented with $1 \%$ sucrose and 0.6\% Plant Agar (Duchefa Biochemie). Adjust pH to 5.8, autoclave and pour in $90 \times 25 \mathrm{~mm}$ sterile culture dishes and sterile baby food jars.

8. Lysis buffer (LBO1) for flow cytometry: $5 \mathrm{mM}$ Tris (hydroxymethyl) aminomethane, $2 \mathrm{mM} \mathrm{Na} \mathrm{N}_{2}$ EDTA, $0.5 \mathrm{mM}$ spermidine $80 \mathrm{mM} \mathrm{KCl}$, $20 \mathrm{mM} \mathrm{NaCl}, 15 \mathrm{mM} \beta$-mercaptoethanol, and $0.1 \%$ (v/v) Triton X100. Adjust $\mathrm{pH}$ to 7.5 .

9. Commercial DAPI-based staining buffer Partec CyStain UV Precise P for flow cytometry (Partec GmbH, Münster, Germany). 
Table 1: Macroelements, microelements, and vitamins of NLN-13 and $\mathrm{B}_{5}$ media for $B$. napus microspore culture, based on the original formulations of NLN by Nitsch 1972 and of B5 by Gamborg et al. 1968. Concentrations are expressed in $\mathrm{mg} / \mathrm{l}$.

\begin{tabular}{|c|c|c|}
\hline & NLN-13 & B5 \\
\hline \multicolumn{3}{|l|}{ Macroelements } \\
\hline $\mathrm{Ca}\left(\mathrm{NO}_{3}\right)_{2}$ & 500 & o \\
\hline $\mathrm{KH}_{2} \mathrm{PO}_{4}$ & 125 & o \\
\hline $\mathrm{KNO}_{3}$ & 125 & $2,500.00$ \\
\hline $\mathrm{MgSO}_{4}$ & 61 & 121.56 \\
\hline $\mathrm{NaH}_{2} \mathrm{PO}_{4}$ & o & 130.44 \\
\hline$\left(\mathrm{NH}_{4}\right)_{2} \mathrm{SO}_{4}$ & o & 134.00 \\
\hline $\mathrm{CaCl}_{2}$ & o & 113.23 \\
\hline \multicolumn{3}{|l|}{ Microelements } \\
\hline $\mathrm{CoCl}_{2} \cdot 6 \mathrm{H}_{2} \mathrm{O}$ & 0.025 & 0.025 \\
\hline $\mathrm{CuSO}_{4} \cdot 5 \mathrm{H}_{2} \mathrm{O}$ & 0.025 & 0.025 \\
\hline FeNaEDTA & 36.7 & 36.70 \\
\hline $\mathrm{H}_{3} \mathrm{BO}_{3}$ & 10 & 3.00 \\
\hline KI & o & 0.75 \\
\hline $\mathrm{MnSO}_{4} \cdot \mathrm{H}_{2} \mathrm{O}$ & 18.95 & 10.00 \\
\hline $\mathrm{Na}_{2} \mathrm{MoO}_{4} \cdot 2 \mathrm{H}_{2} \mathrm{O}$ & 0.25 & 0.25 \\
\hline $\mathrm{ZnSO}_{4} \cdot 7 \mathrm{H}_{2} \mathrm{O}$ & 10 & 2.00 \\
\hline \multicolumn{3}{|c|}{ Vitamins and amino acids } \\
\hline $\mathrm{D}(+)$-Biotine & 0.05 & o \\
\hline Folic Acid & 0.5 & o \\
\hline L-Glutamine & 800 & o \\
\hline Gluthatione (reduced) & 30 & o \\
\hline Glycine & 2 & o \\
\hline Myo-Inositol & 100 & 100 \\
\hline Nicotinic Acid & 5 & 1 \\
\hline Pyridoxine $\mathrm{HCl}$ & 0.5 & 1 \\
\hline L-Serine & 100 & o \\
\hline Thiamine $\mathrm{HCl}$ & 0.5 & 10 \\
\hline Sucrose & 130,000 & \\
\hline
\end{tabular}




\section{Methods}

\section{Donor plant growth conditions}

Donor plants are grown in a growth chamber at $20^{\circ} \mathrm{C}$, light intensity of $200 \mu \mathrm{mol} / \mathrm{m}^{2} / \mathrm{s}$ with a $16 \mathrm{~h}$ photoperiod and $60-65 \%$ relative humidity (See Note 11). When plants start flowering they are transferred to growth chamber with the same conditions but at $15^{\circ} \mathrm{C}$ to increase the difference between the temperature of normal plant growth and the heat shock-based treatment used for embryogenesis induction, which favors the embryogenic response. Soil is supplemented with long-lasting nitrogen sources for rapid, sustained growth (Nitrophoska Fertilizer, for example). After a week at $15^{\circ} \mathrm{C}$ and once the first flowering has occurred, plants can be used as donors for microspore culture. It is important to remove open flowers regularly to increase flower bud production and ensure a regular supply of useful buds at the right developmental stage.

\section{In vitro culture of isolated microspores}

1. Switch on the flood hood, clean and disinfect the working surface, place all the material in (except for cooled flasks and buds) and turn on the UV light during $30 \mathrm{~min}$.

2. Excise inflorescences from plants (Fig. 1A) and place them in a plastic container within a box with ice (See Note 12).

3. Once in the laboratory, under a stereo microscope equipped with micrometer (Fig. 1B), sort buds with different sizes (See Note 13) and place them in separate dishes on ice until finishing this step. Once finished, place buds of each length in separate tea sieves (Fig. 1C).

4. Turn on the refrigerated centrifuge to start cooling to $4^{\circ} \mathrm{C}$. 

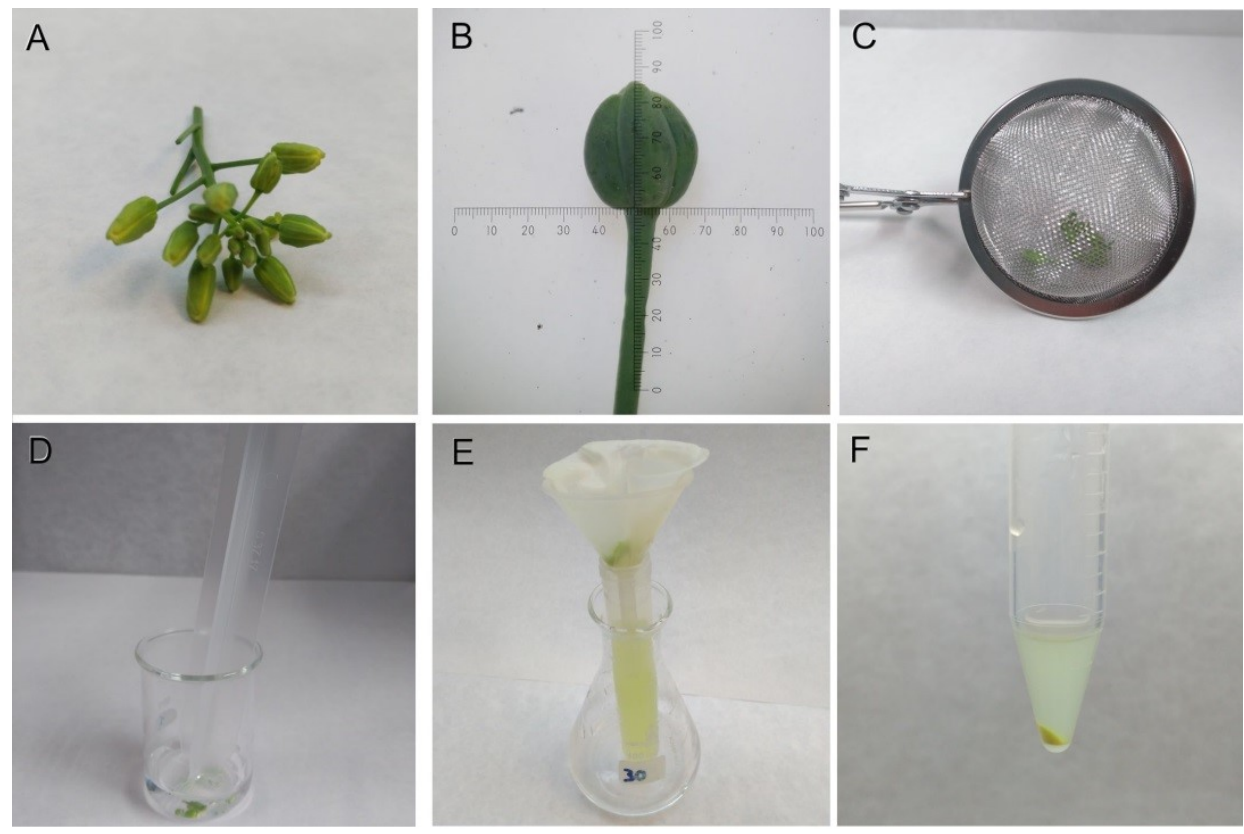

Fig. 1. Steps of the microspore culture protocol. A. B. napus inflorescence with still unopen buds at different stages. It is important to use only the central, small buds (2-4 mm), discarding the rest, too mature. B. Rapeseed flower bud under the stereo microscope. Measurement of the bud is done using the millimeter scale of the micrometer and measuring the entire sepal length. $\mathbf{C}$. Tea sieve with buds, used to sterilize them with bleach while keeping them together. D. Crushing of buds in culture media using a small beaker and a syringe plunger. E. $30 \mu \mathrm{m}$ nylon filter placed in a funnel and previously sterilized by autoclaving. Erlenmeyer serves as a support for the funnel and conical tube used to collect the filtrate. F. Final $1 \mathrm{ml}$ suspension of microspores after the three centrifugation rounds and before resuspension in the final volume.

5. Take buds to the laminar flow hood to start microspore isolation. From now on, everything must be done in a laminar flow hood.

6. Sterilize the selected flower buds. For this, transfer tea sieves through the different pre-cooled jars with the different sterilizing or washing solutions, as follows:

- $30 \mathrm{~s}$ in ethanol $70 \%$ 
- $10 \mathrm{~min}$ in $4 \mathrm{~g} / \mathrm{l}$ sodium hypochlorite while regularly shaking the sieves to remove air bubbles from the bud surface.

- Wash thrice 5 min each by dipping sieves into 3 different jars with cold sterile $\mathrm{dH}_{2} \mathrm{O}$ while shaking the sieves.

After transference of sieves to the next washing jar, soak the syringe plungers in the previous jar to remove ethanol (remember that plungers are stored in $70 \%$ ethanol) and have them ready for use.

7. After the last wash, remove buds from sieves by gently laying them on sterilized Whatman papers to let them dry.

8. Prepare a small beaker with $5 \mathrm{ml}$ of isolation medium and place buds in with a sterile forceps. Gently crush buds with the washed syringe plunger (Fig. 1D) until all buds are crushed. Rinse the plunger with $5 \mathrm{ml}$ of isolation medium to maximize recovery of microspores.

9. Filter the microspore suspension through the $30 \mu \mathrm{m}$ nylon meshes previously fitted in funnels. Collect the filtered suspension in a 15 $\mathrm{ml}$ tube (Fig. 1E). Put the tube on ice. The final volume should be around $10 \mathrm{ml}$ in each tube.

10. Centrifuge the resulting suspension at 1000 rpm for 4 minutes at $4^{\circ} \mathrm{C}$. After each centrifugation round, pour the supernatant off with a fast wrist movement to avoid resuspension of the microspore pellet.

11. Add new fresh isolation medium up to $10 \mathrm{ml}$ and resuspend the pellet by gently shaking the tube. Repeat the centrifugationwashing rounds thrice to remove cell debris and microorganisms.

12. After the third centrifugation, resuspend the purified microspores in $1 \mathrm{ml}$ of isolation medium (Fig. 1F).

13. Resuspend the pellet, calculate the density of the initial $(1 \mathrm{ml})$ microspore suspension (see Note 14), and adjust it to 40,000 microspores/ml (the optimal density established for $B$. napus 
microspore cultures (Huang et al. 1990)), using a hemacytometer counting chamber (Fig. 2).
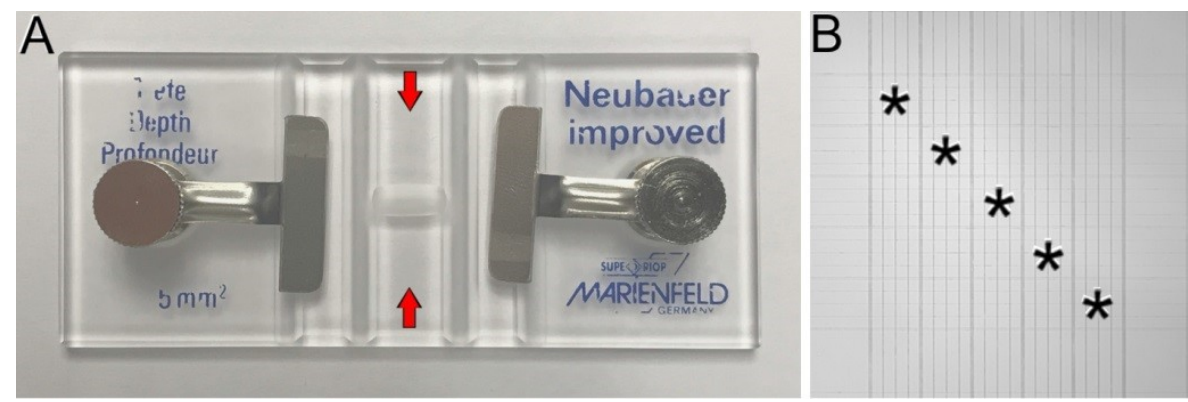

Fig. 2. Neubauer Improved counting chamber. A: Overview. The two red arrows indicate the position of the two counting cells. B: Single counting cell. Asterisk indicate the five squares of a diagonal to be counted. See text for further details.

14. Check microspore viability by FDA staining and, if there are doubts about the developmental stage, double check it by DAPI staining (see Note 15).

15. Pour 1,3 or $10 \mathrm{ml}$ of the final microspore suspension in $3 \mathrm{~cm} \varnothing, 6$ $\mathrm{cm} \varnothing$ or $9 \mathrm{~cm} \varnothing$ culture plates, respectively.

16. Seal with parafilm (double or better triple-seal). Keep plates in darkness (See Note 16) at $32^{\circ} \mathrm{C}$ for heat shock treatment (See Note 17).

17. Upon finishing the treatment, keep dishes in darkness at $25^{\circ} \mathrm{C}$ (See Note 18). To check the efficiency of heat shock, extract a sample from a culture dish 2-6 days after microspore isolation, stain with DAPI (See Note 19), and check for dividing microspores, i.e., microspores with more than one DAPI-stained nuclei within the same exine coat (Figs. 3A, B).

18. Two or three weeks after isolation, MDEs visible under a stereo microscope at low magnification or even with the naked eye, should appear (Figs. 3C, D). Final efficiency of the culture is 
calculated counting the total of MDEs under a stereo microscope (Fig. 3D, see Note 20).
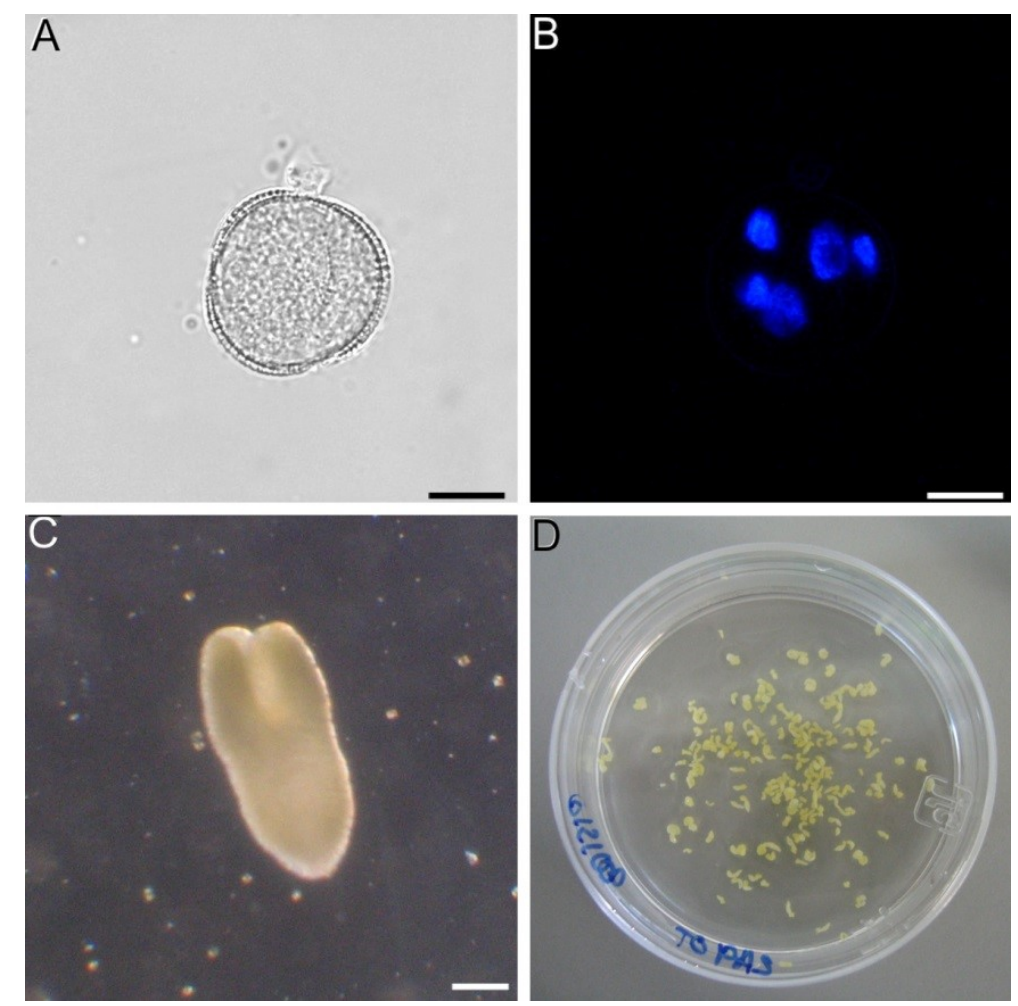

Fig. 3. Different stages during B. napus microspore culture. A, B: Dividing, embryogenic microspore as seen by phase contrast (A) and DAPI staining (B). C: Torpedo-like MDE. D: Culture dish with MDEs mostly at the torpedocotyledonary stages. Bars: A, B: $10 \mu \mathrm{m}$; C: $100 \mu \mathrm{m}$.

\section{MDE germination and acclimation}

1. Pick up MDEs at the cotyledonary stage and place them in solid B5 medium, previously poured into $9 \mathrm{~cm} \varnothing$ high dishes, for germination. Inoculate a maximum of $10 \mathrm{MDEs}$ per dish to allow them to grow without interferences. Germinate them at $25^{\circ} \mathrm{C}$ and $32 \mu \mathrm{mol} / \mathrm{m}^{2} / \mathrm{s}$ light intensity, $12 \mathrm{~h}$ photoperiod. 
2. Transfer germinated seedlings to sterile glass small jars with $30 \mathrm{ml}$ of B5 medium for further growth (See Note 21).

3. Properly developed seedlings can be transferred to plastic pots with wet composite soil.

4. Acclimate plantlets in a growth chamber at $25^{\circ} \mathrm{C}$ and $16 \mathrm{~h}$ photoperiod (See Note 22).

\section{Analysis of the Ploidy Level}

Flow cytometry is used to check DNA content of microspore-derived plantlets and, by comparison with a known diploid donor plant, infer their ploidy level. Thus, diploid donor plants should be analyzed in parallel as controls for $2 \mathrm{C}$ DNA content.

1. Cut out young leafs from plants (see Note 23) and place them in dishes inside a box with ice. Add $0.5 \mathrm{ml}$ of lysis buffer on the top of the leaf.

3. Cut a leaf piece of approximately $1 \mathrm{~cm}^{2}$, and chop it into fine chunks using a razor blade, to release as much intact nuclei as possible to the lysis buffer.

4. Filter the homogenate through to a $30 \mu \mathrm{m}$ filter and collect the filtered nuclei into vials compatible with the loading port of the flow cytometer to be used (see Note 24). Add $1.5 \mathrm{ml}$ of DAPI staining buffer.

5. Incubate vials 2 min on ice before analyzing the samples.

6. Start the analysis with the flow cytometer according to manufacturer specifications. Perform a minimum of 10,000 counts per sample. 


\section{Notes}

1. One of the most important parameters to guarantee successful microspore embryogenesis is the proper identification of the most suitable developmental stages of microspores, which in the case of $B$. napus revolves around the vacuolate microspore and young bicellular pollen stages (Seguí-Simarro and Nuez 2008a). For this, it is typical to isolate microspores/pollen from different previously measured bud sizes, and then stain them with DAPI and observe in the fluorescence microscope, in order to identify the bud length range where the percentages of vacuolate microspores and young bicelular pollen grains are highest.

2. In our case, we use an Eppendorf ${ }^{\circledR}$ Centrifuge $5804 \mathrm{R}$, refrigerated, with A-4-44 rotor (17.5 cm radius) with adapters for $15 / 50 \mathrm{ml}$ conical tubes.

3. The number of tea sieves, beakers and Erlenmeyer flask depends on the number of bud length intervals to be used in parallel (See Note 13).

4. Plating of microspores at the right density is a crucial step for a good embryogenic response. Different counting methods can be used to calculate microspore plating densities, depending on the equipment available in each laboratory. Among them, however, hemacytometers and in particular the Neubauer Improved chamber appears to be the simplest and most suitable approach (Camacho-Fernández et al. 2018).

5. For observation of samples stained with DAPI and FDA, slides and coverslips can be reused for a limited number of times, provided that they are carefully cleaned and stored to avoid scratches and dust deposition. All the waste containing DAPI, including microscope slides, should be stored and disposed of following the corresponding safety rules to avoid contamination of the working area. 
6. Once buds are excised from donor plants, it is essential to keep them on ice to arrest microspore development and slow down the processes of cell death. If the workplace is cool enough, keeping the buds on ice and using cold $\left(4^{\circ} \mathrm{C}\right)$ disinfecting solutions should be sufficient to prevent loss of embryogenic response. If not, additional measures should be taken. For example, we found that keeping both the solutions and the buds on ice during the whole process of microspore isolation, filtration and plating allows for a successful microspore culture, with good embryogenic response, even in warm workspaces, where air cooling is insufficient or absent.

7. In general, the choice of the dish size depends on the goal of the experiment to be performed. If the goal is to obtain mature MDEs or to collect samples at different days of culture, we usually opt for $6 \mathrm{~cm} \varnothing$ plates. If the goal is different, for example to test the effect on embryogenic response of different compounds, we use $3 \mathrm{~cm} \varnothing$ plates with less culture volume, to optimize the number of chemicals tested in a single experiment. However, it must be noted that dish size has been reported to have an effect on the embryogenic response in other species (Kim et al. 2013).

8. For microspore isolation and washing it is possible to use exactly the same NLN-13-based medium used for microspore culture. This would be the easiest and most straightforward alternative. However, preparation of NLN-13 medium is expensive and timeconsuming. First, it must be filtered through sterile $0.2 \mu \mathrm{m}$ membrane filters in order to prevent sucrose breakdown and caramelization. Second, due to the high amount of sucrose and the corresponding viscosity, filtering becomes difficult, filters saturate soon, and a large amount of filters must be used. As an alternative to this, we used to prepare additional isolation and washing medium. This medium has almost the osmotic conditions (mainly derived from sucrose) and the same $\mathrm{pH}$. However, since we only need them for isolation and washings (two relatively rapid steps), there is no need for filtering. It can be autoclaved, which allows for time and money savings, while the efficiency of microspore embryogenesis is not compromised. Once prepared, it must be stored at $4^{\circ} \mathrm{C}$ for a maximum of one month. 
9. NLN basal medium (salts and vitamins) can be prepared from stocks (Table 1) or bought as commercial preparation (from Duchefa Biochemie, The Netherlands).

10. Whereas DAPI working solution can be prepared in advance from stock solution, FDA sorking solution must be prepared immediately before use. This is why it will be described later, in the Methods section, while describing viability determination.

11. It is also possible to keep plants outdoors instead of indoors. The main advantage is that plants grow more, faster and produce a larger number of buds to work with, which is highly recommended when performing large-scale cultures. The limitation is that their optimal growth and performance greatly depend on climatic conditions, especially temperature changes. This limits the optimal outdoor growth to the months when temperatures do not exceed from $20^{\circ} \mathrm{C}$ during light hours and decrease at night. In addition, outdoor growth exposes them to more frequent pest attacks, and to the possibility of snails eating their leaves and birds eating their seeds. To avoid these limitations, it is advisable to keep them in growth chambers under controlled conditions.

12. The number of inflorescences to use depends on the scale of the culture to be carried out. It is better to cut entire inflorescences than individual buds, since this way buds will last longer alive and healthy.

13. As the correlation between bud length and microspore/pollen developmental stage is usually influenced by environmental and donor plant conditions, three consecutive bud length intervals are normally processed in parallel to ensure that at least one of them contains the highest percentage of microspores/pollen at the right developmental stage. For DH4079 and DH12O75 lines, the intervals typically used are 3-3.2 / 3.2-3.4 / 3.4-3.6, and 2.4-2.6 / 2.6-2.8 / 2.8-3.0 mm, respectively.

14. Take $40 \mu \mathrm{l}$ of the initial $1 \mathrm{ml}$ suspension. Pour $10 \mu \mathrm{l}$ in each of the two counting cells of the chamber (Fig. 2A), leaving the remaining $10 \mu \mathrm{l}$ in the tube to be used in the next step. Pipet each $10 \mu \mathrm{l}$ drop on the edge of the chamber coverslip and the suspension will be 
sucked into the chamber by capillarity. With a microscope, count the microspores on each of the five squares of a single diagonal (Fig. 2B). Repeat this step with the second $10 \mu \mathrm{l}$ drop, deposited in the other counting cell. Countings are considered coherent when both counts do not deviate more than $15 \%$. If they do, repeat counts with two new drops. With two coherent counts, the average is calculated and then used to estimate the final volume to which resuspend microspores for a final density of 40,000 microspores/ml, according to the following formula:

$$
\text { Final volume }=\frac{\text { Average count } \times 5}{4}
$$

15. For DAPI and FDA staining, use the $20 \mu \mathrm{l}$ volume remaining from the $40 \mu \mathrm{l}$ taken from the initial microspore suspension (See Note 14). For DAPI staining, mix $10 \mu \mathrm{l}$ of DAPI working solution with 10 $\mu \mathrm{l}$ of the initial microspore suspension. Incubate $15 \mathrm{~min}$ in darkness, mount in a slide, add a coverslip and observe with the fluorescence microscope. It is possible to keep the preparation at $4^{\circ} \mathrm{C}$ in darkness to be observed later on.

For FDA staining, prepare a 1/100 working solution of FDA stock solution in $\mathrm{dH}_{2} \mathrm{O}$ immediately prior to use. Add $5 \mu \mathrm{l}$ of the working solution to the remaining $10 \mu \mathrm{l}$ of the initial microspore suspension. Incubate $10 \mathrm{~min}$ at room temperature in darkness, mount in a slide, add a coverslip and observe in the fluorescence microscope.

16. To better ensure darkness, it is advisable to wrap dishes in aluminum foil or to place dishes in opaque cardboard or plastic boxes.

17. The duration of the heat stress treatment will affect the process in two ways: efficiency of embryogenesis induction and MDE quality. Prolonged treatments produce more MDEs, but they are more prone to present morphological abnormalities. Conversely, shorter treatments produce less MDEs, but of better quality. It also depends on its combined use with other abiotic stresses or chemicals that enhance embryogenesis induction. This parameter 
is genotype-dependent and should therefore be established for each new genotype. In such a case, our advice would be to perform an initial test applying $32^{\circ} \mathrm{C}$ treatments of 24,48 and 72 hours, and then opt for the duration that provides the best compromise between high response and good MDE quality.

18. Depending on the goal of the experiment, it may be necessary to refresh culture medium during $25^{\circ} \mathrm{C}$ incubation. If the goal is to study early stages of embryogenesis, up to development of globular MDEs, the medium initially poured may be enough. If the goal is to study advanced stages of MDE development or to produce $\mathrm{DH}$ plants, it may be necessary to add fresh NLN-13 medium 7 days after culture initiation, to compensate the loss by consumption and evaporation. This will allow for the development of quality MDEs.

19. The procedure of DAPI staining to check for microspore divisions is the same as for stage determination (see Note 15), but using $100 \mu \mathrm{l}$ of cell suspension taken under sterile conditions (in the flow hood). To avoid culture contamination, it is convenient to have a 3 $\mathrm{cm} \varnothing$ extra dish of each treatment to use for this purpose.

20. Efficiency is usually expressed as the number of MDEs per petri dish, per $\mathrm{ml}$ of culture media (dividing by the original volume of each dish counted) or per bud (using the relation of buds per ml, which must be calculated in each culture). The choice depends on the purpose of the study and the use intended for the data obtained.

21. Transference of germinated seedlings from $9 \mathrm{~cm} \varnothing$ dishes to sterile glass jars provides the space needed for a proper development of roots and shoots.

22. Upon transference of plantlets to pots with soil, humidity conditions change dramatically, which may severely affect plant growth. To prevent this, plantlets should be first covered with intact plastic glasses, pinching new holes on the glass every two days. This way, holes would progressively increase transpiration and would acclimatize plants to environmental humidity. After several days, remove the glass. 
23. The use of young tissues for ploidy analysis relates to the fact that young, proliferating tissues have more cells in the $\mathrm{G}_{2}$ stage of the cell cycle. Thus, the $G_{2}$ peak will be more clearly seen in the histogram.

24. In our case, $3.5 \mathrm{ml}$ plastic vials compatible with a Partec CyFlow Ploidy Analyzer.

\section{Acknowledgements}

This work was supported by grant AGL2017-88135-R to JMSS from MINECO jointly funded by FEDER.

\section{References}

Camacho-Fernández C, Hervás D, Rivas-Sendra A, Marín MP, Seguí-Simarro JM (2018) Comparison of six different methods to calculate cell densities. Plant Methods 14 (1):30. doi:10.1186/s13007-018-0297-4

Custers J (2003) Microspore culture in rapeseed (Brassica napus L.). In: Maluszynski M, Kasha KJ, Forster BP, Szarejko I (eds) Doubled haploid production in crop plants. Kluwer Academic Publishers, Dordrecht, The Netherlands, pp 185-193

Dwivedi SL, Britt AB, Tripathi L, Sharma S, Upadhyaya HD, Ortiz R (2015) Haploids: Constraints and opportunities in plant breeding. Biotechnol Adv 33 (6 Pt 1):812-829. doi:http://dx.doi.org/10.1016/j.biotechadv.2015.07.001

Forster BP, Heberle-Bors E, Kasha KJ, Touraev A (2007) The resurgence of haploids in higher plants. Trends Plant Sci 12 (8):368-375. doi:10.1016/j.tplants.2007.06.007

Gamborg OL, Miller RA, Ojima K (1968) Nutrient requirements of suspension cultures of soybean root cells. Exp Cell Res 50 (1):151-158.

doi:http://dx.doi.org/10.1016/o014-4827(68)90403-5 
Huang B, Bird S, Kemble R, Simmonds D, Keller W, Miki B (1990) Effects of culture density, conditioned medium and feeder cultures on microspore embryogenesis in Brassica napus L. cv. Topas. Plant Cell Rep 8 (10):594-597

Kim M, Park E-J, An D, Lee Y (2013) High-quality embryo production and plant regeneration using a two-step culture system in isolated microspore cultures of hot pepper (Capsicum annuum L.). Plant Cell Tissue Organ Cult 112 (2):191-201. doi:10.1007/s11240-012-0222-X

Nitsch JP (1972) Haploid plants from pollen. Z Pflanzenzüchtg 67:3-18

Seguí-Simarro JM (2010) Androgenesis revisited. Bot Rev 76 (3):377-404. doi:10.1007/s12229-010-9056-6

Seguí-Simarro JM, Nuez F (2008a) How microspores transform into haploid embryos: changes associated with embryogenesis induction and microspore-derived embryogenesis. Physiol Plant 134:1-12. doi:10.1111/j.1399-3054.2008.01113.x

Seguí-Simarro JM, Nuez F (2008b) Pathways to doubled haploidy: chromosome doubling during androgenesis. Cytogenet Genome Res 120 (3-4):358369. doi:10.1159/000121085

Shariatpanahi ME, Bal U, Heberle-Bors E, Touraev A (2006) Stresses applied for the re-programming of plant microspores towards in vitro embryogenesis. Physiol Plant 127 (4):519-534 
Block 2 


\section{Chapter 4}

\section{The highly and barely embryogenic populations of B. napus microspore cultures undergo different levels of ER stress, autophagy and programmed cell death}

Patricia Corral-Martínez ${ }^{1}$ Carolina Camacho-Fernández ${ }^{1}$, Sergio Ochatt², Kim Boutilier ${ }^{3}$ and Jose M. Seguí-Simarro ${ }^{1}$

${ }^{1}$ COMAV - Universitat Politècnica de València, Spain

2 UMR 1347 Agroécologie, AgroSup/INRAE/uB, Laboratoire de Physiologie Cellulaire, Morphogenèse et Validation (PCMV), Dijon. France.

3 Plant Development Systems, Wageningen University and Research, Wageningen. The Netherlands.

Running title: ER stress, autophagy and PCD in embryogenic microspores

Keywords: androgenesis, bafilomycin, doubled haploids, endoplasmic reticulum, microspore embryogenesis, obatoclax, PCD, rapeseed, tunicamycin 


\section{Abstract}

Microspore embryogenesis is an in vitro process initiated by a stress treatment, one of whose consequences is the occurrence of endoplasmic reticulum (ER) stress, autophagy and programmed cell death (PCD). It was recently described that the population of cultured microspores is not homogeneous. Actually, there are different types of microspore-derived structures with different embryogenic potential, ranging from highly to barely embryogenic structures. In this work, we focused on the relationship between microspore embryogenesis and ER stress, autophagy and PCD, focusing on how the different types of structures are affected, and whether these processes have a relationship with their different embryogenic potential. We used tunicamycin, bafilomycin and obatoclax to modulate ER stress, autophagy and PCD. We also analyzed the ER and the occurrence of lytic activity in the different structures, demonstrating a strong relationship between these processes and embryogenic commitment. We propose that higher levels of ER stress in barely embryogenic structures would trigger excessive autophagy, leading to PCD. In turn, moderate ER stress levels in highly embryogenic structures would contribute to moderate levels of autophagy and PCD, allowing for their development as MDEs. There seems to be a range of moderate autophagy levels that favors microspore embryogenesis. Below or beyond the range, microspore embryogenesis is not optimal. Finally, obatoclax affects selectively damaged cells of barely embryogenic structures, promoting PCD in these structures and therefore enriching the cultures in highly embryogenic structures. 


\section{Introduction}

The phenomenon of "Unfolded Protein Response" (UPR) consists of the generation of a cellular stress response due to the presence of unfolded and misfolded proteins in the endoplasmic reticulum (ER) lumen (Fanata et al. 2013; Ruberti and Brandizzi 2014). The presence of these anomalous proteins, and therefore of the UPR, can be induced by many different causes, including inhibition of disulfide bond formation or posttranslational modification of secretory proteins, aging, genetic mutation, virus or pathogen infection, loss of ER luminal calcium, heat stress, hypoxia, deprivation of glucose, amino acids or other nutrients, and even the presence of auxins (Liu and Bassham 2012; Fanata et al. 2013; Ruberti and Brandizzi 2014). As a consequence of this, misfolded, non-functional proteins are generated, which accumulate in the ER and generate a stress in the ER (ER stress, defined as any disturbance in ER functions). To alleviate ER stress, the cell triggers the UPR, consisting initially of a decrease in the general synthesis of proteins, except for molecular chaperones, necessary to help correct folding, and whose synthesis increases. If UPR is not enough to avoid ER stress, other mechanisms leading to the induction of autophagy are activated, by which complete ER cisternae, and the misfolded proteins they contain, are eliminated (Liu et al. 2012). Finally, if autophagy is insufficient to mitigate ER stress, programmed cell death (PCD) is directly induced to eliminate damaged cells (Ruberti and Brandizzi 2014).

Microspore embryogenesis is an in vitro process by which microspores can be deviated from their initial gametophytic pathway and induced to develop as haploid, microspore-derived embryos (MDEs), eventually producing entire, fully functional new doubled haploid plants. To induce the developmental switch, this phenomenon requires the in vitro application of a stress treatment which, in turn, is associated to a number of changes and reorganizations at the cellular and molecular levels (Seguí-Simarro and Nuez 2008). Interestingly, there are many coincidences between the causes of UPR above described and some of the stress treatments used to induce microspore embryogenesis, such as heat stress, hypoxia, deprivation of glucose, amino acids or other nutrients, or the presence of hormones 
(Shariatpanahi et al. 2006). It is also interesting to observe that many of the consequences of UPR mentioned above have also been observed as changes during or after the induction of microspore embryogenesis, including a general decrease in protein levels (Maraschin et al. 2005b), the increase in the synthesis of certain stress proteins and molecular chaperones (Seguí-Simarro et al. 2003), the induction of autophagy (Corral-Martínez et al. 2013), and even programmed cell death (Maraschin et al. 2005a). It is also worth to mention that thickened rough ER cisternae with dense contents, which could well be aggregates of misfolded proteins, have been observed in B. napus embryogenic microspores soon after induction (Corral-Martínez et al. 2013).

The coincidences between the factors capable to induce microspore embryogenesis and the cellular causes and consequences of ER stress, autophagy and PCD suggest possible links between these processes. This is why this has been previously studied in the B. napus system as well as in other microspore culture systems, assuming that induced microspores form a homogeneous population that follows similar developmental patterns (Corral-Martínez et al. 2013; Bárány et al. 2018). However, it was recently demonstrated that, at least in B. napus (including the DH4079 and DH12075 lines, respectively characterized by a high and low embryogenic response), different structures are formed, each of them having dramatically different developmental fates, ranging from entering embryogenesis to death (Corral-Martínez et al. 2020b, Chapters 5 and 6). Indeed, not all the dividing microspores become MDEs. Multicellular structures that divide without substantially increasing their volume remain within an intact exine (exine-enclosed structures, EE), and this is determinant for proper MDE development. Other structures (loose bicellular structures, LBS), despite exine rupture, develop a suspensor-like domain and end up forming suspensor-bearing MDEs, although at a percentage lower than exine-enclosed structures. These two types of structures have the highest chances of becoming MDEs, are responsible for nearly all the MDEs produced in B. napus microspore cultures (Corral-Martínez et al. 2020b), and are therefore considered as highly embryogenic structures (Chapters 5 and 6). In turn, the vast majority of the multicellular structures that expand and break the exine at different points and to different extents, form disorganized, either compact or loose, callus structures (CC or LC) that in most cases arrest and/or die. Only in a very low percentage of cases these structures 
end up as MDEs (Corral-Martínez et al. 2020b). This is why they are considered as barely embryogenic structures (Chapters 5 and 6).

The discovery in B. napus of these two clearly defined types of structures, easily identifiable by their cellular phenotypes, led us to focus on the relationship between microspore embryogenesis and ER stress, autophagy and PCD, focusing on how these different populations are affected and on whether this is related to their different embryogenic potential. For this, we used tunicamycin, bafilomycin and obatoclax to modulate ER stress, autophagy and PCD. Tunicamycin is an inhibitor of $\mathrm{N}$-glycosylation that induces autophagy through induction of ER stress (Klionsky et al. 2016). Bafilomycin is an inhibitor of vacuolar $\mathrm{H}^{+}-$ ATPases known to reduce lytic activity by inhibition of fusion of autophagosomes with the vacuole, and by inhibition of vacuolar degradation (Klionsky et al. 2016). Obatoclax (also known as GX15-070) is a drug known to induce autophagy-dependent cell death in a number of animal tumor cells. Obatoclax inhibits antiapoptotic proteins of the Bcl-2 family, which, in turn, induces a caspase-independent cell death primarily by induction of defective autophagy in different tumor cells (Yu et al. 2016; Jiménez-Guerrero et al. 2018; Cournoyer et al. 2019). This is why its use has been evaluated as anticancer drug in several animal models. However, no reports on its use in plant systems are available at present to the best of our knowledge. We also analyzed the ER and the occurrence of lytic activity in the different structures by means of flow cytometry and confocal, light and transmission electron microscopy. We found evidences of higher levels of ER stress, autophagy and PCD in barely embryogenic structures, suggesting a strong relationship between these three processes and non-embryogenic commitment. We propose that higher levels of ER stress would trigger excessive autophagy, thereby leading to PCD and precluding the development of these structures as MDEs. In turn, moderate ER stress levels would contribute to moderate levels of autophagy and PCD, allowing for the development of MDEs. We also found that there seems to be a range of moderate levels of autophagy within which, microspore embryogenesis is favored. Below or beyond the range, microspore embryogenesis is not optimal. Finally, obatoclax affects selectively the more damaged and stressed, barely embryogenic structures, promoting their PCD and therefore enriching the cultures in highly embryogenic forms. 


\section{Materials and methods}

\section{Plant material}

Two Brassica napus L. genotypes were used for microspore culture, Topas DH4079. Plants were grown and cultured as described in CorralMartínez et al. 2020a. Two months after transplanting seedlings to pots, they flowered and became ready for microspore isolation and culture.

\section{Isolated microspore culture}

B. napus microspore cultures were performed as described previously (Corral-Martínez et al. 2020a). Basically, we collected flower buds with microspores at the inducible developmental stage. Then, buds were surface disinfected and crushed in filter-sterilized NLN-13 medium, prepared according to Lichter 1982 and supplemented with $13 \%$ sucrose. Microspores were filtrated from the suspension, purified, resuspended in fresh $\mathrm{NLN}-13$ medium, inoculated in culture dishes at a density of 40,000 microspores $/ \mathrm{ml}$, and incubated in darkness at $32^{\circ} \mathrm{C}$ during three days, after which they were cultured continuously at $25^{\circ} \mathrm{C}$ in darkness.

\section{Chemical treatments}

Tunicamycin, bafilomycin and obatoclax were present in the culture media, at different concentrations as described in Results. Tunicamycin at high concentrations was applied continuously to microspore cultures. For the low concentration experiments, tunicamycin was applied only during the first day of the three-day heat shock treatment. Microspores were transferred to new, fresh medium after the tunicamycin treatment. Bafilomycin was applied during the three days of the heat shock treatment. Then, microspores were transferred to fresh medium. Obatoclax was applied continuously, during the entire duration of the 
cultures. For all the experiments, MDE production was evaluated by counting the number of MDEs/ml after two weeks of culture.

\section{Light and electron microscopy}

Sectioned material for light and transmission electron microscopy (TEM) was prepared from freshly isolated or in vitro cultured microspores. Fresh material was collected following the same isolation procedure as in microspore cultures. In vitro-cultured materials were collected by centrifugation and fixed in Karnovsky fixative (Karnovsky 1965) and post-fixed with $2 \% \mathrm{OsO}_{4}$. To immobilize and concentrate microspores, the buffer was replaced with 1-2 drops of warm, liquid $15 \%$ gelatin. Then, samples were centrifuged (1 min at $800 \mathrm{rpm}$ in a desktop microcentrifuge), cooled on ice for gelatin solidification and incubated overnight at $4^{\circ} \mathrm{C}$ with $20 \mu \mathrm{l}$ of $1 \%$ paraformaldehyde. Then, excess of gelatin was removed and gelatin-embedded samples were cut in small pieces and kept in buffer until use. All solutions were prepared in cacodylate buffer. Samples were dehydrated in progressive methanol series and embedded and polymerized in Embed-812 resin. One $\mu \mathrm{m}$ and $80 \mathrm{~nm}$-thick sections were obtained for light and TEM observation, respectively, with a Leica UC6 ultramicrotome. At least three blocks were used for each sample. Light microscopy sections were mounted with Biomount in glass coverslips and observed in a Nikon Eclipse E100o light microscope. Quantification of vacuoles was performed measuring the total area and the area occupied by vacuoles in 10-15 light microscopy images of each of the different structures studied taken at 100x. TEM sections were mounted on formvar-coated, 200-mesh nickel grids, stained with uranyl acetate and lead citrate, and observed in a Jeol JEM 1010 TEM.

\section{Confocal microscopy}

ER and lytic activity were observed using both fixed and living samples. Fixed samples were stained with 3,3-dihexyloxacarbocyanine $\left(\right.$ DiOC $\left._{6}\right)$ and monodansylcadaverine (MDC). DiOC $_{6}$ is a lipophilic probe that stains internal membranes of the endomembrane system such as 
the ER, Golgi stacks, vesicles, etc. Assuming that the ER membrane network is by far the main component of the endomembrane system, it is assumed that $\mathrm{DiOC}_{6}$ fluorescence can be used to estimate the amount of ER. MDC is a fluorescent probe specific for acidic endomembrane compartments, commonly used to detect lytic activity. Samples were collected at different stages during development and fixed overnight at $4^{\circ} \mathrm{C}$ with $4 \%$ paraformaldehyde in PBS ( $\mathrm{pH} 7.4$ ). Samples were then washed three times with $\mathrm{PBS}$ and stored at $4^{\circ} \mathrm{C}$ in $0.1 \%$ paraformaldehyde in PBS until use. A $50 \mu \mathrm{M}$ working solution in PBS was prepared from a $5 \mathrm{mM}$ stock solution of $\mathrm{DiOC}_{6}$ in DMSO stored at $20^{\circ} \mathrm{C}$. Samples were previously stained with $2.5 \mu \mathrm{g} / \mathrm{ml}$ DAPI and then incubated with $\mathrm{DiOC}_{6}$ working solution for $1 \mathrm{~min}$ and observed directly without washings. For MDC staining, a $20 \mu \mathrm{g} / \mathrm{ml}$ solution of propidium iodide (PI) in PBS was first directly added to the cell suspension and incubated for $10 \mathrm{~min}$. After three $5 \mathrm{~min}$ PBS washes, samples were stained with $0.1 \mathrm{mM}$ MDC for $10 \mathrm{~min}$ and washed three times, $5 \mathrm{~min}$ each. At least 200 structures were examined for each sample. Live samples were stained with ER-Tracker Blue-White DPX dye (Molecular Probes), a molecular probe specific to detect ER accumulation, and with LysoTracker Deep red (Molecular Probes) to detect lytic activity. A 50 $\mathrm{nM}$ working solution of ER-Tracker in PBS was prepared from a $1 \mathrm{mM}$ stock solution in anhydrous DMSO stored at $-20^{\circ} \mathrm{C}$. Cell suspensions were incubated with ER-Tracker for $30 \mathrm{~min}$ and directly observed. A 1 $\mu \mathrm{M}$ working solution of LysoTracker in PBS was prepared from a $1 \mathrm{mM}$ stock solution in anhydrous DMSO stored at $-20^{\circ} \mathrm{C}$. Cell suspensions were incubated with LysoTracker for $60 \mathrm{~min}$ and directly observed. A fluorescence-based live-dead study was performed to evaluate the viability of embryogenic structures in microspore cultures. Fluorescein diacetate (FDA) and PI were simultaneously used to discriminate living and dead cells in the same microspore cultures. A staining solution with $1 \mathrm{ml}$ PBS 1x, $2 \mu \mathrm{FDA}(5 \mathrm{mg} / \mathrm{ml})$ and $10 \mu \mathrm{PI}(10 \mathrm{mg} / \mathrm{ml})$ was prepared first. Fresh staining solution $(100 \mu \mathrm{l})$ was added to the microspore pellet (corresponding to $1 \mathrm{ml}$ of culture) and incubated for $5 \mathrm{~min}$. Then, the staining solution was removed and samples were washed with PBS once before analysis. All samples were incubated in darkness and observed with Leica CTR 5500 and Zeiss LSM 780 microscopes. DAPI, MDC and ER-Tracker were excited with a $405 \mathrm{~nm}$ laser line and the emission at the $458-487,455-489 \mathrm{~nm}$ and $430-540 \mathrm{~nm}$, ranges respectively, was 
recorded. $\mathrm{DiOC}_{6}$ and FDA were excited with a $488 \mathrm{~nm}$ laser line and the emission at $504 \mathrm{~nm}$ and $510 \mathrm{~nm}$ was recorded. PI was excited with a 561 $\mathrm{nm}$ laser line and the emission at $636 \mathrm{~nm}$ was recorded. Finally, LysoTracker was excited with a $640 \mathrm{~nm}$ laser line and the emission at $668 \mathrm{~nm}$ was recorded. Images were processed with Leica Application Suite Advanced Fluorescence (LAS AF) and FIJI software (Schindelin et al. 2012).

\section{Flow cytometry}

To locate the microspore population, adjust the scale, delimit the background noise and the rest of cytometric parameters, $1 \mathrm{ml}$ of sample stained with PI as described above was used. Before analyzing samples, we passed the buffer used to suspend the sample (PBS) without sample to verify the absence of signal. Then, we analyzed an unstained sample of freshly isolated microspores to detect and analyze the autofluorescence of exine. Staining of samples with LysoTracker was performed as described above. Three repeats were made and a minimum of 2,500 structures were measured per repeat. Samples were analyzed with a Partec PAS-II flow cytometer equipped with an argon ion laser $488 \mathrm{~nm}$ and a HBO lamp for UV excitation and with a $25 \mathrm{~mW}$ diode laser at 635 $\mathrm{nm}$. The data were plotted on a semi-logarithmic scale. The data of each peak in the histograms were obtained and analyzed using the Partec DPAC v2.0 software.

\section{Results}

\section{Modulation of autophagy with bafilomycin}

First, we wanted to know whether modulation of autophagy with chemicals would affect cell death and the rate of induction of microspore embryogenesis. The first chemical used was bafilomycin to disrupt autophagy. First, we tried a battery of concentrations ranging from 5 to $200 \mathrm{nM}$ (Fig. 1A), previously proved to have an effect in other B. napus backgrounds (our unpublished results), and counted the number of 116 
MDEs produced after two weeks of culture. With them, we found no significant effect of bafilomycin at any concentration, with the exception of the highest (200 $\mathrm{nM}$ ), where the effect was clearly detrimental. For this reason, we tested a second battery of concentrations, ranging from 0.05 to $5 \mathrm{mM}$ (Fig. 1B). In this case, the response was positive and similar for all the concentrations, approximately doubling the number of MDEs observed in control. Thus, we showed that a slight inhibition of autophagy by using low concentrations of bafilomycin was positive to increase the number of structures effectively committed to form MDEs.
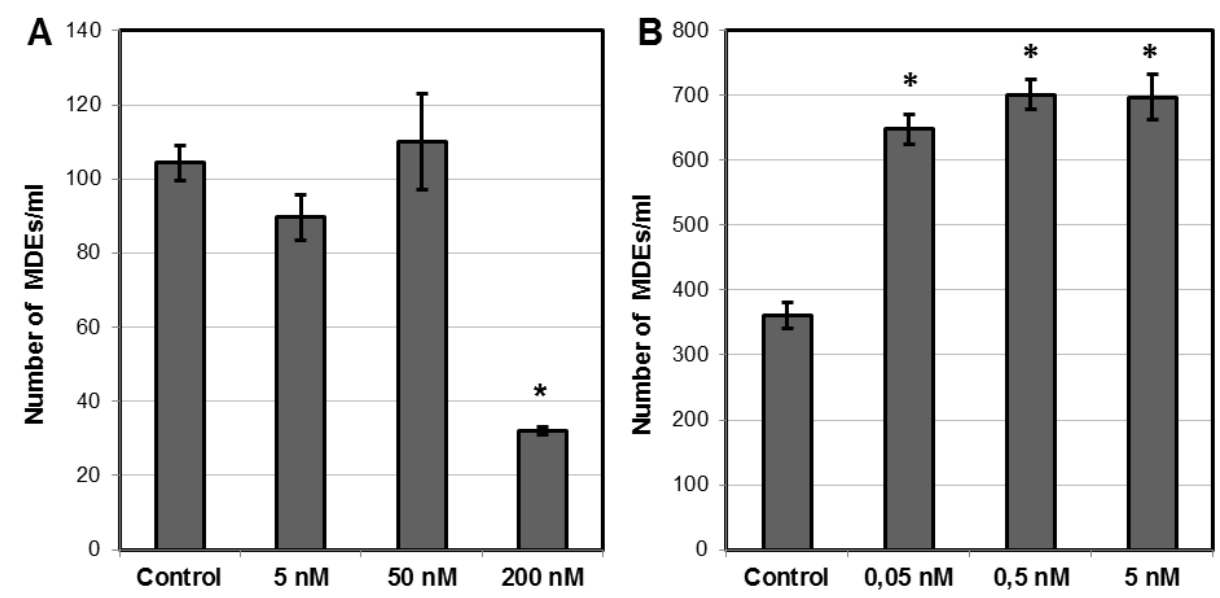

Figure 1: Treatments with bafilomycin. Embryogenic response of cultures treated with high (A) and low (B) concentrations of bafilomycin. Results are expressed as number of MDEs counted per $\mathrm{ml}$ after two weeks of culture. Asterisks represent statistical differences between the treatment and the control according to Dunnett's test. 


\section{Modulation of ER stress with tunicamycin}

To evaluate to what extent ER stress could have an effect in microspore embryogenesis, we applied tunicamycin, known to induce ER stress. First, we tried a wide range of tunicamycin concentrations, from 0.5 to $10 \mu \mathrm{g} / \mathrm{ml}$ and, as a first approach, counted the number of dividing microspores after 3, 4, 5 and 6 days of culture (Fig. 2A). We found that in general, all concentrations of tunicamycin produced more divisions that the control during the first four days. However, after day five the percentage of divisions did not increase further, and even decreased in some cases, except for the lowest concentration ( 0.5 $\mu \mathrm{g} / \mathrm{ml}$ ), which produced more dividing microspores than any other concentration, with percentages similar to control. At day six, $0.5 \mu \mathrm{g} / \mathrm{ml}$ promoted even more divisions than control conditions (25\%, around twice more). After two weeks of culture, results in terms of number of MDEs (Fig. 2B) were clearly negative for 5 and $10 \mu \mathrm{g} / \mathrm{ml}$. However, 0.5 and $2 \mu \mathrm{g} / \mathrm{ml}$ showed no significantly different effects compared to control. Finally, we tried a lower range of tunicamycin concentrations (0,05 and $0,25 \mu \mathrm{g} / \mathrm{ml}$ ) and counted the number of MDEs produced (Supplementary figure S1). Again, low concentrations had no significant effect (neither positive nor negative) in MDE yield. In summary, we concluded that the generation of a severe ER stress with high concentrations of tunicamycin had a markedly negative effect in the rate of MDE production. However, lower levels of ER stress induced with lower concentrations of tunicamycin had no effect at all in such a rate. 

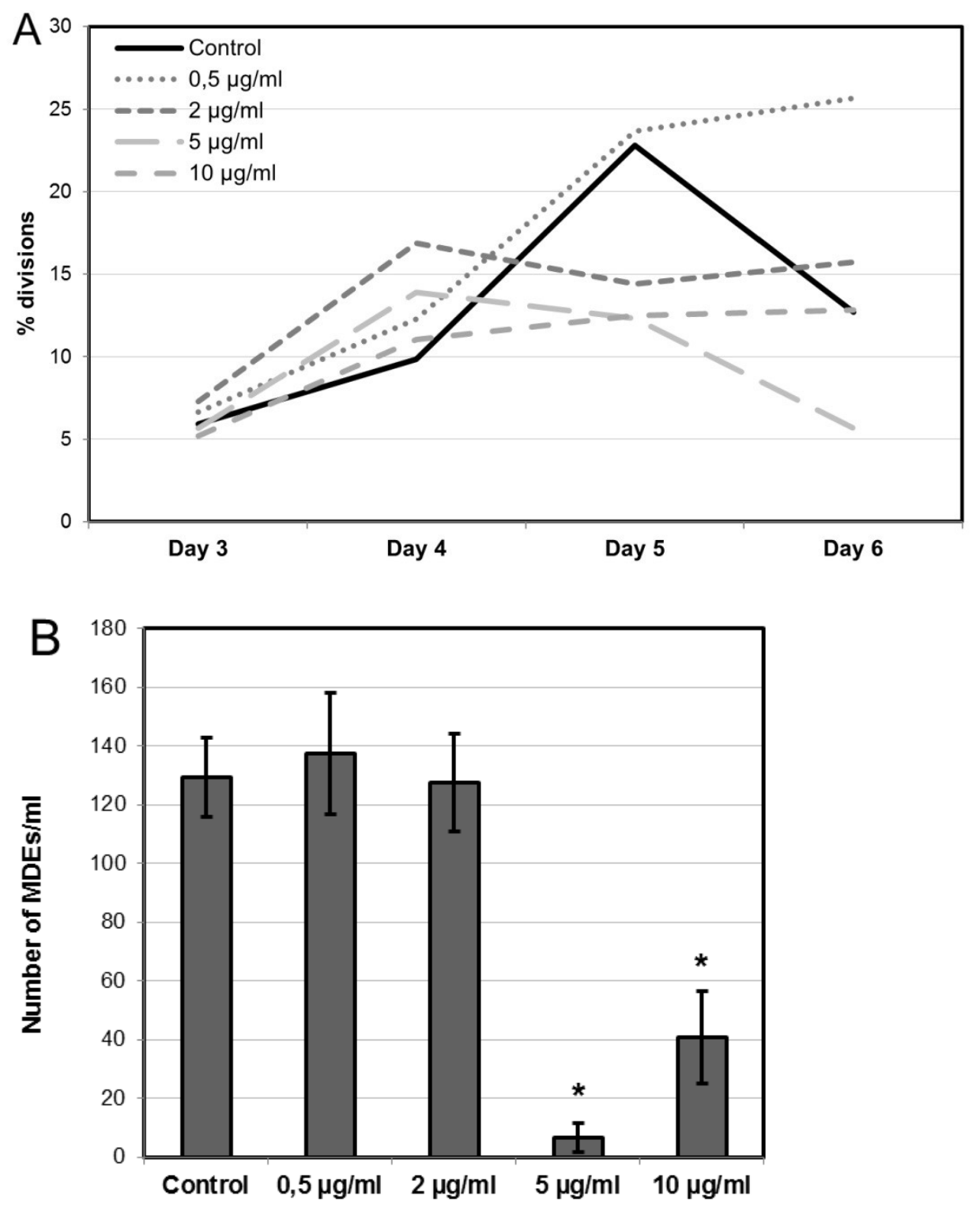

Figure 2: Treatments with tunicamycin. A: Percentage of dividing microspores in cultures with tunicamycin at different days after microspore isolation. B: Embryogenic response of cultures treated with different tunicamycin concentrations. Results are expressed as number of MDEs counted per ml after two weeks of culture. Asterisks represent statistical differences between the treatment and the control according to Dunnett's test. 


\section{Modulation of PCD with obatoclax}

Next, we checked whether modulation of PCD could have an effect in microspore embryogenesis. We used obatoclax to induce PCD in microspore cultures. First, we performed microspore cultures using microspores from young donor plants, as usual, exposed to different obatoclax concentrations (Fig. 3A). Response in number of MDEs obtained per ml of culture was fit in a quadratic model (via ANOVA), showing a significant correlation between the response and the concentration of obatoclax used in the experiment. By that time, we had the opportunity of using an old batch of donor plants (six months after transplanting instead of two), not disposed of when replaced by the new batch we used for the experiments mentioned above. Thus, we decided to perform microspore cultures with these plants, and treat them with obatoclax (Fig. 3B) in the same conditions of the first experiment. As expected for old plants, the response of control cultures was notably lower but, to our surprise, the application of obatoclax increased the embryogenic response even in a higher percentage in comparison with its own control than in young plants, and in a dose-dependent manner. In fact, $500 \mathrm{nM}$ induced the occurrence of five times more MDEs than in controls, whereas in young plants, this difference was less than twice. Response in number of MDEs obtained per ml of culture was fit in a linear model (via ANOVA), showing a significant correlation between the response and the concentration of obatoclax used in the experiment. Both experiments show an increasing trend where a maximum response was not reached yet. Thus, induction of PCD with $500 \mathrm{nM}$ obatoclax promoted a remarkable increase in the number of MDEs from both young and old plants. 

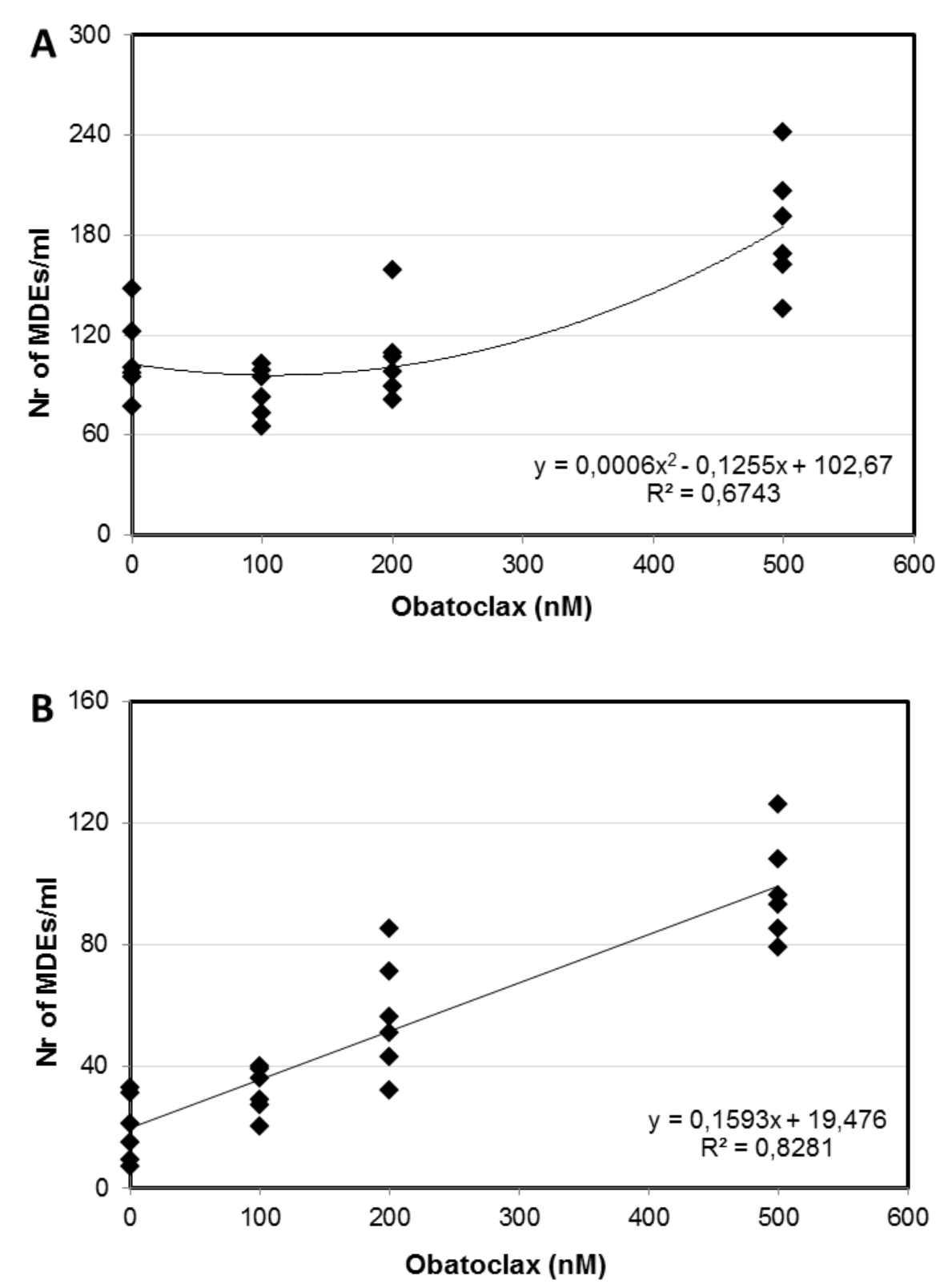

Figure 3: Embryogenic response of cultures treated with different concentrations of Obatoclax using microspores from two month-old (A) and six month-old donor plants (B). Results are expressed as number of MDEs counted per $\mathrm{ml}$ after two weeks of culture. Equation of the fitted model is represented within the graph. 


\section{Analysis of lytic activity by confocal microscopy}

Once we showed that induction of microspore embryogenesis is in general associated to an increase in the autophagy process, and that modulation of ER stress, autophagy and PCD has a reflection in the rate of MDE production, we wanted to check to what extent ER stress, autophagy and PCD occurs in the different microspore-derived structures. First, we analyzed the lytic activity with MDC. In freshly isolated microspores (at day o), no visible lytic activity was observed (Fig. 4A). In five day-old, cultures, pollen-like structures (Fig 4B) and arrested microspores (data not shown) presented in general small spots of MDC signal, suggesting a moderate level of lytic activity. In multinucleated, highly embryogenic structures (Fig. 4C), MDC signal was distributed in small, disperse and very scarce fluorescent foci. At this culture stage, two-to-three-celled, exine-enclosed structures were also occasionally found. They appeared to be developmentally arrested or at least, to develop slower than the former, and presented larger and more abundant foci of MDC staining (Fig 4D), never observed in multinucleated highly embryogenic structures, and indicative of higher levels of autophagy. Barely embryogenic structures, characterized by few but larger cells, extensive vacuolation and one or more exine ruptures, showed a more heterogeneous pattern of MDC staining. Indeed, some of these callus structures showed large and intense foci in some of their cells (Fig 4E), whereas others showed a scarce and faint staining (Fig 4F). In 8 day-old cultures, pollen-like structures (Fig. 4G) and arrested microspores (data not shown) presented a MDC signal dispersed in small foci, similar to that of day 5. In globular MDEs (Fig. 4H), MDC signal was scarce and discrete, in the form of small foci similar to that of day 5. In barely embryogenic structures, MDC signal was heterogeneous as at day 5. In many structures, MDC signal appeared as abundant and very large foci (Fig. 4I). There were, however, individual cells of these structures or even entire structures where MDC staining was much less intense (Fig 4J). Interestingly, these structures have been identified in $B$. napus $\mathrm{DH} 12 \mathrm{O} 75$ as non-responsive to FDA staining, indicating that they might be dying or dead as a result of massive autophagy induction (Corral-Martínez et al. 2020b). To check this possibility out, we performed a live/dead test (Figs. $4 \mathrm{~K}-\mathrm{N}$ ), which confirmed that some of the cells of callus-like structures, and even the entire structures, were dying or dead. 

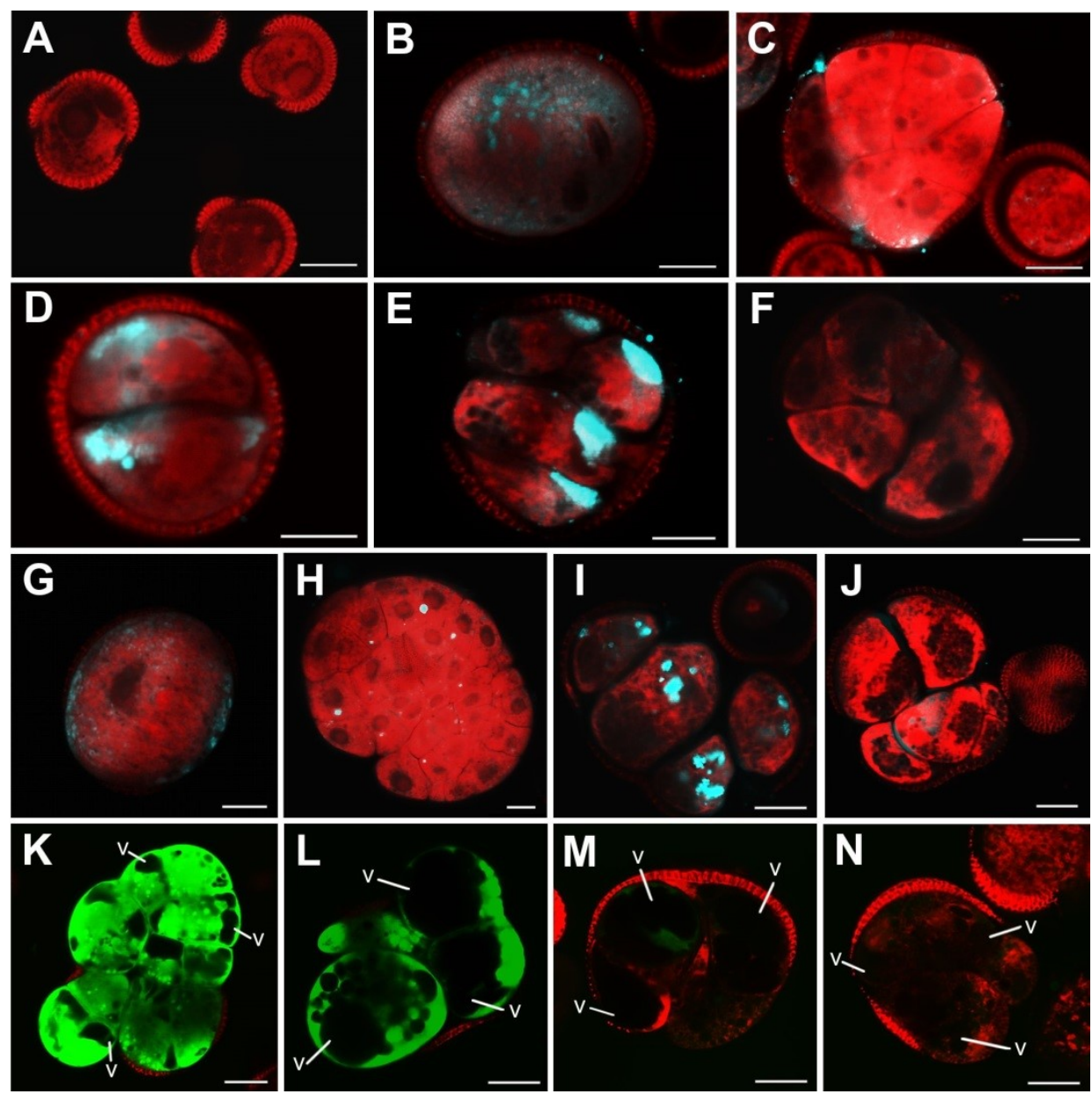

Figure 4: Analysis of lytic activity and cell viability by confocal microscopy in DH4079 microspore-derived structures. A-J: Staining with MDC to detect lytic activity. A: Freshly isolated microspores. B: Pollen-like structure at day 5. C: Highly embryogenic, exine-enclosed structure at day 5. D: Arrested or slowgrowing exine-enclosed structure at day 5. E: Barely embryogenic, callus-like structure at day 5 with high lytic activity. F: Barely embryogenic, callus-like structure at day 5 with low lytic activity. G: Pollen-like structures at day 8. H: Globular MDEs at day 8. I: Barely embryogenic, callus-like structures at day 8 with high lytic activity. J: Barely embryogenic callus-like structure at day 8 with low lytic activity. K-N: Cell viability analysis at day 8 of culture, showing barely embryogenic callus-like structures stained with FDA (for viable cells) and PI (for dead cells). The different levels of FDA staining (highest in $\mathrm{K}$ and absent in $\mathrm{N}$ ) represent different stages during the death of these structures. v: vacuoles. Bars: $10 \mu \mathrm{m}$. 
In the MDC+PI images, and also in the live/dead test images, it was evident that barely embryogenic structures presented more vacuoles, revealed as dark spaces with no stain. Large vacuoles were principally observed in dying and dead cells (Figs. 4L-N). There seemed to be a relationship between lytic activity, cell death and vacuolation. To check this out, we used our light microscope images of pollen-like structures (Fig. 5A), highly embryogenic structures (Fig. 5B) and barely embryogenic structures (Fig. $5 \mathrm{C}$ ) to quantify the percentage of area occupied by vacuoles in the different structures at day 5 of culture, as an indirect but complementary indicator of lytic activity and autophagy. As seen in Fig. 5D, pollen-like structures showed no vacuolation, as expected for cells following a gametophytic-like pathway. Highly embryogenic structures showed a moderate vacuolation, and barely embryogenic structures showed the highest level of vacuolation, consistent with our observations with light and confocal microscopy.

In summary, we found that barely embryogenic callus structures consistently presented larger and more abundant foci of lytic activity, compatible with higher levels of autophagy, which in some cases led to cell death. These foci were also present, but to a much lower extent, in pollen-like structures. Highly embryogenic structures presented the lowest levels of activity. 

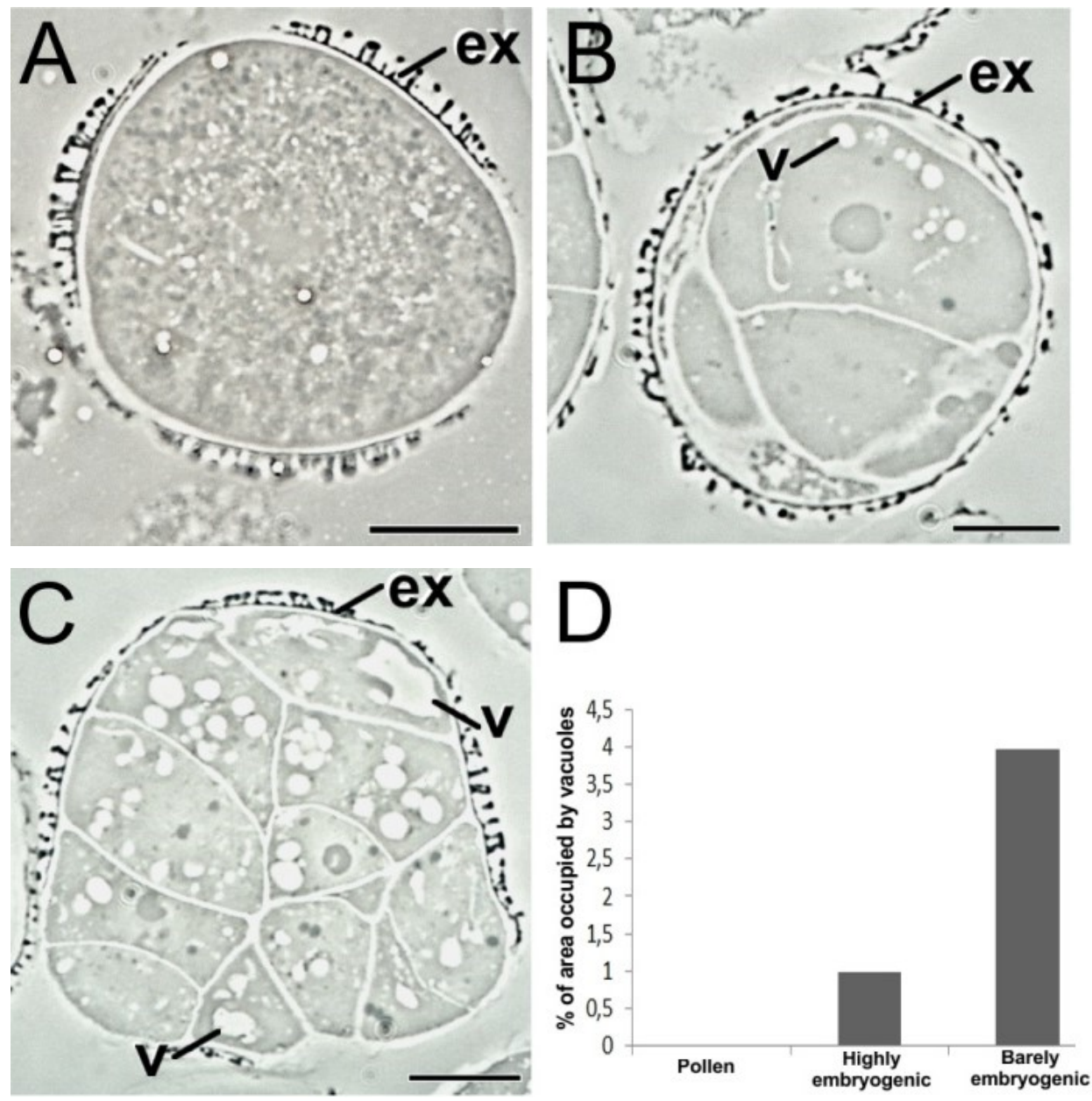

Figure 5: Study of vacuoles in microspore cultures as an indirect measure of macroautophagy processes. A: Pollen-like structure. B: Highly embryogenic structure. C: Barely embryogenic structure. D: Area occupied by vacuoles at day 5 in DH4079 microspore culture. Bars: $10 \mu \mathrm{m}$. 


\section{Analysis of lytic activity by flow cytometry}

To assess the validity of our observations at a wider scale, we used LysoTracker, a fluorescent probe specific for acidic endomembrane compartments, to stain our microspore cultures prior to analysis by flow cytometry. First, we analyzed the signal of the buffer used, PBS, as a negative control. As expected, no signal was obtained (Fig. 6A). Then, we analyzed microspore cultures at day o, just after microspore isolation, without (Fig. 6B) and with Lysotracker (Fig. 6C). Comparing both samples, we confirmed that it was possible to differentiate between the autofluorescence signal emitted by the exine (Fig. 6B) and the basal lytic activity of the microspores during isolation (Fig. 6C), since the means of the observed histogram peaks were remarkably different. Indeed, when the mean Lysotracker signal of cultures at days o and 5 was compared, statistically significant differences were observed (Supplementary figure S2). As opposed to the single population of day o cultures (Fig. 6C), two different populations were observed in 5 day-old cultures (Fig. 6D) emitting at different fluorescence intensities. In addition, the blue area covered by the highest LysoTracker peak (defined by the peak height and spread of the epifluorescence intensity) was notably larger than the corresponding area of day o samples (62.4\% and 39.36\%, respectively; Supplementary Table $\mathrm{S} 1$ ). Thus, we were able to detect by flow cytometry specific differences in the lytic activity of microspore cultures at days 0 and 5. These differences would be compatible with an increase in the number of microspores undergoing lytic activity, and with the division of the homogeneous microspore population of day $o$ in two different populations, formed by different types of structures, with different levels of lytic activity. 

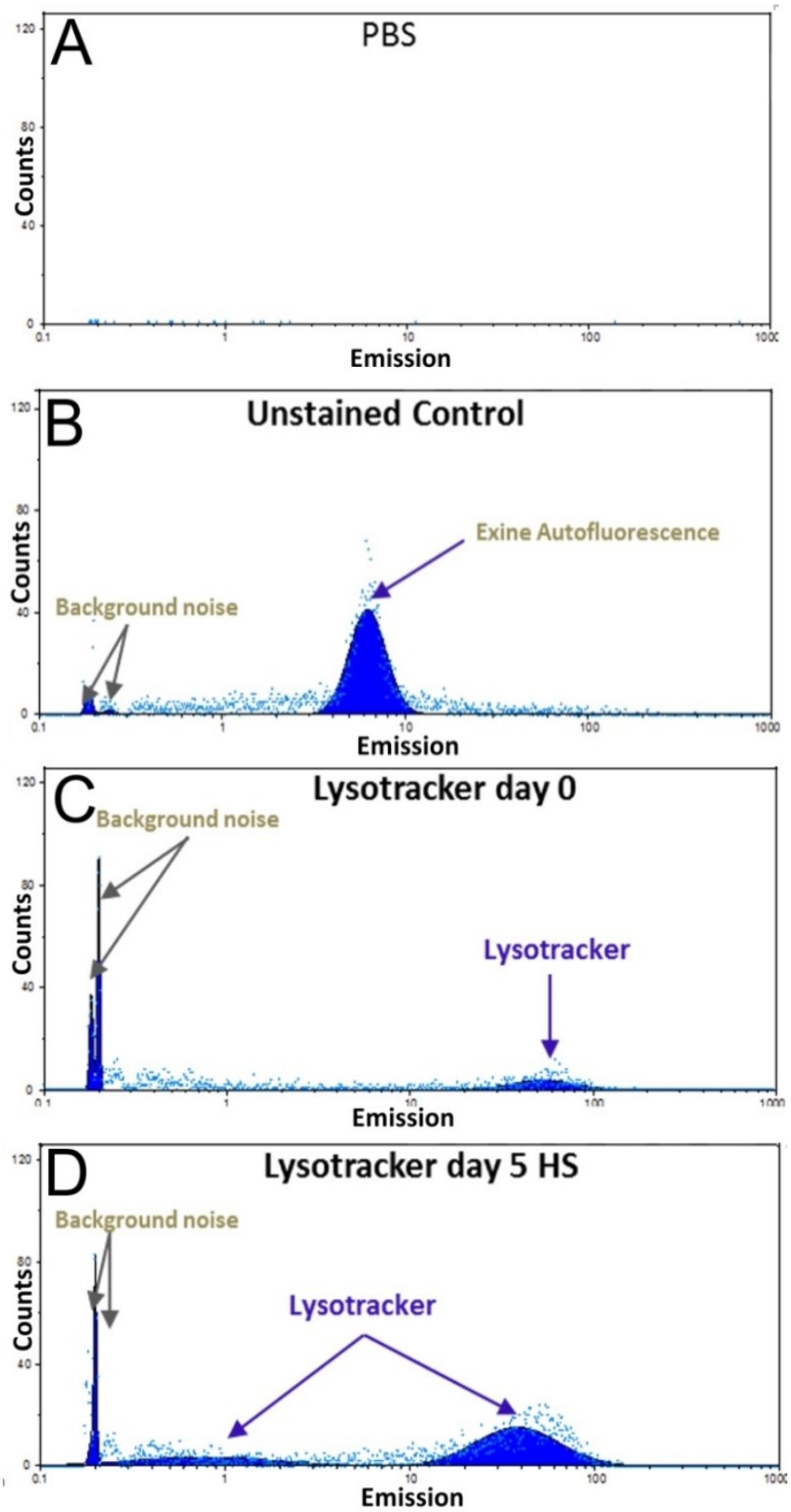

Figure 6: Flow cytometry analysis of Brassica napus microspore cultures. APBS: buffer used to dilute the sample for analysis. B- Unstained sample at day o after isolation to detect endogenous autofluorescence. C- Stained sample with LysoTracker at day o after isolation. D- Stained sample with LysoTracker at day 5 after isolation and heat stress. 
Flow cytometric data come from the total population, with no possible discrimination among the contribution of the different structures coexisting in the cultures. However, our hypothesis was further confirmed by the percentages of viability of our cultures, which progressively dropped down as the culture progressed (Supplementary figure S3A) and by direct observation with the confocal microscope of samples stained with LysoTracker. In general, staining with LysoTracker in the different stages studied evidenced a lower lytic activity in highly embryogenic structures and increased activity in barely embryogenic callus structures (Supplementary figures $\mathrm{S}_{3} \mathrm{~B}, \mathrm{C}$ ), thereby confirms our observations with MDC staining and flow cytometry. In summary, our data indicate that the highest emission peaks found at days $\mathrm{o}$ and 5 would come from a subset of microspores that undergo massive lytic activity and cell death. After the heat shock treatment and five days of in vitro culture, the size of this population, most likely composed at this stage by barely embryogenic structures, was dramatically higher than just after isolation, when there were few dying microspores. On the other hand, the lowest emission peak, negligible at day o, would correspond to a second subset of individuals, composed of pollen-like structures that continue with the gametophytic-like development and are still alive, and the highly embryogenic structures, undergoing lytic activity at different levels (which would explain the extended width of the peak), but being these levels lower and always compatible with life and embryo development. These data confirmed our MDC and LysoTracker observations and extended it to the whole population of cultured cells. Together, all these results indicated that disorganized, barely embryogenic structures experienced a series of changes (increased levels of lytic activity, vacuolation and eventually cell death), which are not undergone, at least to the same extent, by highly embryogenic structures. 


\section{Study of the endomembrane system during microspore embryogenesis}

Next, we wanted to explore whether autophagy and autophagyassociated ER stress could have a reflection in the ER. For this, we stained fixed microspore cultures with $\mathrm{DiOC}_{6}$ and living cultures with ER-Tracker. In freshly isolated microspores, prior to the heat shock treatment (Fig. 7A), we found a faint, almost negligible level of $\mathrm{DiOC}_{6}$ signal, and only in approximately $2 \%$ of the microspores observed. In mid (bicellular, Fig. 7B) and mature (tricellular, Fig. $7 \mathrm{C}$ ) in vivo pollen grains, the signal was similarly faint. However, the scenario changed dramatically after the heat shock. Nearly 30\% of the cells present in cultures (a percentage close to that shown in Supplementary figure S3A for viable microspores after the heat shock) presented a visible $\mathrm{DiOC}_{6}$ signal. Nevertheless, signal intensity was not equivalent in all the structures present in cultures. In 2 day-old cultures, $\mathrm{DiOC}_{6}$ signal was moderate and concentrated in large, discrete foci in pollen-like structures (Fig. 7D). In proliferating structures, however, differences could be observed among highly embryogenic structures, where signal was faint (Fig. $7 \mathrm{E}$ ), and barely embryogenic structures, including compact callus (Fig. $7 \mathrm{~F}$ ) and loose callus (Fig. $7 \mathrm{G}$ ), where signal was more intense, clearly visible, and disperse throughout the cytoplasm. In 5 day-old cultures, DiOC $_{6}$ signal was more intense in general. Pollen-like structures presented a moderate and uniform cytoplasmic signal (Fig. $7 \mathrm{H}$ ). Highly embryogenic structures (Fig. 7I) presented a moderate signal, but always lower than disorganized, barely embryogenic structures (Figs. $7 \mathrm{~J}, \mathrm{~K}$ ). In some cases, the latter presented defined areas of very intense fluorescence, typically at the cell periphery, indicative of regions of high concentration of ER (arrowheads in Figs. $7 \mathrm{~J}, \mathrm{~K}$ ). A similar scenario was found in 8 day-old cultures, with moderate and uniform cytoplasmic $\mathrm{DiOC}_{6}$ signal in pollen-like structures (Fig. 4L), low signal in globular embryos (Fig. $7 \mathrm{M}$ ), and brighter peripheral signals in barely embryogenic structures (Figs. $7 \mathrm{~N}, \mathrm{O}$ ), where signal was more heterogeneous, presenting cells with defined peripheral, very intensely stained regions (arrowheads in Figs. $7 \mathrm{~N}, \mathrm{O}$ ) and cells where signal decreased with respect to that found at day 5 (arrows in Figs. $7 \mathrm{~N}, \mathrm{O}$ ), probably due to cell death. 

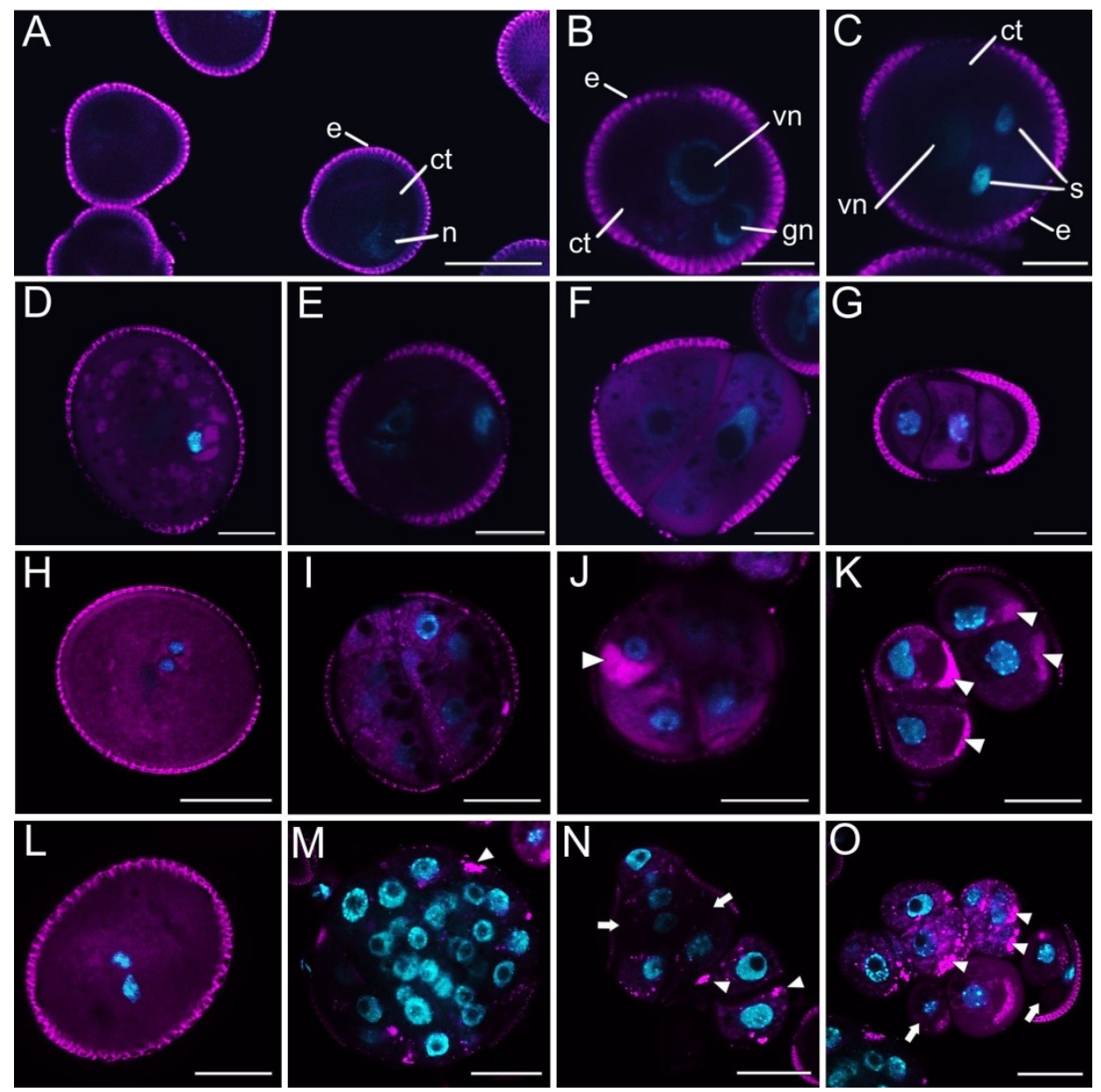

Figure 7: $\mathrm{DiOC}_{6}$ and DAPI staining of DH4O79 microspore cultures. A: Freshly isolated microspores (day o). B, C: In vivo pollen development. D-G: Two dayold cultures. D: In vitro pollen-like structure. E: Highly embryogenic exineenclosed structure. F: Barely embryogenic compact callus structure. G: Barely embryogenic loose callus structure. H-K: Five day-old cultures. H: Pollen-like structure. I: Highly embryogenic exine-enclosed structure. J: Barely embryogenic compact callus structure. K: Barely embryogenic loose callus structure. Arrowheads in J, K point to intensely stained regions, indicative of ER accumulation. L-O: Eight day-old cultures. L: Pollen-like structure. M: Highly embryogenic exine-enclosed structure. N: Barely embryogenic compact callus structure. O: Barely embryogenic loose callus structure. Arrowheads in $\mathrm{N}$ and $\mathrm{O}$ point to intensely stained regions, indicative of ER accumulation; whereas arrows point to cells with faint staining, less than at day 5. Bars: A: $20 \mu \mathrm{m}$; B-G: $10 \mu \mathrm{m}$; H-O: $20 \mu \mathrm{m}$. 
With ER-tracker, the pattern observed at the different days was similar (Supplementary figure S4), confirming that the changes observed with $\mathrm{DiOC}_{6}$ were mostly due to changes in the amount of ER. Finally, we analyzed these structures with transmission electron microscopy and confirmed that the moderate staining observed in pollen-like and highly embryogenic structures correlated with a moderate presence of ER cisternae (Figs. 8A, B, respectively), whereas the intense staining of cell peripheral regions in barely embryogenic structures corresponded to regions of massive accumulation of stacked ER (Fig. 8C). Indeed, a quantification of the presence of subcellular regions with stacked ER revealed that they were present in $\sim 5 \%$ of the pollen-like structures, in $\sim 4 \%$ of the cells of highly embryogenic structures, and in $\sim 25 \%$ of the cells of barely embryogenic structures. In addition, we observed the presence of swollen ER regions, filled with electron dense material, most likely defectively folded proteins. These regions were almost absent in pollen-like structures (Fig. 8A), present in highly embryogenic structures as scarce, small bodies (Fig. 8B), and more abundant and larger in barely embryogenic structures (Fig. 8C). Altogether, these data indicated that upon exposure to the heat shock inductive treatment, the ER of the different structures was affected, showing some of the subcellular features of ER stress. However, the degree of such affection was different, being higher in barely embryogenic structures and lower in highly embryogenic structures. 

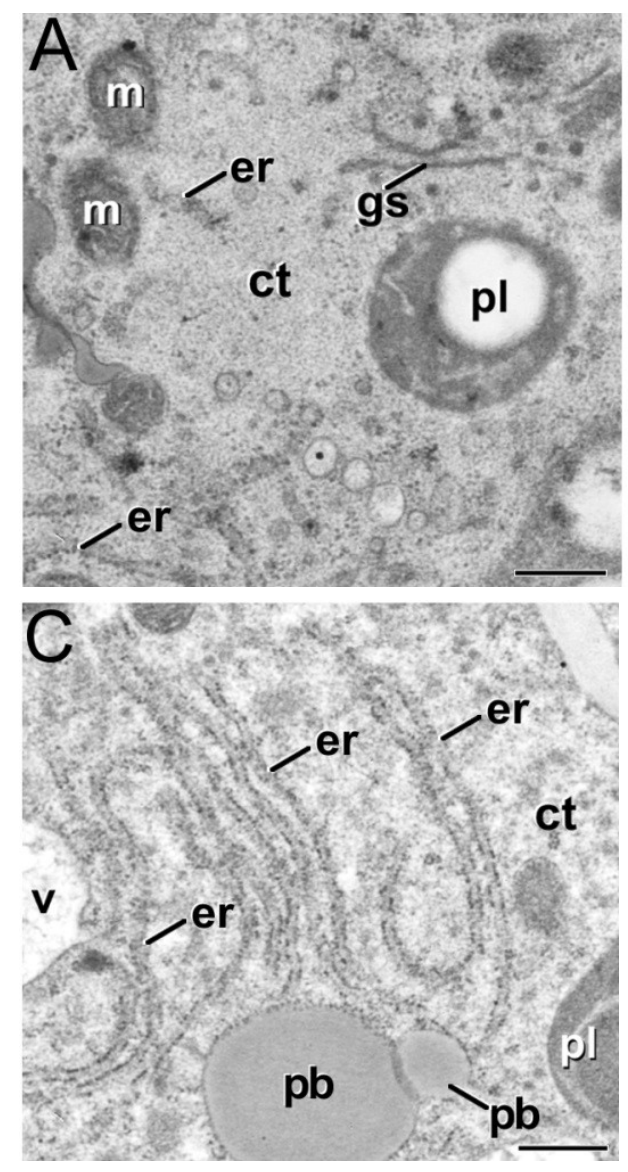

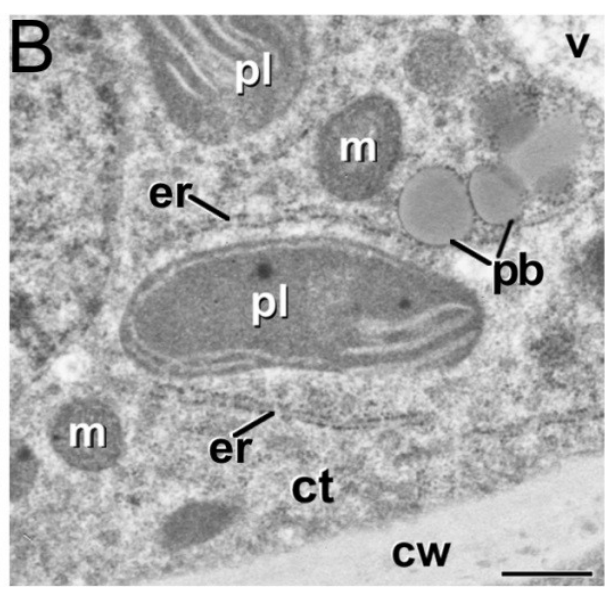

Figure 8: Transmission electron microscopy images of different structures from 5 day-old cultures. Note the different levels of ER (er) and protein body $(\mathrm{pb})$ accumulation from moderate in pollen-like structures (A) and highly embryogenic structures (B) to high in barely embryogenic structures (C). ct: cytoplasm; cw: cell wall; gs: Golgi stack; m:

mitochondrion; pl: plastid; v: vacuole. Bars: $500 \mathrm{~nm}$.

\section{Discussion}

In this work, we showed a tight relationship between induction of microspore embryogenesis and a series of processes that have a profound impact in the final fate of the microspores, namely induction of ER stress, autophagy and PCD. It was previously shown that one of the consequences of microspore embryogenesis was the occurrence of extensive phenomena of autophagy at different levels, both in cytoplasmic regions (Corral-Martínez et al. 2013) and organelles (ParraVega et al. 2015). With the use of different drugs that modulate the occurrence of ER stress, autophagy and PCD, we provided evidences of how these processes influence the final rate of the MDEs produced. We 
showed that a mild inhibition of autophagy with bafilomycin and induction of PCD with obatoclax are beneficial for MDE production, whereas induction of ER stress with tunicamycin seems detrimental. However, our analysis of these processes at the cellular and subcellular levels proved that these processes are not equally undergone by the different microspore-derived structures in culture, thereby conditioning their final fate and therefore the rate of MDE production, as detailed next.

\section{Excessive ER stress promotes the occurrence of barely embryogenic structures}

We showed that one of the consequences of the heat shock treatment was a general increase in the amount and stacking of ER membrane and the presence of swollen ER regions filled with dense, apparently proteinaceous material. Stacks of rough ER sheets are typical of cells actively engaged in protein production, mostly for secretion, but have also been described in non-secretory cells when cultured in vitro (Terasaki et al. 2013), as in our system. In mammal cells, where ER stress has been best studied, it was shown that induction ER stress by depletion of Rab7a, a modulator of ER morphology and homeostasis, produced enlarged sheet-like ER structures that spread towards the cell periphery (Mateus et al. 2018). This is what we observed, principally in cells of barely embryogenic structures. The swollen ER regions of these structures were highly resembling the protein bodies described in other plant systems under natural and experimental processes such as protein accumulation in cereal aleurone and aggregation of recombinant proteins in transgenic plants (Yasuda et al. 2009; Joseph et al. 2012; Holding 2014). It is therefore reasonable to assume that these features are indicative of the occurrence of severe ER stress in barely embryogenic structures. On the contrary, highly embryogenic and pollen-like structures produced relatively lower amounts of additional ER and protein bodies.

Although ER stress can trigger autophagy (Rashid et al. 2015), induction of ER stress with tunicamycin does not seem to be positive for increased MDE yield since the rate of MDE induction at higher 
tunicamycin concentrations was lower than in controls, and at lower tunicamycin concentrations, such rate was not higher than controls. However, it was neither lower. Indeed, all concentrations showed a percentage of divisions (an estimator of the induction rate) higher than controls at day four, and with $0.5 \mu \mathrm{g} / \mathrm{ml}$ tunicamycin, the percentage of divisions was twice than in controls at day 6 . Thus, it seems that a mild induction of ER stress would be positive to increase the number of dividing microspores at the beginning of the culture. It is therefore pertinent to ask why such an increase is not reflected in the final number of MDEs produced. As mentioned above, barely embryogenic structures show in general higher levels of ER alterations, compatible with higher levels of ER stress. According to this, our results would be suggesting that the extra amount of microspores that enter division with $0.5 \mu \mathrm{g} / \mathrm{ml}$ tunicamycin are mostly barely embryogenic structures, where ER accumulates to levels incompatible with embryogenesis, as in compact and loose callus structures. In other words, low tunicamycin concentrations would permit the induction of a similar percentage of highly embryogenic forms, and additionally, would be inducing enrichment in barely embryogenic forms that after some proliferation end up arresting cell development, entering PCD and eventually dying. In turn, severe increases of ER stress with higher tunicamycin concentrations would increase the proportion of barely embryogenic forms with higher levels of ER stress, arresting divisions at even earlier stages and having a direct reflection on MDE production.

All these considered, moderate levels of ER stress may be a direct consequence of the heat shock, common to all the cultured microsporederived structures including highly embryogenic and pollen-like structures. We propose that highly embryogenic structures would be able to deal with ER stress better than barely embryogenic structures. Perhaps by early triggering of UPR, highly embryogenic structures would avoid massive ER accumulation and malfunction, and the massive formation of protein bodies. In turn, defective or insufficient UPR in barely embryogenic structures would lead to excessive ER and protein body accumulation. When microspores undergo excessive levels of ER stress (induced by tunicamycin, for example), they simply cannot manage it and fail to develop as proper MDEs. In any case, the inability to properly manage ER stress has been described to induce autophagy in stressed plant cells (Rashid et al. 2015). This could well be a trigger for 
the massive autophagy we observed in cells of barely embryogenic forms, prior to developmental arrest and death.

\section{Barely embryogenic structures undergo massive autophagy ending up in PCD}

One of the consequences of embryogenesis induction is the occurrence of autophagy. This work is not the first showing evidences of this in the highly responsive $\mathrm{DH}_{4079}$ line of $B$. napus. Other studies have investigated the occurrence of autophagy during microspore embryogenesis (Corral-Martínez et al. 2013; Bárány et al. 2018), considering the population of induced microspores as a homogeneous pool of structures following similar patterns of development. However, recent studies revealed that $B$. napus microspore cultures are far from being homogeneous. In fact, different structures with dramatically different embryogenic potential coexist. Our results on the study of lytic activity, viability, PCD and vacuolation levels revealed that highly embryogenic structures underwent variable but always moderate levels of lytic activity and vacuolation, compatible with further development, whereas barely embryogenic structures presented in general much higher levels of lytic activity and vacuolation, together with selective death of highly vacuolated cells. Interestingly, these are the most abundant among the dividing structures present in cultures (CorralMartínez et al. 2020b). In summary, the combination of our results with previous reports points to barely embryogenic structures as the major contributors to the increase of autophagy and PCD observed in microspore cultures. Since these structures showed also higher levels of ER stress, it is reasonable to relate the three phenomena. The excessive ER stress of barely embryogenic structures would explain their higher levels of autophagy and PCD. 


\section{Moderate autophagy levels favor embryogenesis and allow for the progression of highly embryogenic structures to MDEs}

We showed that a mild inhibition of autophagy by reducing lytic activity with bafilomycin is beneficial for MDE production, whereas severe inhibition of autophagy is not positive and at the highest levels, it is negative. A first conclusion of these results would be that at least a basal threshold of autophagy is needed for a microspore to be induced to embryogenesis. Inhibition of autophagy below this threshold may compromise the embryogenic commitment, since autophagy was previously proposed as a cellular mechanism for cytoplasmic cleaning, needed to recycle all the molecular and cellular machinery of the initial gametophytic program in parallel to the reprogramming towards embryogenesis (Corral-Martínez et al. 2013). A second conclusion would be that above such threshold, increased autophagy does not increase induction. Indeed, with the control levels of autophagy (when no autophagy inhibitors were used), the MDEs produced were less than when autophagy was mildly inhibited. It is known that excessive autophagy leads to cell death (Batoko et al. 2017). Thus, there seems to be a "safe range" of moderate autophagy levels within which microspore cultures can benefit from autophagy to increase the number of induced microspores. Below the lower threshold, autophagy is insufficient for optimal induction. Beyond the upper threshold, cells would die. Since most of the structures undergoing massive autophagy were barely embryogenic, a reduction of their autophagy levels within the "safe range" should mostly benefit them, thereby rescuing some of them to continue differentiation towards MDEs instead of irreversibly surpass the upper threshold, becoming destined to death.

It is also interesting to note that in our initial trial we used, with no positive results (Fig. 2A), the bafilomycin concentrations known to be beneficial for MDE production in the low response DH12O75 line (our unpublished results). Positive results were only obtained at lower concentrations. It thus seems that microspores of the $\mathrm{DH} 4079$ line undergo autophagy at levels lower than the DH12O75 line, which seems to need a more severe inhibition of autophagy to increase the MDE yield. Perhaps, the low response of DH12O75 could be related to such increased autophagy levels. 


\section{Induction of PCD with obatoclax favors the selective elimination of non-embryogenic structures, thereby favoring the development of MDEs}

In animal cells, obatoclax has been used to fight against cancer by selectively inducing cell death in some tumor cells through induction of defective autophagy ( $\mathrm{Yu}$ et al. 2016; Jiménez-Guerrero et al. 2018; Cournoyer et al. 2019). We showed that the use of obatoclax (500 nM) in microspore cultures increased the MDE yield in about 50\% (Fig. 3A). This positive effect suggests that promotion of PCD must not be general, but focused in some cell types, which facilitates the progression of the rest. According to our results with the live/dead test, the structures undergoing selective cell death were compact and loose calli, both barely embryogenic, which showed higher levels of cell damage and autophagy. It is reasonable to deduce that when increased levels of selective PCD are induced with obatoclax, the more stressed and damaged structures would be more affected, thereby increasing their death rate. In other words, increased PCD mediated by obatoclax would preferentially eliminate damaged, barely embryogenic structures, enriching the population in highly embryogenic structures, which would then have more space and resources to grow successfully. Our results on the use of obatoclax with microspores from old plants, known to be less viable and therefore less efficient in terms of MDE yield (compare the control bars of Figs. 3A and B), would be confirming this notion. In these cultures, a larger population of stressed/damaged structures would be selectively eliminated, allowing for the highly embryogenic ones to develop with less interference, thereby reaching levels comparable to those of young plants. 


\section{Conclusions}

In summary, our data demonstrate a clear differentiation between highly embryogenic structures and barely embryogenic structures not only in terms of embryogenic commitment, as already demonstrated (Corral-Martínez et al. 2020b), but also with respect to a series of phenomena related to ER stress, autophagy and PCD that, together, may explain the differences in embryogenic commitment. Autophagy-related processes are necessary for the developmental switch from gametophytic to sporophytic pathway, but the correct regulation of these processes is crucial for the embryogenic success.

\section{Acknowledgements}

Thanks are due to the Electron Microscopy Service of Universitat Politècnica de València, Marisol Gascón (IBMCP Microscopy Service), This work was supported by grants AGL2014-55177-R, AGL2017-88135$\mathrm{R}$ to JMSS from MINECO jointly funded by FEDER and by a Marie Skłodowska-Curie Individual Fellowship (656579) to PC-M.

\section{References}

Bárány I, Berenguer E, Solís M-T, Pérez-Pérez Y, Santamaría ME, Crespo J-L, Risueño MC, Díaz I, Testillano PS (2018) Autophagy is activated and involved in cell death with participation of cathepsins during stressinduced microspore embryogenesis in barley. J Exp Bot:erx455-erx455. doi:10.1093/jxb/erx455 
Batoko H, Dagdas Y, Baluska F, Sirko A (2017) Understanding and exploiting autophagy signaling in plants. Essays Biochem 61 (6):675-685. doi:10.1042/ebc20170034

Corral-Martínez P, Camacho-Fernández C, Seguí-Simarro JM (2020a) Isolated Microspore Culture in Brassica napus. In: Bayer M (ed) Plant Embryogenesis: Methods and Protocols, vol 2122. Methods in Molecular Biology,. Springer US, New York, NY, pp 269-282. doi:10.1007/978-1-0716-0342-0_19

Corral-Martínez P, Parra-Vega V, Seguí-Simarro JM (2013) Novel features of Brassica napus embryogenic microspores revealed by high pressure freezing and freeze substitution: evidence for massive autophagy and excretion-based cytoplasmic cleaning. J Exp Bot 64 (10):3061-3075. doi:10.1093/jxb/ert151

Corral-Martínez P, Siemons C, Horstman A, Angenent GC, de Ruijter N, Boutilier K (2020b) Live Imaging of embryogenic structures in Brassica napus microspore embryo cultures highlights the developmental plasticity of induced totipotent cells. Plant Reprod. doi:10.1007/s00497-020-00391-z

Cournoyer S, Addioui A, Belounis A, Beaunoyer M, Nyalendo C, Le Gall R, Teira P, Haddad E, Vassal G, Sartelet H (2019) GX15-070 (Obatoclax), a Bcl2 family proteins inhibitor engenders apoptosis and pro-survival autophagy and increases Chemosensitivity in neuroblastoma. BMC Cancer 19 (1):1018. doi:10.1186/s12885-019-6195-y

Fanata WID, Lee SY, Lee KO (2013) The unfolded protein response in plants: A fundamental adaptive cellular response to internal and external $\begin{array}{lllll}\text { stresses. Journal of Proteomics } 93 & \text { (0):356-368. }\end{array}$ doi:http://dx.doi.org/10.1016/j.jprot.2013.04.023

Holding DR (2014) Recent advances in the study of prolamin storage protein organization and function. Front Plant Sci 5 (276). doi:10.3389/fpls.2014.00276

Jiménez-Guerrero R, Gasca J, Flores ML, Pérez-Valderrama B, Tejera-Parrado C, Medina R, Tortolero M, Romero F, Japón MA, Sáez C (2018) Obatoclax and paclitaxel synergistically induce apoptosis and overcome paclitaxel resistance in urothelial cancer cells. Cancers 10 (12):490

Joseph M, Ludevid MD, Torrent M, Rofidal V, Tauzin M, Rossignol M, Peltier JB (2012) Proteomic characterisation of endoplasmic reticulum-derived protein bodies in tobacco leaves. BMC Plant Biol 12 (1):36. doi:10.1186/1471-2229-12-36

Karnovsky MJ (1965) A formaldehyde-glutaraldehyde fixative of high osmolality for use in electron microscopy. J Cell Biol 27 (2):137A-138A 
Kay R, Chan A, Daly M, McPherson J (1987) Duplication of CaMV 35S promoter sequences creates a strong enhancer for plant genes. Science 236 (4806):1299-1302

Klionsky DJ et al. (2016) Guidelines for the use and interpretation of assays for monitoring autophagy (3rd edition). Autophagy 12 (1):1-222. doi:10.1080/15548627.2015.1100356

Lichter R (1982) Induction of haploid plants from isolated pollen of Brassica napus. Z Pflanzenphysiol 105 (5):427-434

Liu Y, Bassham DC (2012) Autophagy: Pathways for Self-Eating in Plant Cells. Ann Rev Plant Biol 63 (1):215-237. doi:doi:10.1146/annurev-arplant042811-105441

Liu Y, Burgos JS, Deng Y, Srivastava R, Howell SH, Bassham DC (2012) Degradation of the Endoplasmic Reticulum by Autophagy during Endoplasmic Reticulum Stress in Arabidopsis. Plant Cell 24 (11):46354651. doi:10.1105/tpc.112.101535

Livak KJ, Schmittgen TD (2001) Analysis of Relative Gene Expression Data Using Real-Time Quantitative PCR and the $2^{-\Delta \Delta \mathrm{Ct}}$ Method. Methods 25 (4):402-408. doi:https://doi.org/10.1006/meth.2001.1262

Maraschin SDF, Gaussand G, Pulido A, Olmedilla A, Lamers GEM, Korthout H, Spaink HP, Wang M (2005a) Programmed cell death during the transition from multicellular structures to globular embryos in barley androgenesis. Planta 221 (4):459-470

Maraschin SF, de Priester W, Spaink HP, Wang M (2005b) Androgenic switch: an example of plant embryogenesis from the male gametophyte perspective. J Exp Bot 56 (417):1711-1726

Mateus D, Marini ES, Progida C, Bakke O (2018) Rab7a modulates ER stress and ER morphology. Biochimica et Biophysica Acta (BBA) - Molecular Cell Research $1865 \quad$ (5):781-793. doi:https://doi.org/10.1016/j.bbamcr.2018.02.011

Parra-Vega V, Corral-Martínez P, Rivas-Sendra A, Seguí-Simarro JM (2015) Formation and excretion of autophagic plastids (plastolysomes) in Brassica napus embryogenic microspores. Front Plant Sci 6 (94). doi:doi: 10.3389/fpls.2015.00094

Rashid H-O, Yadav RK, Kim H-R, Chae H-J (2015) ER stress: Autophagy induction, inhibition and selection. Autophagy 11 (11):1956-1977

Ruberti C, Brandizzi F (2014) Conserved and Plant-Unique Strategies for Overcoming Endoplasmic Reticulum Stress. Front Plant Sci 5. doi:10.3389/fpls.2014.00069 
Schindelin J, Arganda-Carreras I, Frise E, Kaynig V, Longair M, Pietzsch T, Preibisch S, Rueden C, Saalfeld S, Schmid B, Tinevez JY, White DJ, Hartenstein V, Eliceiri K, Tomancak P, Cardona A (2012) Fiji: an opensource platform for biological-image analysis. Nature methods 9 (7):676-682. doi:10.1038/nmeth.2019

Seguí-Simarro JM, Nuez F (2008) How microspores transform into haploid embryos: changes associated with embryogenesis induction and microspore-derived embryogenesis. Physiol Plant 134:1-12. doi:10.1111/j.1399-3054.2008.01113.x

Seguí-Simarro JM, Testillano PS, Risueño MC (2003) Hsp7o and Hsp9o change their expression and subcellular localization after microspore embryogenesis induction in Brassica napus L. cv Topas. J Struct Biol $142(3): 379-391$

Shariatpanahi ME, Bal U, Heberle-Bors E, Touraev A (2006) Stresses applied for the re-programming of plant microspores towards in vitro embryogenesis. Physiol Plant 127 (4):519-534

Tan H, Yang X, Zhang F, Zheng X, Qu C, Mu J, Fu F, Li J, Guan R, Zhang H, Wang G, Zuo J (2011) Enhanced Seed Oil Production in Canola by Conditional Expression of Brassica napus LEAFY COTYLEDON1 and LEC1-LIKE in Developing Seeds. Plant Physiol 156 (3):1577-1588. doi:10.1104/pp.111.175000

Terasaki M, Shemesh T, Kasthuri N, Klemm Robin W, Schalek R, Hayworth Kenneth J, Hand Arthur R, Yankova M, Huber G, Lichtman Jeff W, Rapoport Tom A, Kozlov Michael M (2013) Stacked Endoplasmic Reticulum Sheets Are Connected by Helicoidal Membrane Motifs. Cell 154 (2):285-296. doi:10.1016/j.cell.2013.06.031

Yasuda H, Hirose S, Kawakatsu T, Wakasa Y, Takaiwa F (2009) Overexpression of BiP has Inhibitory Effects on the Accumulation of Seed Storage Proteins in Endosperm Cells of Rice. Plant Cell Physiol 50 (8):15321543. doi:10.1093/pcp/pcpo98

Yu L, Wu WK, Gu C, Zhong D, Zhao X, Kong Y, Lin Q, Chan MT, Zhou Z, Liu S (2016) Obatoclax impairs lysosomal function to block autophagy in cisplatin-sensitive and -resistant esophageal cancer cells. Oncotarget 7 (12):14693-14707. doi:10.18632/oncotarget.7492 


\section{Supplementary materials}

Supplementary Table S1: Comparison between peaks of stained samples at different days of culture. Minimum counts of reach measure: 2,500 counts. pvalue $\leq 0.05$. $t$-statistics $>1.645$.

\begin{tabular}{lcccc} 
& Mean & CV & Sx & Chi-Square \\
\hline Autofluorescence & 460.71 & 0.056 & 25.75 & 1.05 \\
Day 0 & 698.34 & 0.065 & 45.67 & 0.63 \\
Day 5 HS & 661.29 & 0.084 & 55.28 & 0.84 \\
\hline
\end{tabular}

\begin{tabular}{lcc} 
& t-statistics & p-value \\
\hline Autofluorescence vs Day o & 226.61 & 0 \\
Autofluorescence vs Day 5 & 164.44 & 0 \\
Day o vs Day 5 HS & 5.17 & $5.8 \times 10^{-7}$ \\
\hline
\end{tabular}

Peak 1

\begin{tabular}{lcccc} 
& Mean & Area \% & Mean & Area \% \\
\hline Day o & o & o & 698.34 & 39.36 \\
Day 5 HS & 225.85 & 25.69 & 661.29 & 62.40 \\
\hline
\end{tabular}




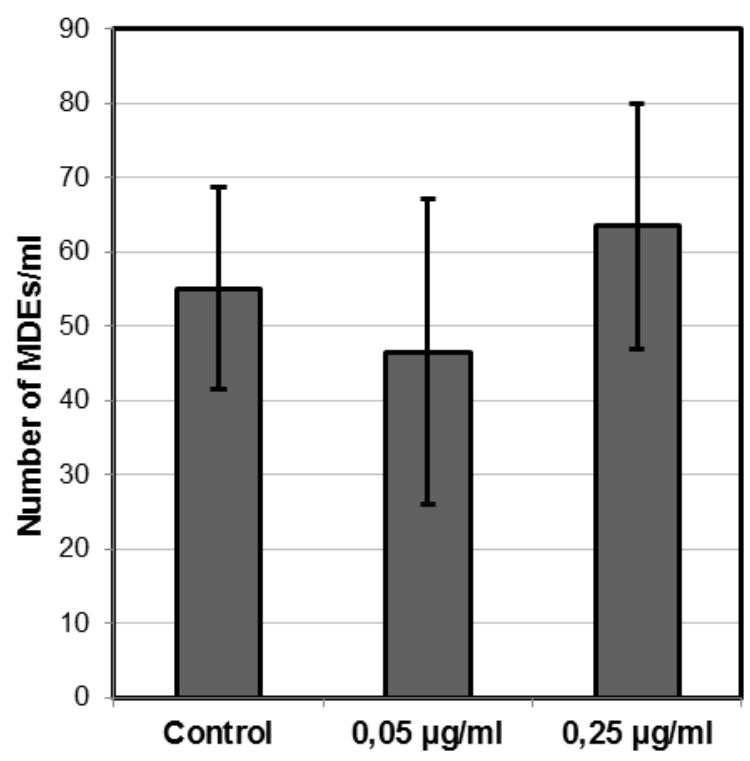

Supplementary figure S1: Embryogenic response of cultures treated with different tunicamycin concentrations. Results are expressed as number of MDEs counted per ml after two weeks of culture. Dunnett's test did not detect significant differences between treatments and control.

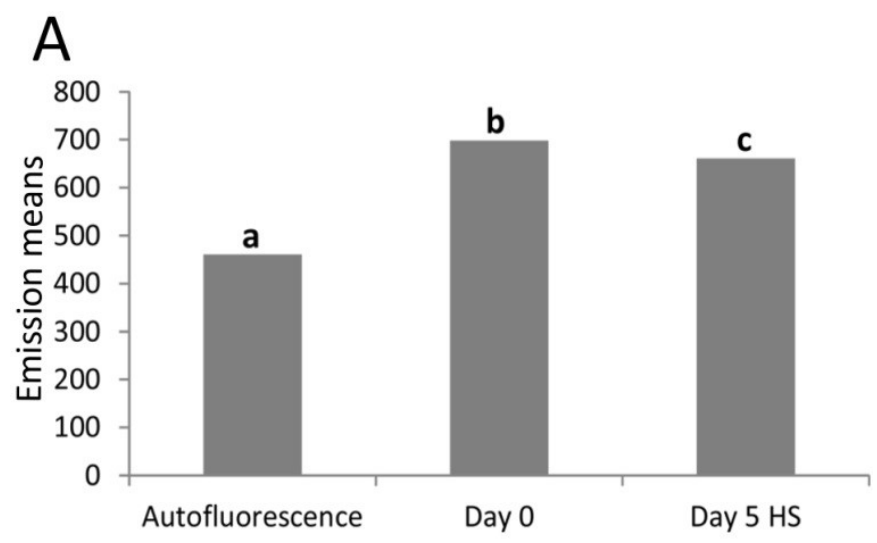

Supplementary figure S2: Statistical analysis of Lysotracker flow cytometry data. Mean comparison of independent samples. 


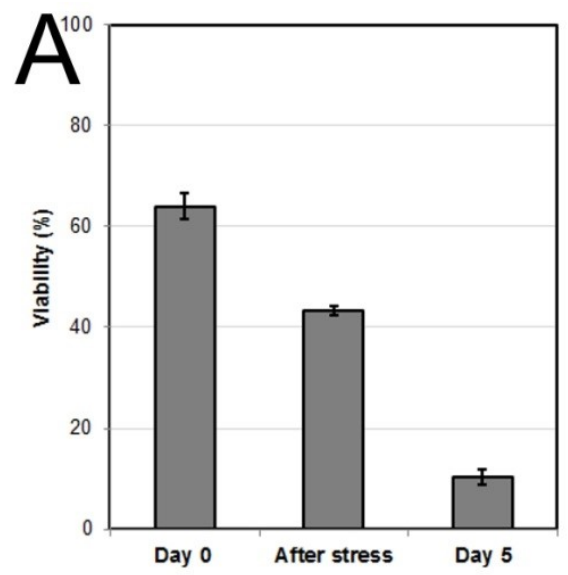

\section{Supplementary figure S3:}

Viability of microspore cultures (A) and Lysotracker staining (B, C). B: Highly embryogenic, exine-enclosed structure. C: Barely embryogenic, compact callus. Arrowheads point to lytic activity detected by staining, cw: cell wall, ex: exine. Bars: $10 \mu \mathrm{m}$.
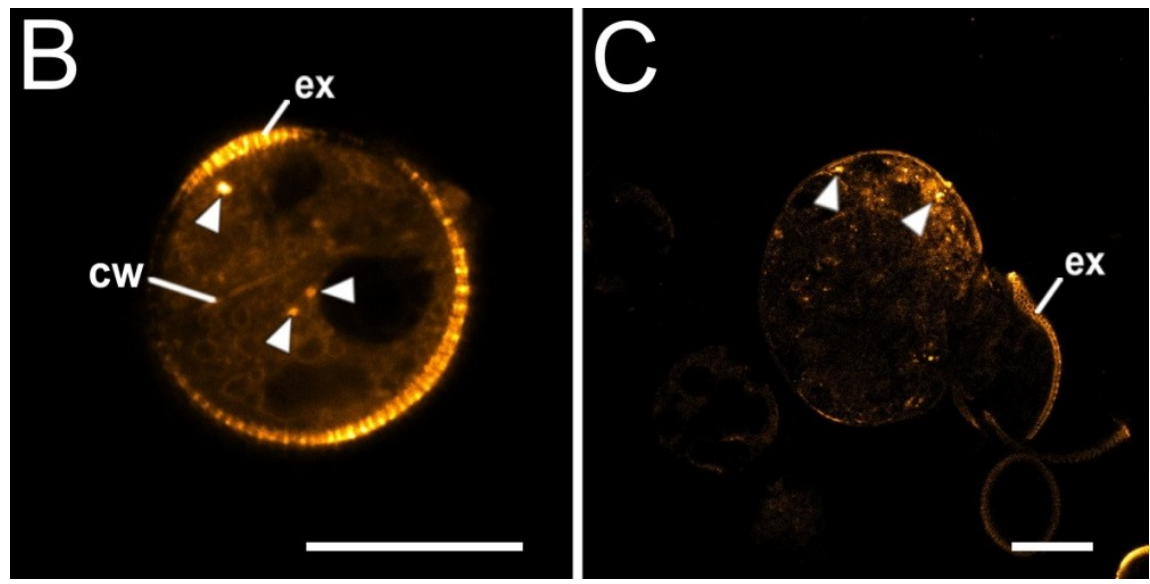

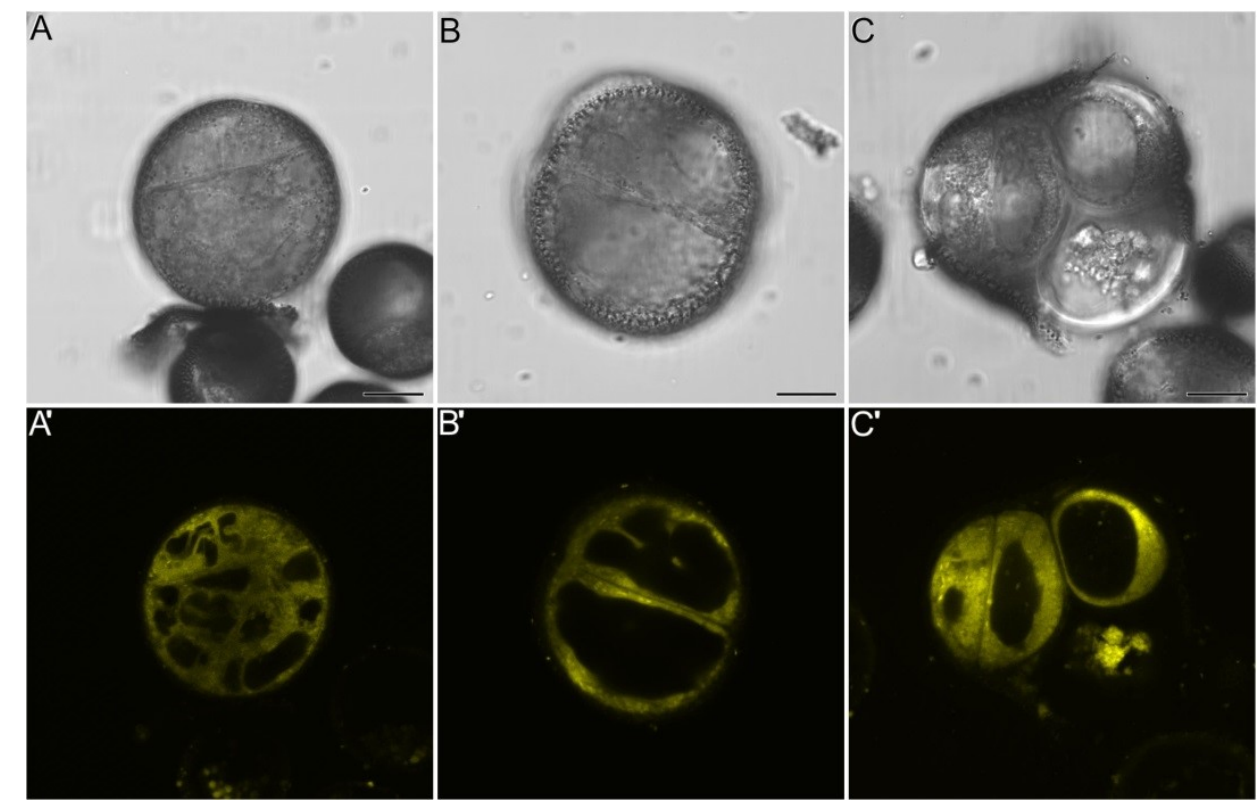

Supplementary figure S4: Microspore-derived structures from 5 day-old microspore cultures stained with ER-tracker and observed under DIC optics (AC) and fluorescence (A'-C'). A, A': Highly embryogenic, exine-enclosed structure. B, B': Highly embryogenic, loose bicelular structure. C, C': Barely embryogenic, loose callus structure. Bars: $10 \mu \mathrm{m}$. 


\section{Chapter 5}

\section{Cell wall composition and structure defines the developmental fate of embryogenic microspores in Brassica napus}

Carolina Camacho-Fernández¹, Kim Boutilier², Jose M. Seguí-Simarro ${ }^{1, *}$, and Patricia Corral-Martínez ${ }^{1}$

${ }^{1}$ COMAV - Universitat Politècnica de València, Spain

2 Plant Development Systems, Wageningen University and Research, The Netherlands.

Keywords: androgenesis, arabinogalactan proteins, callose, cell wall, cellulose, microspore embryogenesis, pectin, subintinal layer. 


\section{Abstract}

Microspore cultures generate a heterogeneous population of dividing structures which can be classified according to their embryogenic potential in highly embryogenic structures, including exine-enclosed (EE) and loose bicellular structures (LBS), and barely embryogenic structures, including compact (CC) and loose callus structures (LC). Apart from their different embryogenic response, very little is known about the factors behind such different responses. In this study we performed a comparative analysis of the composition and architecture of the cell walls of each structure by confocal and quantitative electron microscopy. Each structure presented specific cell wall characteristics that defined their developmental fate. In particular, EE structures, responsible for most of the embryos produced, showed a specific profile with thin walls rich in arabinogalactan proteins (AGPs), highly and low methyl-esterified pectin and callose, and a subintinal layer not necessarily thick, but with a remarkably high callose concentration. The different cell wall profiles of EE and LBS structures would determine their developmental fate as suspensorless and suspensor-bearing embryos, respectively. In contrast, the less viable forms (LC structures) presented the widest cell walls and the lowest values for almost all the studied cell wall components. These cell wall properties would be the less favorable for cell proliferation and embryo progression. High levels of highly methyl-esterified pectin are necessary for cell wall flexibility and growth of highly embryogenic structures. AGPs seem to play a role in cell wall stiffness due to their putative role as calcium capacitors, which would explain the relationship between embryogenic potential and calcium levels. 


\section{Introduction}

During the development of the male gametophyte (microsporogenesis and microgametogenesis), cells go through several stages before becoming mature, functional pollen grains. After meiosis, four young microspores are released from the tetrad. Microspores grow and mature and eventually divide asymmetrically to give rise to pollen grains, within which the male gametes will be produced. This natural pathway can be altered when microspores/pollen are cultured in vitro. Microspore embryogenesis is a process whereby, under specific in vitro conditions, microspores are induced to become microspore-derived embryos (MDEs). This amazing ability of plant cells allows them to regenerate new structures or even an entire organism. There are several ways to induce microspore embryogenesis, but all of them rely on a stress treatment to induce the developmental switch from microgametogenesis to embryogenesis (Seguí-Simarro and Nuez 2008). Brassica napus is considered a model species to study this process, since most of the knowledge gained in the last decades comes from the use of this species to investigate molecular, cellular, physiological and developmental aspects of microspore embryogenesis (Corral-Martínez et al. 2013; Soriano et al. 2013; Rivas-Sendra et al. 2017; Rivas-Sendra et al. 2019; Corral-Martínez et al. 2020b). In this species, as in many others, microspore embryogenesis is triggered by the in vitro application of an inductive heat stress treatment prior to isolated microspore culture (Telmer et al. 1995; Corral-Martínez et al. 2020a). This is associated to a series of cellular changes and rearrangements at different levels, involving the cytoskeleton, nucleus, cytoplasm and cell wall (Simmonds and Keller 1999; Seguí-Simarro and Nuez 2008; Corral-Martínez et al. 2013; Rivas-Sendra et al. 2019).

The cell wall is not only the protective layer of a plant cell, but also its connection with the environment and neighboring cells, and the mechanical force that compensates cell turgor and keeps cells firmly attached. Plant cell walls are formed by different polysaccharides, including pectin, hemicellulose and cellulose. Cell walls may have different proportions of these polysaccharides, in different cell types, which relates to their specific roles. In fact, the specific polysaccharide 
composition of a cell wall defines its properties. Different polysaccharides may establish different physical and chemical interactions among them, thereby conferring different properties to the wall. Thus, a combined analysis of the different cell wall components is needed to obtain a good overview of the types and functions of the different cell walls.

Pectin is a polymer of galacturonic acid, represented by three major types: homogalacturan (HG), rhamnogalacturonan-I (RH-I) and -II (RH-II). They are synthesized in the Golgi system and then packed into vesicles and transported along the actin cytoskeleton to the cell wall, where they form the middle lamella separating adjacent cell walls. Pectin levels and modifications in the middle lamella are crucial to regulate cellular adhesion (Bou Daher and Braybrook 2015). The stiffness of cell walls is also regulated by pectin composition, as well as by other factors including the presence of calcium, the level of pectin esterification and the presence of cell wall-remodelling enzymes such as pectin methylesterases (PMEs) or polygalacturonases (PGs) (Palin and Geitmann 2012; Bou Daher and Braybrook 2015). Cellulose (1,4-glucan) is a linear polymer essential first for cell plate stabilization, and then for maintaining cell wall shape and rigidity (Chen et al. 2018). Arabinogalactan proteins (AGPs) are a large family of heavily glycosylated hydroxyproline-rich proteins, present in all higher plants (Gaspar et al. 2001; Pereira et al. 2015). These cell surface glycoproteins are involved in many different aspects of plant growth and development such as differentiation, cell division, cell-cell recognition, plant-microbe interaction, programmed cell death and, specifically during embryogenesis, in cell survival and embryo patterning (Gaspar et al. 2001; Seifert and Roberts 2007). Several studies have remarked their role in plant reproduction (Cheung and Wu 1999; Pereira et al. 2014), but their precise role is still unknown. In 2013, a new model about the role of periplasmic AGPs (Lamport and Varnai 2013) proposed AGPs as calcium capacitors, thereby releasing calcium to the cytoplasm for cell signaling. Callose is a $\beta-1,3$-glucan polymer involved in different plant processes, including plant pathogen response and sexual reproduction, where it is present at different stages. During microsporogenesis, callose is first present in the tetrad cell walls. After microspore release, a thin callose layer was shown to have a role in exine patterning (Dong et al. 2005). In pollen grains, the generative cell is transiently surrounded by a 
callose-rich wall (Gorska-Brylass 1967). Finally, callose is also present beneath the intine at the aperture regions of mature pollen grains, at the pollen tube tip, and in the plugs formed during pollen tube growth (Ferguson et al. 1998; Chebli et al. 2012). However, the most general role of callose relates to cell wall formation, since it is essential for cell plate establishment (Seguí-Simarro et al. 2008).

All these cell wall components are sequentially added during cell wall biogenesis. The first component transported to the nascent cell plate is HG-pectin. Next, callose is locally synthesized for cell plate expansion. Then, it is removed in parallel to the onset of cellulose biosynthesis (Brown and Lemmon 2009) and transport of hemicellulose. Cellulose combines with hemicellulose to create a cellulose-hemicellulose network, while pectin reorganizes into the middle lamella (Albersheim et al. 2011). During microspore embryogenesis, the cell wall must adapt from covering a single cell, the microspore, to cover a larger, multicellular structure. It seems reasonable to predict that such adaptation must imply profound changes in cell wall structure and composition. In fact, during the earliest stages of microspore embryogenesis, the sequence of steps described above and the mechanisms of synthesis and/or deposition of cell wall components are altered, originating the transient formation of abnormal, irregular and fragmented cell walls separating the first divided cells, which have profound consequences in further embryo development (Parra-Vega et al. 2015). These changes are paralleled by the presence of altered levels of xyloglucans, pectin and arabinogalactan proteins (Corral-Martínez et al. 2019), and the formation of a unique, callose-rich cell wall beneath the intine of the microspore, the subintinal layer (Parra-Vega et al. 2015). This layer was proposed to act as a transient physical barrier that protects induced microspores from osmotic changes in the surrounding in vitro environment (Rivas-Sendra et al. 2019). Although its role in microspore embryogenesis remains still obscure, AGPs seem also important for embryo viability and development (Borderies et al. 2004; Seguí-Simarro and Nuez 2008; Corral-Martínez and Seguí-Simarro 2014). In fact, they were found to differentially accumulate in the newly formed cell walls (inner walls and subintinal layer) of induced microspores (CorralMartínez et al. 2019). 
It is widely accepted that microspore cultures are heterogeneous systems where different populations coexist (Seguí-Simarro and Nuez 2008). Some microspores are not induced and stay developmentally arrested or die. Others follow a gametophytic-like development, becoming pollen-like structures that express some of the features of mature pollen grains. A third group of the microspore population enters cell division and start proliferation. However, not all the proliferating structures are similar. Previous studies in B. napus showed the presence of exine-enclosed, suspensorless structures and suspensor-bearing structures, described as embryogenic based on the expression of embryo-reporter genes (Soriano et al. 2013; Soriano et al. 2014); and of callus-like structures, initially described as non-embryogenic but expressing embryo reporter genes too (Li et al. 2014). Recently, a timelapse imaging study shed light on this aspect defining the presence of four different types of embryogenic (expressing embryo-reporter genes) structures, each of them with a different developmental fate (CorralMartínez et al. 2020b): (1) exine-enclosed (EE) structures, (2) suspensor-bearing embryos (SUS), (3), compact callus (CC) structures, and (4) loose callus (LC) structures. This study revealed that the population of induced microspores is more complex than previously thought and, most importantly, proved that there are two main groups of induced microspore-derived structures accoding to their ability to eventually become embryos. On the one hand, EE and SUS were considered as highly embryogenic structures because they mostly develop as differentiated embryos, although they may also give rise to callus-type structures at a much lower percentage. On the other hand, CC and LC were considered as barely embryogenic structures because they present a very low rate of conversion into embryos. Due to this remarkable heterogeneity in microspore in vitro development, which has a dramatic impact in the final MDE yield, and the well known role of cell wall in shaping in vitro morphogenesis, a new approach for understanding cell wall dynamics in each particular microspore-derived structure is required to determine the relationship between the cell wall characteristics of each structure and their competence for successful completion of embryo development.

In this work, we performed a detailed study of the cell wall structure and composition focusing on pectin (both highly and low methylesterified), callose and AGPs in the different structures found in $B$. 
napus microspore cultures using confocal and transmission electron microscopy (TEM), and immunogold labeling. Our results relate cell wall composition and structure with the developmental fate of each type of microspore-derived structure, providing interesting insights on the role of callose, AGPs and pectin with different levels of esterification during microspore embryogenesis and, in general, in morphogenic processes such as in vitro embryogenesis.

\section{Materials and methods}

\section{Plant material}

DH4079 (a DH line derived from Brassica napus L. cv. Topas highly responsive to induction of microspore embryogenesis) plants were used as donor plants for microspore culture. Plants were grown at $20^{\circ} \mathrm{C}$ in growth chambers in $20 \mathrm{~cm}$ pots at $60 \%$ relative humidity and $16 / 8$ photoperiod, until flowering and then transferred to $15^{\circ} \mathrm{C}$.

\section{Microspore culture}

Flower buds containing a majority of vacuolated microspores and young pollen grains were collected from donor plants. The isolation and induction treatments were performed according to Corral-Martínez et al. 2020a. Flower buds were surface sterilized with $4 \mathrm{~g} / \mathrm{l}$ sodium hypochlorite and then washed three times with sterile water. Microspores were isolated from anthers by crushing buds with a sterile syringe piston in induction medium and filtering the suspension through a $30 \mu \mathrm{m}$ nylon mesh (Millipore). This was followed by three rounds of centrifugation at $100 \mathrm{~g}$ for $4 \mathrm{~min}$ each. Microspore density was adjusted with a hemocytometer (Camacho-Fernández et al. 2018) and adjusted to 40,000 microspores/ml. Microspores were induced by incubating culture plates in darkness for 1 day at $32^{\circ} \mathrm{C}$. Afterwards, plates were kept at $25^{\circ} \mathrm{C}$ in darkness for progression of embryogenesis. 


\section{Staining and observation by confocal laser scanning microscopy}

B. napus microspore cultures were collected at several time-points and fixed overnight at $4^{\circ} \mathrm{C}$ with $4 \%$ paraformaldehyde in PBS (pH 7.4). Afterwards, samples were washed three times with PBS and then stored at $4{ }^{\circ} \mathrm{C}$ in $0.1 \%$ paraformaldehyde in PBS until use. Staining of callose and cellulose in microspores was performed according to Parra-Vega et al. 2015, Rivas-Sendra et al. 2019. For callose detection, samples were double stained incubating first with $10 \mu \mathrm{g} / \mathrm{ml}$ propidium iodide (PI; Fluka) for $10 \mathrm{~min}$, and then with $0.1 \%$ anilin blue (AB; Fluka) for $20 \mathrm{~min}$. PBS was used for preparation of all staining solutions and for the three washes after each staining. Samples were mounted in 17\% Mowiol 4-88 (Sigma-Aldrich) and 33\% glycerol (v/v) in PBS. For cellulose detection, samples were stained with 0.01\% Direct Red (Sigma) in 0.1 M PBS for 30 min, washed thrice with PBS, mounted in a 1:1 mix of Mowiol and 2.5 $\mu \mathrm{g} / \mathrm{ml} \mathrm{4}$, 6 -diamidine-2'-phenylindole dihydrochloride (DAPI; SigmaAldrich) prepared as described in Custers 2003, and incubated for at least $15 \mathrm{~min}$. Fluorochromes were excited with 405-nm (for DAPI and aniline blue) and 561-nm (for PI and Direct Red) laser lines, and emission was recorded between 450-490nm and 580-650nm, respectively. All the samples were incubated in darkness and observed with a ZEISS 780 Axio Observer confocal laser scanning microscope. Images were processed with ZEN and FIJI software (Schindelin et al. 2012).

To observe the thickness of the cell walls, the fixed samples were stained with Direct red as described above and with SCRI Renaissance Cell 2200 (SR2200). Staining of SCRI Renaissance 2200 was performed according to Musielak et al. 2015, incubating samples $30 \mathrm{~min}$ before observation. SR2200 was excited with a 405-nm laser line and emission was recorded between 415 and $476 \mathrm{~nm}$. At least 100 embryogenic structures were examined with a Leica $\mathrm{SP}_{5}$ confocal laser scanning microscope. Images were processed with Leica Application Suite Advanced Fluorescence (LAS AF) and FIJI software (Schindelin et al. 2012). 


\section{Processing of samples for transmission electron microscopy}

Five-day-old cultured microspores were collected for transmission electron microscopy (TEM). Processing was performed as described in Seguí-Simarro and Nuez 2007 with some modifications. Samples were fixed in Karnovsky fixative (Karnovsky 1965), post-fixed with $2 \%$ OsO4 in $0.05 \mathrm{M}$ cacodylate buffer and washed thrice with $0.025 \mathrm{M}$ cacodylate. Microspores were immobilized and concentrated as follows: cacodylate buffer was removed and 1-2 drops of warm (liquid) $15 \%$ gelatin in cacodylate buffer were added. Microspores were then resuspended in the liquid gelatin, centrifuged ( $1 \mathrm{~min}$ at $125 \mathrm{~g}$ ) and allowed to cool on ice for gelatin solidification. Once solid, $20 \mu \mathrm{l}$ of $1 \%$ paraformaldehyde in cacodylate buffer was added, keeping the samples overnight at $4^{\circ} \mathrm{C}$. Finally, gelatin-embedded samples were cut in small pieces and kept in cacodylate buffer until use. Samples were dehydrated in a progressive methanol series and embedded and polymerized in Embed 812 resin (Electron Microscopy Sciences). Ultrathin (80 $\mathrm{nm}$ ) sections were obtained from at least three different blocks of each sample with a Leica UC6 ultramicrotome for TEM observation. Sections were mounted on carbon and formvar-coated, 200-mesh nickel grids (Electron Microscopy Sciences), stained with uranyl acetate in 70\% methanol (6 min) and lead citrate (30 s). Images were taken with a Jeol JEM 1010 TEM. For morphometric studies of the cell wall, the minimum number of images required was determined using the progressive mean test (Williams 1977) according to Corral-Martínez et al. 2019. For each type of structure, the width of the intine and subintinal layer of the cell walls was measured using FIJI software (Schindelin et al. 2012). Significant statistical differences between samples, regarding measurements of cell wall and subintinal layer width, were determined using a least significant difference (LSD) test with $\mathrm{p} \leq 0.05$.

\section{Immunogold labelling}

For callose detection, an anti-callose monoclonal antibody (mAb) specifically recognizing linear $(1 \rightarrow 3)-\beta$-oligosaccharide segments in $(1 \rightarrow 3)$ - $\beta$-glucans was used. For AGP detection, the following antibodies were used: JIM13, a rat IgM mAb recognizing the AGP2 epitope present 156 
in different plant exudates such as gum arabic and gum ghatti (Knox et al. 1991). For pectin detection, the following antibodies were used: JIM7, a rat IgA mAb cross-reacting with highly methyl-esterified epitopes of the homogalacturonan domain of pectic polysaccharides (Knox et al. 1990; Willats et al. 2000) and JIM5, a rat IgG mAb cross-reacting with low methyl-esterified epitopes of homogalacturonan (Knox et al. 1990; Willats et al. 2000).

For immunolocalization of cell wall components, sections were hydrated with PBS for $1 \mathrm{~min}$. Non-specific binding was prevented by incubation with $0.2 \%$ BSA and $3 \%$ skimmed milk in PBS for 30 min. For the anti-callose antibody (Biosupplies Australia), sections were incubated with the primary antibody diluted 1:5000 in 1\% BSA in PBS for $1 \mathrm{~h}$ at $25^{\circ} \mathrm{C}$. For the rest of antibodies, sections were incubated with the primary antibody diluted 1:5 (JIM13, PlantProbes, Leeds, UK) or 1:2 (JIM7 and JIM5, PlantProbes, Leeds, UK) in $0.2 \%$ BSA in PBS for $1 \mathrm{~h}$ at $25^{\circ} \mathrm{C}$. For all antibodies, sections were then washed six times during 5 min with $0.2 \%$ BSA in PBS. Secondary antibodies (goat anti-mouse for anti-callose antibody and goat anti-rat for the rest) conjugated with 10 nm gold particles (BBI solutions, UK) were diluted 1:25 with $0.2 \%$ BSA in PBS (1\% BSA for the anti-callose antibody) and incubated with the sections for $45 \mathrm{~min}$ at $25^{\circ} \mathrm{C}$. Finally, sections were washed five times with PBS, 5 min each, post-fixed with $2 \%$ glutaraldehyde in PBS for $10 \mathrm{~min}$ and washed again with PBS and distilled water as the last step. Samples were then counterstained with uranyl acetate in $70 \%$ methanol (6 min) and lead citrate (30 s). Controls excluding primary antibodies were performed to check for non-specific binding of the secondary antibody.

\section{Quantification of immunogold labeling}

Three different blocks were randomly selected and micrographs were taken systematically always at the same magnification. Several micrographs were taken randomly from all the structures of interest on each grid. The minimum number of micrographs was determined using the progressive mean test (Williams 1977), with a minimum confidence limit of $\alpha=0.05$. In general, around 15-20 micrographs per antibody and type of structure were studied. Labeling density of each compartment under study was manually calculated by counting the number of 
particles and dividing this by the area where they were counted, being expressed as particles $/ \mu \mathrm{m}^{2}$. For all the structures studied in this work, the analyzed compartments were (1) Golgi stacks and cytoplasmic vesicles, (2) inner cell walls and (3) outer cell walls (the intine and the subintinal layer formed in microspore-derived structures) but excluding the outermost exine layer. Particles over regions where the presence of the studied epitopes is not expected (the cytoplasm excluding Golgi stacks and vesicles, cytoplasmic organelles and nucleus), were considered as background noise, and was estimated as the particle density of these regions. The area in $\mu^{2}{ }^{2}$ was measured using a square lattice composed of $11 \times 16$ squares of $15 \times 15 \mathrm{~mm}$ each.

Four different types of embryogenic structures with different cell fate were considered, according to Corral-Martínez et al. 2020b. Labeling density was expressed as the average labeling density of all micrographs \pm standard error. Comparisons of mean labeling densities were performed by one-way ANOVA tests using StatGraphics software. In cases were data were not homoscedastic, Mood's median test was used. Means were separated using a least significant different (LSD) test with $\mathrm{p} \leq 0.05$. Histograms of the same antibody in different subcellular compartments were built using the same $\mathrm{Y}$-axis scale in order to facilitate comparisons.

\section{Results}

DH4O79 microspore cultures comprise a heterogeneous population of structures that respond differently to the treatments for embryogenesis induction

During B. napus microspore culture, not all microspores are equally sensitive to the heat stress treatment and therefore follow different pathways. The majority of microspores either followed a gametophyticlike pathway and became pollen-like structures or arrested in development and eventually died. Depending on the genotype and 
culture conditions, microspore embryogenesis may occur in a variable percentage of microspores. Our study focused on the highly responsive DH4079 line. Previously, the only embryogenic structures described in this system were exine-enclosed embryos (Soriano et al. 2014). However, we observed more types of structures (Fig. 1). The starting point of this process, before induction, was a population comprising mostly vacuolated microspores (Fig. 1A), but also some young pollen grains, freshly isolated from the anthers. After the heat stress treatment, a subset of the initial microspores and pollen grains became dead or arrested, and another subset entered a pollen-like development, as widely described for microspore cultures (Satpute et al. 2005). A third subset of microspores entered cell division, becoming multicellular, proliferating structures. Among them, four different types were found, which varied in their size, level of cellular organization and adhesion, and degree of exine coverage. First, we observed exine-enclosed structures (EE, Fig. 1B left), which accounted for $1.61 \%$ of the total population. They were highly compact and organized (defined as having straight cell walls and regular division patterns) multicellular structures fully covered by exine, with thin inner cell walls and closely connected cells. Second, we observed compact callus (CC, Fig. 1C), which accounted for $3.14 \%$ of the total population. They were similar to EE structures but more disorganized, less compact, with thicker inner cell walls, less cellular adhesion and more extensive exine breakage. We also found a very small subset (0.75\% of the total population) of structures with loosely connected cells and large surface areas devoid of exine. A careful inspection of this subset revealed two types of structures: loose callus (LC, Fig. 1D), which were very disorganized callus structures with weak cellular adhesion and where exine was completely broken or even absent, and loose bicellular structures (LBS, Fig. 1B right), which were structures with 2-3 loosely connected cells and partial exine rupture, but showing a level of cell organization higher than LC and similar to EE, resembling in some cases the embryogenic structures described as suspensor embryos in DH12075 (Corral-Martínez et al. 2020b). These four proliferating structures were considered separately in all the analyses described next. 

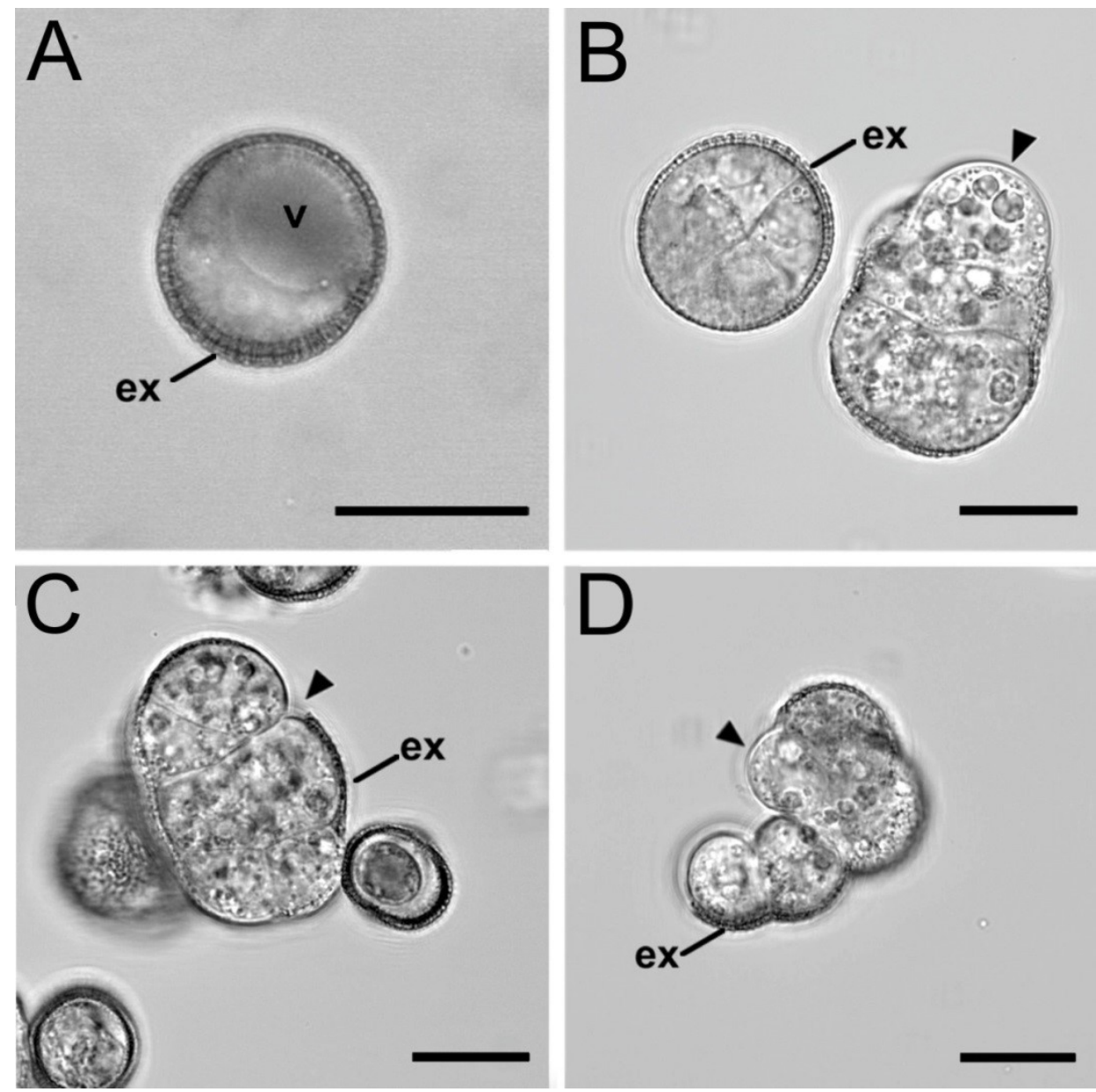

Figure 1: Development of microspores in culture in confocal microscopy images. A. Vacuolated microspore at the start of culture (day o). B. Left: Exine enclosed structure. Right: Loose bicellular structure. C: Compact callus. D: Loose callus. Arrow heads point to areas devoid of exine (ex). Bar: $20 \mu \mathrm{m}$. 


\section{External cell walls have a different width in different types of proliferating structures}

Analysis of embryogenic structures in $\mathrm{DH} 12075$ showed that the callus-like structures (LC and CC) have thicker cell walls than EE (Corral-Martínez et al. 2020b). We therefore examined cell wall thickness in the $\mathrm{DH} 4079$ proliferating structures and paid extra attention to the two cell wall layers observed previously in dividing microspores, the subintinal layer and the intine (Fig. 2A, (Parra-Vega et al. 2015). For this goal, we used SCRI Renaissance Cell 2200 and observed the cell walls of the different structures. EE structures (Fig. 2A) and the young globular embryos derived from them (Fig. 2B) showed cell walls thinner than disorganized and looser structures (CC and LC, Figs. ${ }_{2} \mathrm{C}$ and $\mathrm{D}$, respectively). To quantify cell wall thickness, we measured both the subintinal layer and total cell wall width in TEM images (Fig. 2E-F). We observed that the cell wall of callus-like structures (CC and LC) was wider than that of organized structures (EE and LBS; Fig. 2F). Consistent with this, the width of the subintinal layer was also higher in less organized structures (Fig. 2E), and proportional to the total cell wall width, which was always around $70-80 \%$, with no significant differences among structures.

In summary, we showed that there are significant differences between the cell wall width of the different DH4079 microspore-derived structures: they are wider in loose and highly disorganized structures. In addition, the percentage of subintinal layer is similar for the different structures, which suggests that differences in cell wall dynamics between structures are not related to differences in the percentage of cell wall occupied by the subintinal layer. 

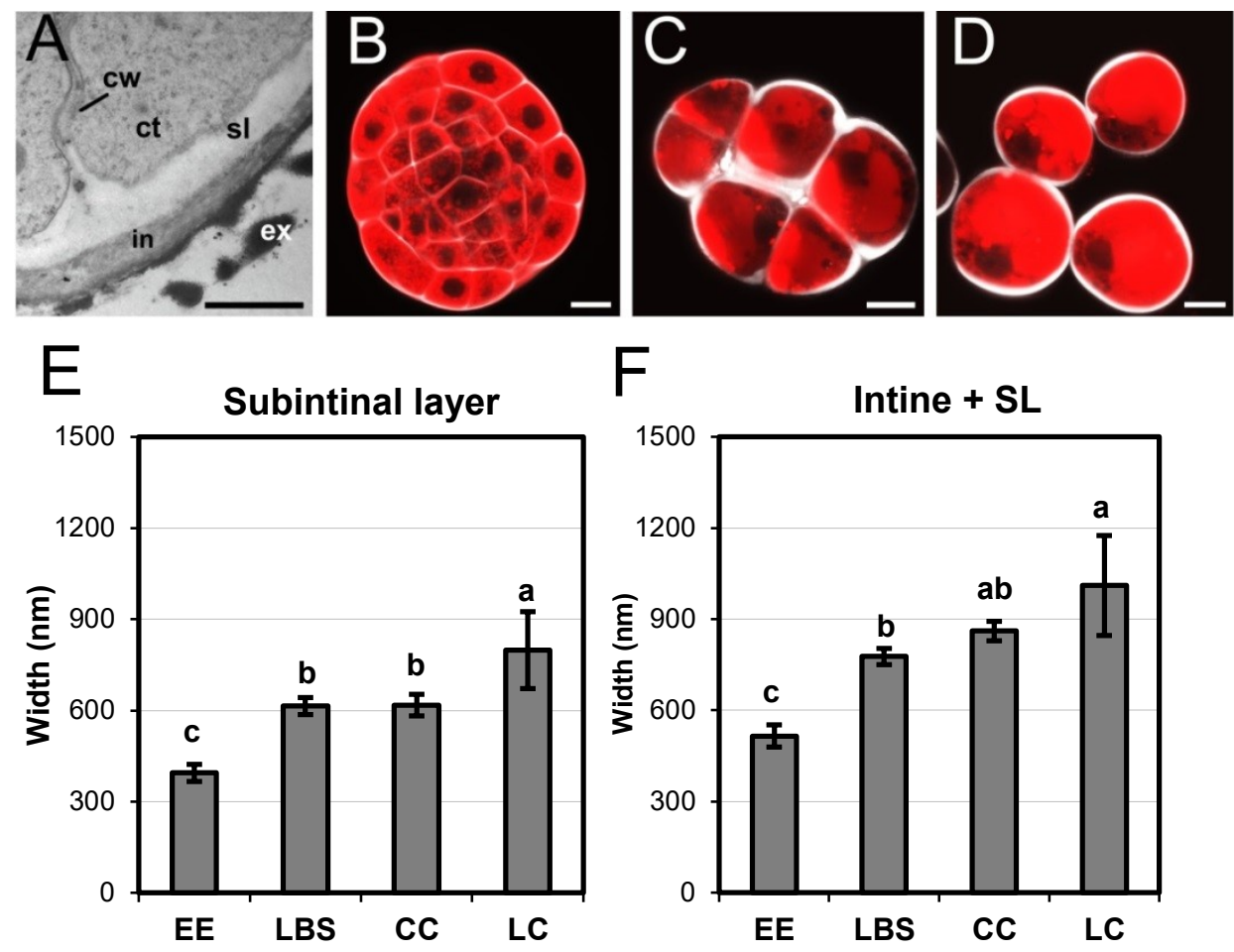

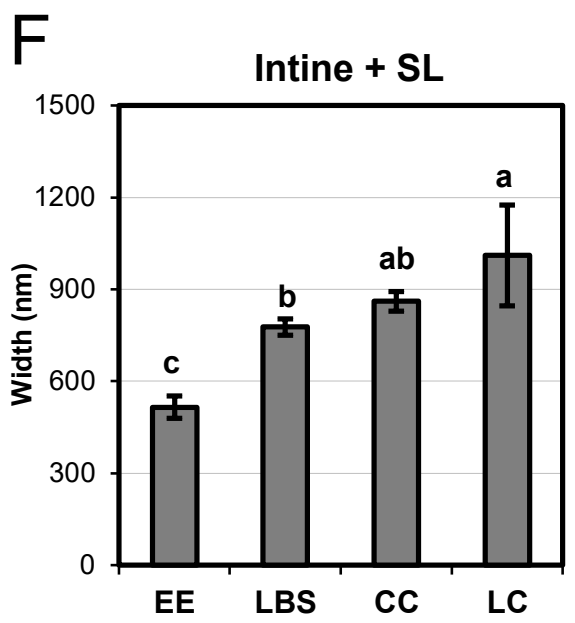

Figure 2: Cell wall width. A: Electron microscopy image of an EE structure, showing the inner cell wall (cw), subintinal layer (sl), intine (in) and exine (ex). ct: cytoplasm. B-D: Images of structures stained with SCRI Renaissance Cell 2200 observed by confocal microscopy. B: young, EE-derived embryo, C: compact callus (CC). D: loose callus (LC). E: subintinal layer width (in $\mathrm{nm}$ ) in each type of structure. F: Width (in $\mathrm{nm}$ ) of the intine + subintinal layer in each type of structure. Different letters represent significant differences according to the LSD test. Bars: A: $500 \mathrm{~nm}$; B-D: $10 \mu \mathrm{m}$. 


\section{EE and LBS structures accumulate more callose in internal and external cell walls}

Next, we examined the composition of the cell wall in the four different types of structures. As a first step, callose was detected using two techniques, confocal microscopy and immunolocalization. In general, callose was present in large amounts in cell walls of all structures during the first stages of embryogenesis, but it was reduced upon culture progression (Figs. 3A-C). Cellulose dynamics showed the opposite pattern, with low amounts of cellulose observed in cell walls during the first stages of embryogenesis, followed by cellulose accumulation in parallel with callose reduction at later stages (Figs. 3A'C').
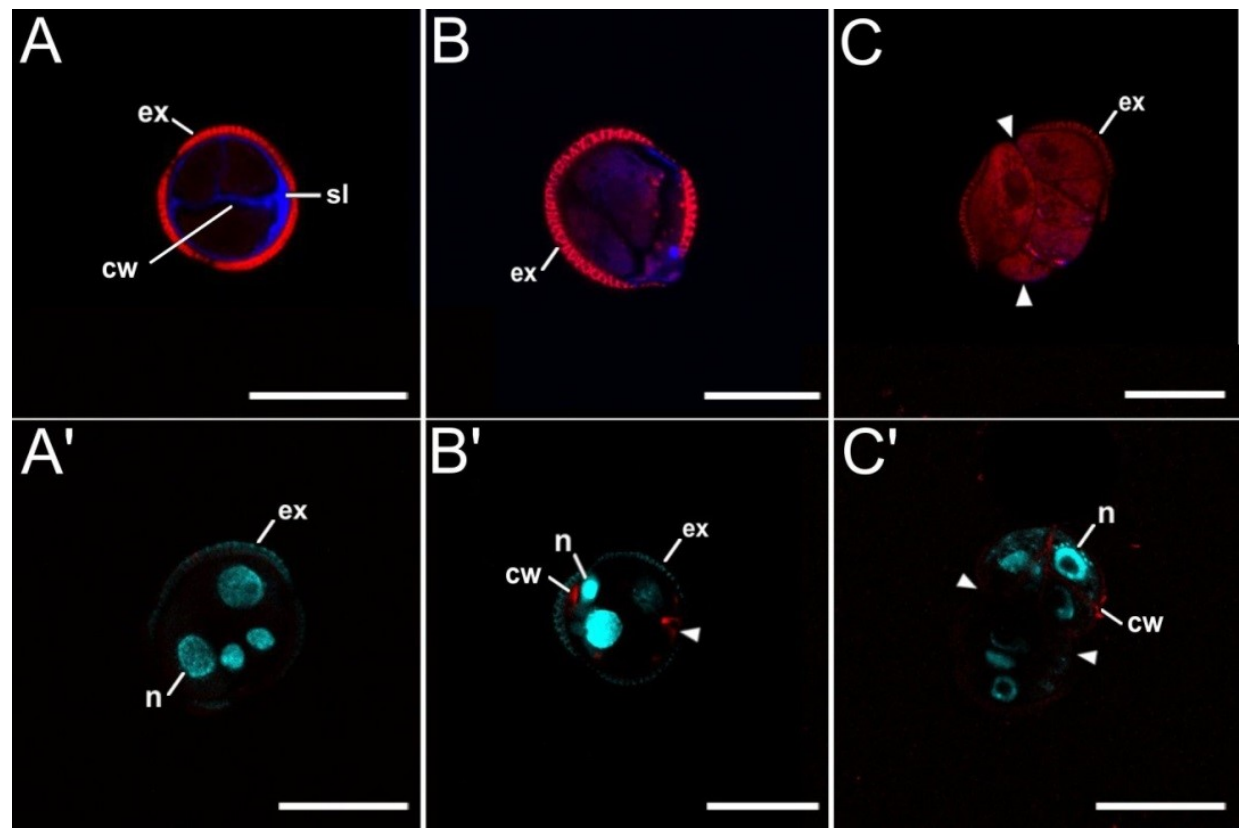

Figure 3: Confocal microscopy images of EE structures at 2 (A, A'), 5 (B, B') and 8 days of culture (C, $C^{\prime}$ ), stained with aniline blue for callose (blue in A, B, C) together with propidium iodide (red), and with Direct Red for cellulose (red in A', B', C') together with DAPI (blue). Arrowheads indicate regions of exine (ex) rupture or absence, cw: cell wall, n: nucleus, sl: subintinal layer. Bars: 20 $\mu \mathrm{m}$. 
Next, we performed a more detailed ultrastructural analysis of callose localization. The unspecific labelling density observed in the cytoplasm and organelles (background noise) was consistently low in comparison with that of cell walls, as expected. No significant differences among structures were observed in cell walls between adjacent cells within the same structure. However, different structure types presented different levels of callose in their cell walls. In highly embryogenic structures (EE and LBS), anti-callose labeling was present in higher amounts than in barely embryogenic structures (LC and CC), in both internal (Figs. 4A-C) and external walls (Figs. 4D-F), although at different levels. In general, inner cell walls showed more anti-callose labeling than external walls in all types of structures (Figs. $4 \mathrm{G}, \mathrm{H}$ ). Statistically significant differences among structure types were found in internal (Fig. 4G) and external cell walls (Fig. 4H). EE showed a significantly higher content in callose in inner cell walls than the rest of the structures, while in LC it was significantly lower than in the rest. In outer walls (intine + subintinal layer), two groups were observed according to callose labelling density: EE and LBS presented higher anticallose labeling than $\mathrm{CC}$ and LC, where labeling density was near zero. 

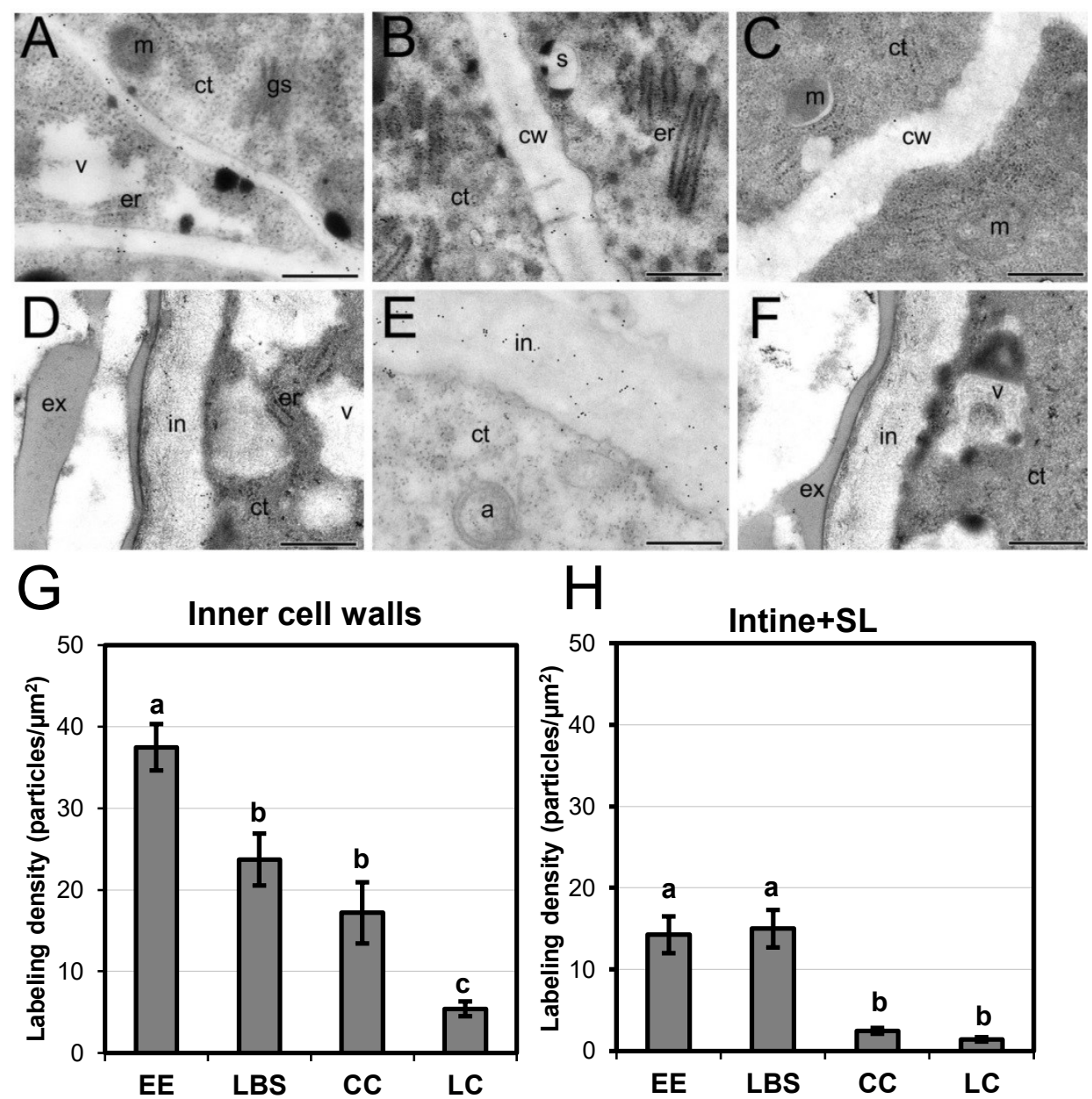

Figure 4: Callose detection by immunogold labeling and quantification in TEM images. A-C: Inner cell wall images from EE (A), LBS (B) and LC (C) structures. D-F: Outer cell wall images from EE (D), LBS (E) and CC (F) structures. G. Callose labelling density in inner cell walls. H. Callose labelling density in external cell walls. Different letters represent significant differences according to the LSD test. Labelling density is expressed in number of particles per $\mu \mathrm{m}^{2}$. a: autophagosome, ct: cytoplasm, cw: cell wall, er: endoplasmic reticulum, ex: exine, gs: Golgi stack, in: intine, m: mitochondrion, s: starch, v: vacuole. Bars: $500 \mathrm{~nm}$. 


\section{EE and LBS cell walls accumulate more JIM13- crossreacting AGPs than CC and LC}

We studied differences in abundance and distribution of these AGPs in different structures (Fig. 5). EE (Fig. 5A) and LBS inner walls showed higher JIM13 labelling density than those of CC and LC (Fig. 5B), although no significant differences between structures were observed in cell walls connecting adjacent cells (Fig. 5C). In outer walls, EE structures (Fig. 5D) exhibited a significantly higher JIM13 labelling density than LBS, CC and LC structures. It was previously shown (Corral-Martínez et al. 2019) that JIM13 epitopes accumulate only in the subintinal layer. Thus, we can reasonably assume that the JIM13 labeling observed in outer cell walls was restricted to the subintinal layer. In general, EE and LBS structures showed higher levels of JIM13crossreacting AGPs (Figs. 5A, D, E) than callus-like structures (CC and LC; Figs. 5B, F) in their cell walls. In addition, we detected JIM13 epitopes in the cytoplasm, although at much lower densities, and with no differences between structures (Fig. 5G). Background noise was always negligible.

Although the distribution of immunogold labeling in cell walls was similar to that of callose, quantification of JIM13 immunogold labeling revealed that, unlike callose, both inner and outer walls of a given structure presented similar levels (Figs. $5 \mathrm{H}-\mathrm{I}$ ). Statistically significant differences among structures were found in inner (Fig. $5 \mathrm{H}$ ) and outer walls (Fig. 5I), showing that barely embryogenic structures (LC and CC) had a significantly lower labeling density than highly embryogenic structures (EE and LBS). In summary, AGPs carrying the JIM13 epitope accumulated in a different manner in all cell walls of the different proliferating structures, more abundant in highly embryogenic and scarcer in barely embryogenic structures. 

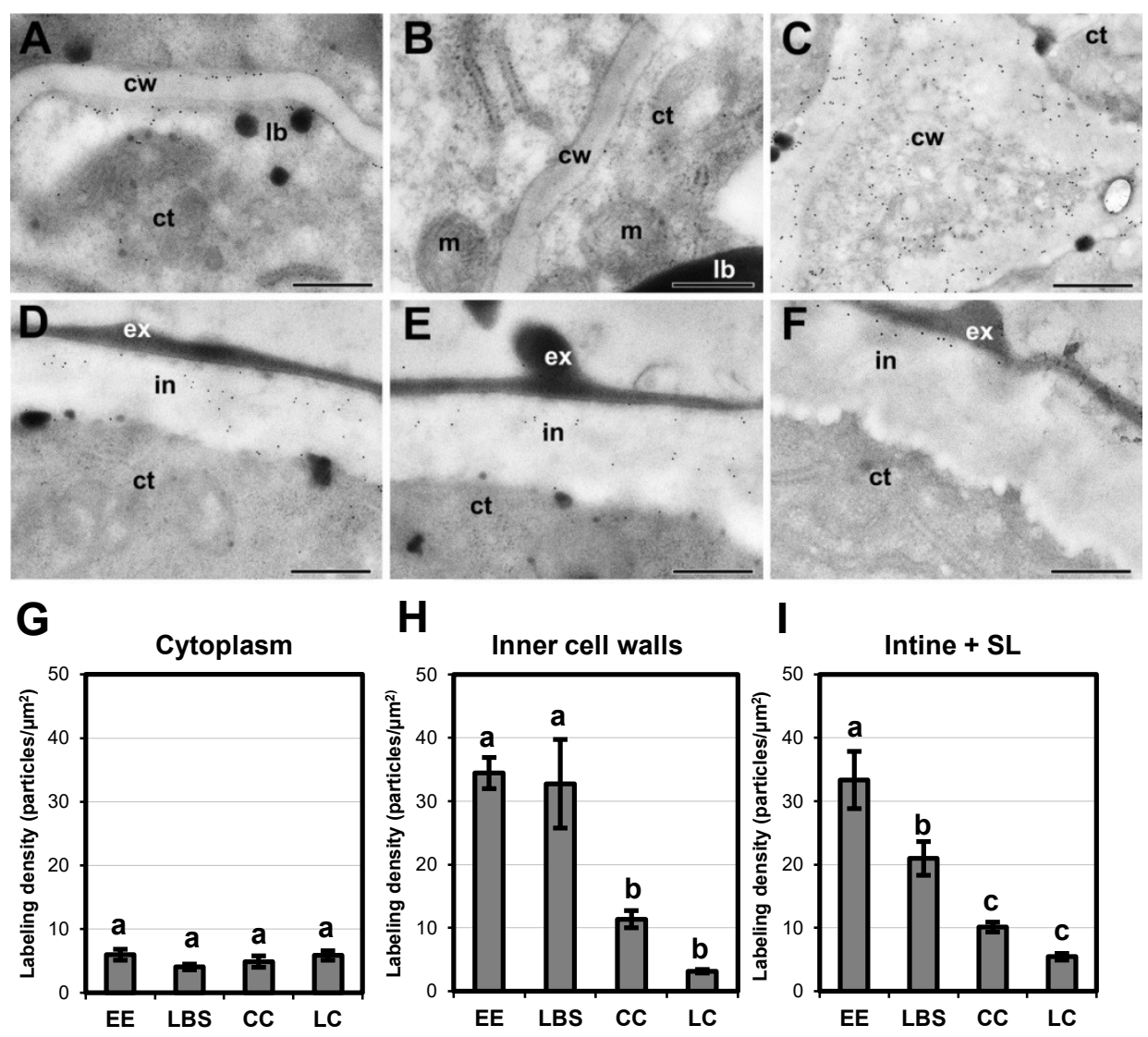

Figure 5: Detection of JIM13 cross-reacting AGPs by immunogold labeling and quantification in TEM images. A-B: Inner cell wall images of EE (A) and LC structures (B). C: Region of the union of three cell walls in an EE structure. D-F: Outer cell wall (intine + subintinal layer) images of EE (D), LBS (E) and CC structures (F). G: Quantification of JIM13-crossreacting AGPs in the cytoplasm. H. Quantification of JIM13 cross-reacting AGPs in inner cell walls. I. Quantification of JIM13 cross-reacting AGPs in outer cell walls (intine + subintinal layer). Labeling density is expressed as number of particles $/ \mu \mathrm{m}^{2}$. Different letters represent significant differences according to the LSD test., ct: cytoplasm, cw: cell wall, er: endoplasmic reticulum, ex: exine, gs: Golgi stack, in: intine, $\mathrm{m}$ : mitochondria, v: vacuole. Bars: $500 \mathrm{~nm}$. 


\section{Structures with less intercellular adhesion have reduced levels of low methyl-esterified pectin}

We performed immunogold labeling with JIM5 antibody to detect possible differences among structures in low methyl-esterified pectin levels (Fig. 6). For all the structures, JIM5 signal was present in both the intine and subintinal layer, as well as in cytoplasmic Golgi stacks and transport vesicles. Background (considered as cytoplasmic organelles, nuclei, the resin outside cells, etc.) labelling density was always negligible, irrespective of the sample studied. In general, compact structures such as EE (Fig. 6A) and CC presented more JIM5 labeling in inner cell walls than loose structures such as LBS and LC (Fig. 6B). This trend was also observed in outer walls (Fig. 6C), although the differences observed were not statistically significant. In the cytoplasm, LBS showed a labeling density remarkably lower than the other structures. Consistent with this, significant and structure-specific differences in labelling density were also observed in the cytoplasm (Fig. 6D) and in both types of walls, where LBS seemed to present the lowest density of low methylesterified pectin of all types of structures, followed by LC (Figs. 6E-F). Together, these results pointed to a relationship between levels of low methyl-esterified pectin and the degree of cellular adhesion between cells of the same structure. In particular, compact structures with higher cell adhesion (EE and CC) showed higher levels of low methyl-esterified pectin than loosely connected structures (LBS and LC). 

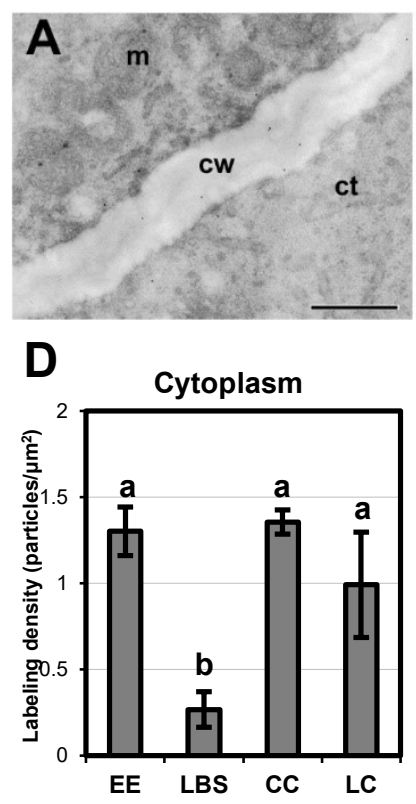
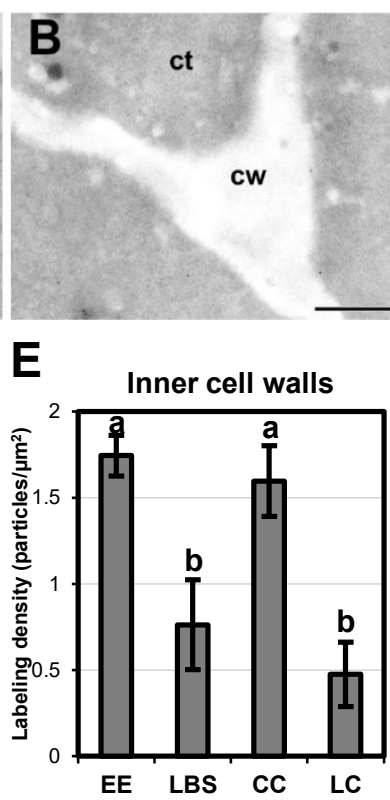
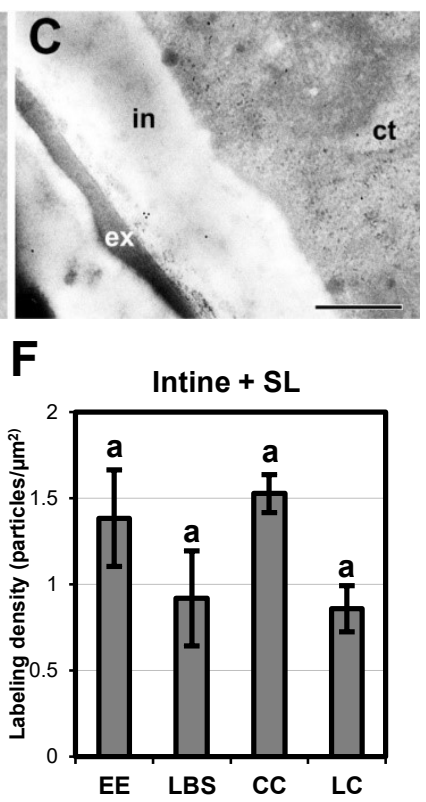

Figure 6: Detection of JIM5 cross-reacting low methyl-esterified pectin by immunogold labeling and quantification in TEM images. A-B: Inner cell wall images of EE (A) and LC (B). C: Outer cell wall image of EE. D: Quantification of JIM5 cross-reacting low methyl-esterified pectin in cytoplasm. E: Quantification of JIM5 cross-reacting low methyl-esterified pectin in inner cell walls. F: Quantification of JIM5 cross-reacting low methyl-esterified pectin in outer cell walls (intine + subintinal layer). Labelling density is expressed in number of particles per $\mu m^{2}$. Different letters represent statistically significant differences according to the LSD test. ct: cytoplasm, cw: cell wall, ex: exine, in: intine, m: mitochondrion. Bars: $500 \mathrm{~nm}$.

EE and LBS structures accumulate more highly methyl-esterified pectin in their internal and external cell walls

Immunogold labeling with JIM7 antibody was used to detect highly methyl-esterified pectin. Highly methyl-esterified pectin was present in cytoplasmic Golgi stacks and transport vesicles, inner walls and both layers (intine and subintinal layer) of outer walls. Background noise, considered as for JIM5 labeling, was always negligible. Average labeling density in outer and inner walls was similar (Fig. 7). Cell walls showed a 
pattern of JIM7 immunolocalization similar to that of JIM13 and anticallose: highly embryogenic structures such as EE (Figs. 7A, B) and LBS showed higher densities than barely embryogenic structures such as $\mathrm{CC}$ (Figs. 7C, D) and LC.

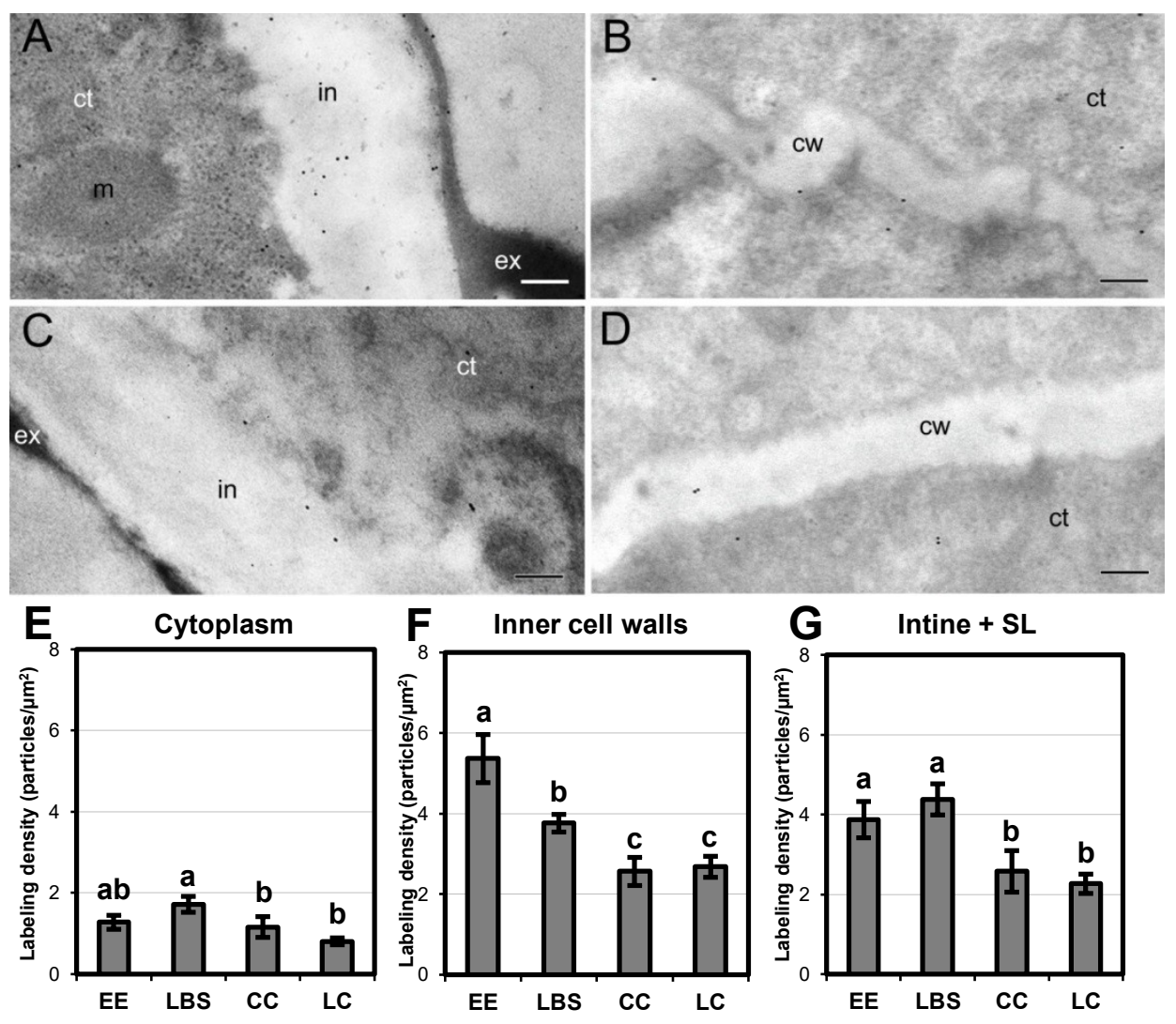

Figure 7: Detection of JIM7-crossreacting highly methyl-esterified pectin by immunogold labeling and quantification in TEM images. A-B: External cell wall images of EE (A) and CC (B). C-D: Inner cell wall images of EE (C) and CC (D). E: Quantification of JIM7-crossreacting highly methyl-esterified pectin in cytoplasm. F: Quantification of JIM7-crossreacting highly methyl-esterified pectin in inner cell walls. G: Quantification of JIM7-crossreacting highly methyl-esterified pectin in outer cell walls (intine + subintinal layer). Labeling density is expressed in number of particles per $\mu \mathrm{m}^{2}$. Different letters represent statistically significant differences according to LSD test. ct: cytoplasm, cw: cell wall, ex: exine, in: intine, m: mitochondria. Bars: $200 \mathrm{~nm}$. 
Differences were found between these structures for both inner and outer walls, as well as for the cytoplasm (Figs. $7 \mathrm{E}-\mathrm{G}$ ). Labeling density in the cytoplasm (always considered as Golgi stacks and transport vesicles, fig. 7 E) was lower than in cell walls, showing a pattern similar to outer walls. In inner walls (Fig. $7 \mathrm{~F}$ ), JIM7 epitopes were significantly more abundant in EE and LBS structures than in CC and LC. No differences in JIM7 labeling density were found in outer walls between EE and LBS (Fig. $7 \mathrm{G}$ ), but labeling density in these structures was higher than in LC and CC.

In addition to the general patterns observed in the quantitative analysis, and to the differences observed among different wall and layer types, we detected remarkable differences among structures in the cell walls separating adjacent cells, and in particular, in the outermost region of these walls, where they connect with the subintinal layer and intine. Depending on the presence or absence of exine covering these regions, the differences in labeling density were dramatic. EE structures, completely covered by exine (Fig. 8A) presented levels of JIM7 epitopes in these regions much higher than structures devoid of exine in the equivalent regions (Fig. 8B, LBS). In structures partially covered by exine (CC and LC), the regions covered by exine (Fig. 8C) presented a much higher labeling density than equivalent regions devoid of exine of the same structure (Fig. 8D). Statistical analysis of labelling density (Fig. $8 \mathrm{E}$ ) confirmed all these observations. These results suggested that the presence or absence of exine covering regions where the edges of cell walls between adjacent cells connect with the outer walls influenced the accumulation of highly methyl-esterified pectin in these regions, which was reduced in structures with lower levels of cell compaction and adhesion. Therefore, exine presence seemed to play a role in the accumulation of highly methyl-esterified pectin in these regions and in the adhesion properties of cell wall edges. 

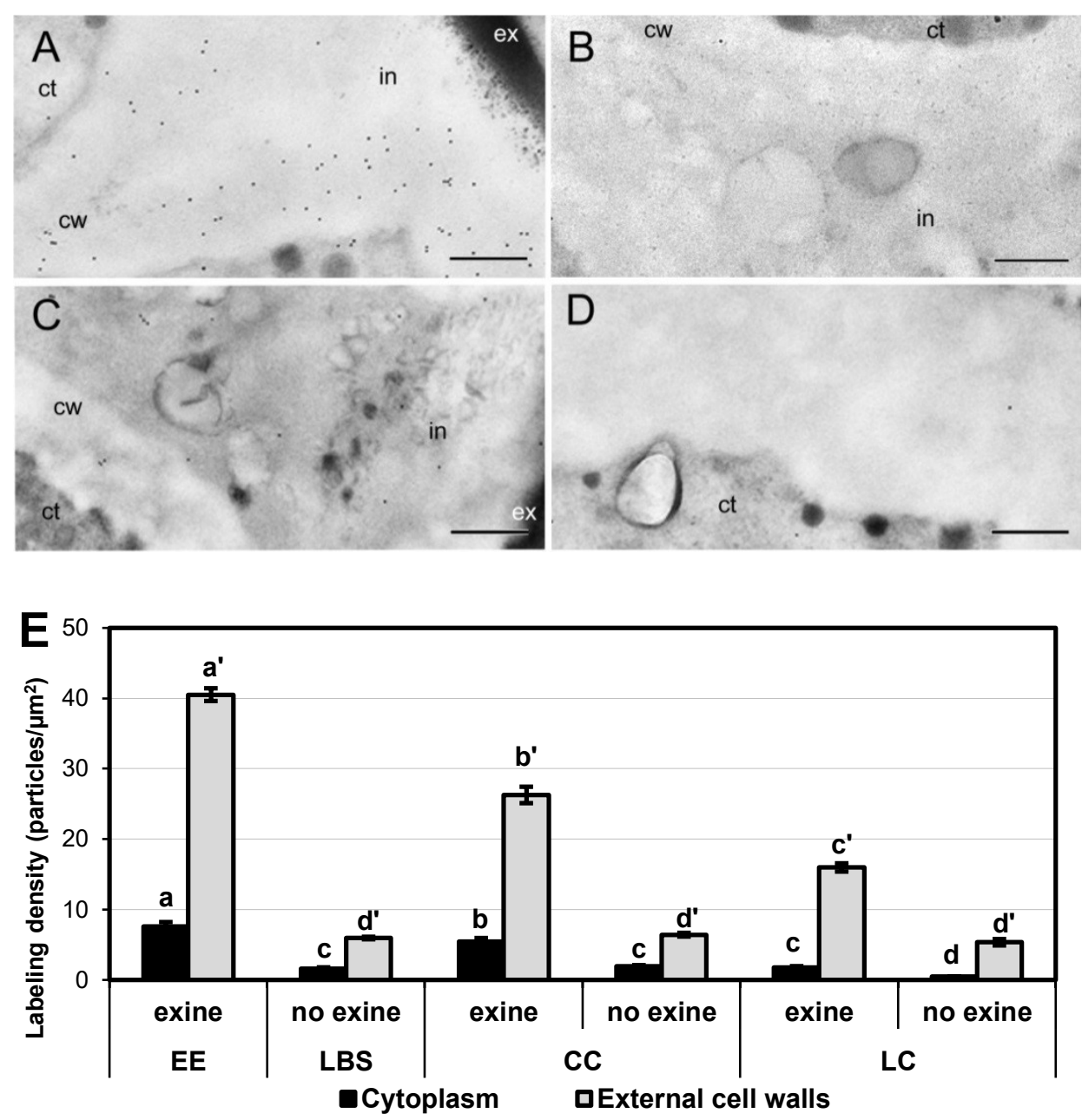

Figure 8: Detection of $\mathrm{JIM}_{7}$ cross-reacting highly methyl-esterified by immunogold labeling and quantification in TEM images of cell wall regions connecting to outer walls. A-D: Images of cell wall regions connecting with outer walls in EE (A), LBS without exine (B) and LC with (C) and without exine (D). E: Quantification of JIM7-crossreacting highly methyl-esterified pectin in cytoplasm and cell wall in different types of structures and in areas with or without exine. Labelling density is expressed in number of particles per $\mu \mathrm{m}^{2}$. Different letters represent statistically significant differences obtained with LSD test. ct: cytoplasm, cw: cell wall, ex: exine, in: intine. Bars: $200 \mathrm{~nm}$. 


\section{Discussion}

It is widely accepted that microspore culture is a heterogeneous system where different populations with different developmental fates coexist. However, it was initially assumed that the population of dividing microspores, sensitive to the induction treatment, follow the same pathway towards embryogenesis. Using the $\mathrm{DH} 4079$ line of B. napus, this idea changed when two different types of structures, exine-enclosed, suspensorless embryos and suspensor-bearing embryos were found to coexist as the only embryogenic structures in microspore culture (Supena et al. 2008). This notion was further refined in B. napus DH12075 microspore cultures, where in addition to exine-enclosed and suspensor embryos, compact and loose calli were described (CorralMartínez et al. 2020b). Embryo cell identity and embryo fate were unambiguously assigned to these multicellular structures using embryo fluorescent reporters and time-lapse imaging (Li et al. 2014; Soriano et al. 2014; Corral-Martínez et al. 2020b). However, not all these estructures were equally embryogenic. EE and LBS were shown to be highly embryogenic, producing the vast majority of the embryos, whereas CC and LC were barely embryogenic. In this work we showed that in $\mathrm{DH} 4079$ microspore cultures, very similar structures are also induced, demonstrating that the range of embryogenic cell types in DH4079 is much wider than previously assumed. We observed EE, CC and LC structures anatomically equivalent to those described in DH12075. We also observed LBS, structures that resemble the suspensor embryos (SUS) described for DH12075 (Corral-Martínez et al. 2020b), but grow slightly slower, having less cells and a less prominent suspensor at day 5 , when observations were made in both genotypes. Since we did not track the whole development of each structure type until their final fate, and SUS at day 5 (the starting point of both studies) were only produced with the use of Trichostatin A, not used here, we initially considered LBS as a different type of structure. However, after completion of our study, we can reasonably assume that the embryogenic structures formed in $\mathrm{DH}_{4079}$ and their development are equivalent to the embryogenic structures observed in DH12075, including SUS, based on the following premises: (1) they are two 
different backgrounds of the same species, (2) the structures observed at day 5 are anatomically similar for both backgrounds, (3) the protocols used to induce embryogenesis are essentially the same (Corral-Martínez et al. 2020a), (4) both backgrounds have been consistently proved to eventually produce equivalent microspore-derived embryos (Li et al. 2014; Corral-Martínez et al. 2020a) although with different efficiency, and (5) most importantly, the study of the cell wall of the different structures revealed equivalent differences between compact (EE and CC) and loose structures (LC and LBS/SUS), as well as equivalent similarities between the highly embryogenic structures (EE and LBS/SUS) and the barely embryogenic structures (CC and LC). Such differences and similarities and their significance in the context of in vitro morphogenesis are discussed next.

\section{Different microspore-derived structures present specific cell wall characteristics that define their developmental fate}

Combining the data hereby presented and previous studies, we can conclude that each type of structure has a different cell wall profile and a different potential for differentiated embryo formation, often through different developmental pathways (Li et al. 2014; Soriano et al. 2014; Corral-Martínez et al. 2020b). Here we examined these cell wall properties in detail by studying the thickness of outer cell walls (intine + subintinal layer), as well as the composition of inner and outer cell walls in terms of callose, cellulose, high and low methyl-esterified pectin and AGPs. The most relevant differences are summarized in Fig. 9. Our data indicate that EE structures, shown to be by far the most viable structures and the main source of embryos in DH12075 (Corral-Martínez et al. 2020b), had the thinnest walls of all the structures, but with the highest labeling density for almost all the antibodies used in this study. This clearly points to this specific cell wall profile as the most favorable for cell proliferation and embryo progression. 


\begin{tabular}{|l|c|c|c|c|}
\hline Type of structure & EE & LBS & CC & LC \\
\hline Cell wall width & c & b & ab & a \\
\hline Subintinal layer width & c & b & b & a \\
\hline Callose & a & b & b & c \\
\hline Inner walls & a & a & b & b \\
\hline Outer walls & a & a & b & b \\
\hline JIM13 - AGPs & a & b & c & c \\
\hline Inner walls & a & b & a & a \\
\hline Outer walls & a & b & a & b \\
\hline Low methyl-esterified pectin & a & a & a & a \\
\hline Cytoplasm & ab & a & b & b \\
\hline Inner walls & a & b & c & c \\
\hline Outer walls & a & a & b & b \\
\hline Highly methyl-esterified pectin & a \\
\hline Cytoplasm & a & b & c \\
\hline Inner walls & & d & d & d \\
\hline Outer walls &
\end{tabular}

Figure 9. Summary of the differences in cell wall composition of different microspore-derived structures. Different letters represent statistically significant differences in labeling density according to the LSD test, ranging from a (the highest labeling density) to $d$ (the lowest labeling density). For a better comparison among structures, each letter is associated to a different background color.

In contrast, CC structures, shown to produce almost no embryos and to be the main source of calli (Corral-Martínez et al. 202ob), had cell walls thicker than EE and an overall lower antibody signal, except for low methyl-esterified pectin, where a strong signal was observed in all cell walls. This cell wall profile, opposite to that of EE except for low methyl-esterified pectin, would confirm that embryo progression is favored by thin walls and high density of callose, AGPs and high methylesterified pectin. It is interesting to note that the two compact structures, $\mathrm{EE}$ and CC, showed similarly high levels of low methyl-esterified pectin but completely different developmental fates. This assigns a role for low methyl-esterified pectin in the manteinance of cell adhesion and structural compactness, but not in the embryogenic competence of the structures. Loose structures (LBS/SUS and LC), shown to have a very low viability (Corral-Martínez et al. 2020b), tended to have the thickest cell walls and the lowest density of certain components, specially in inner cell walls. It appears that these features accounted for the low levels of cell adhesion found between cells and eventually for their low viability. However, the few embryos they produced were all suspensorbearing embryos (Corral-Martínez et al. 2020b). In this case it seems 
also clear that this particular cell wall profile determined their developmental fate as low viable structures with potential to become suspensor-bearing embryos. In particular, LC structures presented the widest cell walls and the lowest values for almost all the studied cell wall components. They also presented the lowest values of viability, with nearly $83 \%$ of them being arrested or undergoing only few cell divisions (Corral-Martínez et al. 2020b). These cell wall properties, totally opposite to those of EE structures, could be defined as the less favorable for cell proliferation and embryo progression. In conclusion, we showed that each embryogenic structure has a specific cell wall profile that directly correlates with its ability to form embryos. The cell wall profile of each structure would define its developmental fate.

\section{The newly formed cell walls that support embryo} formation are thin, plastic, and callose-rich

Inner cell walls formed in $\mathrm{DH}_{4079}$ embryogenic microspores between neighbor cells just upon induction are plastic, irregular, incomplete, and rich in callose, an amorphous polymer that confers flexibility and fluidity to nascent cell plates (Samuels et al. 1995), and also to cell walls when it is not timely removed (Parra-Vega et al. 2015). This combination of properties allows cell expansion and growth but is also required for spontaneous genome doubling (Parra-Vega et al. 2015). This description adjusts perfectly to the thin inner walls found in highly embryogenic structures (EE and LBS/SUS) in both DH4079 (this work) and DH12075 (Corral-Martínez et al. 2020b). In turn, it markedly differs from the thick walls found in barely embryogenic structures (CC and LC). The width of the cell wall is a crucial characteristic of multicellular structures. It affects not only the compactness of the structure, but also the communication between cells (Parra-Vega et al. 2015). Cell-to-cell communication is required to organize and functionally coordinate the role of cells within the same tissue or organ. Cell-to-cell communication proceeds through plasmodesmata, cell wall channels between neighboring cells that originate when endoplasmic reticulum cisternae are trapped by the cell plate during cell division (Seguí-Simarro et al. 2004). Cells interconnected by plasmodesmata share chemical signals and form symplastic domains of shared communication. In plant zygotic embryogenesis, the first cells produced by division of the zygote form a 176 
single symplast where all cells are connected up to the stage of heartshaped embryo, where different symplasts are formed to start with organ differentiation (Kim and Zambryski 2005). Keeping cells connected maintains the identity of the early zygotic embryo, and it can be assumed that also of the microspore-derived embryo. Connections are easier in cells with thin and incomplete walls, where in addition to plasmodesmata, gaps and fenestrae permit the contact of neighboring cytoplasms (Parra-Vega et al. 2015). If inner walls become excessively thick as in barely embryogenic structures (LC and CC), plasmodesmata would collapse and wall gaps would occlude, thereby reducing or cancelling cell-to-cell communication. It is not surprising then that those structures with thinner and more tightly connected cell walls (EE and LBE/SUS) have a higher probability to form a differentiated embryo (Corral-Martínez et al. 2020b).

Here, we also examined the biological significance of the subintinal layer. This callose-rich layer is a good predictor for the ability to form differentiated embryos (Parra-Vega et al. 2015) and allows cells to create an impermeable layer underneath the intine that protects cells from osmotic changes in the in vitro culture environment, which has a positive impact in their viability (Rivas-Sendra et al. 2019). Upon embryogenesis induction, callose accumulates only in the subintinal layer (Parra-Vega et al. 2015), which implies that the anti-callose labelling observed in outer cell walls can only be attributed to the subintinal layer. Our results showed remarkable differences in callose accumulation, abundant in highly embryogenic structures (EE and LBS) and very scarce in barely embryogenic structures (CC and LC). This suggests that differences in callose accumulation in the subintinal layer are related to the level of cellular organization and embryogenic competence of the different structures. In cell walls, callose tends to form highly hydrated but semipermeable gels, ideal to act as physical and chemical barriers (Albersheim et al. 2011). During plant morphogenesis, callose is used by cells to isolate them from the surrounding environment, thereby protected from swelling or bursting and able to express a new morphogenic program without interferences. Examples include natural processes such as male and female meiocytes (Heslop-Harrison and Mackenzie 1967; Zhang et al. 2002; Abramova et al. 2003), and in vitro processes such as induction of organogenesis (Fortes et al. 2002) and somatic embryogenesis (Maheswaran and Williams 1985; Dubois et al. 
1991; Pedroso and Pais 1992; You et al. 2006). Our observation that callose highly accumulated in the subintinal layer of outer cell walls of highly embryogenic structures (EE and LBS/SUS) is in line with these studies and provides an additional evidence in a different in vitro morphogenic system. This happened even when the subintinal layer itself was not thicker than in barely embryogenic structures (LC and CC), which indicates that rather than thickness the level of callose accumulation would be the critical parameter of outer cell walls to support microspore embryogenesis.

Upon embryogenesis induction, callose accumulated only in the subintinal layer (Parra-Vega et al. 2015), implying that the anti-callose labelling observed in outer cell walls can only be attributed to the subintinal layer. Together, our results showed remarkable differences in callose accumulation, abundant in highly embryogenic structures (EE and LBS) and very scarce in barely embryogenic structures (CC and LC). This suggests that differences in callose accumulation in the subintinal layer are related to the level of cellular organization and embryogenic competence of the different structures.

Thus, cell wall properties that support differentiated embryo formation are thin, plastic, irregular and callose-rich inner walls that bring flexibility and permit close communication between cells inside the structures during the first stages of growth, and the presence of a subintinal layer with a high callose concentration that isolates the structure to a certain degree from the external environment, allowing it to establish an organized embryogenic growth pattern.

\section{High levels of highly methyl-esterified pectin are} necessary for cell wall flexibility and growth of highly embryogenic structures

Microspores are programmed to follow a gametophytic pathway that results in formation of a pollen grain with a vegetative cell and two sperm cells. Pollen is covered by a protective layer, the exine, determinant for survival outside the plant. The exine is a relatively rigid coat whose flexibility is largely determined by the number and type of pollen apertures. However, during in vitro embryo culture this layer 
must eventually break to allow the release of the developing embryo. The specific place where exine breaks was shown to be very important for the fate of the structure (Tang et al. 2013; Corral-Martínez et al. 2020b). We showed that different embryogenic structures have a different timing for exine rupture: earlier and to a larger extent in LBS/SUS, then in CC, LC and EE, where exine breaks later. The fact that EE and LBS/suspensor structures are by far the most embryogenic (Corral-Martínez et al. $2020 b$ ) indicates that the timing of exine rupture is not critical for embryo production. However, EE structures produced only suspensorless embryos, whereas LBS/SUS produced only suspensorbearing embryos (Corral-Martínez et al. 2020b), which points to a critical role for exine presence in the developmental pathway adopted by the structure.

Highly methyl-esterified pectin was described to accumulate in the intine of embryogenic microspores more abundantly than in pollen-like structures (Corral-Martínez et al. 2019). We used the same experimental approach to analyze pectin content but separately in the different types of structures. We found that highly methyl-esterified pectin is present in both inner walls and the intine, and was more abundant in organized, highly embryogenic structures (EE and LBS/SUS; Fig. 7). During somatic-type cytokinesis, pectin is synthesized in the Golgi stacks in a methyl-esterified form, and delivered through the cytoplasm via vesicles to the growing cell wall, where pectin is de-esterified by pectin methylesterases (PME). Once de-esterified, they are cross-linked by calcium, becoming stiff and thereby providing rigidity to the cell wall (Bou Daher and Braybrook 2015). A similar mechanism has been described for pollen tube formation (Palin and Geitmann 2012). It was described that during the first stages of microspore embryogenesis, B. napus PME (BnPME) showed low levels of expression, and levels of highly methylesterified pectins were high (Solis et al. 2016). Our results, in line with these results, point to highly embryogenic structures (EE and LBS/SUS) as the main contributors to the high levels of highly methyl-esterified pectins previously described. The higher levels of highly methylesterified pectin, not yet de-esterified and cross-linked, found in EE and LBS/SUS would be indicating that these structures are the most actively growing at this stage. 
Surprisingly, we also found that highly methyl-esterified pectin was more abundant at the region of the edges of inner cell walls that connect with outer walls, including the adjacent cytoplasm, but much more abundant where these regions were covered by exine (Fig. 8), indicating a clear relationship between exine presence and deposition of highly methyl-esterified pectin. The fact that the cytoplasm adjacent to these cell wall regions had also high levels of immunogold labeling, and proportional in all cases to the labeling found in the corresponding cell wall regions, suggests that highly methyl-esterified pectin is being actively sinthesized at this stage and selectively transported to exinecovered regions. In pollen tubes, it was demonstrated that methylesterified pectin promoted the occurrence of loose walls at the tube tip, necessary for expansion and tip growth (Li et al. 1994). Out of the tip, pectin de-esterification generated rigid walls that provided stability to the pollen tube. Consistent with this, the high levels of highly methylesterified pectin in the inner cell wall edge regions would imply that these regions are growing more actively to adapt cell wall width to the increasing size of these growing cells, and their pectin is not yet deesterified. Thus, it is reasonable to propose that this pectin composition, typical of growing walls, is what permits the cell walls to produce the expanding force necessary for exine rupture. In fact, it is frequent to find points of exine rupture precisely at these regions where inner walls connect with outer walls (Fig. 1C). In turn, regions devoid of exine would be indicative of cell wall regions where expansion has already taken place and walls are transitioning to a more stable, non-growing state, as revealed by their lower contents in highly methyl-esterified pectin. This notion would be supported by the fact that loose structures (LBS and LC) are the structures were less exine remains attached to the walls, and less levels of highly methyl-esterified pectin were observed.

The particular combination of pectin, AGPs and calcium levels would determine the developmental fate of $\mathrm{EE}$ and LBS/SUS structures as suspensorless and suspensor-bearing embryos, respectively

The role of AGPs in microspore embryogenesis has been object of study for many years. The AGP composition of the microspore walls change drastically when microspores enter the embryogenic pathway, 180 
getting rich in certain AGPs (Corral-Martínez et al. 2019). Indeed, AGPs are known to play an important role in different microspore culture systems, since their addition to the culture medium promotes embryogenesis, whereas their depletion inhibits it (Borderies et al. 2004; Tang et al. 2006; Corral-Martínez and Seguí-Simarro 2014; Makowska et al. 2017). However, their specific role is still unknown. On the other hand, calcium was proposed to play a role in the embryogenic commitment of microspore-derived structures, since the levels of cytoplasmic calcium dramatically increased only in embryogenic microspores and not in callus-like structures during ths first stages of the embryogenic switch (Rivas-Sendra et al. 2017). The relationship between calcium and AGPs during cell wall growth is long known. In growing pollen tubes, AGP depletion inhibited pollen tube growth, whereas calcium influx promoted the delivery of exocytosis vesicles (Gaffal et al. 2007). More recently, it was shown that periplasmic AGPs can act as calcium capacitors, releasing calcium when the $\mathrm{pH}$ in the apoplast changes as a consequence of the activation of $\mathrm{H}^{+}$-ATPs pumps by the tensional force that occurs in the plasma membrane during cell growth (Lamport and Varnai 2013).

We showed that highly embryogenic structures (EE and LBS/SUS) have the highest density of JIM13-detected AGPs in both outer and inner cell walls. They correspond to the structures where the highest levels of intracellular calcium were detected soon after induction of embryogenesis (Rivas-Sendra et al. 2017). According to the model described in Lamport and Varnai (2013), AGPs may provide these structures with more capacity to release $\mathrm{Ca}^{+2}$ when needed for the embryogenic switch. When the plasma membrane stretches as a consequence of cell growth, calcium would be released by AGPs, thereby signaling the need for more cell wall synthesis and activating the delivery of exocytosis vesicles, as it happens for pollen tube growth. This sets off a postive feedback loop that increases the amount of AGPs in the cell wall and in turn, of calcium. Calcium is also required for gelification of low methyl-esterified pectin to provide cellular adhesion (Palin and Geitmann 2012; Bou Daher and Braybrook 2015). In general, inner cell walls presented a higher density of low methyl-esterified pectin in compact structures (EE and $\mathrm{CC}$ ), which indicates that low methylesterified pectin are important for cell adhesion in microspore-derived stuctures. However, the combined high levels of AGPs, pectin and 
calcium in EE structures would confer these structures unique properties to combine cell adhesion with high embryogenic potential.

Nevertheless, LBS/SUS structures showed an unusual pattern of AGP accumulation. They presented high amounts of AGPs in their inner walls and high amounts of both low and highly methyl-esterified pectin in their outer walls. Their high degree of pectin esterification in outer walls and the detachment of exine would make these walls flexible, but the low degree of pectin esterification in inner cell walls would keep cells attached to each other. In other words, these structures are loose because the exine is not present to restrict their expansion and their outer walls allow for it, but the conection between cells is enough to keep intercellular communication. It is reasonable to deduce that this combination of cell wall properties provides the optimal conditions for their development as suspensor-bearing embryos, nearly impossible with any other cell wall type. Supporting this notion, LC structures, with a similar pectin composition in both inner and outer walls, were only able to produce suspensor-bearing embryos in $\mathrm{DH}$ 12075, although at a very low percentage due to their very low viability (Corral-Martínez et al. 2020b). In this case, the difference in cell wall thickness and in the rest of components would account for their low embryo response.

\section{Conclusions}

This study provides relevant data to further understand the role of cell wall during the initial stages of microspore embryogenesis, and how different cell wall profiles are related to different developmental fates. We describe the characteristic levels of callose, AGPs and pectin in the different types of structures described in microspore culture populations of $B$. napus, which allows to associate the optimal structure and composition of the cell wall in microspore-derived structures for embryogenic development. 


\section{Acknowledgements}

Thanks are due to the Electron Microscopy Service of Universitat Politècnica de València, Marisol Gascón (IBMCP Microscopy Service). This work was supported by grant AGL2017-88135-R to JMSS from MICINN jointly funded by FEDER and by a Marie Skłodowska-Curie Individual Fellowship (656579) to PC-M.

\section{References}

Abramova LI, Avalkina NA, Golubeva EA, Pyzhenkova ZS, Golubovskaya IN (2003) Synthesis and deposition of callose in anthers and ovules of meiotic mutants of maize (Zea mays). Russian Journal of Plant Physiology 50 (3):324-329. doi:10.1023/a:1023866019102

Albersheim P, Darvill A, Roberts K, Sederoff R, Staehelin A (2011) Plant cell walls. Garland Science, New York, USA

Aouar L, Chebli Y, Geitmann A (2010) Morphogenesis of complex plant cell shapes: the mechanical role of crystalline cellulose in growing pollen tubes. Sex Plant Reprod 23 (1):15-27. doi:10.1007/s00497-009-0110-7

Borderies G, le Bechec M, Rossignol M, Lafitte C, Le Deunff E, Beckert M, Dumas C, Matthys-Rochon E (2004) Characterization of proteins secreted during maize microspore culture: arabinogalactan proteins (AGPs) stimulate embryo development. Eur J Cell Biol 83 (5):205-212

Bou Daher F, Braybrook SA (2015) How to let go: pectin and plant cell adhesion. Front Plant Sci 6:523-523. doi:10.3389/fpls.2015.00523

Brown RC, Lemmon BE (2009) Callose in cell division. In: Bacic A, Fincher GB, Stone BA (eds) Chemistry, Biochemistry, and Biology of (1-3)-b-Glucans and Related Polysaccharides. Elsevier Science, pp 425-438

Camacho-Fernández C, Hervás D, Rivas-Sendra A, Marín MP, Seguí-Simarro JM (2018) Comparison of six different methods to calculate cell densities. Plant Methods 14 (1):30. doi:10.1186/s13007-018-0297-4

Corral-Martínez P, Camacho-Fernández C, Seguí-Simarro JM (2020a) Isolated Microspore Culture in Brassica napus. In: Bayer M (ed) Plant Embryogenesis: Methods and Protocols, vol 2122. Methods in 
Molecular Biology,. Springer US, New York, NY, pp 269-282. doi:10.1007/978-1-0716-0342-0_19

Corral-Martínez P, Driouich A, Seguí-Simarro JM (2019) Dynamic Changes in Arabinogalactan-Protein, Pectin, Xyloglucan and Xylan Composition of the Cell Wall During Microspore Embryogenesis in Brassica napus. Front Plant Sci 10 (332). doi:10.3389/fpls.2019.00332

Corral-Martínez P, Parra-Vega V, Seguí-Simarro JM (2013) Novel features of Brassica napus embryogenic microspores revealed by high pressure freezing and freeze substitution: evidence for massive autophagy and excretion-based cytoplasmic cleaning. J Exp Bot 64 (10):3061-3075. doi:10.1093/jxb/ert151

Corral-Martínez P, Seguí-Simarro JM (2014) Refining the method for eggplant microspore culture: effect of abscisic acid, epibrassinolide, polyethylene glycol, naphthaleneacetic acid, 6-benzylaminopurine and arabinogalactan proteins. Euphytica $195 \quad$ (3):369-382. doi:10.1007/s10681-013-1001-4

Corral-Martínez P, Siemons C, Horstman A, Angenent GC, de Ruijter N, Boutilier K (2020b) Live Imaging of embryogenic structures in Brassica napus microspore embryo cultures highlights the developmental plasticity of induced totipotent cells. Plant Reprod. doi:10.1007/s00497-020-00391-z

Custers J (2003) Microspore culture in rapeseed (Brassica napus L.). In: Maluszynski M, Kasha KJ, Forster BP, Szarejko I (eds) Doubled haploid production in crop plants. Kluwer Academic Publishers, Dordrecht, The Netherlands, pp 185-193

Chebli Y, Kaneda M, Zerzour R, Geitmann A (2012) The Cell Wall of the Arabidopsis Pollen Tube-Spatial Distribution, Recycling, and Network Formation of Polysaccharides. Plant Physiol 160 (4):1940-1955. doi:10.1104/pp.112.199729

Chen H-W, Persson S, Grebe M, McFarlane HE (2018) Cellulose synthesis during cell plate assembly. Physiol Plant 164 (1):17-26. doi:10.1111/ppl.12703

Cheung AY, Wu HM (1999) Arabinogalactan proteins in plant sexual reproduction. Protoplasma 208 (1-4):87-98

Dong X, Hong Z, Sivaramakrishnan M, Mahfouz M, Verma DPS (2005) Callose synthase (CalS5) is required for exine formation during microgametogenesis and for pollen viability in Arabidopsis. Plant J 42 (3):315-328. doi:10.1111/j.1365-313X.2005.02379.x 
Dubois T, Guedira M, Dubois J, Vasseur J (1991) Direct somatic embryogenesis in leaves of Cichorium: a histological and SEM study of early stages. Protoplasma 162:120-127

Ferguson C, Teeri TT, Siika-aho M, Read SM, Bacic A (1998) Location of cellulose and callose in pollen tubes and grains of Nicotiana tabacum. Planta 206 (3):452-460. doi:10.1007/soo4250050421

Fortes AM, Testillano PS, Risueno MD, Pais MS (2002) Studies on callose and cutin during the expression of competence and determination for organogenic nodule formation from internodes of Humulus lupulus var. Nugget. Physiol Plant 116 (1):113-120

Gaffal KP, Friedrichs GJ, El-Gammal S (2007) Ultrastructural evidence for a dual function of the phloem and programmed cell death in the floral nectary of Digitalis purpurea. Ann Bot 99 (4):593-607. doi:10.1093/aob/mcmoo2

Gaspar Y, Johnson K, McKenna J, Bacic A, Schultz C (2001) The complex structures of arabinogalactan-proteins and the journey towards understanding function. Plant Mol Biol 47 (1-2):161-176. doi:10.1023/a:1010683432529

Gorska-Brylass A (1967) Transitory callose envelope surrounding the generative cell in pollen grains. Acta Soc BotPoloniae 36 (2):419-422

Heslop-Harrison J, Mackenzie A (1967) Autoradiography of soluble [2-I4C] thymidine derivatives during meiosis and microsporogenesis in Lilium anthers. J Cell Sci 2:387-400

Karnovsky MJ (1965) A formaldehyde-glutaraldehyde fixative of high osmolality for use in electron microscopy. J Cell Biol 27 (2):137A-138A

Kim I, Zambryski PC (2005) Cell-to-cell communication via plasmodesmata during Arabidopsis embryogenesis. Curr Opin Plant Biol 8 (6):593-599. doi:https://doi.org/10.1016/j.pbi.2005.09.013

Knox JP, Linstead PJ, King J, Cooper C, Roberts K (1990) Pectin esterification is spatially regulated both within cell walls and between developing tissues of root apices. Planta 181 (4):512-521. doi:10.1007/bfoo193004

Knox JP, Linstead PJ, Peart J, Cooper C, Roberts K (1991) Developmentally regulated epitopes of cell surface arabinogalactan proteins and their relation to root tissue pattern formation. Plant $\mathrm{J} 1$ (3):317-326

Lamport DT, Varnai P (2013) Periplasmic arabinogalactan glycoproteins act as a calcium capacitor that regulates plant growth and development. New Phytol 197 (1):58-64. doi:10.1111/nph.12005 
Li H, Soriano M, Cordewener J, Muiño JM, Riksen T, Fukuoka H, Angenent GC, Boutilier K (2014) The histone deacetylase inhibitor Trichostatin A promotes totipotency in the male gametophyte. Plant Cell 26 (1):195209. doi:10.1105/tpc.113.116491

Li YQ, Chen F, Linskens HF, Cresti M (1994) Distribution of unesterified and esterified pectins in cell walls of pollen tubes of flowering plants. Sex Plant Reprod 7 (3):145-152. doi:10.1007/bfoo228487

Maheswaran G, Williams EG (1985) Origin and development of somatic embryoids formed directly on immature embryos of Trifolium repens in vitro. Ann Bot 56:619-630

Makowska K, Kałużniak M, Oleszczuk S, Zimny J, Czaplicki A, Konieczny R (2017) Arabinogalactan proteins improve plant regeneration in barley (Hordeum vulgare L.) anther culture. Plant Cell Tissue Organ Cult 131 (2):247-257. doi:10.1007/s11240-017-1280-x

Musielak TJ, Schenkel L, Kolb M, Henschen A, Bayer M (2015) A simple and versatile cell wall staining protocol to study plant reproduction. Plant Reprod 28 (3-4):161-169. doi:10.1007/s00497-015-0267-1

Palin R, Geitmann A (2012) The role of pectin in plant morphogenesis. Biosystems 109 doi:https://doi.org/10.1016/j.biosystems.2012.04.006

(3):397-402.

Parra-Vega V, Corral-Martínez P, Rivas-Sendra A, Seguí-Simarro JM (2015) Induction of embryogenesis in Brassica napus microspores produces a callosic subintinal layer and abnormal cell walls with altered levels of callose and cellulose. Front Plant Sci 6:1018. doi:10.3389/fpls.2015.01018

Pedroso MC, Pais MS (1992) A scanning electron-microscopy and X-raymicroanalysis study during induction of morphogenesis in Camellia japonica L. Plant Sci 87 (1):99-108. doi:10.1016/0168-9452(92)90197-t

Pereira AM, Masiero S, Nobre MS, Costa ML, Solís M-T, Testillano PS, Sprunck S, Coimbra S (2014) Differential expression patterns of arabinogalactan proteins in Arabidopsis thaliana reproductive tissues. J Exp Bot 65 (18):5459-5471. doi:10.1093/jxb/eru30o

Pereira AM, Pereira LG, Coimbra S (2015) Arabinogalactan proteins: rising attention from plant biologists. Plant Reprod 28 (1):1-15. doi:10.1007/s00497-015-0254-6

Rivas-Sendra A, Calabuig-Serna A, Seguí-Simarro JM (2017) Dynamics of Calcium during In vitro Microspore Embryogenesis and In vivo Microspore Development in Brassica napus and Solanum melongena. Front Plant Sci 8:1177. doi:10.3389/fpls.2017.01177 
Rivas-Sendra A, Corral-Martínez P, Porcel R, Camacho-Fernández C, CalabuigSerna A, Seguí-Simarro JM (2019) Embryogenic competence of microspores is associated with their ability to form a callosic, osmoprotective subintinal layer. J Exp Bot 70 (4):1267-1281. doi:10.1093/jxb/ery 458

Samuels AL, Giddings TH, Jr., Staehelin LA (1995) Cytokinesis in tobacco BY-2 and root tip cells: a new model of cell plate formation in higher plants. $J$ Cell Biol 130 (6):1345-1357

Satpute G, Long H, Seguí-Simarro JM, Risueño MC, Testillano PS (2005) Cell architecture during gametophytic and embryogenic microspore development in Brassica napus. Acta Physiol Plant 27 (4B):665-674

Schindelin J, Arganda-Carreras I, Frise E, Kaynig V, Longair M, Pietzsch T, Preibisch S, Rueden C, Saalfeld S, Schmid B, Tinevez JY, White DJ, Hartenstein V, Eliceiri K, Tomancak P, Cardona A (2012) Fiji: an opensource platform for biological-image analysis. Nature methods 9 (7):676-682. doi:10.1038/nmeth.2019

Seguí-Simarro JM, Austin JR, White EA, Staehelin LA (2004) Electron tomographic analysis of somatic cell plate formation in meristematic cells of arabidopsis preserved by high-pressure freezing. Plant Cell 16 (4):836-856

Seguí-Simarro JM, Nuez F (2007) Embryogenesis induction, callogenesis, and plant regeneration by in vitro culture of tomato isolated microspores and whole anthers. J Exp Bot 58 (5):1119-1132

Seguí-Simarro JM, Nuez F (2008) How microspores transform into haploid embryos: changes associated with embryogenesis induction and microspore-derived embryogenesis. Physiol Plant 134:1-12. doi:10.1111/j.1399-3054.2008.01113.x

Seguí-Simarro JM, Otegui MS, Austin JR, Staehelin LA (2008) Plant cytokinesis - Insights gained from electron tomography studies. In: Verma DPS, Hong Z (eds) Cell Division Control in Plants, vol 9. Plant Cell Monographs. Springer, Berlin/Heidelberg, pp 251-287. doi:10.1007/7089_2007_131

Seifert GJ, Roberts K (2007) The biology of arabinogalactan proteins. Ann Rev Plant Biol 58:137-161. doi:10.1146/annurev.arplant.58.032806.103801

Simmonds DH, Keller WA (1999) Significance of preprophase bands of microtubules in the induction of microspore embryogenesis of Brassica napus. Planta 208 (3):383-391

Solis MT, Berenguer E, Risueño MC, Testillano PS (2016) BnPME is progressively induced after microspore reprogramming to embryogenesis, correlating with pectin de-esterification and cell 
differentiation in Brassica napus. BMC Plant Biol 16 (1):176. doi:10.1186/s12870-016-0863-8

Soriano M, Li H, Boutilier K (2013) Microspore embryogenesis: establishment of embryo identity and pattern in culture. Plant Reprod 26 (3):181-196. doi:10.1007/s00497-013-0226-7

Soriano M, Li H, Jacquard C, Angenent GC, Krochko J, Offringa R, Boutilier K (2014) Plasticity in Cell Division Patterns and Auxin Transport Dependency during in vitro Embryogenesis in Brassica napus. Plant Cell 26 (6):2568-2581. doi:10.1105/tpc.114.126300

Supena EDJ, Winarto B, Riksen T, Dubas E, van Lammeren A, Offringa R, Boutilier K, Custers J (2008) Regeneration of zygotic-like microsporederived embryos suggests an important role for the suspensor in early embryo patterning. J Exp Bot 59:803-814

Tang X, Liu Y, He Y, Ma L, Sun M-x (2013) Exine dehiscing induces rape microspore polarity, which results in different daughter cell fate and fixes the apical-basal axis of the embryo. J Exp Bot. doi:10.1093/jxb/ers327

Tang XC, He YQ, Wang Y, Sun MX (2006) The role of arabinogalactan proteins binding to Yariv reagents in the initiation, cell developmental fate, and maintenance of microspore embryogenesis in Brassica napus L. cv. Topas. J Exp Bot 57 (11):2639-2650

Telmer CA, Newcomb W, Simmonds DH (1995) Cellular changes during heat shock induction and embryo development of cultured microspores of Brassica napus cv. Topas. Protoplasma 185:106-112

Willats WGT, Limberg G, Buchholt HC, van Alebeek G-J, Benen J, Christensen TMIE, Visser J, Voragen A, Mikkelsen JD, Knox JP (2000) Analysis of pectic epitopes recognised by hybridoma and phage display monoclonal antibodies using defined oligosaccharides, polysaccharides, and enzymatic degradation. Carbohydrate Research 327 (3):309-320. doi:10.1016/Sooo8-6215(00)00039-2

Williams MA (1977) Quantitative methods in biology (Practical methods in electron microscopy, vol 6, part 2), vol 6. Practical methods in electron microscopy. North Holland/American Elsevier, Amsterdam, The Netherlands

You XL, Yi JS, Choi YE (2006) Cellular change and callose accumulation in zygotic embryos of Eleutherococcus senticosus caused by plasmolyzing pretreatment result in high frequency of single-cell-derived somatic embryogenesis. Protoplasma 227 (2-4):105-112. doi:10.1007/s00709006-0149-3 
Zhang C, Guinel FC, Moffatt BA (2002) A comparative ultrastructural study of pollen development in Arabidopsis thatiana ecotype Columbia and male-sterile mutant apt1-3. Protoplasma 219 (1-2):59-71 


\section{Chapter 6}

\section{TSA influences cell wall composition and structure in embryogenic microspores of Brassica napus}

Carolina Camacho-Fernández¹, Kim Boutilier², Jose M. Seguí-Simarro ${ }^{1, *}$, and Patricia Corral-Martínez ${ }^{1}$

${ }^{1}$ Cell Biology Group, COMAV, Universitat Politècnica de València, Ciudad Politécnica de la Innovación (CPI), Edificio 8E - Acceso I, c/ Ingeniero Fausto Elio, s/n, 46011 Valencia. Spain.

2 Plant Development Systems, Wageningen University and Research, P.O. Box 16, 6700 AA Wageningen, The Netherlands.

* Corresponding author. e-mail: seguisim@btc.upv.es Tel/Fax: +34963879047

Keywords: trichostatin A, androgenesis, arabinogalactan proteins, callose, cell wall, cellulose, microspore embryogenesis, pectin, subintinal layer. 


\section{Abstract}

Microspore embryogenesis is an in vitro process that can be induced in many species, but its dependence on the genotype makes difficult the optimization of protocols. In the present study, we applied Trichostatin A (TSA) to microspore cultures of the low responsive DH12075 line and the highly responsive $\mathrm{DH} 4079$ line, both of Brassica napus. We studied and compared the cell wall structure and composition in the different microspore-derived structures (MDE) from both lines. The DH4079 line was negatively affected by TSA, obtaining very few microspore-derived structures. TSA promoted a loss of cell adhesion in microspore-derived structures. The effect of different treatments with TSA in the width of the outer wall and the subintinal layer of embryogenic structures differed in genotypes with different embryogenic competence. In general, TSA treatments did not affect the percentage of the cell wall occupied by the subintinal layer in DH4079, while in DH12O75 0.5 $\mu \mathrm{M}$ TSA led to a higher percentage of the subintinal layer than in structures treated with 0.05 $\mu \mathrm{M}$ TSA, reaching levels similar to $\mathrm{DH}_{4079}$ in control conditions. TSA did not increase callose deposition and TSA-related changes in callose and cellulose deposition had no remarkable impact in cell walls. TSA promoted a generalized decrease of JIM13 epitopes and increased the presence of low-methyl esterified pectin only in the outer walls of compact structures. The levels of highly methyl-esterified pectin were not affected by TSA except in cell walls union areas where they dramatically decreased. TSA promoted the rigidity of outer cell walls by modifying their pectin composition. In summary, TSA promoted the formation of cell walls whose composition is typical of barely embryogenic structures. Notwithstanding this, it may be useful for increasing induction in some low responsive genotypes as DH12075. 


\section{Introduction}

Plant breeding is nowadays focusing on producing hybrids. For the production of a hybrid variety, pure lines with high homozygosity level are needed to obtain a uniform offspring. With traditional methods, this high homozygosity can be reached via selfing for several generations. However, androgenesis has been used during years to obtain doubled haploids, i.e. 100\% homozygous plants (Seguí-Simarro 2010; Datta 2005). During androgenesis, microspores or pollen precursors are reprogrammed to become an embryo with only the paternal genome, which is eventually duplicated either naturally or applying chemical treatments (Soriano et al. 2007). The process of how a vacuolated microspore or a young bicellular pollen, which come from a very determining developing pathway (gamethophytic), become an individual plant following a new pathway (sporophytic) (Seguí-Simarro and Nuez 2008), is the perfect example of plant cell totipotency. Nevertheless, it exist a genetic basis for the capability of responding to the environmental conditions that switch their development (Seguí-Simarro and Nuez 2008). Brassica napus has been described many times as a model species for androgenesis (Custers et al. 2001; Seguí-Simarro 2016), either via anther or microspore culture, but even within the same species some genotypes show high or low response to the same protocols (Beckert 1998). As examples, DH4079 (DH line derived from cv. Topas, also of $B$. napus) is considered as a high responsive genotype while DH12075 (DH line derived from cv. Westar x Cresor of B. napus) shows poor response to androgenic induction using standard protocols (Malik et al. 2008; Li et al. 2014). Therefore, understanding the origins of differences in response between genotypes could be a great help to improve protocols for doubled haploid production in order to be applicable to a wider spectrum of genotypes.

Usually, microspore culture gives rise to a heterogeneous population of different types of structures, coming from the same types of cells but with a different developmental fate. Some of them arrest their development and die, some others become pollen until a further stage and some start dividing sporophytically (Corral-Martínez et al. 2013; Li et al. 2014). Previously, a deeper analysis of the sporophytically dividing 
population obtained in $\mathrm{DH} 12075$ microspore culture has shown that several types of structures can become an embryo (Corral-Martínez et al. 2020). Four types of microspore-derived structures were described as embryogenic: (1) exine enclosed (EE), structures that at five-day stage are completely compact and covered by exine, mostly contributing to mature embryo development; (2) suspensor-bearing embryos (LBS/SUS), that together with EE structures are considered highly embryogenic; (3) compact callus (CC), structures whose cells have thick cell walls and poor cell adhesion in exine breakage points; and (4) loose calli (LC), similar to CC but with no exine attached and poorly connected cells, which together with $\mathrm{CC}$ are considered as barely embryogenic structures. Later on, equivalent types of structures were confirmed to be present also in $\mathrm{DH}_{4079}$ microspore cultures (Chapter 5). Using Time Lapse Imaging, Corral-Martínez et al. 2020 demonstrated that a loss of cell adhesion in compact structures results in a development as loose calli. Therefore, this loss of cell adhesion is closely related to their embryogenic development and fate. These studies highlighted the importance of breakage exine point as determinant for development as well as compactness of cells within the structure. In fact, each type of structure develops a different cell wall composition and structure, which determines its cell adhesion properties (Chapter 5), among other aspects with a direct impact in the development fate of the structure.

Cell wall characteristics have shown to be related to the embryogenic process. Some of the main components of a plant cell wall are: pectin, polymers of galacturonic acid that are fundamental for regulation of the stiffness of the cell wall and responsible of cell-to-cell adhesion (Palin and Geitmann 2012; Bou Daher and Braybrook 2015); other structural polysaccharides as hemicellulose and cellulose (Scheller and Ulvskov 2010; Chen et al. 2018); and arabinogalactan proteins (AGPs), cell surface glycoproteins involved in numerous processes of plant growth and development (Gaspar et al. 2001; Pereira et al. 2015). However, embryogenic microspores have shown special characteristics of their cell walls (Parra-Vega et al. 2015). Subintinal layer (SL), a callose-rich layer underneath intine described to appear in embryogenic microspores (Parra-Vega et al. 2015), is a key component of cell wall in microspore derived structures because of its role in regulating important factors, as inner osmolality (Rivas-Sendra et al. 2019), compromising success of embryogenic development. Subintinal layer has been studied in several 
genotypes and differences between them were found in relation to the width and callose-enrichment, which are related to the potential to succeed in androgenesis (Rivas-Sendra et al. 2019). Apart from the unusual accumulation of this polysaccharide -callose is only present during cell division and in plasmodesmata of mature walls (Brown and Lemmon 2009)-, other components of the cell wall, like AGPs and pectin, have been described to play a role in microspore embryogenesis (Corral-Martínez et al. 2019).

Several studies have shown the positive effect of certain compounds when added to culture media in microspore culture (Shariatpanahi et al. 2006). Among them, Trichostatin A (TSA) showed to increase embryo yield in $\mathrm{DH} 12 \mathrm{O} 75$ to values comparable to $\mathrm{DH} 4079$ (Li et al. 2014). TSA addition to rapeseed microspore cultures (DH12075) increased the proportion of cells that change their developmental fate from pollen to embryogenesis (Li et al. 2014). TSA specifically inhibits histone deacetylases (HDACs), involved in the regulation of gene expression by chromatin remodeling. In particular, HDACs act changing the level of compaction of DNA in nucleosomes, which ultimately affect cell division and differentiation (Bie et al. 2020). Inhibition of HDAC with TSA induced a massive embryogenic proliferation in rapeseed microspores, even in absence of heat shock, suggesting that HDAC mediated pathways could play a role in stress-mediated initiation of haploid embryogenesis (Li et al. 2014). In addition, TSA has shown to affect the percentage of different types of structures that are obtained in microspore culture (Corral-Martínez et al. 2020), which can finally influence embryo yield. However, there is still much to know about the mechanisms through which TSA affects microspore embryogenesis. For example, the effect of TSA in the composition and structure of the cell wall has not been studied yet.

Due to the importance of cell wall dynamics in successful microspore embryogenesis, in this work we focus on the study of the effect of TSA in the cell wall characteristics of the different microsporederived embryogenic structures, to determine whether distinct TSA effect in different genotypes is related to a different cell wall composition and/or structure. Using electron and confocal microscopy, together with immunolocalization of the different components of the cell wall, we study here how TSA would be affecting the observed dedifferentiation 
apparently related to cell adhesion and how other cell wall properties could be influencing this behavior.

\section{Materials and methods}

\section{Plant materials}

Plants of DH4O79 and DH12075, DH Brassica napus lines with high and low androgenic response, respectively, were used as donor plants for microspore culture. Plants were grown in $20 \mathrm{~cm}$ pots at $60 \%$ relative humidity and a $16 \mathrm{~h} / 8 \mathrm{~h}$ photoperiod at $20^{\circ} \mathrm{C}$ until flowering and then transferred to $15^{\circ} \mathrm{C}$ under the same relative humidity and photoperiod.

\section{Microspore culture}

Isolation and establishment of microspore culture was performed as described in Chapter 5. Flower buds containing mostly late uninucleated microspores and early binucleated pollen were collected and were surface-sterilized with $4 \mathrm{~g} / \mathrm{l}$ sodium hypochlorite followed with three washes with distilled water. Microspores were isolated from them by crashing flower buds with a sterile syringe piston in culture medium and filtering through a $30 \mu \mathrm{m}$ nylon mesh (Millipore). Microspore density was adjusted to 40,000 microspores/ml using a hemacytometer (Camacho-Fernández et al. 2018). In addition to heat shock (1 day at $32^{\circ} \mathrm{C}$ ), Trichostatin A (TSA) was added to B. napus microspore culture (both genotypes) at the following concentrations: $0.05 \mu \mathrm{M}$ and $0.5 \mu \mathrm{M}$. After the induction period, medium was refreshed to remove TSA and plates were kept at $25^{\circ} \mathrm{C}$ in darkness. Control cultures followed the same procedure without the addition of TSA. 


\section{Confocal laser scanning microscopy}

Samples of microspore cultures from both genotypes and different treatments were collected by centrifugation at several time-points and fixed overnight at $4^{\circ} \mathrm{C}$ with $4 \%$ paraformaldehyde in PBS ( $\mathrm{pH} 7.4$ ). Afterwards, samples were washed three times with PBS and then stored at $4^{\circ} \mathrm{C}$ in $0.1 \%$ paraformaldehyde in PBS until use. Staining of callose and cellulose in cultured microspore samples was carried out as described in Parra-Vega et al. 2015 and Rivas-Sendra et al. 2019. For callose detection, samples were first incubated during $10 \mathrm{~min}$ with propidium iodide (PI; Fluka) at $10 \mu \mathrm{g} / \mathrm{ml}$ and later during 20 min with $0,1 \%$ anilin blue (AB; Fluka) in PBS. For cellulose detection, samples were incubated during 30 min with $0.01 \%$ Direct red (Sigma) in $0.1 \mathrm{M}$ PBS and later mounted with a 1:1 mix of Mowiol (17\% Mowiol 4-88 (Sigma-Aldrich) and 33\% glycerol (v/v) in PBS) and $2.5 \mu \mathrm{g} / \mathrm{ml} \mathrm{4} 4^{\prime}, 6-$ diamidine-2'-phenylindole dihydrochloride (DAPI; Sigma-Aldrich) prepared as described in Custers 2003. Finally, samples were incubated for at least $15 \mathrm{~min}$ and washed three times with PBS, prior to observation. All the samples were incubated in darkness and observed with a Leica CTR 5500 and a Zeiss LSM 780 confocal laser scanning microscope. Series of images were processed with Leica Application Suite Advanced Fluorescence (LAS AF) and FIJI software (Schindelin et al. 2012).

\section{Scanning electron microscopy}

Samples of five-day-old cultures treated with $0.05 \mu \mathrm{M}$ TSA were collected by centrifugation, fixed in Karnovsky solution and then washed three times with $0.025 \mathrm{M}$ cacodylate. Post-fixation in $1 \%$ osmium tetroxide solution for $60 \mathrm{~min}$ at room temperature followed by three washes in distilled $\mathrm{H}_{2} \mathrm{O}$ was performed the day before imaging. The samples were then dehydrated in series of increasing ethanol concentrations of (25\%, 50\%, 75\%, 90 and 100\%, 15 minutes each) and stored overnight in absolute ethanol. The next day, samples were incubated twice in $100 \%$ absolute ethanol for 60 min. Subsequently, critical point drying was performed according to Robards and Wilson 1993. Imaging was conducted using a Zeiss Ultra 55 electron microscope. 


\section{Light and transmission electron microscopy}

Samples of five-day-old cultured microspores (control and TSAtreated) of B. napus $\mathrm{DH}_{4079}$ and DH12075 were collected for light and transmission electron microscopy (TEM). Samples were fixed in Karnovsky fixative (Karnovsky 1965) and post-fixed with $2 \% \mathrm{OsO}_{4}$ in 0.05M cacodylate. $15 \%$ gelatin in cacodylate buffer was used to immobilize and concentrate microspores by resuspending them in liquid gelatin and centrifuging afterwards ( $1 \mathrm{~min}$ at $125 \mathrm{~g}$ ). Gelatin was solidified by letting sample tubes on ice. 1\% paraformaldehyde was added on top of the samples. Samples were kept overnight at $4^{\circ} \mathrm{C}$, cut in small pieces and kept in cacodylate buffer until use. Samples were dehydrated in progressive methanol series and embedded and polymerized in Embed 812 resin (Electron Microscopy Sciences). Three different blocks of each treatment and genotype were used to produce thin $(1 \mu \mathrm{m})$ and ultrathin $(80 \mathrm{~nm})$ sections with a Leica UC6 ultramicrotome for light microscopy and TEM observation, respectively. For TEM, sections were mounted on carbon and formvar-coated, 200mesh nickel grids (Electron Microscopy Sciences), stained with uranyl acetate in $70 \%$ methanol (6 min) and lead citrate (30 s). Images of all the cell types and structures of interest were taken with a Jeol JEM 1010 TEM. The progressive mean test (Williams 1977) was used according to Corral-Martínez et al. 2019 for defeminizing the minimum number of images for morphometric studies of the cell wall. Four different types of embryogenic structures with different cell fate were considered, according to Corral-Martínez et al. 2020. For each type of structure, width of intine and subintinal layer of the cell walls was measured using FIJI software (Schindelin et al. 2012). Significant statistical differences between samples, regarding measurements of cell wall and subintinal layer width, were determined using Kolmogorov-Smirnov test comparing data distribution.

\section{Immunogold labelling}

Different components of cell walls were detected as described in Corral-Martínez et al. (2016 and 2019) in samples collected from all genotypes and treatments. Four different antibodies were used in this 
experiment: JIM13, a rat IgM mAb recognizing the AGP2 epitope (Knox et al. 1991); JIM7, a rat IgA mAb crossreacting with highly methylesterified epitopes of the homogalacturonan domain of pectic polysaccharides (Knox et al. 1990; Willats et al. 2000) and JIM5, a rat IgG mAb crossreacting with low methyl-esterified epitopes of homogalacturonan (Knox et al. 1990; Willats et al. 2000). Sections were hydrated with PBS for 1 min and then incubated with a $0.2 \%$ BSA and $3 \%$ skimmed milk solution in PBS for 30 min to prevent non-specific binding. For the anti-callose antibody (Biosupplies Australia), sections were incubated with the primary antibody diluted 1:5000 in 1\% BSA in PBS for $1 \mathrm{~h}$ at $25^{\circ} \mathrm{C}$. For the rest of antibodies, sections were incubated with the primary antibody diluted 1:2 (JIM7 and JIM5, PlantProbes, Leeds, UK) or 1:5 (JIM13, PlantProbes, Leeds, UK) in 0.2\% BSA in PBS for $1 \mathrm{~h}$ at $25^{\circ} \mathrm{C}$. Sections were washed six times during 5 min with $0.2 \%$ BSA in PBS. $10 \mathrm{~nm}$ gold conjugated secondary antibodies (goat antimouse for anti-callose antibody and goat anti-rat for the rest, BBI solutions, UK) were diluted in a 1:25 ratio with $0.2 \%$ BSA in PBS (1\% BSA for the anti-callose antibody). Sections were incubated with the secondary antibodies during $45 \mathrm{~min}$ at $25^{\circ} \mathrm{C}$ and washed with PBS (5 times, 5 min each). Finally, they were post-fixed with $2 \%$ glutaraldehyde in PBS for 10 min and washed again with PBS and distilled water. Prior to observation, sections were counterstained with uranyl acetate in $70 \%$ methanol $(6 \mathrm{~min})$ and lead citrate (30 s). Controls followed the same procedure excluding primary antibodies to check for non-specific binding of the secondary antibody.

\section{Quantification of immmunogold labeling}

The procedure for the quantification of inmunogold labeling was as previously described in Corral-Martínez et al. (2016) and CorralMartínez et al. (2019). Micrographs of all the structures of interest were taken on each grid. The minimum number of micrographs was determined using the progressive mean test (Williams 1977), with a minimum confidence limit of $\alpha=0.05$. On average, around 15 to 20 micrographs per type of structure, treatment and genotype were studied for each antibody. For all the structures, the compartments analyzed were (1) the golgi stacks and cytoplasmic vesicles, (2) inner cell walls and (3) outer cell walls (the intine and the subintinal layer formed in 200 
microspore-derived structures), but excluding the outermost exine layer. Background signals were determined by quantifying particles over regions where the presence of the epitopes were not expected (the cytoplasm excluding Golgi stacks and vesicles, cytoplasmic organelles and nucleus). The labeling density of each compartment was calculated by hand by counting the number of particles and dividing it by the area where they were counted, expressed as particles $/ \mu \mathrm{m}^{2}$. The area in $\mu \mathrm{m}^{2}$ was measured using a square lattice composed of $11 \times 16$ squares of $15 \mathrm{x}$ $15 \mathrm{~mm}$ each.

Labeling density of each group of samples was expressed as the average labeling density of all micrographs \pm the standard error. Comparisons between groups of data from different samples were performed using the Kolmogorov-Smirnov test to evaluate goodness of fit between two data distributions. Histograms of same antibody in different subcellular compartment were built using the same Y-axis scale.

\section{Results}

\section{The highly responsive B. napus genotype DH4O79 was negatively affected by TSA}

When microspores from different B. napus lines were cultured with TSA, their androgenic response was remarkably different from that without TSA. DH12075 presents a very low response in standard conditions (Li et al. 2014). In fact, the very scarce response of DH12O75 made impossible for us to have enough samples to collect TEM data about cell walls in standard conditions (in control cultures without TSA). However, DH12075 is known to accelerate the growth of microsporederived structures and to increase notably the rate of MDE production with the use of TSA (Li et al. 2014). In turn, DH4079, a highly responsive line in standard conditions, was negatively affected by TSA treatments (Fig. 1). When applied during 24h, TSA treatment of $\mathrm{DH} 4079$ microspores completely prevented MDE proliferation both at 0.05 and $0.5 \mu \mathrm{M}$ (Fig. 1A). Shorter periods of time were used for the TSA 
treatment, but only when applied during $10 \mathrm{~min}$, TSA slightly increased the number of MDEs (Fig. 1B). These results evidence the remarkable differences between both genotypes in terms of the effect of TSA in the androgenic response.
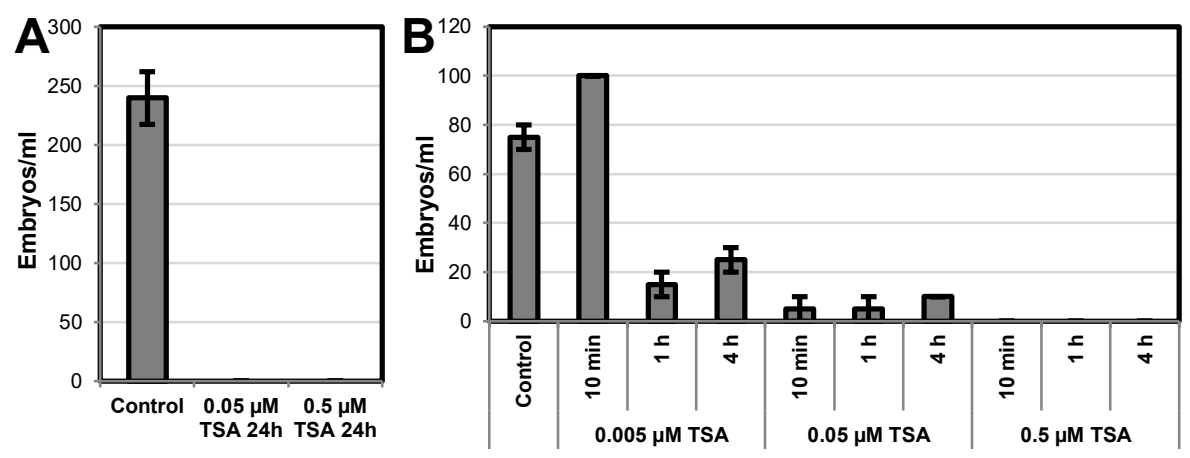

Figure 1: Effect of TSA in DH4079 microspore cultures. A. Number of embryos obtained after treatment with 0.05 and $0.5 \mu \mathrm{M}$ TSA for $24 \mathrm{~h}$. B. Number of embryos obtained after shorter treatments with TSA at lower concentrations. Error bars represent standard error.

\section{TSA affected cell adhesion in microspore-derived structures}

In DH4079 TSA-treated microspore cultures, we observed that microspore-derived structures appeared in general earlier than in cultures without TSA, indicative of an accelerated growth rate, as in DH12075. These structures presented different levels of cell adhesion. Figs. 2A-D illustrates this with different callus structures (CC and LC) showing decreasing levels of cell adhesion. Field Emission Scanning Electron Microscopy (FESEM) images (Figs. 2E-H) showed the detailed aspect of the exine and external cell wall in the different types of structures. In highly embryogenic EE structures (Fig. 2E), exine remained unbroken until the day 5 stage. In 5 day-old CC structures (Fig. 2 F-G), exine was already broken in some areas, and cells showed evidences of loss of intercellular adhesion. In LC structures (Fig. 2H) exine only covered some parts of the structures and loss of cell adhesion was high. We found that loose connections in peripheral regions were 202 
frequently accompanied by absence of exine in these areas (Fig. 2I). In almost detached adjacent cells, only a few connecting fibers were observed between them (Fig. 2J). Thus, there was a clear relationship between the different types of embryogenic structures found in $\mathrm{DH} 4079$ and adhesion properties of their cell walls, as also reported for DH12075 (Corral-Martínez et al. 2020).

In DH12075, it was also reported that the use of different concentrations of TSA had a marked effect in the percentages of each structure obtained microspore cultures (Corral-Martínez et al. 2020). Then, we wanted to know how TSA affects the percentages of each structure in the DH4079 line. We counted 100 structures of the same culture dish at each time point (day 5 and 8 after isolation) and TSA concentration ( $0,0.05$ and $0.5 \mu \mathrm{M})$, and represented the percentages of each structure type. As seen in Fig. 2K, in normal (control) conditions, there was a percentage of compact (EE and $\mathrm{CC}$ ) structures that transformed into loose (LC) structures during the transition from day 5 to day 8. Such percentage was slightly higher with the use of $0.05 \mu \mathrm{M}$ TSA, and dramatically higher with the use of $0.5 \mu \mathrm{M}$ TSA. Such increase in the percentage of loose structures at day 8 was accompanied by a dramatic decrease in the percentage of compact structures (principally EE). In other words, high TSA concentrations promoted the transformation of compact structures into loose, barely embryogenic structures, which were the vast majority (nearly 80\%) of the structures found in 8-day-old cultures. These results are consistent with the negative effect described above for TSA in the percentage of MDEs obtained in DH4079 and indicate an effect of TSA in the loss of cell adhesion that leads to the transformation of compact structures into loose structures. 

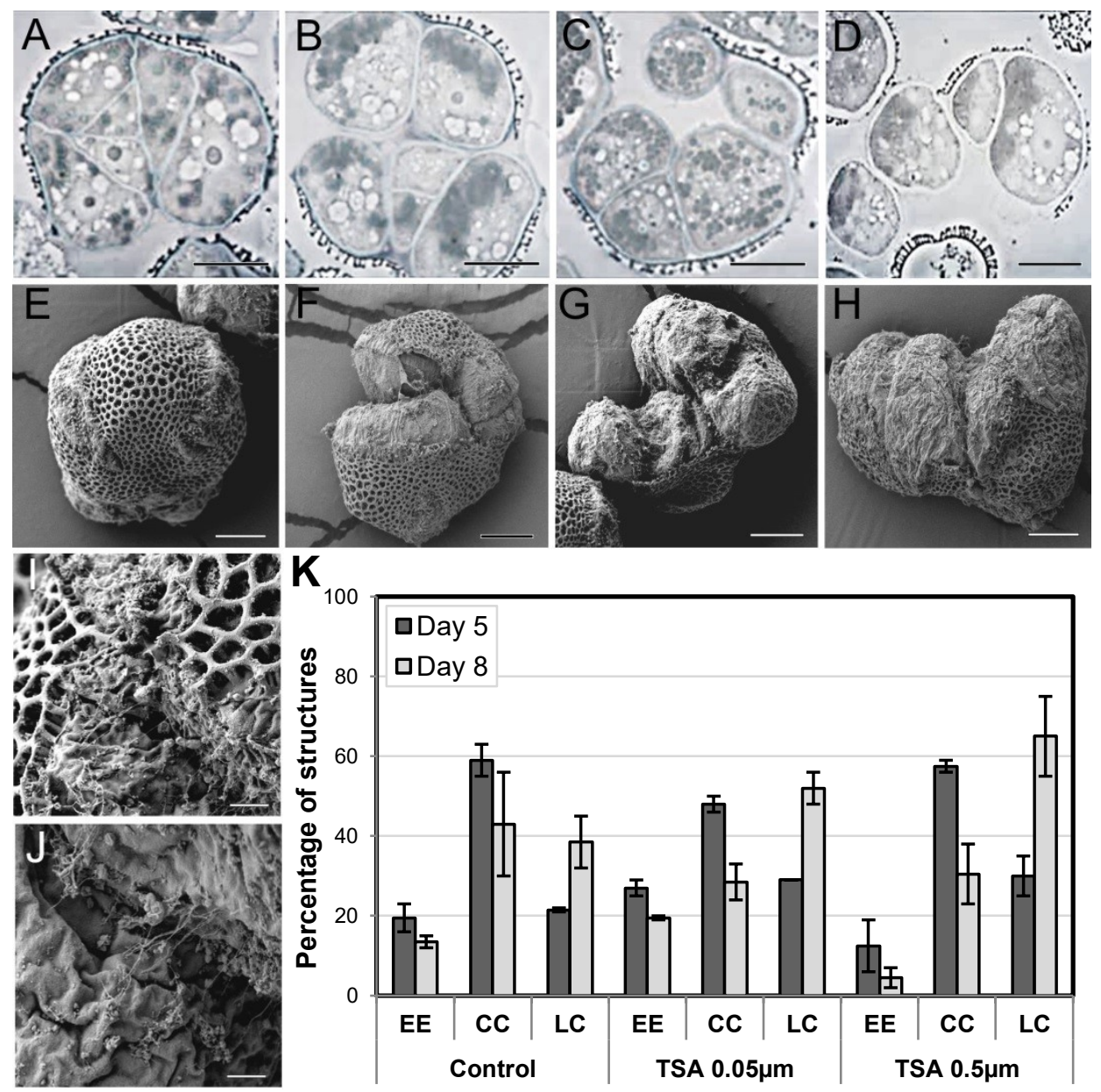

Figure 2: Loss of cell adhesion in B. napus (DH4079) microspore cultures. A-D: Light microscopy images in 5-day-old cultures in TSA-treated samples. Different types of callus-like structures with different degrees of loss of cell adhesion. E-J: FESEM images of embryogenic structures loosing cell adhesion. E: Compact embryogenic structure (EE) that breaks exine at one point. F: Compact callus type structure with clear separation between two of its cells. G: Compact callus structure with evident separation between several of its cells. H: Loose callus type structure where the cells are already only connected two by two. I-J: Detail of the area between two cells of a callus-like structure where the exine has ruptured. I: Image at the exine breaking point when the loss of adhesion begins. J: Image where there is no longer exine and a bigger separation between cells is observed and only a few fibers connect the cells. $\mathrm{K}$ : Percentages of the different embryogenic structures at different time points and with different TSA concentrations. EE: exine-enclosed, compact structure; CC: compact callus; LC: loose callus. Bars: A-H: $10 \mu \mathrm{m}$; I-J: $2 \mu \mathrm{m}$. 


\section{The effect of TSA in the width of the outer wall and} the subintinal layer of embryogenic structures differed in genotypes with different embryogenic competence

Once established the relevance of TSA in the maintenance of cell adhesion, we checked how TSA affects different structural and compositional features of outer cell walls. First, we focused on cell wall width, since it was previously shown that different embryogenic structures present different cell wall widths (Chapter 5), with compact structures having thinner cell walls than loose structures. We measured the outer wall width and the percentage occupied by the subintinal layer in both genotypes (Figs. 3A-E). These two cell wall layers can be distinguished by their difference in electron density and texture in TEM micrographs (Chapter 5, Parra-Vega et al. 2015). In DH4079, treatment with $0.05 \mu \mathrm{M}$ TSA had a clear effect in the width of outer cell walls, since it was reduced in LBS and CC, and increased in EE (Fig. 3A). With 0.5 $\mu \mathrm{M}$, only LC and LBS walls were affected, where an increased width in comparison to $0.05 \mu \mathrm{M}$ could be observed. By contrast, in DH12075 low TSA concentrations generated in all structures (Supplementary figure 1A) outer walls slightly thicker than their control DH4O79 counterparts, whereas the treatment with $0.5 \mu \mathrm{M}$ TSA tended was not significantly different from the $0.05 \mu \mathrm{M}$ treatment.

The percentage of cell wall occupied by subintinal layer (\%SL) was differently affected in structures of different genotypes. In DH4079, EE structures showed almost no differences at any TSA concentration, whereas in DH12075 0.5 $\mu \mathrm{M}$ TSA produced a significant increase in \%SL with respect to $0.05 \mu \mathrm{M}$ TSA (Fig. 3B). LBS structures showed no significant differences among conditions (Fig. $3 \mathrm{C}$ ). No differences among treatments were found in $\mathrm{DH} 4079$ CC structures, but in $\mathrm{DH} 120750.5$ $\mu \mathrm{M}$ TSA produced a significant increase in \%SL (Fig. 3D). In LC structures, TSA promoted a reduction in \%SL in a dose-dependent manner, and for both genotypes (Fig. $3 \mathrm{E}$ ). It is interesting to note that, except for LC structures, high doses of TSA in DH12075 approached the \%SL values to those observed in $\mathrm{DH} 4079$, the genotype where more embryogenic structures are found under control conditions (without TSA). Thus, we can conclude that in general, TSA did not affect \%SL in DH4079, while in DH12075 0.5 $\mu \mathrm{M}$ TSA led to an increase of \%SL to levels similar to control $\mathrm{DH} 4079$. The only exception to this trend was 
LC structures, where in both genotypes high concentration of TSA reduced \%SL in comparison with low concentration of TSA.
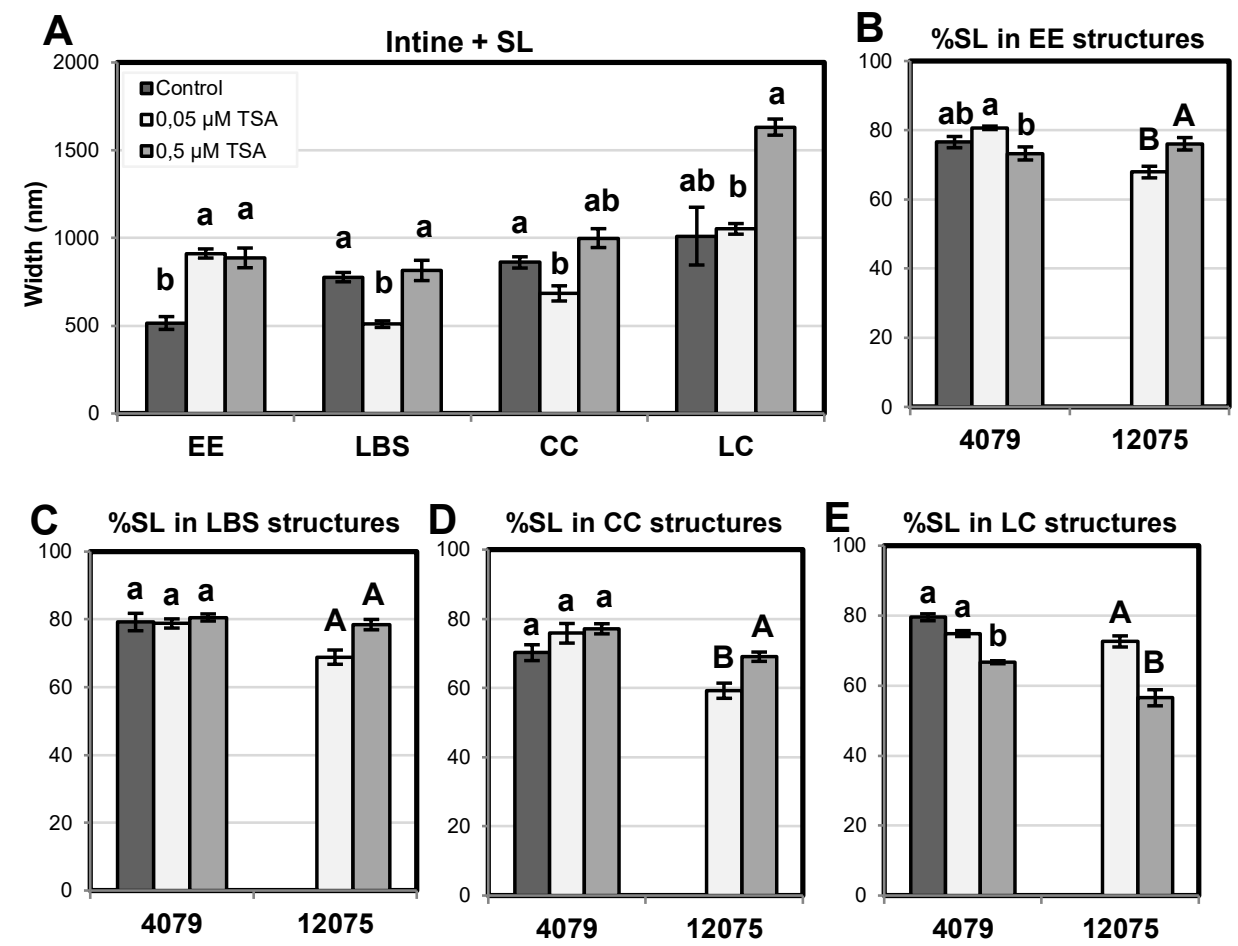

Figure 3: Effect of TSA in cell wall width and subintinal layer percentage. A: Outer cell wall width $(\mathrm{nm})$ in different treatments on $\mathrm{DH}_{4079}$ structures. B-E: Percentage of cell wall occupied by subintinal layer in $\mathrm{DH}_{4079}$ and DH12075 EE (B), LBS (C), CC (D) and LC (E) structures in different treatments. Different letters represent significant differences according to the KS test. Labelling density is expressed as number of particles per $\mu \mathrm{m}^{2}$. ct: cytoplasm, cw: cell wall, ex: exine. Bars: $1 \mu \mathrm{m}$.

\section{TSA did not increase callose deposition in any embryogenic structure}

We next analyzed the effect of TSA in callose and cellulose deposition. When DH12075 microspore-derived structures were stained with anilin blue (Fig. 4A-L), only 3-day-old highly embryogenic 
structures under control conditions presented callose in both inner and outer walls (Fig. 4A). Barely embryogenic structures showed low callose content at day 3 (Fig. 4B), and null at day 6 (Figs. 4C-D). In TSA-treated samples, the detected amount of callose was severely reduced in highly embryogenic structures (Figs. 4E, I, G, K) compared with controls. Almost no callose staining was observed in barely embryogenic structures at any TSA concentration (Figs. 4F, J, H, L). In $\mathrm{DH}_{4079}$ control cultures, the levels of callose in 3-day-old microspore-derived structures were high in both inner and outer walls, but decreased at day 6 (Supplementary figure 2), as previously described (Parra-Vega et al. 2015; Rivas-Sendra et al. 2019). As for DH12075, TSA at both concentrations reduced callose deposition (Supplementary figure 2).

As to cellulose, DH12075 control cultures at day 3 presented very faint levels of cellulose deposition in the inner and outer walls of highly embryogenic structures (Fig. 4M), and higher, clearly visible levels in barely embryogenic structures (Fig. $4 \mathrm{~N}$ ). At day 6, the levels of cellulose increased in all structures, but principally in highly embryogenic structures (Figs. 4O, P). Low (0.05 $\mu \mathrm{M}$ ) TSA concentration produced no clear changes in the levels of cellulose deposition, neither at day 3 nor at day 6 (Figs. 4Q-T), but high $(0.5 \mu \mathrm{M})$ TSA concentrations seemed to induce a reduction in cellulose deposition in EE structures, both at day 3 and 6 (Figs. 4U-X). In contrast, TSA induced a slight increase in cellulose deposition in DH4079 structures, both at days 3 and 6 (Supplementary figure 2). 


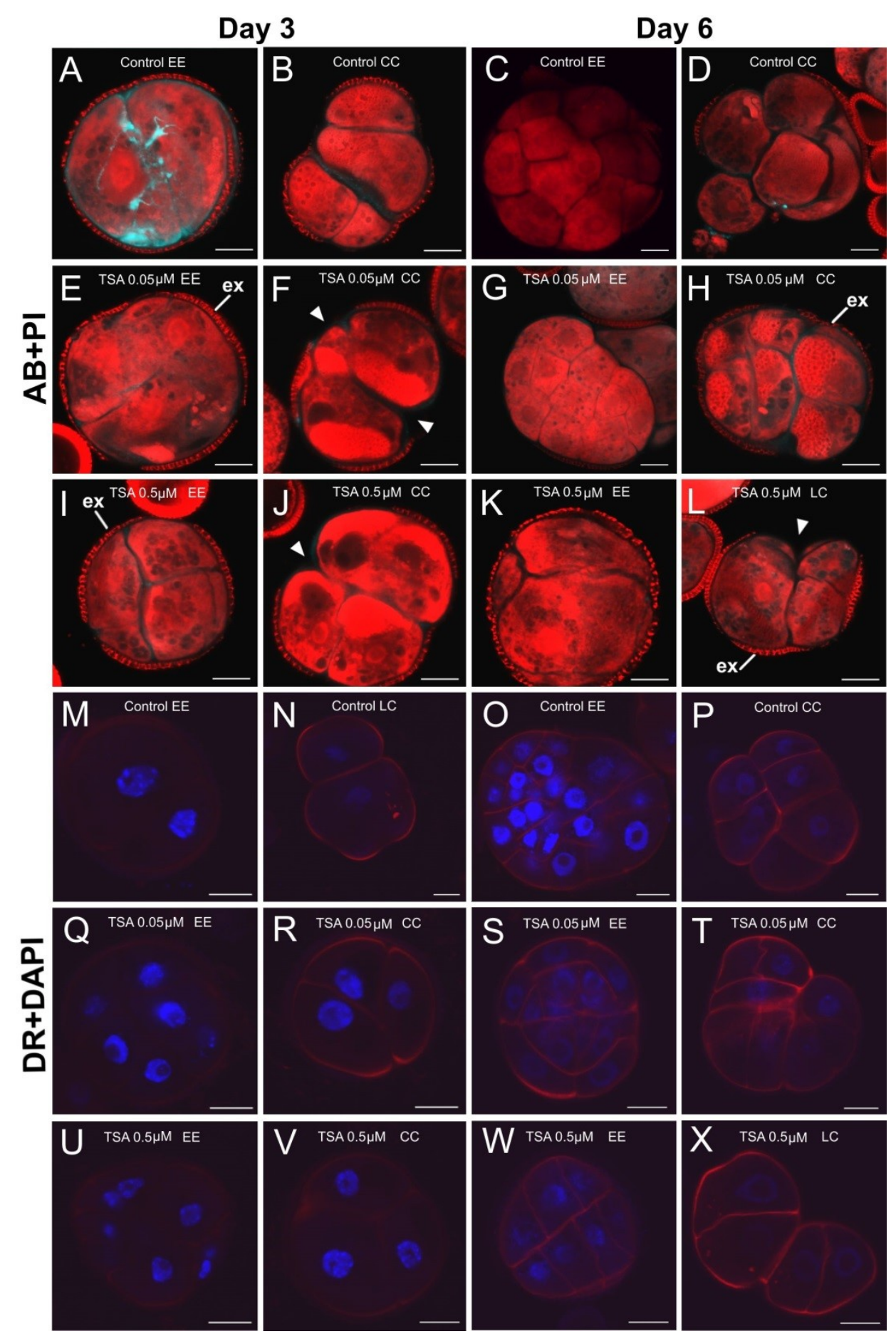


4 Figure 4: Detection of callose and cellulose in DH12075 microsporederived structures stained with aniline blue for callose (cyan in A-L) together with propidium iodide (red), and with Direct Red for cellulose (red in M-X) together with DAPI (blue). Images represent highly embryogenic (EE) and barely embryogenic, callus-like structures (CC, LC) at days 3 (A-B, E-F, I-J, M$\mathrm{N}, \mathrm{Q}-\mathrm{R}$ and $\mathrm{U}-\mathrm{V})$ and 6 (C-D, G-H, K-L, O-P and S-T) under different TSA treatments (control: A-D and M-P; $0.05 \mu \mathrm{M}$ TSA: E-H and Q-T; 0.5 $\mu \mathrm{M}$ TSA: I-L and $\mathrm{U}-\mathrm{X}$ ). Arrowheads indicate regions of exine (ex) rupture or absence. Bars: $20 \mu \mathrm{m}$

Anti-callose immunogold labeling confirmed the results of aniline blue staining and provided additional insights into the effects of TSA in callose deposition, due to its much higher sensitivity. TSA treatments significantly reduced callose levels in inner walls of compact structures (EE and CC), while loose structures (LBS and LC) were not affected (Figs. 5A-C). In general, the presence of irregular, fragmented or gapped inner walls, as those previously described for DH4079 (Parra-Vega et al. 2015), was reduced in TSA-treated structures. In outer cell walls, callose is only present in the subintinal layer (Parra-Vega et al. 2015), which implies that labeling density in external cell walls corresponds to the subintinal layer. In this layer, TSA did not have any effect at any concentration; with the only exception of $0.5 \mu \mathrm{M}$ TSA in EE structures (Figs. 5D-F). In DH12075 cultures treated with TSA, the patterns of anticallose immunogold labeling did not differ from TSA treated DH4079 structures, where no statistically differences between the two TSA treatments were found (Supplementary figure $1 \mathrm{~B}-\mathrm{C}$ ). Thus, TSA promoted in general a reduction of callose deposition in the inner cell walls of compact structures, having almost no effect in other structure types. As to outer walls, TSA showed a minor effect compared to inner walls. 


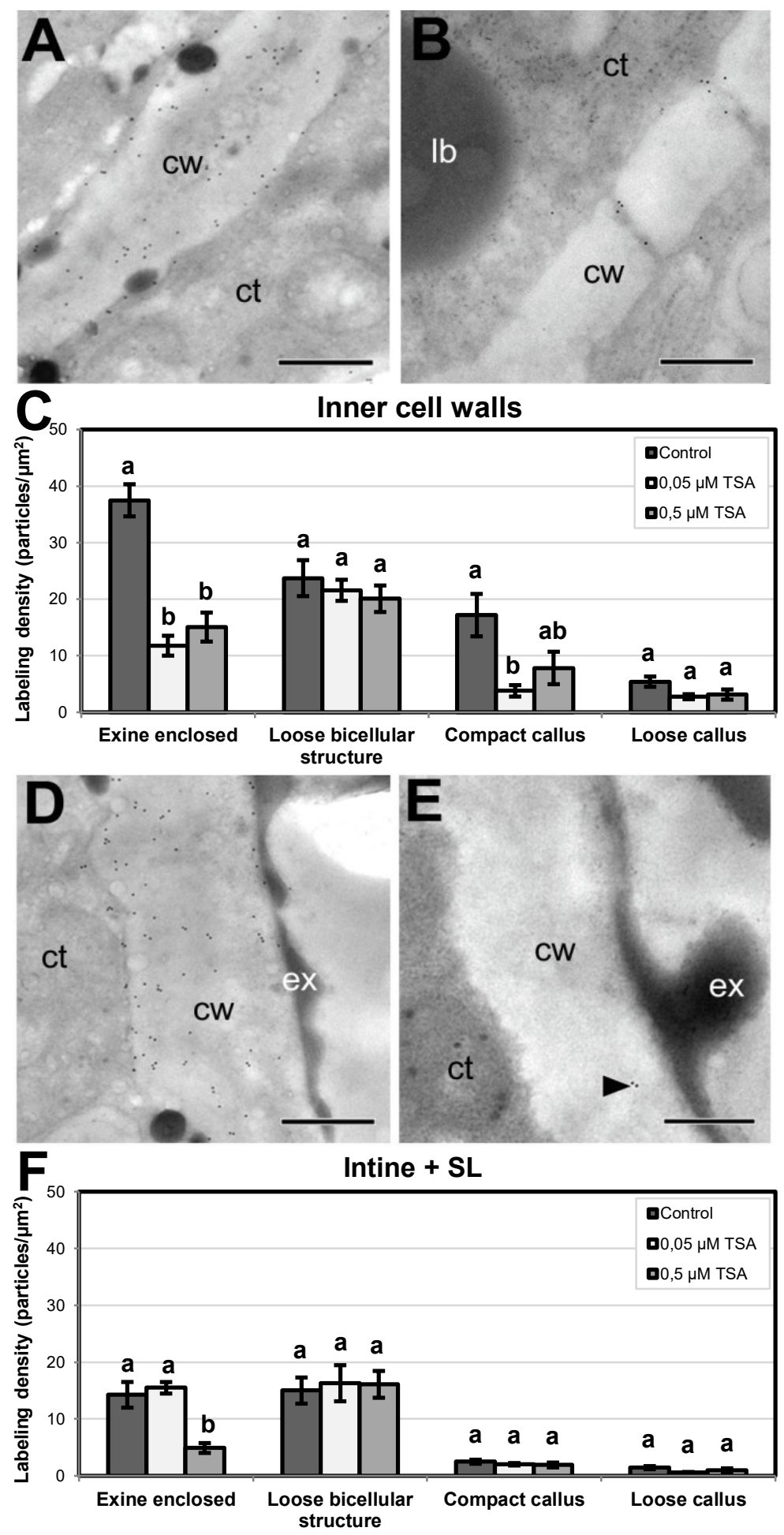




\section{Figure 5: Callose detection in DH4079 cell walls by immunogold} labeling and quantification in TEM images. A-B: Inner cell wall images

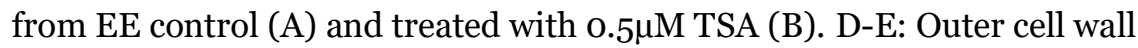

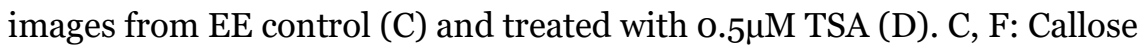
labelling density in inner (C) and outer (F) cell walls of DH4O79 structures under different TSA treatments. Different letters represent significant differences according to the KS test. Labelling density is expressed in number of particles per $\mu \mathrm{m}^{2}$. Arrowheads point to immune-gold particles, ct: cytoplasm, cw: cell wall, ex: exine, lb: lipid body. Bars: 50onm.

\section{TSA promoted a generalized decrease of JIM13 epitopes}

We next studied the effect of TSA in the AGP composition of cell walls. By immunogold labeling, we specifically detected JIM13crossreacting AGPs. Both density and distribution of immunogold labeling was remarkably similar in inner and outer walls, in both genotypes. For this reason we grouped the results all walls together in this case. In DH4O79 (Fig. 6A-C), TSA decreased JIM13 labeling density in all structures, although the decrease seemed more pronounced and dose-dependent in barely embryogenic structures. In general, both TSA treatments in DH12075 (Fig. 6D-E) presented similar JIM13 labeling densities and, for each treatment, densities were comparable to those observed in the $\mathrm{DH}_{4079}$ equivalent. TSA treatments promoted a generalized reduction in JIM13 labeling density in all cell walls, irrespective of the concentration. In TSA-treated structures, the levels of JIM13-detected AGPs were similar in both genotypes (Fig. 6G-H). For both genotypes, TSA-treated samples showed higher JIM13 labeling density in highly embryogenic structures (EE and LBS) than in barely embryogenic structures (CC and LC). The decrease, however, was proportional to the levels observed in controls. It thus appeared that in general, TSA promoted a decrease in JIM13 labeling density, similar for all structures and independent of the TSA concentration used. 

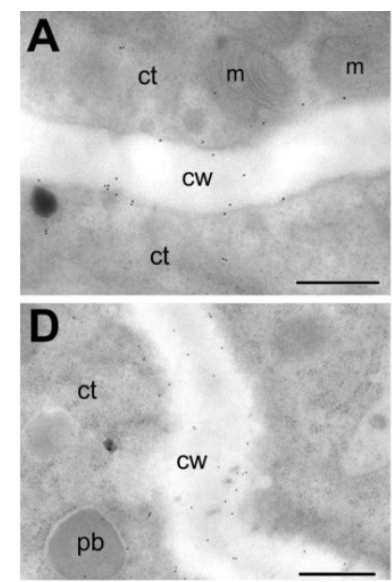

G
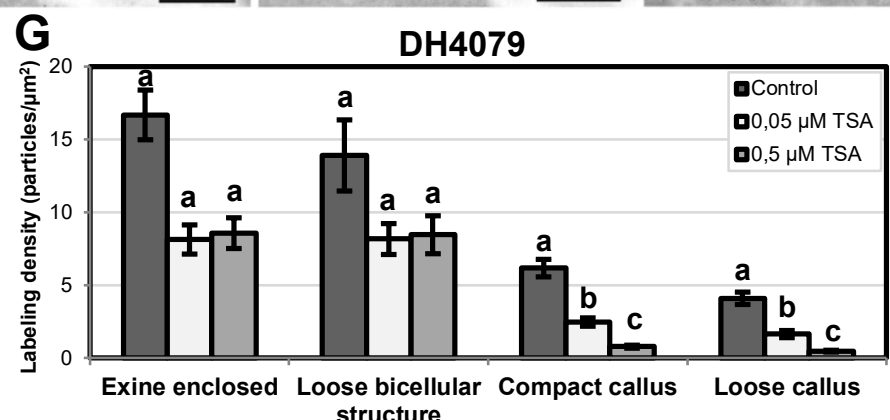

H
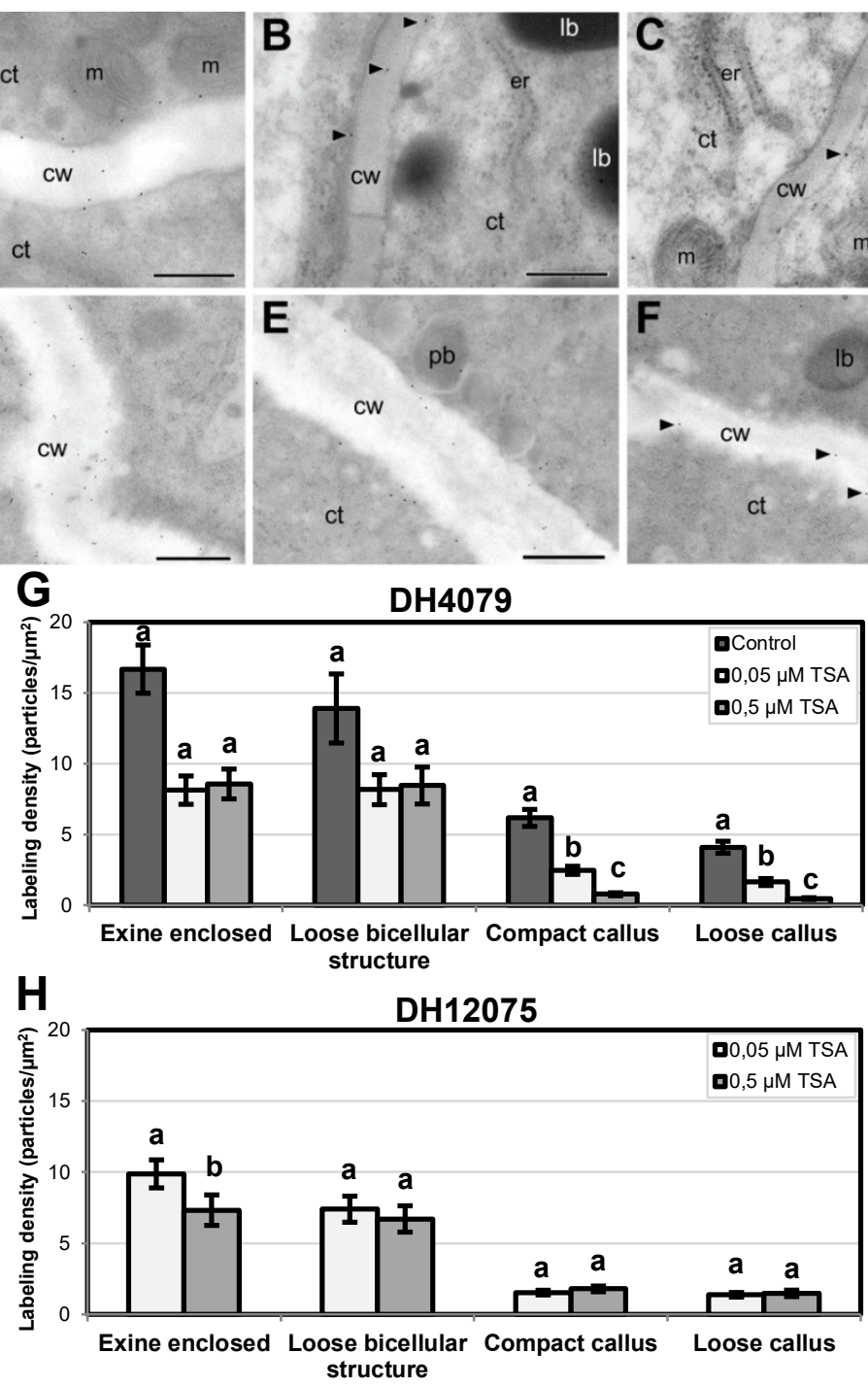

CW

ct

DH4079

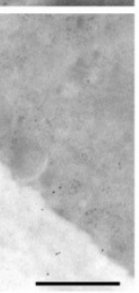

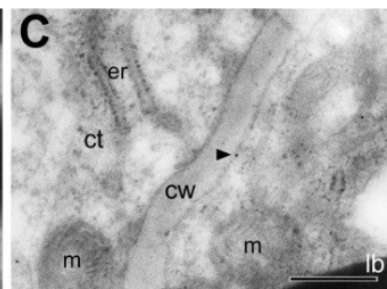

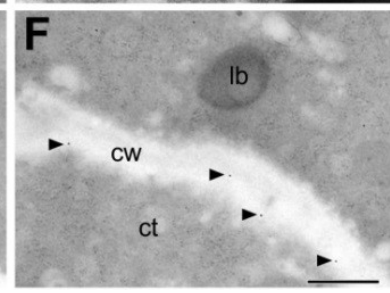




\section{TSA increased the presence of low-methyl esterified pectin only in the outer walls of compact structures}

We studied the effect of TSA in the presence and distribution of lowmethyl esterified pectin in the cell walls of the different 5 -day-old structures by JIM5 immunogold labeling. In $\mathrm{DH}_{4}$ 079, no statistically significant differences were observed among treatments in inner walls of the different structures (Fig. 7A). However, 0.05 $\mu \mathrm{M}$ TSA produced a significant increase in the abundance of JIM5 epitopes in the outer cell walls of compact structures (EE and CC) (Fig. 7B). In DH12075 JIM5 immunolabeling showed a similar pattern, with no significant differences between 0.05 and $0.5 \mu \mathrm{M}$ in inner walls and a higher labeling in outer walls of compact structures (EE and CC) with $0.05 \mu \mathrm{M}$ than with $0.5 \mu \mathrm{M}$ TSA (Supplementary figure 3). In conclusion, for DH4079 structures, TSA did not have an effect in the presence of lowmethyl esterified pectin epitopes in the inner walls of any structure, but increased it in the outer walls of compact structures. 


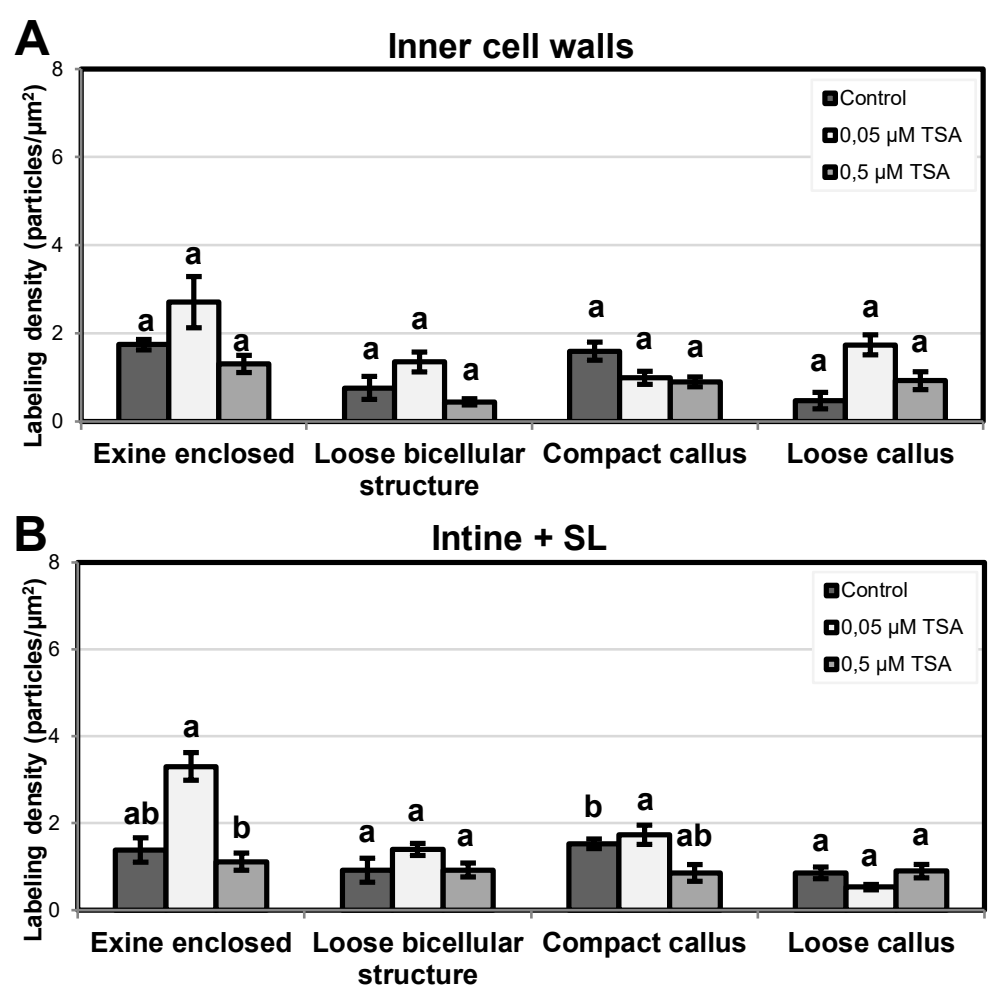

Figure 7: Quantification of JIM5-crossreacting low methyl-esterified pectin by immunogold labeling in TEM images of DH4079 structures under different TSA treatments. A: inner cell walls. B: outer cell walls (intine+SL). Different letters represent significant differences according to the KS test. Labelling density is expressed as number of particles per $\mu m^{2}$.

\section{Levels of highly methyl-esterified pectin are not affected by TSA except in cell walls union areas}

TSA did not affect JIM7 levels in DH4079 and DH12075 levels were comparable to the same treatment in DH4079. Labeling density of JIM7 in cytoplasm was low and no significant differences were found among TSA treatments (Supplementary figure 4 A-B), which suggests that TSA did not influence highly methyl-esterified pectin synthesis. In inner and outer cell walls, some differences were observed when analyzing labeling density, but in general TSA did not strongly affect levels of pectin. EE structures showed a decreasing trend of highly methyl-esterified pectin 
level in inner cell walls when the highest TSA concentration was applied (Fig. 8A), while LBS showed a decreasing trend labeling density in outer cell walls (Fig. 8B).
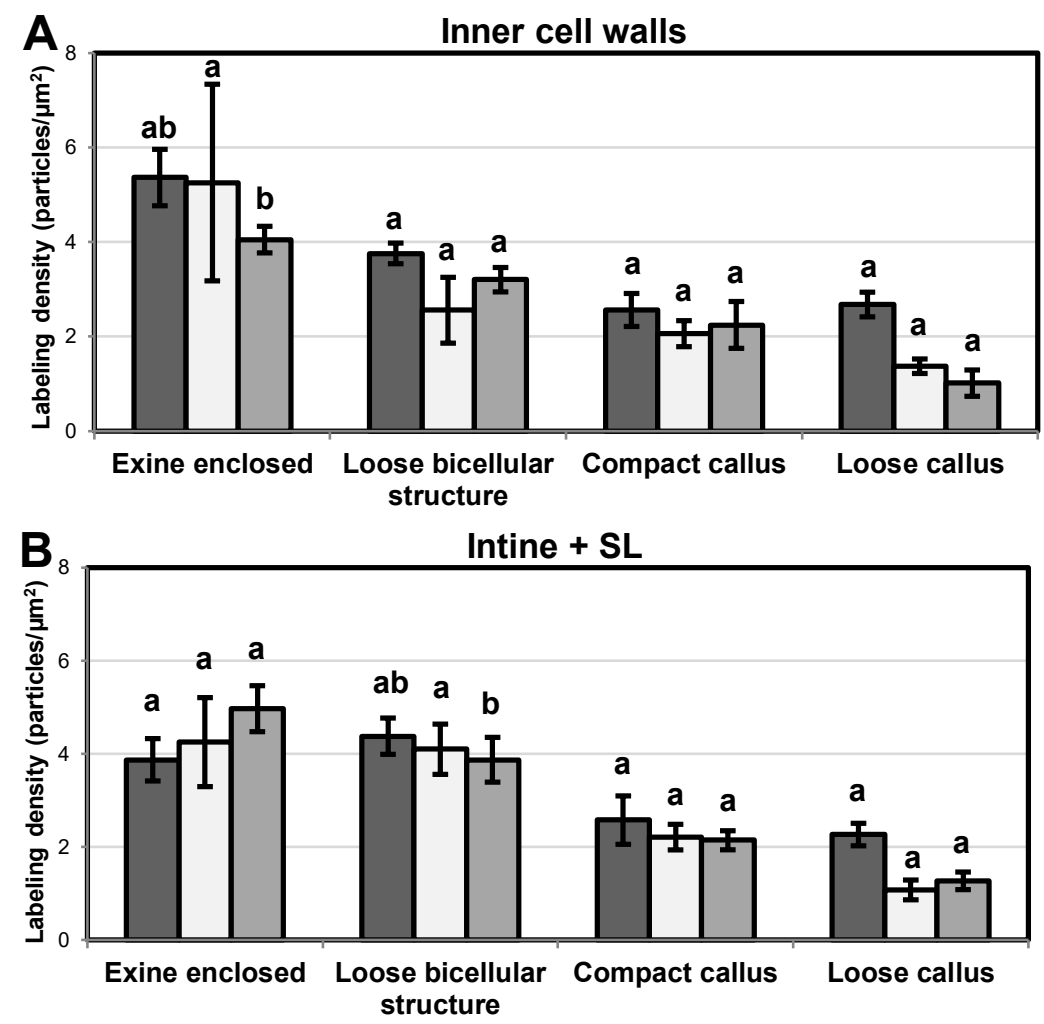

Figure 8: Quantification of JIM7-crossreacting highly methylesterified pectin by immunogold labeling in TEM images of DH4079 structures under different TSA treatments. A: Inner cell walls. B: Outer cell walls (intine+SL). Different letters represent significant differences according to the KS test. Labelling density is expressed as number of particles per $\mu \mathrm{m}^{2}$. 
Notwithstanding this, we observed that certain specific regions of the cell walls differed from the general trend above described. We previously observed dramatic JIM7 labeling differences in the outermost region of inner walls, where they connect with the subintinal layer and the intine (Chapter 5). We focused on these regions and found that their labeling densities were highly increased in comparison with the rest of the cell wall (compare Figs. 9A and B). A similar result was found in DH12075 structures (Supplementary figure 4C-D). DH4079 TSA-treated samples always presented lower levels of $\mathrm{JIM}_{7}$ labeling than control samples in the cytoplasm, the cell walls and also in the cell wall regions connecting with outer walls (Fig. 9C). The reduction of JIM7 labeling density induced by TSA was equivalent for all types of structure (e.g. CC, Fig. 9D-F). For each structure, TSA labeling was also different in regions covered by exine and devoid of exine (Fig. 9C), as showed in CC images (Fig. 9G-I). In summary, TSA had not a significant effect in the levels of highly methyl-esterified pectin in any cell wall, except for the cell wall regions connecting inner with outer walls, where it dramatically decreased. 

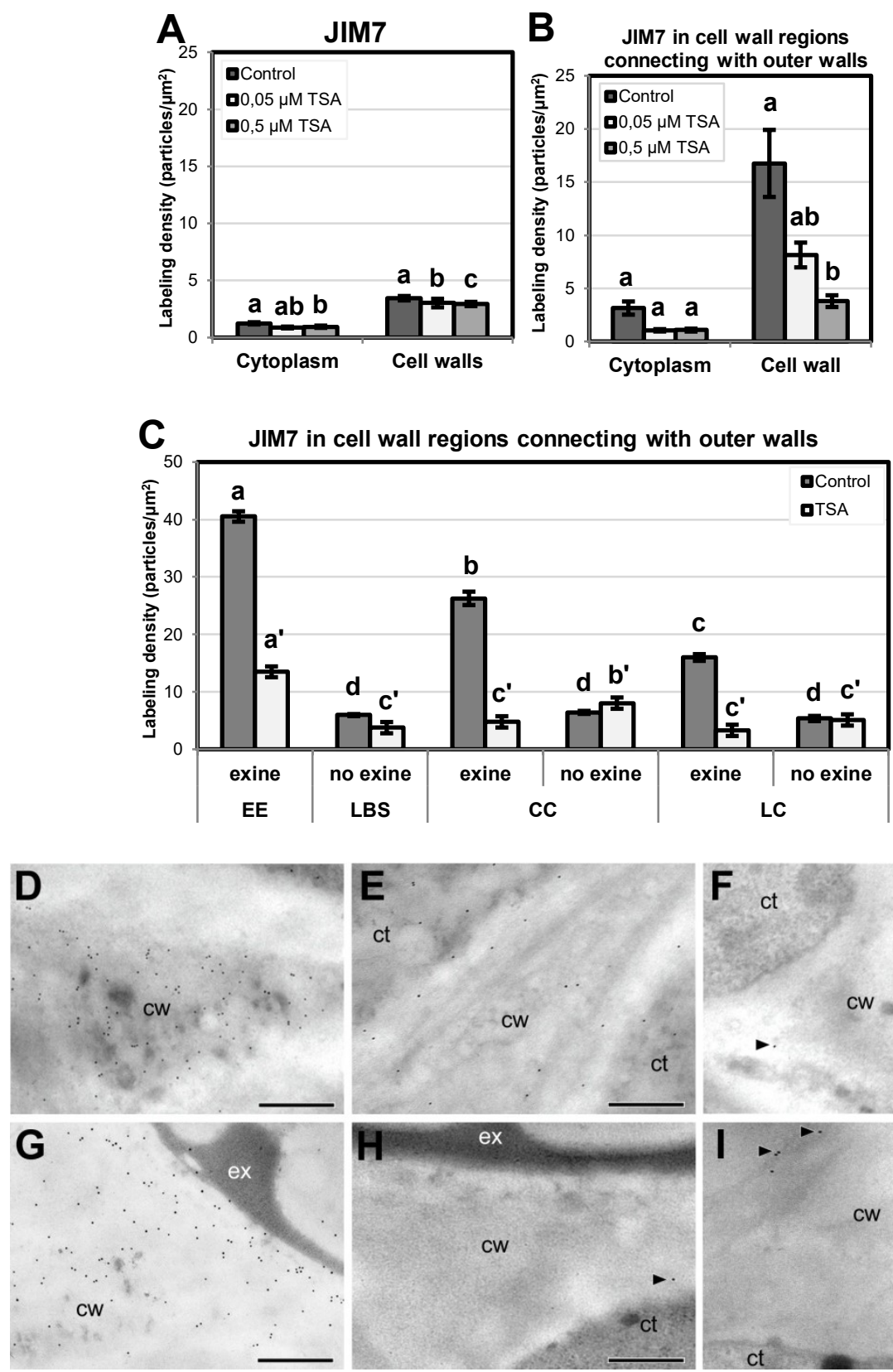

Figure 9: Detection of JIM7-crossreacting highly methyl-esterified by immunogold labeling and quantification in TEM images of cell wall union areas. A-B: Quantification of JIM7-crossreacting highly methylesterified pectin in the cytoplasm and cell walls of embryogenic microspores under different TSA treatments. A: Average levels of JIM7 labeling in the 
cytoplasm and the cell walls of different embryogenic structures. B: Average levels of JIM7 labeling specifically in the cell wall regions connecting with outer walls of the different embryogenic structures. C: Levels of JIM7 labeling specifically in inner cell wall regions connecting with outer walls separately for each structure type and for regions covered by or devoid of exine, in structures of control (DH4079) and TSA-treated cultures (both DH4O79 and DH12075).

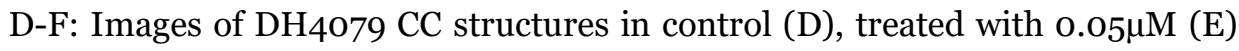

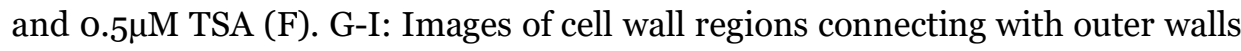
from CC structures of control cultures $(\mathrm{G})$, and of cultures treated with $0.5 \mu \mathrm{M}$ TSA in presence $(\mathrm{H})$ or absence (I) of exine. Different letters represent significant differences according to the KS test. Labelling density is expressed as number of particles per $\mu \mathrm{m} 2$. Arrowheads point to immunogold particles, lb: lipid body, ct: cytoplasm, cw: cell wall, ex: exine. Bars: $500 \mathrm{~nm}$.

\section{Discussion}

It was previously shown by time-lapse imaging that upon induction of embryogenesis, different embryogenic structures are formed, each of them having a different ability to become embryos (Corral-Martínez et al. 2020). Initially compact, highly embryogenic structures, totally or partially surrounded by exine, undergo a loss of cellular adhesion that leads to the occurrence of undifferentiated, loose structures with low embryogenic potential, unable in most cases to form differentiated MDEs (Corral-Martínez et al. 2020). This study was performed using the low responsive DH12075 line of B. napus, and adding $0.05 \mu \mathrm{M}$ TSA during the heat shock treatment to increase the percentage of induced microspores and of MDEs formed. The same four different types of embryogenic structures, with the same types of embryogenic fates, have also been observed in the high response $\mathrm{DH} 4079$ B. napus line (Chapter 5). These structures presented differences in total cell wall and subintinal layer width, as well as in their composition in terms of callose AGPs and pectin (Chapter 5). When exposed to TSA, these structures did not respond to embryogenesis induction as those of DH12075. Considering that the four types of structures are present in microspore cultures of the two B. napus lines but respond differently to different concentrations of TSA, we conducted a series of experiments to study the 
putative differences in terms of cell wall structure and composition derived from the application of TSA to microspore cultures of both $B$. napus lines. The results are described next.

TSA reduces cell adhesion of inner walls and the embryogenic potential of microspores of the highly responsive $\mathrm{DH}_{4079}$ line

We showed that TSA, when applied in the same conditions, has a different effect in DH4079 and in DH12075. While TSA increases MDE yield in DH12075 (Li et al. 2014), it inhibited MDE production in DH4079 (Fig. 1). However, the effect of TSA was not related to an overall growth inhibition, since calli were produced with all the TSA concentrations used. The effect of TSA mostly consisted in the transformation of highly embryogenic structures, characterized by being compact, with cells firmly attached, into loose, barely embryogenic calli, where cells are weakly connected between them. These structures rarely become MDEs. This indicated that the reduction in MDE yield in DH4079 is related to the modification of cell walls to produce structures with loosely attached cells. This was paralleled by a transformation of compact callus into loose callus. Although these structures are both barely embryogenic and this transformation had no impact in the final percentage of MDEs obtained, such a change reinforces the notion that the main effect of TSA is the promotion of loose walls, where the capacity of keeping cells firmly attached, is reduced.

Figure $2 \mathrm{~K}$ shows that without TSA (in control conditions), there was a transition from compact (EE and CC) to loose (LC) structures upon time. However, this figure also shows that TSA $0.05 \mu \mathrm{M}$ increased the percentages of loose structures and reduced the percentages of compact structures at the two time points studied. This effect was much more evident with $0.5 \mu \mathrm{M}$ TSA, where almost $80 \%$ of the structures identified at day 8 were loose, barely embryogenic calli. Therefore, we can conclude that in the highly responsive $\mathrm{DH} 4079$ line, TSA reduces cell adhesion in a dose-dependent manner, accelerating the transformation of compact structures into loose structures, and thereby reducing the number of compact, highly embryogenic forms. 
It is known that low methyl-esterified pectin plays an important role in the maintenance of a proper cell wall adhesion. This way, reduced levels of low methyl-esterified pectin are widely acknowledged to promote weak intercellular adhesion (Knox et al. 1990; Iwai et al. 2002; Majewska-Sawka et al. 2004). According to Darley et al. 2001, pectin in a low methyl-esterified state becomes more accessible for pectin matrixremodeling polygalacturonases. Indeed, we previously showed that in control DH4079 cultures, without TSA, compact structures (EE and CC) presented in their inner walls higher levels of this pectin type than loose structures (Chapter 5). However, in the 5-day-old cultures we used for the immunogold labeling study of pectin composition, we did not observe any relevant change in the presence of low methyl-esterified pectin in the inner cell walls of any TSA-treated structure. Reasonably assuming that the important loss of cellular adhesion observed in the transition from 5 to 8-day-old cultures (see Fig. 2) is due to pectin deesterification, as it happens in many other plant cell systems, we believe that such a remodeling must occur after day 5 of culture, in such a way that at day 8, the effects are already visible as an increase in the percentage of loose structures present in cultures.

\section{TSA promotes rigidity of outer cell walls by modifying their pectin composition}

In general, TSA did not have a dramatic impact on the pectin levels of outer walls, at least in 5-day-old cultures, although there were two particular cases were differences between TSA and control samples could be relevant. Immunogold labeling with $\mathrm{JIM}_{5}$ antibodies revealed that TSA did not affect the levels of low methyl esterified pectin epitopes in the inner walls of any structure of any genotype, but increased their levels in the outer walls of compact structures. As to the levels of highly methyl-esterified pectin, TSA showed no effect in the inner cell walls or in the outer cell walls of any structure, except for the cell wall regions connecting to outer walls, where these levels dramatically decreased. Therefore, TSA promoted the occurrence of outer walls where the levels of highly methyl-esterified pectin are reduced in the regions connecting with inner walls, and the levels of low methyl esterified pectin are increased, principally in compact structures. Highly methyl-esterified 
pectin is typically associated to the plastic cell walls of actively growing or elongating cells, whereas low methyl esterified pectin are known to impart rigidity to mature cell walls that do not elongate (Li et al. 1994). Indeed, in Arabidopsis, there is a minimum threshold of pectin methylesterification below which, cell elongation is reduced (Derbyshire et al. 2007). This led to associate high levels of low methyl-esterified pectin with reduced cell elongation. Thus, we deduce that one of the main effects of TSA in the outer cell walls is to promote the occurrence of rigid cell walls, mostly in compact structures. In other words, TSA would be precluding cell growth and wall elongation.

We previously observed that in the outermost region of inner walls separating adjacent cells, where they connect with the subintinal layer and the intine, there were dramatic differences in labeling density in certain structures, depending on the presence or absence of exine covering these regions (Chapter 5 ). Structures with large regions covered by exine (EE structures) presented levels of highly methyl-esterified pectin much higher than regions devoid of exine. This was indicative of active growth in these regions, and would account for the expanding force that eventually pushes the exine to break, thereby releasing the mechanic constraint that prevents the growth of embryogenic microspores (Chapter 5). In this context, the remodeling of the pectin content in the outer walls of TSA-treated microspores would be creating more rigid walls, thereby reducing such an expansive force and conceivably, the cell growth needed for further proliferation.

\section{The TSA-derived changes in callose and cellulose deposition have no remarkable impact in cell walls}

In this work, the dynamics of callose deposition in control cultures of both $B$. napus lines was similar to that previously described, being less abundant in DH12075 than in DH4079, and being progressively removed upon culture progression (Parra-Vega et al. 2015; Rivas-Sendra et al. 2019, Chapter 5). We found that TSA promoted a general reduction of callose deposition in the inner cell walls of compact (EE and CC) structures, having almost no effect in other structure types. As to cellulose, TSA promoted a decrease in $\mathrm{DH} 12 \mathrm{O} 75$, and a slight increase in 
DH4079 in inner walls. The unusual callose accumulation, together with the unusual low levels of cellulose in the inner walls of young embryogenic microspores was described to produce irregular, defective walls prone to break and collapse, which was proposed as a cause for further nuclear fusion and genome doubling (Parra-Vega et al. 2015). Consistent with this, we observed less incomplete, irregular inner walls in cells of TSA-treated cultures. However, this should not have a direct effect in cell adhesion or in the increase of MDE yield.

As to the outer walls, we showed that TSA had a minor, almost negligible effect in callose accumulation in $\mathrm{DH}_{4079}$. This is consistent with the negligible effect we hereby describe for TSA in the width of the subintinal layer. In the subintinal layer, callose deposition was shown to be high in $\mathrm{DH} 4079$, where it was related to the formation of an osmoprotective layer beneficial for in vitro microspore viability (RivasSendra et al. 2019). Thus, we deduce that TSA does not alter neither the levels of callose in the subintinal layer nor its role in $\mathrm{DH}_{4079}$ embryogenic microspores. In DH12075, treatment with $0.5 \mu \mathrm{M}$ TSA promoted the occurrence of thicker subintinal layers than with $0.05 \mu \mathrm{M}$ TSA. However, structures cultured under different TSA treatments did not differ in callose deposition. Thus, the thickening of the subintinal layer should be attributable to the deposition of other cell wall components different from callose. In summary, we can conclude that, in general, the alterations of callose and cellulose deposition derived from the use of TSA in B. napus microspore cultures has not a remarkable impact in cell wall function, being the effects of TSA attributable to other causes.

\section{TSA consistently reduces the levels of JIM13- crossreacting AGPs}

AGPs in general, and JIM13-crossreacting AGPs in particular, have been related to the competence of microspores to be induced to embryogenesis (Borderies et al. 2004; Corral-Martínez et al. 2019; Chapter 5). This notion was reinforced by the finding that highly embryogenic structures present levels of these AGPs notably higher than barely embryogenic structures (Chapter 5 ). In general, TSA promoted a decrease in the JIM13 labeling density of all structures proportional to 
the levels observed in their respective controls. In cultures treated with TSA, the levels of JIM13-crossreacting AGPs remained higher in highly embryogenic structures (EE and LBS) than in barely embryogenic structures (CC and LC). In addition, the labeling density values of TSAtreated cultures of the DH4079 and the DH12075 lines were remarkably similar. They were similarly high for highly embryogenic structures of both lines, and similarly low for the respective barely embryogenic structures. Thus, we can conclude that TSA consistently reduces the levels of JIM13-crossreacting AGPs. However, according to the assigned role of JIM13-crossreacting AGPs in microspore embryogenesis, it is reasonable to assume that the decrease observed in the cell walls of highly embryogenic forms will have an impact in the final rate of MDEs. Our results in $\mathrm{DH} 4079$ on the rate of conversion of highly embryogenic structures into barely embryogenic structures and on the rate of MDE production confirm this notion. In DH12075, the effect of TSA in the presence of JIM13-crossreacting AGPs in the cell walls of highly embryogenic structures would not have a similar reflection, since the initial percentages of highly embryogenic structures use to be extremely low ( 0.2\%, Corral-Martínez et al. 2020).

\section{TSA promotes the formation of cell walls whose composition is typical of barely embryogenic structures}

We previously proposed that cell wall thickness and composition is a relevant factor for the embryogenic fate of microspores, being thinner walls with high labeling densities for nearly all the antibodies used in this study the most favorable for promotion of embryogenesis (Chapter 5). In turn, thicker walls with the lowest values for almost all the studied cell wall components were proposed as the less favorable for embryogenic development due to their difficulty to maintain cell cohesion and communication (Chapter 5). In this work, we showed that, in general, the use of TSA produced thinner outer walls in DH4079. However, there was a relevant exception to this trend in the case of EE structures, the most embryogenic forms, where width increased with the use of TSA up to the levels found in other, barely embryogenic structures. Consistent with this, we observed that 5-day-old structures treated with TSA showed a reduction on the levels of callose, JIM13- 
crossreacting AGPs and highly methyl-esterified pectin, at least in the regions where they connect with the outer wall. These changes would be approaching the cell walls of highly embryogenic structures (principally EE) to the structure and composition of the cell walls of barely embryogenic structures, which would be favoring the transition observed from highly to barely embryogenic structures (Fig. 2K). Thus, TSA would be promoting in EE structures the formation of cell walls that preclude their proper development as MDEs, thereby facilitating their conversion to barely embryogenic forms, and reducing the MDE yield OF DH4O79 cultures, as observed.

This effect at the cell wall level would be similar in both $B$. napus lines (DH4079 and DH12075). However, the different initial scenarios of each case would account for the different final effect of TSA in these species. In DH4079, the percentage of highly embryogenic structures before the transition (23\%, Fig. 2K) is markedly higher that in DH12O79 (Corral-Martínez et al. 2020). Thus, the massive transition to barely embryogenic forms mediated by TSA will necessarily imply a decrease in the number of highly embryogenic structures, which will have a dramatic negative impact in the number of MDEs produced. Instead, the percentage of highly embryogenic structures in DH12075 is extremely low, almost negligible ( 0.2\%, Corral-Martínez et al. 2020). The TSAmediated transition of these structures to barely embryogenic forms will have no impact in the final rate of MDE production. In this case, the TSA-mediated increase of the final rate of MDE production will come from the transformation of some of the barely embryogenic forms into MDEs, as described to occur in a very small percentage of cases where these forms develop into loose suspensor-bearing embryos, rather than into exine-enclosed embryos (Corral-Martínez et al. 2020). In DH12075, TSA is known to increase dramatically the percentages of barely embryogenic forms, up to $\sim 65 \%$ of the total structures found in the cultures, versus $\sim 0.6 \%$ without TSA (Corral-Martínez et al. 2020). Thus, such transformation will eventually produce much more MDEs than without TSA, even occurring at a very low rate, because the population of barely embryogenic structures undergoing such transformation is enormously higher. 


\section{Conclusions}

In this work we shed light on the mechanisms that TSA is altering regarding the cell wall structure and composition in genotypes with different response levels as a consequence of the effect on cell division regulation. TSA promote a significant loss of cell adhesion in inner cell walls and promotes the formation of cell walls whose composition is typical of barely embryogenic structures, accelerating the transition of compact structures towards loose structures. Our results provide information that could help understand how TSA produces different phenotypes in genotypes with low or high response in microspore culture.

\section{References}

Beckert M (1998) Genetic analysis of in vitro androgenetic response in maize. In: Chupeau Y, Caboche M, Henry Y (eds) Androgenesis and haploid plants. Springer-Verlag, Berlin, Heidelberg, pp 24-37

Bie XM, Dong L, Li XH, Wang H, Gao X-Q, Li XG (2020) Trichostatin A and sodium butyrate promotes plant regeneration in common wheat. Plant Signaling \& Behavior:1820681. doi:10.1080/15592324.2020.1820681

Borderies G, le Bechec M, Rossignol M, Lafitte C, Le Deunff E, Beckert M, Dumas C, Matthys-Rochon E (2004) Characterization of proteins secreted during maize microspore culture: arabinogalactan proteins (AGPs) stimulate embryo development. Eur J Cell Biol 83 (5):205-212

Bou Daher F, Braybrook SA (2015) How to let go: pectin and plant cell adhesion. Front Plant Sci 6:523-523. doi:10.3389/fpls.2015.00523

Brown RC, Lemmon BE (2009) Callose in cell division. In: Bacic A, Fincher GB, Stone BA (eds) Chemistry, Biochemistry, and Biology of (1-3)-b-Glucans and Related Polysaccharides. Elsevier Science, pp 425-438

Camacho-Fernández C, Hervás D, Rivas-Sendra A, Marín MP, Seguí-Simarro JM (2018) Comparison of six different methods to calculate cell densities. Plant Methods 14 (1):30. doi:10.1186/s13007-018-0297-4 
Corral-Martínez P, Driouich A, Seguí-Simarro JM (2019) Dynamic Changes in Arabinogalactan-Protein, Pectin, Xyloglucan and Xylan Composition of the Cell Wall During Microspore Embryogenesis in Brassica napus. Front Plant Sci 10 (332). doi:10.3389/fpls.2019.00332

Corral-Martínez P, García-Fortea E, Bernard S, Driouich A, Seguí-Simarro JM (2016) Ultrastructural immunolocalization of arabinogalactan protein, pectin and hemicellulose epitopes through anther development in Brassica napus. Plant Cell Physiol 57 (10):2161-2174. doi:10.1093/pcp/pcw133

Corral-Martínez P, Parra-Vega V, Seguí-Simarro JM (2013) Novel features of Brassica napus embryogenic microspores revealed by high pressure freezing and freeze substitution: evidence for massive autophagy and excretion-based cytoplasmic cleaning. J Exp Bot 64 (10):3061-3075. doi:10.1093/jxb/ert151

Corral-Martínez P, Siemons C, Horstman A, Angenent GC, de Ruijter N, Boutilier K (2020) Live Imaging of embryogenic structures in Brassica napus microspore embryo cultures highlights the developmental plasticity of induced totipotent cells. Plant Reprod. doi:10.1007/s00497-020-00391-Z

Custers J (2003) Microspore culture in rapeseed (Brassica napus L.). In: Maluszynski M, Kasha KJ, Forster BP, Szarejko I (eds) Doubled haploid production in crop plants. Kluwer Academic Publishers, Dordrecht, The Netherlands, pp 185-193

Custers JBM, Cordewener JHG, Fiers MA, Maassen BTH, van LookerenCampagne MM, Liu CM (2001) Androgenesis in Brassica: a model system to study the initiation of plant embryogenesis. In: Bhojwani SS, Soh WY (eds) Current trends in the embryology of angiosperm. Kluwer Academic Publishers, Dordrecht, The Netherlands, pp 451-470

Chen H-W, Persson S, Grebe M, McFarlane HE (2018) Cellulose synthesis during cell plate assembly. Physiol Plant 164 (1):17-26. doi:10.1111/ppl.12703

Darley CP, Forrester AM, McQueen-Mason SJ (2001) The molecular basis of plant cell wall extension. Plant Mol Biol 47 (1-2):179-195

Datta SK (2005) Androgenic haploids: Factors controlling development and its application in crop improvement. Curr Sci 89 (11):1870-1878

Derbyshire P, McCann MC, Roberts K (2007) Restricted cell elongation in Arabidopsishypocotyls is associated with a reduced average pectin esterification level. BMC Plant Biol 7 (1):31. doi:10.1186/1471-2229-7-31

Gaspar Y, Johnson K, McKenna J, Bacic A, Schultz C (2001) The complex structures of arabinogalactan-proteins and the journey towards 
understanding function. Plant Mol Biol 47 (1-2):161-176. doi:10.1023/a:1010683432529

Iwai H, Masaoka N, Ishii T, Satoh S (2002) A pectin glucuronyltransferase gene is essential for intercellular attachment in the plant meristem. Proc Natl Acad Sci USA 99 (25):16319-16324. doi:10.1073/pnas.252530499

Karnovsky MJ (1965) A formaldehyde-glutaraldehyde fixative of high osmolality for use in electron microscopy. J Cell Biol 27 (2):137A-138A

Knox JP, Linstead PJ, King J, Cooper C, Roberts K (1990) Pectin esterification is spatially regulated both within cell walls and between developing tissues of root apices. Planta 181 (4):512-521. doi:10.1007/bfoo193004

Knox JP, Linstead PJ, Peart J, Cooper C, Roberts K (1991) Developmentally regulated epitopes of cell surface arabinogalactan proteins and their relation to root tissue pattern formation. Plant $\mathrm{J} 1$ (3):317-326

Li H, Soriano M, Cordewener J, Muiño JM, Riksen T, Fukuoka H, Angenent GC, Boutilier K (2014) The histone deacetylase inhibitor Trichostatin A promotes totipotency in the male gametophyte. Plant Cell 26 (1):195209. doi:10.1105/tpc.113.116491

Li YQ, Chen F, Linskens HF, Cresti M (1994) Distribution of unesterified and esterified pectins in cell walls of pollen tubes of flowering plants. Sex Plant Reprod 7 (3):145-152. doi:10.1007/bfoo228487

Majewska-Sawka A, Munster A, Wisniewska E (2004) Temporal and spatial distribution of pectin epitopes in differentiating anthers and microspores of fertile and sterile sugar beet. Plant Cell Physiol 45 (5):560-572. doi:10.1093/pcp/pcho66

Malik MR, Wang F, Dirpaul J, Zhou N, Hammerlindl J, Keller W, Abrams SR, Ferrie AMR, Krochko JE (2008) Isolation of an embryogenic line from non-embryogenic Brassica napus cv. Westar through microspore embryogenesis. J Exp Bot 59 (10 ):2857-2873. doi:10.1093/jxb/ern 149

Palin R, Geitmann A (2012) The role of pectin in plant morphogenesis. Biosystems 109 doi:https://doi.org/10.1016/j.biosystems.2012.04.006

(3):397-402.

Parra-Vega V, Corral-Martínez P, Rivas-Sendra A, Seguí-Simarro JM (2015) Induction of embryogenesis in Brassica napus microspores produces a callosic subintinal layer and abnormal cell walls with altered levels of callose and cellulose. Front Plant Sci 6:1018. doi:10.3389/fpls.2015.01018

Pereira AM, Pereira LG, Coimbra S (2015) Arabinogalactan proteins: rising attention from plant biologists. Plant Reprod 28 (1):1-15. doi:10.1007/s00497-015-0254-6 
Rivas-Sendra A, Corral-Martínez P, Porcel R, Camacho-Fernández C, CalabuigSerna A, Seguí-Simarro JM (2019) Embryogenic competence of microspores is associated with their ability to form a callosic, osmoprotective subintinal layer. $J$ Exp Bot 70 (4):1267-1281. doi:10.1093/jxb/ery458

Robards AW, Wilson AJ (1993) Procedures in Electron Microscopy. John Wiley \& Sons, Chichester, UK

Scheller HV, Ulvskov P (2010) Hemicelluloses. Ann Rev Plant Biol 61 (1):263289. doi:10.1146/annurev-arplant-042809-112315

Schindelin J, Arganda-Carreras I, Frise E, Kaynig V, Longair M, Pietzsch T, Preibisch S, Rueden C, Saalfeld S, Schmid B, Tinevez JY, White DJ, Hartenstein V, Eliceiri K, Tomancak P, Cardona A (2012) Fiji: an opensource platform for biological-image analysis. Nature methods 9 (7):676-682. doi:10.1038/nmeth.2019

Seguí-Simarro JM (2010) Androgenesis revisited. Bot Rev 76 (3):377-404. doi:10.1007/s12229-010-9056-6

Seguí-Simarro JM (2016) Doubled haploidy in model and recalcitrant species. Frontiers Media, Lausanne, Switzerland. doi:10.3389/978-2-88919783-5

Seguí-Simarro JM, Nuez F (2008) How microspores transform into haploid embryos: changes associated with embryogenesis induction and microspore-derived embryogenesis. Physiol Plant 134:1-12. doi:10.1111/j.1399-3054.2008.01113.x

Shariatpanahi ME, Bal U, Heberle-Bors E, Touraev A (2006) Stresses applied for the re-programming of plant microspores towards in vitro embryogenesis. Physiol Plant 127 (4):519-534

Soriano M, Cistué L, Vallés MP, Castillo AM (2007) Effects of colchicine on anther and microspore culture of bread wheat (Triticum aestivum L.). Plant Cell Tissue Organ Cult 91 (3):225-234. doi:10.1007/s11240-0079288-2

Willats WGT, Limberg G, Buchholt HC, van Alebeek G-J, Benen J, Christensen TMIE, Visser J, Voragen A, Mikkelsen JD, Knox JP (2000) Analysis of pectic epitopes recognised by hybridoma and phage display monoclonal antibodies using defined oligosaccharides, polysaccharides, and enzymatic degradation. Carbohydrate Research 327 (3):309-320. doi:10.1016/Sooo8-6215(00)ooo39-2

Williams MA (1977) Quantitative methods in biology (Practical methods in electron microscopy, vol 6, part 2), vol 6. Practical methods in electron microscopy. North Holland/American Elsevier, Amsterdam, The Netherlands 


\section{Supplementary material}
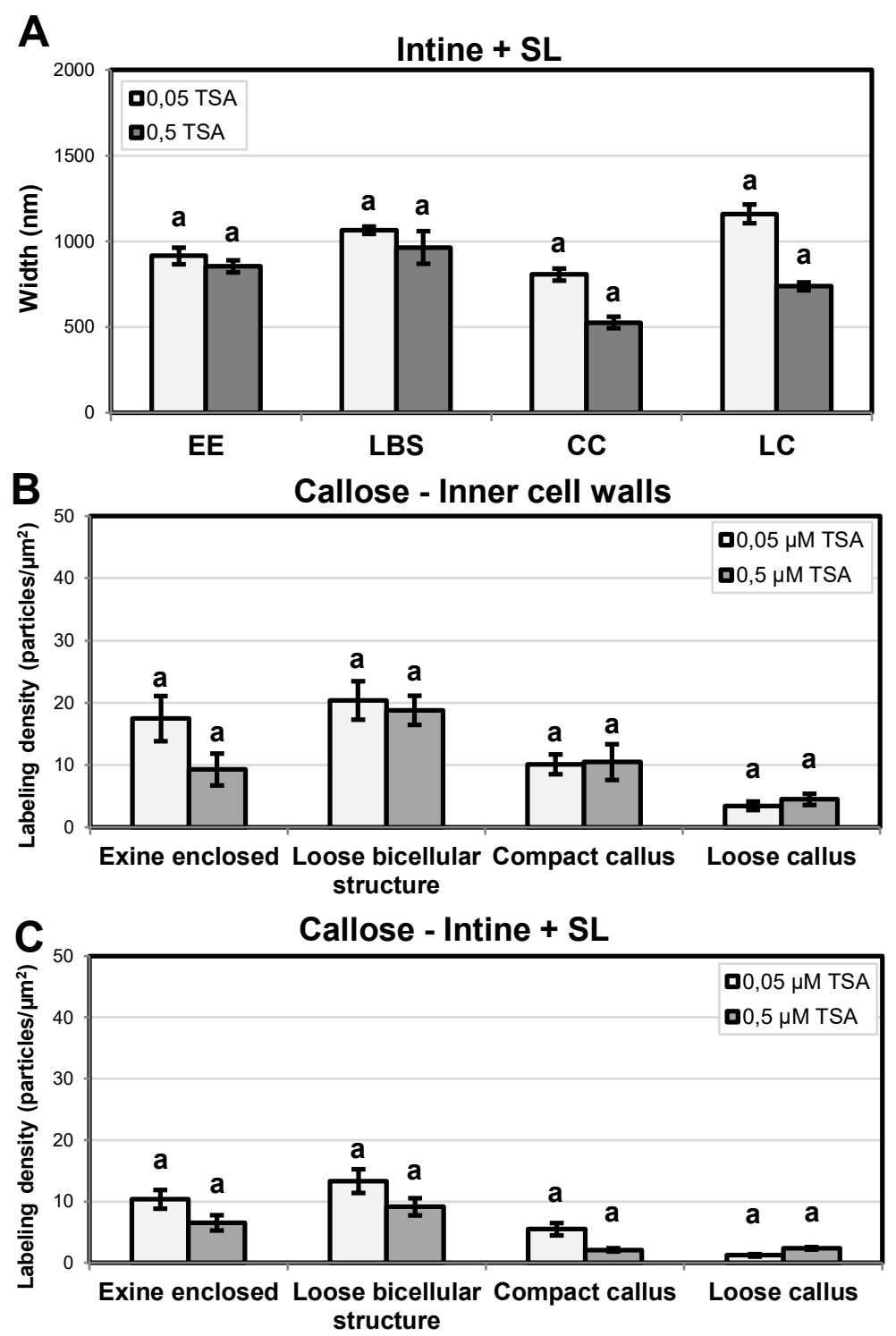

Supplementary figure 1. Cell wall width measurements and callose deposition quantification in DH12075 structures cultured under different TSA treatments. A: Outer cell wall width (nm). B-C: Callose detection by immunogold labeling and quantification in TEM images in inner (B) and outer (C) cell walls. Different letters represent statistically significant differences according to KS test. 


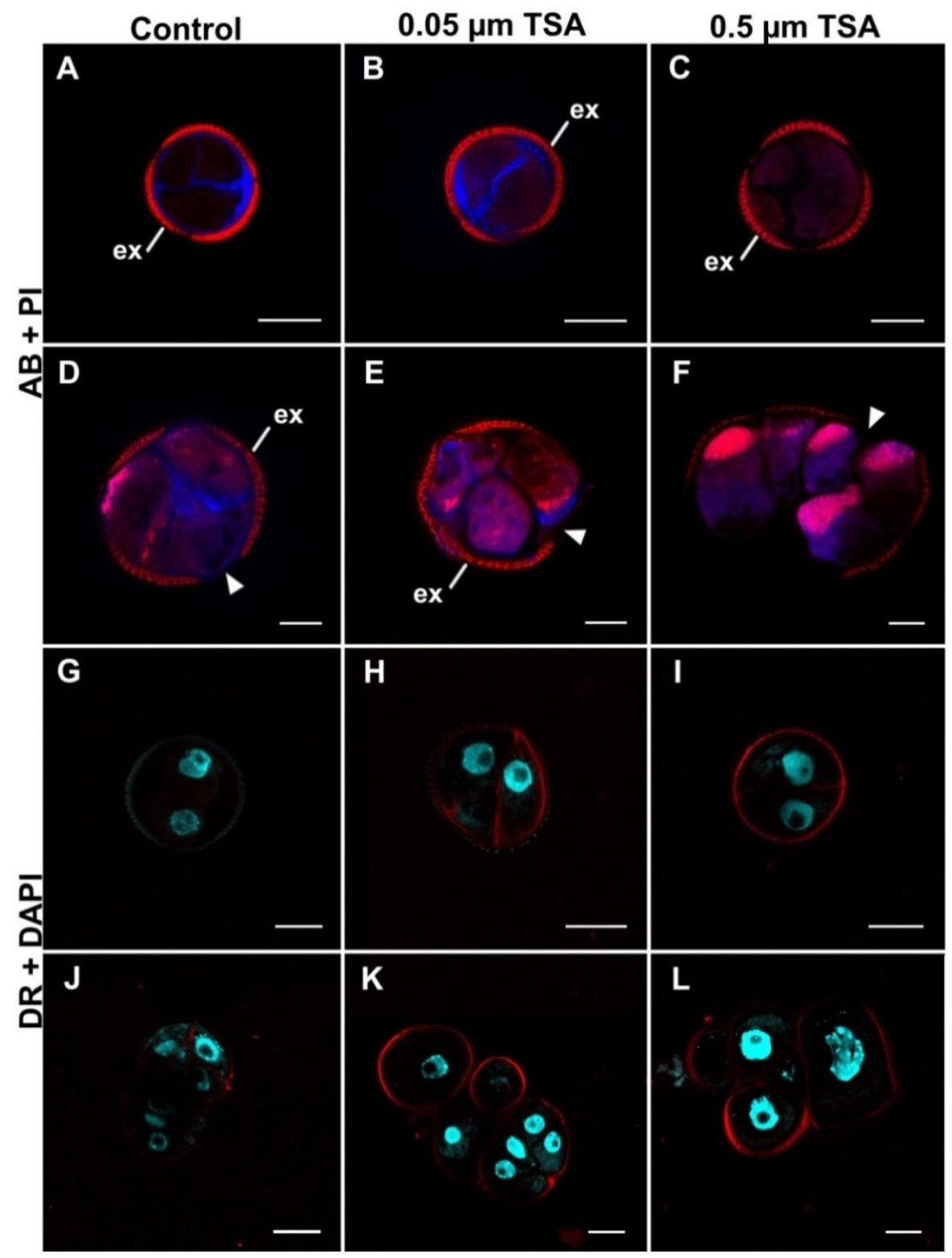

Supplementary figure 2. Detection of callose and cellulose in DH4079 microspore-derived structures stained with aniline blue for callose (blue in A-F) together with propidium iodide (red), and with Direct Red for cellulose (red in G-L) together with DAPI (cyan). Images represent structures at days 3 (A-C and G-I) and 6 (D-F and J-L) under different TSA treatments (control, 0.05 $\mu \mathrm{M}$ TSA and $0.5 \mu \mathrm{M}$ TSA). Arrowheads indicate regions of exine (ex) rupture or absence. Bars: $10 \mu \mathrm{m}$. 

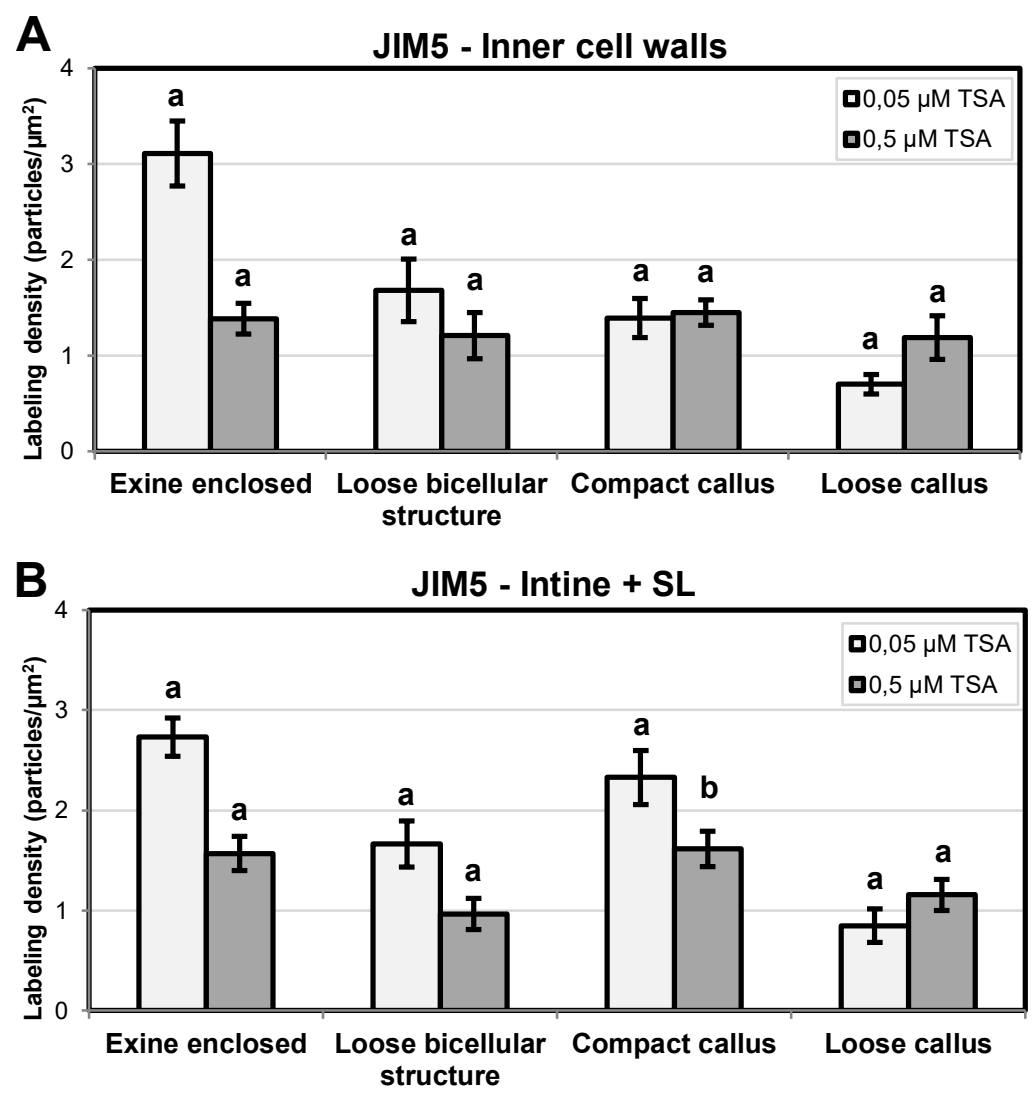

Supplementary figure 3: Quantification of JIM5-crossreacting, low methyl-esterified pectin by immunogold labeling in TEM images of DH12075 structures under different TSA treatments. A: Inner cell walls. B: Outer cell walls (intine+SL). Different letters represent statistically significant differences according to KS test. Labelling density is expressed as number of particles per $\mu \mathrm{m}^{2}$. 

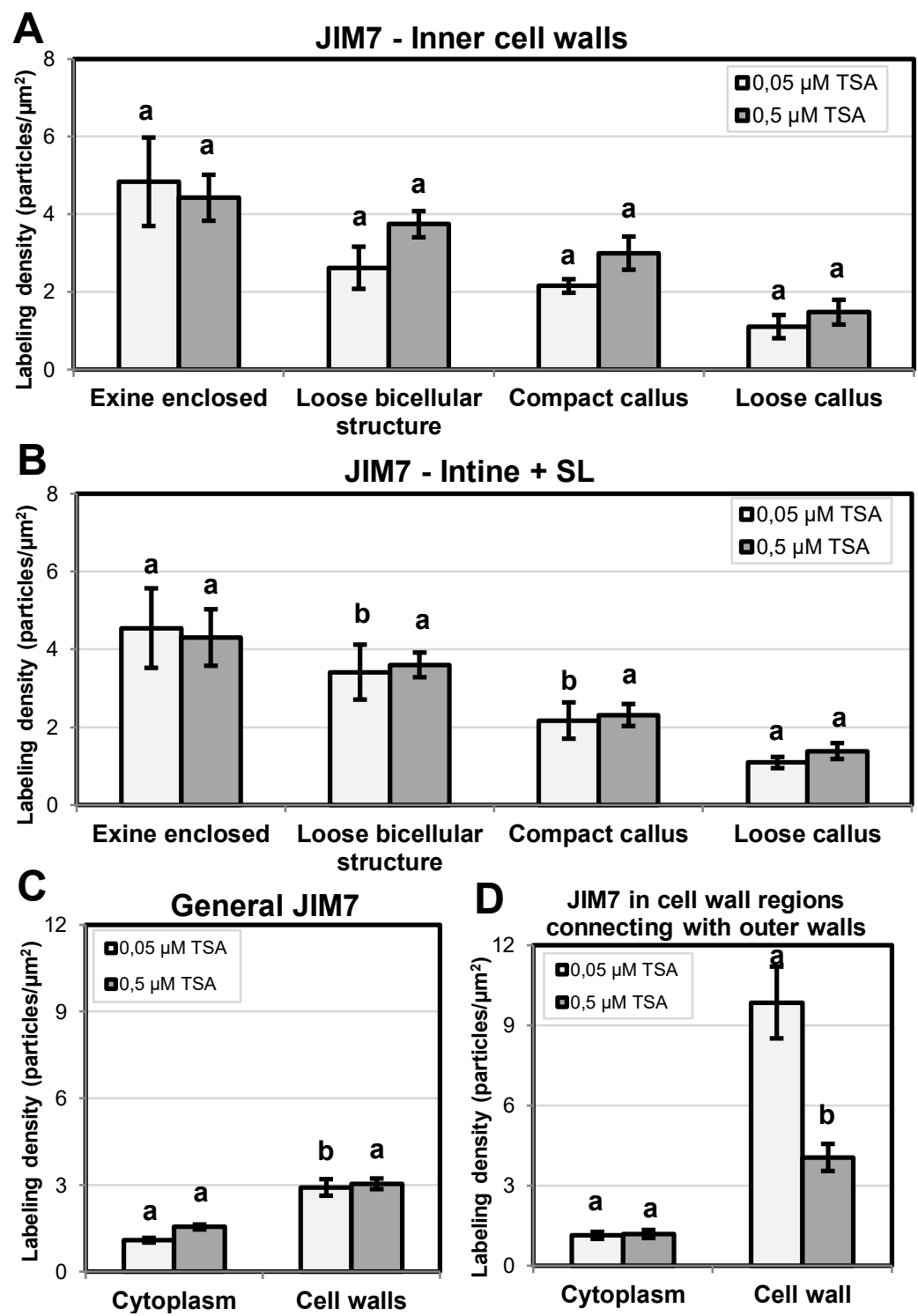

Supplementary figure 4: Quantification of JIM7-crossreacting highly methyl-esterified pectin by immunogold labeling in TEM images of DH12075 structures cultured under different TSA treatments. A: Inner cell walls. B: Outer cell walls (intine+SL). Different letters represent statistically significant differences according to KS test. Labelling density is expressed as number of particles per $\mu \mathrm{m}^{2}$. 


\section{General discussion}




\section{General discussion}

Nowadays, the world population is rising while the cultivable land is being progressively reduced by human activities. Hence, it is necessary to obtain more efficient crops with a higher yield. On the other hand, in developed countries, a higher quality is demanded in food products. All these kinds of issues are solved thanks to breeding techniques, which include the creation of hybrid varieties or pure lines with increased yield and homogeneity. As described in the introduction, doubled haploid production is a great tool for many breeding procedures.

In the present Doctoral Thesis, different approaches have been applied in an attempt to understand the processes involved in microspore embryogenesis, the most efficient and widely used technique for obtaining doubled haploids. In the first block, including Chapters from 1 to 3 , an experimental approach was used, while in the second block, Chapters from 4 to 6 , we tried to shed light on the cellular and molecular bases of the changes undergone by the microspores upon induction of embryogenesis. Traditionally, in vitro culture research aimed to increase the efficiency of protocols and did not focus too much in understanding the internal changes of cells or tissues where a deep reprograming process is taking place. Due to the scarce knowledge about the behavior of microspores when cultured in vitro, studies like those presented in Chapters 4-6 are necessary for the further development of in vitro protocols techniques in a correct direction. Furthermore, in vitro models could also be helpful to understand natural processes difficult to study in vivo. This is especially relevant in microspore embryogenesis because we can obtain a lot of information about plant cell processes such as the switch in developmental fate from a determined cell type towards embryogenesis, embryo development, response to stress, response to growth regulators, etc. That is why probably the best way to optimize an in vitro procedure should consider both approaches in parallel: experimental and basic. 


\section{Refining the methods for microspore embryogenesis}

Even though microspores are not part of a tissue where interconnections among cells are essential, communication between cells in suspension have been demonstrated to be necessary in several systems (Paire et al. 2003; Borderies et al. 2004). Therefore, a correlation between cell density, competition for resources, as nutrients and oxygen, and communication ability in suspension cultures might exist. In microspore culture, a fine tune of the environmental conditions is necessary due to the absence of the regulatory effect of the anther wall tissues, necessary for a correct development of the microspores. Cell density is one of the factors that need optimization in microspore culture, as discussed in Chapters 1 and 2. In Chapter 1, several methods were analyzed in order to determine the best way to adjust cell density, evaluating precision, accuracy and reproducibility. Thanks to those experiments, we can choose a method according to our preferences. The most recommendable one is the Neubauer chamber, which is widely used in cell suspensions and has demonstrated to provide a better accuracy and precision with an affordable price. Surprisingly, methods based in flow cytometry, even able to process a high amount of cells, showed problems with volume measurement, and image-based methods had problems related to image acquisition. The Neubauer chamber was therefore the chosen method for all the experiments in the present Doctoral Thesis, including the cell density tests described in Chapter 2, which provided a good overview of what happens when too many or too less cells are coexisting in the same Petri dish. Higher densities promoted higher infection rates due to the increase of the initial bacterial inoculum, impossible to eliminate during sterilization without damaging the tissue of interest. In turn, very low densities prevented any further development, maybe due to the lack of communication between cells in suspension via hormones or other molecules that could promote other cells development. An optimal cell density was obtained where communication, inhibition signals and infection rate was in the perfect balance to allow microspore development.

Culture media is composed by numerous nutrients: salts, vitamins, sugars, growth regulators, etc. The type and concentration of all of them must be optimized for the best response. A positive effect on the reduction of the concentration of growth regulators in eggplant microspore culture was described previously (Corral-Martínez and Seguí-Simarro 2014; Rivas- 
Sendra et al. 2020). Interestingly, growth regulators are usually absent in model species protocols, as B. napus (Chapter 3) or tobacco (Touraev and Heberle-Bors 2003). In our experimental system, eggplant microspore culture, a reduction of growth regulators in the culture medium after several days showed to be beneficial for the development of microsporederived structures showing that a clearly different morphology can be obtained (Chapter 2). Thus, there is still room for improvement on eggplant microspore culture protocol via different modifications, as concentration and cytokinin/auxin ratio, which will probably have an interaction between them.

Obtaining a standard protocol for microspore embryogenesis is not an easy task. Several protocols have been described to obtain haploid embryos via microspore culture in B. napus (Fletcher et al. 1998; Custers 2003; Prem et al. 2012) and different stress treatments have been tested for improvement of the response, ranging from heat shock to gamma irradiation and colchicine (Pechan and Keller 1988; Zaki 1995; Zhao et al. 1996). Among them, the most commonly used stress is heat shock, but also the temperature and time of incubation could vary depending on the system or the genotypes (Gil-Humanes et al. 2008; Prem et al. 2012). Due to the different possibilities regarding the system that could be used for B. napus microspore culture, we described the protocol we used in all the experiments that were further performed in Block 2 in detail (Chapter 3 ).

\section{A step further in the knowledge about microspore embryogenesis}

In the three chapters conforming Block 2 (Chapters 4, 5 and 6) the main goal was to gain a better understanding of the cellular processes taking place during the reprogramming of the microspore fate. It was previously described that there is a certain level of autophagy occurring during microspore embryogenesis (Corral-Martínez et al. 2013). Through several chemical treatments and staining of specific intracellular structures, we were able to go deeper into processes related with endoplasmic reticulum stress, autophagy and programmed cell death, as described in Chapter 4. Thanks to the recent description of the different types of structures obtained in B. napus microspore cultures (Corral-Martínez et al. 
2020) we could focus on aspects that promote a better embryogenic response by comparing between different types of structures.

A series of reports have documented the relationship between ER stress, autophagy and PCD, both in animals and more recently, in plant cells. The sequence starts with ER stress. When ER stress cannot be well resolved through UPR, autophagy is triggered as a mechanism to mitigate cell damage. When autophagy is excessive and cell function is compromised, PCD is triggered. In this work we showed that this sequence operates during in vitro microspore embryogenesis, and depending on how and to what extent these steps are modulated, the developmental fate of microspores can be changed. It seems that highly embryogenic structures have lower levels of ER stress and autophagy, possibly due to a better UPR function, which keeps them under the "safe range" of autophagy that permits their progression to MDEs. Barely embryogenic structures would be closer to the upper threshold of the range, and any increase might lead to PCD. Thus, it appears that manipulation of ER stress and autophagy levels may have a general positive or negative effect, depending on the case, in the whole population of microspore-derived structures. Instead, promotion of PCD with obatoclax would have a selective effect on damaged cells, mostly present in barely embryogenic structures, thereby enriching the population of highly embryogenic structures.

The main conclusion of this study is that a certain level of autophagy is necessary to produce embryogenic structures, probably due to their capacity of cleaning the cytoplasm and removing inductors of the gametophytic program. However, when autophagy is promoted via the application of e.g. tunicamycin, the embryogenic capacity is reduced and programmed cell death is triggered. Thus, the developmental switch from pollen formation to embryogenesis requires complex rearrangements inside the cells that, precisely regulated, may lead to an embryo, but in cases where they are out of this fine control, uncontrolled proliferation and dedifferentiation may take place as a result of the lack of such precise regulation. Eventually, cells within structures or even the entire structure will die.

Once microspores are induced by the stress treatment, they start to proliferate. Plant cell proliferation requires cell wall synthesis, an essential process for the maintenance of the cellular structure and for the protection from the surrounding environment. Therefore, it is a key process in 238 
microspore embryogenesis. In Chapter 5 , we described the composition and structure of cell walls in different types of structures with different embryogenic competence, based on Corral-Martínez et al. 2020. We could observe how stiffness, flexibility, width, composition, etc. of cell walls is related to the success rate.

We demonstrated that each type of structure has a different cell wall composition and structure. The structures with highest probability to become embryos (EE) have thin walls that allow them to keep cells close and communicated, a callose-rich subintinal layer that allows them to isolate from the environment and to create their own embryo identity, and a specific pectin and AGP composition that determines their development as embryos. Other structures with different cell wall profiles, are also able to become embryos, but through different pathways and with lower rates of success (Corral-Martínez et al. 2020b). There seems to be an optimal profile to become an embryo, but such profile is not the only possible. Other profiles would allow for embryogenesis, but less efficiently. That would be the case of loose callus (LC), structures with the lowest probability to become embryos, which have shown to have thick cell walls, low levels of callose, AGPs and highly-esterified pectin. From a developmental perspective, we could say that each structure finds its way to progress towards embryogenesis, but their success would be determined by their cell wall profile. The next question to pose would be why each embryogenic structure has a different cell wall profile. We previously showed that the first cell walls formed by embryogenic microspores are defective and have an irregular composition, rich in callose and deficient in cellulose, due to the partial impairment of conventional cytokinesis during the heat shock (Parra-Vega et al. 2015). These problems are undergone by each microspore to different extents, leading to different cell walls with different properties in terms of adhesion, stiffness and permeability, among others. From this starting point, each microspore may manage the situation differently, trying to compensate the defficiencies through different ways. This has been demonstrated to occur during pollen tube growth, a similar system where cell walls have untypically low cellulose contents. In this system, when cellulose deposition is compromised, alternative compensatory meachanisms for increased pectin synthesis and/or deposition are activated (Aouar et al. 2010; Palin and Geitmann 2012). This way, pollen tubes are able to adapt their cell wall properties to a new scenario. Since both pollen tubes and cell walls of embryogenic microspores are formed from the 
microspore/pollen plasma membrane and cell wall, their initial composition and chemical environment should be similar. Given the similarities between both cell walls, it is plausible to propose that similar, pectin-based compensatory mechanisms may operate in both cases.

In general, thinner cell walls are present in highly embryogenic structures while they are thicker in the barely embryogenic ones. Callose is more abundant in inner and outer cell walls and AGPs are more present in highly embryogenic structures. Pectins have shown to play an interesting role in maintaining the cell adhesion and stiffness of the cell walls of these structures in balance. This first description of the cell wall profile of each type of structure is the base for the comparison between genotypes and treatments with Trichostatin A (TSA) made in Chapter 6. The knowledge of the cell wall behavior in each type of structure helped to create a relationship between cell wall characteristics and embryogenic competence.

TSA has been shown to promote a dramatic increase in the MDE yield of the low responding DH12O75 line of B. napus (Li et al. 2014). However, we showed that this effect is the opposite in the DH4079 line, which typically produces much more MDEs, but when exposed to TSA, the yield is dramatically reduced. In fact, some of the components of the cell wall presented similar levels in control DH4079 structures and in TSA-treated DH12O75 (Chapter 6). This phenomenon is related with the effect of TSA in embryogenesis induction. TSA is an inhibitor of HDACs and, when applied to microspore cultures, it is supposed to enhance the histone acetylation processes that normally take place as a result of the heat shock used as inductive treatment ( $\mathrm{Li}$ et al. 2014; Corral-Martínez et al. 2020). The combination of heat shock and TSA is therefore considered as a more severe form of abiotic stress (Corral-Martínez et al. 2020). We saw in DH4079 that autophagy is necessary to switch to embryogenesis, which probably is closely related with gene expression during the reprogramming. A possible relationship between autophagy and cell fate reprogramming would not be surprising, since a very new start is required and some of the old material that promotes pollen development should be discarded. Though, a process that seems to work very well in $\mathrm{DH} 4079$ in control conditions could be enhanced by the application of TSA, causing a detrimental effect in $\mathrm{DH} 4079$ but promoting enough the induction of the reprograming machinery in DH12O75. 
TSA affects epigenetics by making available genes that were compacted in the nucleosomes thanks to its activity as histone deacetylase inhibitor. So it is pertinent to ask what genes would be activated by the combined stress of TSA and heat shock. At the cell wall level, a candidate would be the pectin methyl esterase (PME) gene family. We showed that one of the main consequences of the application of TSA at the cell wall level is the promotion of loose inner walls with a reduced ability to keep cells firmly attached, and of stiffer outer walls that reduce the ability of microsporederived structures to grow. Low methyl esterified pectin is synthesized in the Golgi stacks in a highly methyl-esterified, fluid form, and then transported to cell walls, where they are locally de-esterified by PMEs, which allows them to gel in the presence of $\mathrm{Ca}^{+2}$ (Palin and Geitmann 2012). In other plant systems, PME was shown to activate as a consequence of the application of a heat shock stress. It is tempting to speculate that TSA is amplifying the effects of the heat shock, as previously proposed, affecting in this case the expression of the PME genes responsible for the pectin remodeling observed. A second, independent hypothesis would be that TSA, together with the heat shock, could be altering the regulation of cell division, thereby producing cell walls with abnormal architectures and compositions. This hypothesis would be consistent with our observations of accelerated growth in TSA-treated microspore cultures. In conclusion, in this work, we shed light on several mechanisms, operating at the cell wall level, which could explain how TSA produces the phenotypes observed in $B$. napus microspore cultures.

Genotype is a very limiting factor for the application of doubled haploids in breeding programs as some genotypes are high responsive while some other are not responding at all. The application of chemicals to modify autophagy, ER stress or gene expression may be the solution to expand the range of genotypes where the production of doubled haploids is possible, now that we know how important it is for the success of the embryogenic process. Trying different compounds at different concentrations could solve the problem of low efficiency in some species, cultivars or genotypes that, while they are very interesting for breeding, are not responsive to standard protocols. With this Doctoral Thesis, we aimed to contribute to that knowledge, provide tools and research lines to follow in order to optimize microspore culture in other crops. 


\section{References}

Borderies G, le Bechec M, Rossignol M, Lafitte C, Le Deunff E, Beckert M, Dumas C, Matthys-Rochon E (2004) Characterization of proteins secreted during maize microspore culture: arabinogalactan proteins (AGPs) stimulate embryo development. Eur J Cell Biol 83 (5):205-212

Corral-Martínez P, Parra-Vega V, Seguí-Simarro JM (2013) Novel features of Brassica napus embryogenic microspores revealed by high pressure freezing and freeze substitution: evidence for massive autophagy and excretion-based cytoplasmic cleaning. J Exp Bot 64 (10):3061-3075. doi:10.1093/jxb/ert151

Corral-Martínez P, Seguí-Simarro JM (2014) Refining the method for eggplant microspore culture: effect of abscisic acid, epibrassinolide, polyethylene glycol, naphthaleneacetic acid, 6-benzylaminopurine and arabinogalactan proteins. Euphytica 195 (3):369-382. doi:10.1007/s10681-013-1001-4

Corral-Martínez P, Siemons C, Horstman A, Angenent GC, de Ruijter N, Boutilier K (2020) Live Imaging of embryogenic structures in Brassica napus microspore embryo cultures highlights the developmental plasticity of induced totipotent cells. Plant Reprod. doi:10.1007/s00497-020-00391-z

Custers J (2003) Microspore culture in rapeseed (Brassica napus L.). In: Maluszynski M, Kasha KJ, Forster BP, Szarejko I (eds) Doubled haploid production in crop plants. Kluwer Academic Publishers, Dordrecht, The Netherlands, pp 185-193

Fletcher, R. \& Coventry, J. \& Kott, Laima. (1998). Doubled haploid technology for spring and winter Brassica napus (revised edition). Technical Bulletin. 142.

Gil-Humanes, Javier \& Barro, F. (2008). Production of Doubled Haploids in Brassica. 10.1007/978-1-4020-8854-4_4.

Li H, Soriano M, Cordewener J, Muiño JM, Riksen T, Fukuoka H, Angenent GC, Boutilier K (2014) The histone deacetylase inhibitor Trichostatin A promotes totipotency in the male gametophyte. Plant Cell 26 (1):195-209. doi:10.1105/tpc.113.116491

Paire A, Devaux P, Lafitte C, Dumas C, Matthys-Rochon E (2003) Proteins produced by barley microspores and their derived androgenic structures promote in vitro zygotic maize embryo formation. Plant Cell Tissue Organ Cult 73 (2):167-176

Pechan PM, Keller WA (1988) Identification of potentially embryogenic microspores in Brassica napus. Physiol Plant 74:377-384 
Prem D, Solís MT, Bárány I, Rodríguez-Sanz H, Risueño MC, Testillano PS (2012) A new microspore embryogenesis system under low temperature which mimics zygotic embryogenesis initials, expresses auxin and efficiently regenerates doubled-haploid plants in Brassica napus. BMC Plant Biology 2012, 12:127

Rivas-Sendra A, Corral-Martínez P, Camacho-Fernández C, Porcel R, SeguíSimarro JM (2020) Effects of growth conditions of donor plants and in vitro culture environment in the viability and the embryogenic response of microspores of different eggplant genotypes. Euphytica 216 (11):167. doi:10.1007/s10681-020-02709-4

Touraev A, Heberle-Bors E (2003) Anther and microspore culture in tobacco. In: Maluszynski M, Kasha KJ, Forster BP, Szarejko I (eds) Doubled haploid production in crop plants. Kluwer Academic Publishers, Dordrecht, The Netherlands, pp 223-228

Zaki M, Dickinson H (1995) Modification of cell development in vitro: The effect of colchicine on anther and isolated microspore culture in Brassica napus. Plant Cell Tissue Organ Cult 40 (3):255-270. doi:10.1007/bfooo48132

Zhao JP, Simmonds DH, Newcomb W (1996) Induction of embryogenesis with colchicine instead of heat in microspores of Brassica napus L cv Topas. Planta 198 (3):433-439 


\section{Conclusions}




\section{Conclusions}

In this Thesis:

- We evaluated the precision, accuracy and reproducibility of different methods for cell density measurement: the Neubauer Chamber, flow cytometry, an automated image-based cell counter and manual counting with a microscope. Among the studied methods, the Neubauer Chamber showed the best performance due to its precision and accuracy.

- We evaluated the effect of cell density in eggplant microspore culture and we established the best density in 200,000 cells $/ \mathrm{ml}$.

- We evaluated the effect of growth regulators in eggplant microspore culture medium and we demonstrated that a reduction in the concentration of growth regulators after 7 or 12 days can be beneficial for the progression of microspore-derived structures.

- We described a standard protocol for B. napus and used it for the rest of the experiments.

- We studied the effect of tunicamycin, obatoclax and bafilomycin and showed that an induction of programmed cell death remarkably increased the response.

- We studied the processes of ER stress, autophagy and programmed cell death and demonstrated that certain level of autophagy is needed for the correct development of the structures in microspore embryogenesis. 
- We described the structure and composition of cell walls in different types of structures obtained in B. napus microspore culture and demonstrated that highly embryogenic structures present thin cell walls, high callose and AGPs content, and that a good regulation of methyl-esterification of pectin is necessary for cell wall stiffness and cell adhesion.

- We compared the structure and composition of cell walls of two $B$. napus genotypes with different androgenic response treated with Trichostatin A and demonstrated that TSA promoted the occurrence of cell walls typical of barely embryogenic structures. However, this has a different consequence in each genotype, since the response in DH4O79 is reduced, and increased in DH12O75. 